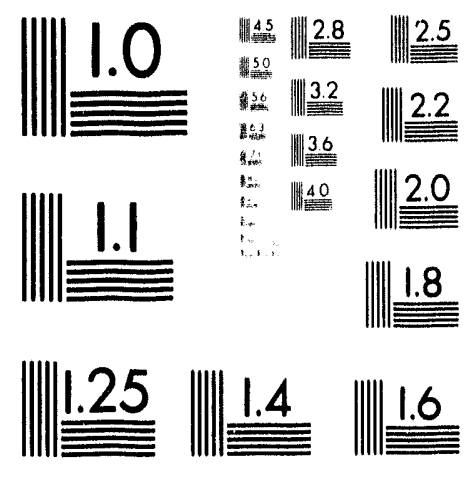



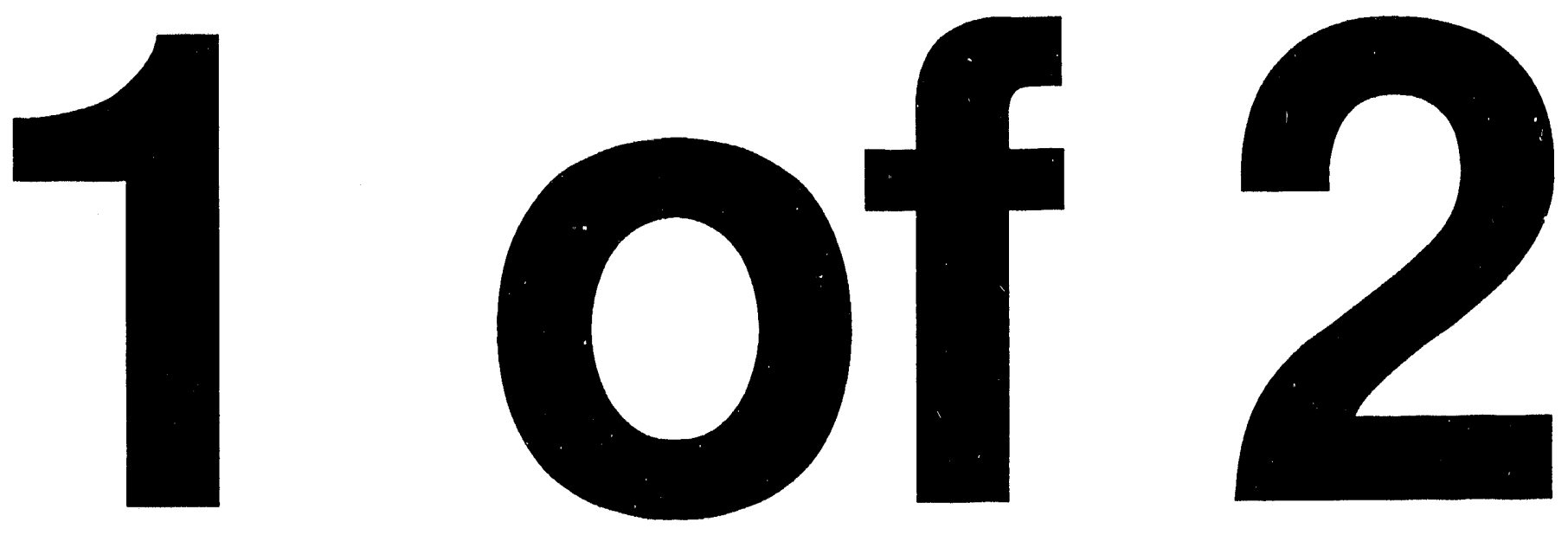


\section{CONTRACTOR REPORT}

SAND92 - 7293

Unlimited Release

UC -235

\section{Wind Effects on Convective Heat Loss From a Cavity Receiver for a Parabolic Concentrating Solar Collector}

Robert Y. Ma

Department of Mechanical Engineering

California State Polytechnic University

Pomoma, CA 91768

Prepared by Sandia National Laboratories Albuquerque, New Mexico 87185

and Livermore, California 94550 for the United States Department of Energy

under Contract DE-AC04-76DP00789

Printed September 1993 
Issued by Sandia National Laboratories, operated for the United States Department of Energy by Sandia Corporation.

NOTICE: This report was prepared as an account of work sponsored by an agency of the United States Government. Neither the United States Government nor any agency thereof, nor any of their employees, nor any of their contractors, subcontractors, or their employees, makes any warranty, express or implied, or assumes any legal liability or responsibility for the accuracy, completeness, or usefulness of any information, apparatus, product, or process disclosed, or represents that its use would not infringe privately owned rights. Reference herein to any specific commercial product, process, or service by trade name, trademark, manufacturer, or otherwise, does not necessarily constitute or imply its endorsement, recommendation, or favoring by the United States Government, any agency thereof or any of their contractors or subcontractors. The views and opinions expressed herein do not necessarily state or reflect those of the United States Government, any agency thereof or any of their contractors.

Printed in the United States of America. This report has been reproduced directly from the best available copy.

Available to DOE and DOE contractors from

Office of Scientific and Technical Information

PO Box 62

Oak Ridge, TN 37831

Prices available from (615) 576-8401, FTS 626-8401

Available to the public from

National Technical Information Service

US Department of Commerce

5285 Port Royal Rd

Springfield, VA 22161

NTIS price codes

Printed copy: A04

Microfiche copy: A01 
SAND92-7293

Distribution

Unlimited Release

Printed September 1993

Category UC-235

\title{
WIND EFFECTS ON CONVECTIVE HEAT LOSS FROM A CAVITY RECEIVER FOR A PARABOLIC CONCENTRATING SOLAR COLLECTOR
}

\author{
Robert Y. Ma \\ Department of Mechanical Engineering \\ California State Polytechnic University \\ Pomoma, California 91768
}

Tests were performed to determine the convective heat loss characteristics of a cavity receiver for a parabolid dish concentrating solar collector for various tilt angles and wind speeds of $0-24 \mathrm{mph}$. Natural (no wind) convective heat loss from the receiver is the highest for a horizontal receiver orientation and negligible with the reveler facing straight down. Convection from the receiver is substantially increased by the presence of side-on wind for all receiver tilt angles. For head-on wind, convective heat loss with the receiver facing straight down is approximately the same as that for side-on wind. Overall it was found that for wind speeds of 20-24 mph, convective heat loss from the receiver can be as much as three times that occurring without wind. 


\section{Table of Contents}

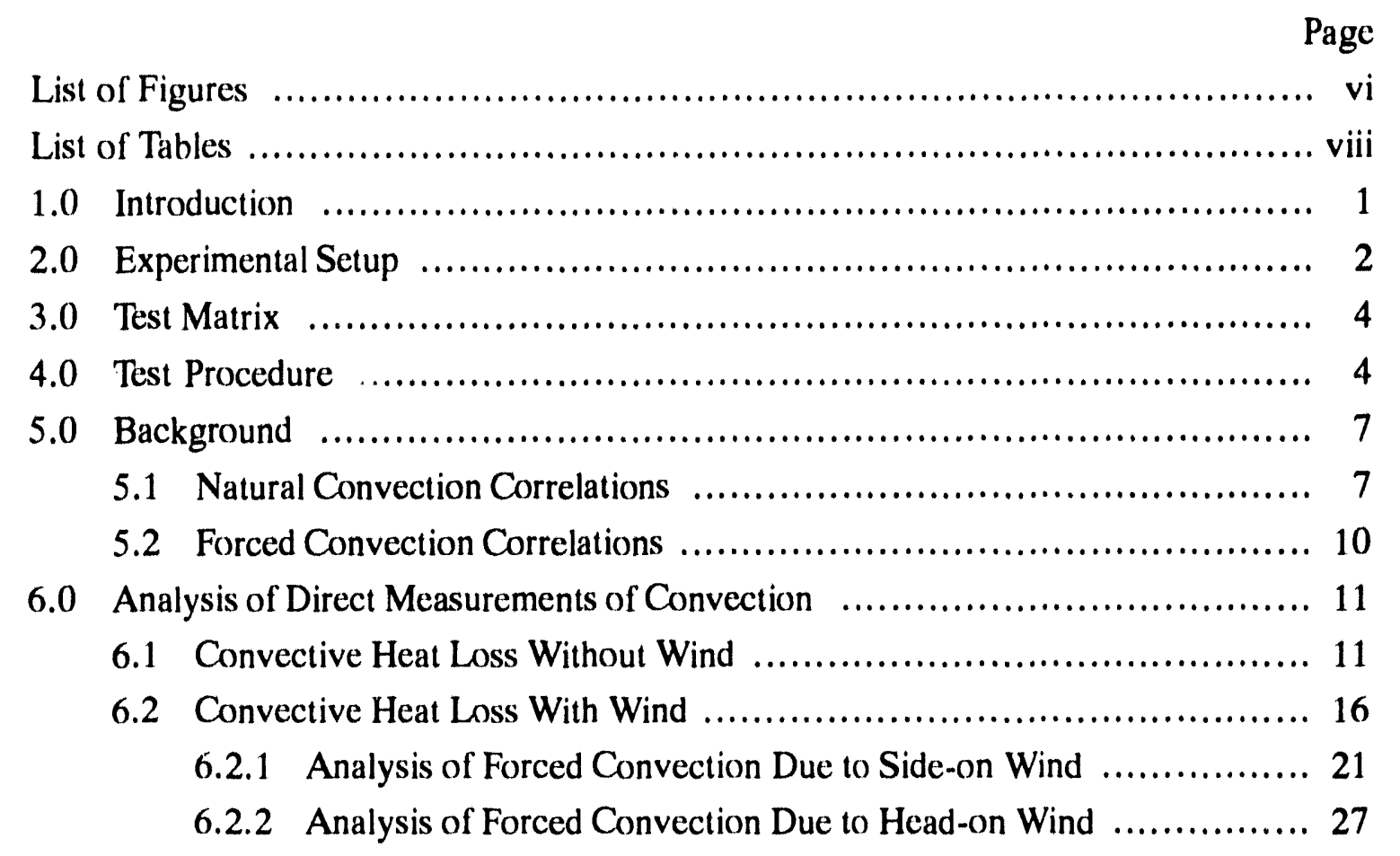

7.0 Analysis of Measured Air Temperatures and Average Internal

Heat Transfer Coefficients ................................................ 35

7.1 Measured Air Temperatures Inside Receiver ............................ 35

7.1.1 No-Wind Tests ............................................ 35

7.1.2 Side-on Wind Tests .......................................... 42

7.1.3 Head-on Wind Tests ........................................... 48

7.2 Average Air Temperatures and Internal Heat Transfer Coefficients .......... 48

7.2.1 No-Wind Tests ............................................ 53

7.2.2 Side-on Wind Tests ........................................... 55

7.2.3 Head-on Wind Tests ............................................ $\quad 59$

7.3 Hypothesized Flow Patterns In and Around the Receiver ................... 59

8.0 Reliability of Test Results ................................................ 65

8.1 Uncertainty in Temperature Measurements .............................. 65

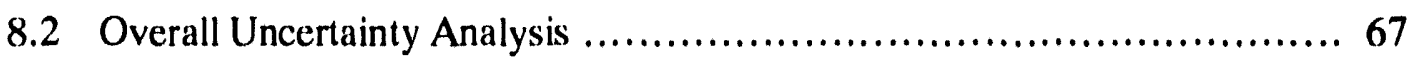

9.0 Comparison of Analytical Predictions to Experimental Results .................. 70

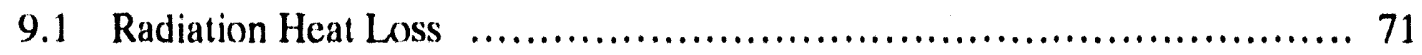

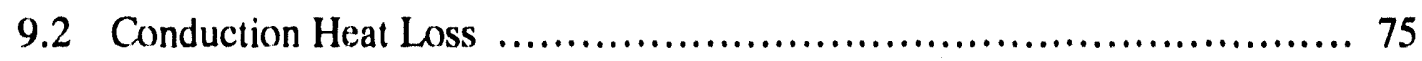




\begin{tabular}{|c|c|}
\hline & Page \\
\hline $10.0 \mathrm{Co}$ & 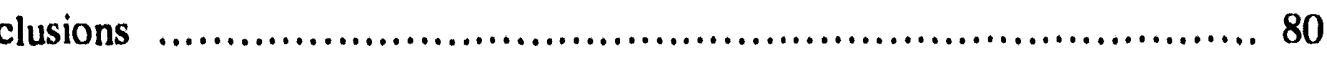 \\
\hline Referenc & s \\
\hline List of S & 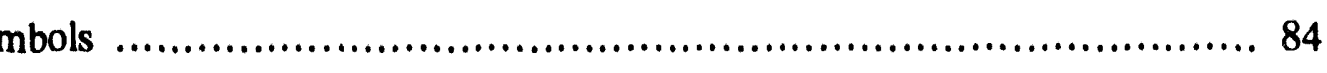 \\
\hline Appendi & \\
\hline A & 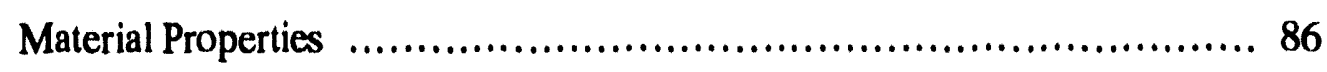 \\
\hline B & 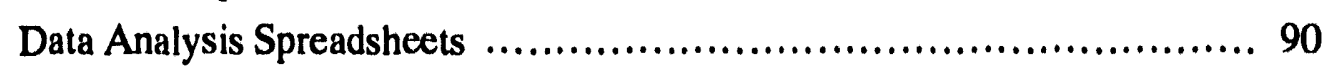 \\
\hline $\mathrm{C}$ & Tabulated Summary of Receiver Heat Loss Results ..................... 127 \\
\hline $\mathrm{D}$ & Tabulated Measured Receiver Temperatures $\ldots . \ldots \ldots \ldots \ldots \ldots \ldots \ldots \ldots \ldots \ldots . \ldots \ldots$ \\
\hline $\mathrm{E}$ & Thermoelectric Characteristics of Type-K Thermocouples ............... 140 \\
\hline $\mathbf{F}$ & 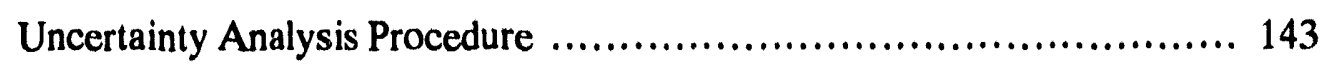 \\
\hline
\end{tabular}




\section{List of Figures}

Figure

Page

1 Illustration of cavity receiver tested $\ldots \ldots \ldots \ldots \ldots \ldots \ldots \ldots \ldots \ldots \ldots \ldots \ldots \ldots \ldots, 3$

2 Receiver-orientation and wind-direction conventions ..................... 5

3 Natural convective heat loss from receiver at $530^{\circ} \mathrm{F} \ldots \ldots \ldots \ldots \ldots \ldots \ldots \ldots . . . \ldots 12$

4 Illustration of stagnant and convective zones in a cavity receiver ........... 14

5 Predicted and experimental natural convective heat loss from

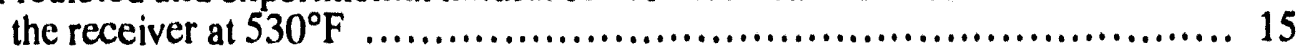

6 Average conduction, radiation, and convection heat loss for the six no-wind test sets $\left(530^{\circ} \mathrm{F}\right.$ receiver temperature) $\ldots \ldots \ldots \ldots \ldots \ldots \ldots \ldots \ldots$

7 Heat loss components from receiver at $530^{\circ} \mathrm{F}$ without wind

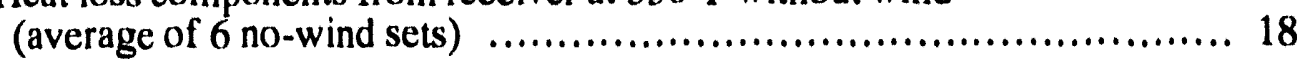

8 Convective heat loss from receiver at $530^{\circ} \mathrm{F}$ for side-on winds

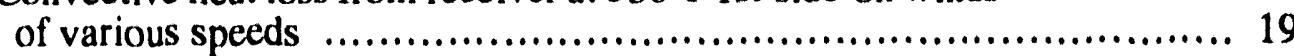

9 Convective heat loss from receiver at $530^{\circ} \mathrm{F}$ for head-on winds of various speeds

10 Convective heat loss from receiver as a function of wind speed for side-on winds $\left(530^{\circ} \mathrm{F}\right.$ receiver temperature)

11 Convective heat loss from receiver as a function of wind speed for head-on winds $\left(530^{\circ} \mathrm{F}\right.$ receiver temperature)

12 Increased convective heat loss from receiver due to side-on wind, i.e., total convective heat loss minus natural convective heat loss $\left(530^{\circ} \mathrm{F}\right.$ receiver temperature)

13 Increased convective heat loss due to side-on wind: experimental vs. predictions $\left(530^{\circ} \mathrm{F}\right.$ receiver temperature $) \ldots \ldots \ldots \ldots \ldots . \ldots 26$

14 Receiver heat loss components at $530^{\circ} \mathrm{F}$ for 20 -mph side-on wind ......... 28

15 Increased convective heat loss from receiver due to head-on wind, i.e., total convective heat loss minus natural convective heat loss $\left(530^{\circ} \mathrm{F}\right.$ receiver temperature)

16 Convective heat loss results from all head-on wind tests $\left(530^{\circ} \mathrm{F}\right.$ receiver temperature)

17 Comparison of increased convective heat loss due to head-on wind obtained experimentally and using the correlation of Eq. (14) $\left(530^{\circ} \mathrm{F}\right.$ receiver temperature)

18 Increased convective heat loss due to head-on wind: experimental vs. correlation of Eq. (14) $\left(530^{\circ} \mathrm{F}\right.$ receiver temperature) 34

19 Receiver thermocouple locations 
20 Vertical coordinate system used for plotting air temperatures inside receiver

21-24 Air temperature as a function of vertical location in the receiver for various receiver tilt angles and no wind (all six no-wind test sets)

25-28 Air temperature as a function of vertical location in the receiver for various receiver tilt angles and side-on winds

29-32 Air temperature as a function of vertical location in the receiver for various recuiver tilt angles and head-on winds

33 Average air temperatures inside receiver for the six no-wind lest sets

34 Average internal heat transfer coefficients for the six no-wind test sets ..... 56

35 Average air temperatures inside receiver for side-on winds $\ldots \ldots \ldots \ldots \ldots \ldots . .57$

36 Average internal heat transfer coefficients for side-on winds . ............. 58

37 Average air temperatures inside receiver for head-on winds ...............60

38 Average internal heat transfer coefficients for head-on winds $\ldots \ldots \ldots \ldots \ldots$ 6]

39 Illustration of natural convection from cavity receiver tested . ..............62

40 Illustration of receiver convection due to head-on and side-on winds ....... 64

41 Comparison of direct and indirect measurements of temperature difference

42 Receiver heat loss uncertainties

43 Computer thermal model used to help predict radiation and conduction heat loss from the receiver

44 Typical temperature distribution on the receiver interior surfaces ( $90^{\circ}$ no-wind test from 6-mph side-on wind test set)

45 Predicted radiation heat loss from the receiver as a function of nominal receiver temperature

46 Receiver structure conduction paths

A1 Specific heat of Syltherm ${ }^{\circledR} 800$ heat transfer fluid ........................ 87

A2 Density of Syltherm ${ }^{\circledR} 800$ heat transfer fluid ............................ 88

A3 Thermal conductivity of Kaowool insulation ............................ 89

E1 Thermoelectric voltage of a type-K thermocouple for the temperature range of interest

E2 Thermoelectric sensitivity of a type-K thermocouple for the temperature range of interest 


\section{List of Tables}

Table

B1-B3 Data Analysis Spreadsheets - Side-on Wind ........................ 91-102

B4-B6 Data Analysis Spreadsheets - Head-on Wind ........................ 103-114

B7-B9 Data Analysis Spreadsheets - Additional Head-on Wind Tests (Second Test Series)

C1 Summary of Conduction, Radiation, and Convection Heat Losses from the Receiver at $530^{\circ} \mathrm{F}$ for the No-Wind Tests (6 Sets Corresponding to 6 Wind-Condition Sets) from the First Test Series

C2 Summary of Conduction, Radiation, and Convection Heat Losses from the Receiver at $530^{\circ} \mathrm{F}$ for Side-on Wind Tests from the First Test Series

C3 Summary of Conduction, Radiation, and Convection Heat Losses from the Receiver at $530^{\circ} \mathrm{F}$ for Head-on Wind Tests from the First Test Series

C4 Summary of Conduction and Convection Heat Losses from the Receiver at $530^{\circ} \mathrm{F}$ for Head-on Wind Tests from the Second Test Series

D1-D3 Measured Receiver Temperatures - Side-on Wind $134-136$

D4-D6 Measured Receiver Temperatures - Head-on Wind $137-139$ 


\subsection{Introduction}

One of the parameters which affects the overall system efficiency of parabolic-dish concentrating solar energy systems is the efficiency of the receiver used. An understanding of the various modes of heat transfer from the receiver is required in order to adequately predict receiver efficiency. Radiation and conduction heat losses from the receiver can be predicted reasonably well by analytical techniques; however, convection from the cavity is much more complicated and, at present time, is not amenable to analytical predictions. Wind effects and varying receiver orientation make it an even more difficult phenomenon to predict analytically. Because of these reasons, convective heat loss from a cavity receiver is usually determined experimentally.

In the past few years, several test series have been conducted by the Mechanical Engineering Department at California State Polytechnic University, Pomona, to determine the convective heat loss characteristics of a cavity receiver for a parabolic-dish concentrating solar collector. The goal early in these test series was to determine natural convective heat losses from the receiver for variou. receiver tilt angles, temperatures, and apertures sizes. Recently, however, test efforts have concentrated on the effects of wind on convective heat loss from the cavity receiver. Wind speeds up to $24 \mathrm{mph}(10.7 \mathrm{~m} / \mathrm{s})$ from two directions have been tested in conjunction with various receiver tilt angles, from aperture facing horizontally to aperture facing down.

This thesis presents and interprets the results from these latest tests, which are focused on wind effects. Data from these tests are reduced to obtain convective heat loss correlations for the different wind conditions, and an uncertainty analysis is performed in order to determine data reliability. An attempt is made to explain some of the physical phenomena underlying the convective transport for the various test conditions. Where possible, test results are compared with results from past studies. The convective heat loss correlations developed should aid in the design process and serve as background for future studies. 


\subsection{Experimental Setup}

The cavity receiver tested is from a parabolic-dish concentrating solar collector from the Shanandoah Project, located in Shanandoah, Georgia. The receiver, shown in Figure 1 , is a tube-wound type and is cylindrical in shape. Onc end of the receiver is a closed conical frustum, and the other end consists of a cylindrical section with an 18-inch $(46-\mathrm{cm})$ diameter aperture. The maximum receiver internal diameter is 26 inches $(66 \mathrm{~cm})$ and the internal length is 27 inches $(69 \mathrm{~cm})$. The receiver tubing is 0.5 inch $(12.7 \mathrm{~mm})$ outer diameter and is made of stainless stecl. The region outside the tubing is packed with Kaowool ${ }^{1 M}$ (Babcock and Wilcox) insulation and the entire assembly is covered with a chrome-plated-steel shell. The receiver is mounted in a stand which permits 180 degrees of rotation in $15^{\circ}$ increments, from aperture-down $\left(+90^{\circ}\right)$ to aperture-up $\left(-90^{\circ}\right)$, with $0^{\circ}$ defined as the aperture facing horizontally. (In these tests, only receiver tilt angles of $0^{\circ}$ to $+90^{\circ}$ were examined).

The tests were performed in a laboratory environment without solar insolation. The basic methodology for determining receiver heat loss was to flow hot heat transfer fluid (Syltherm ${ }^{\circledR} 800$, Dow Corning) through the receiver and calculate overall receiver heat loss based on the measured temperature drop of the heat tra.sfer fluid. The heat transfer fluid was supplied from a flow loop containing pumps, electric heaters, and appropriate controls and expansion volume. When wind was required, it was generated by a $4^{\prime} \times 4^{\prime} \times 14^{\prime}$ wind machine driven by a 4-ft diameter fan. The airstream was run through several honeycombed screens to ensure that the air velocity was uniform at the receiver.

The primary test measurements were recorded on a digital data acquisition system. At the receiver inlet and uutlet, the heat transfer fluid temperature was measured with two type-K immersion thermocouple probes, located at piping bends to provide good flow mixing. One probe at earh location was connected directly to the cold-junction compensation of the data acquisition system, providing a measurement of absolute fluid temperature. The other two probes were connected together to obtain a direct measurement of temperature difference between the receiver inlet and outlet. Volumetric flow of heat transfer fluid to the receiver was measured by a turbine-type flow meter. 


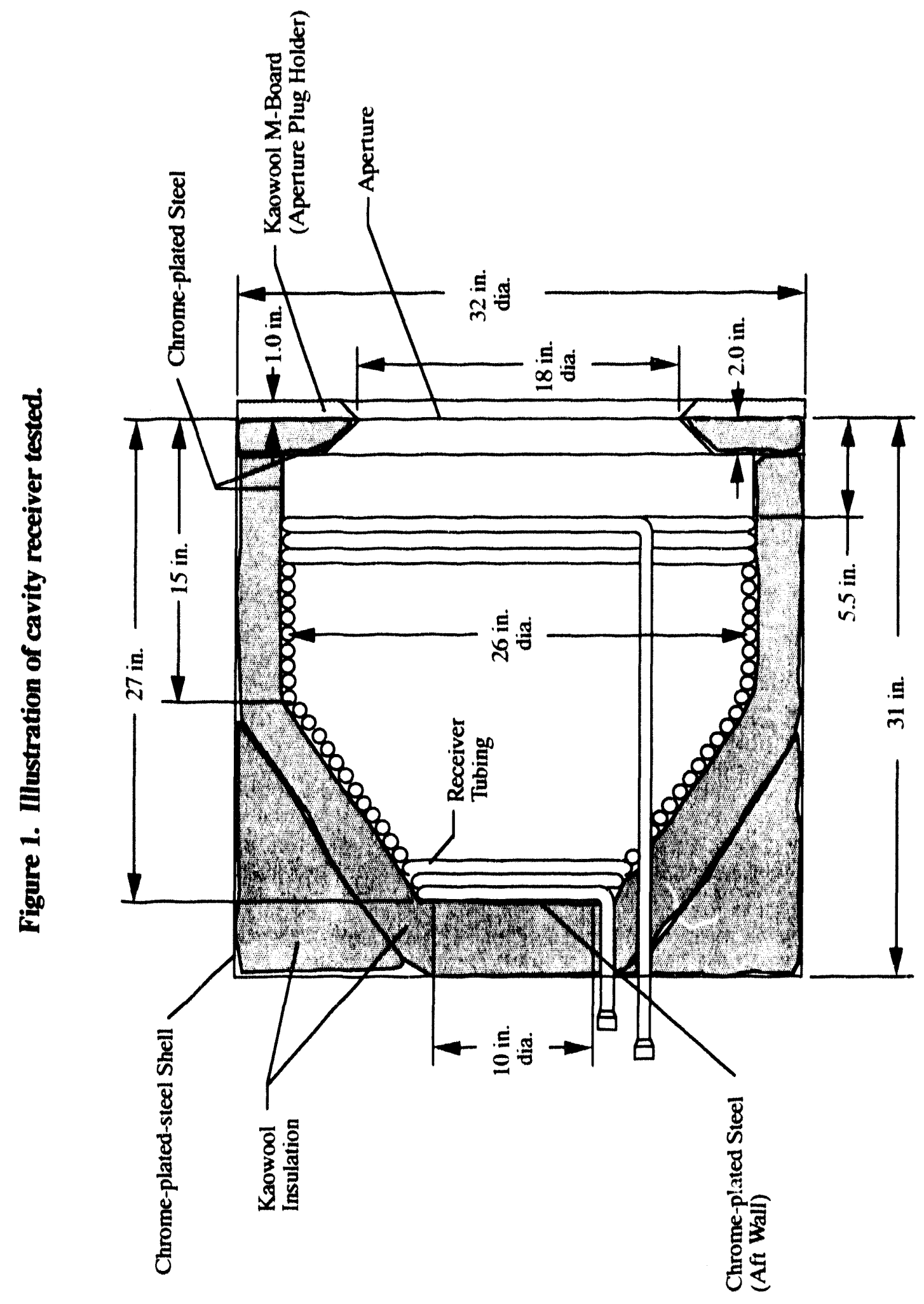


A more detailed description of the experimental apparatus is documented in Haddad (1991). Earlier tests dealing with natural convective heat loss, for various receiver temperatures, orientations, and aperture sizes, are described in McDonald (1992).

\subsection{Test Matrix}

The test results presented are from the two most recent receiver test series. The majority of this thesis focuses on the first of the two series, which was conducted in order to determine receiver convective heat loss for different wind conditions and receiver tilt angles. Head-on and side-on winds of 6,8 , and $20 \mathrm{mph}(2.7,3.6$, and $8.9 \mathrm{~m} / \mathrm{s})$ were tested in conjunction with receiver tilt angles of $0^{\circ}, 30^{\circ}, 60^{\circ}$, and $90^{\circ}$. Figure 2 illustrates the wind-direction convention relative to the receiver. For this first test series, the no-wind condition was tested every time a new wind speed and direction were tested, so that a total of six no-wind test sets were conducted. In this way, the level of convective heat loss without wind was fully established.

As the data from the first test series were being examined, it became clear that some interesting and counter-intuitive convective heat loss results were occurring for the head-on wind tests. Therefore, to confirm some of these results and to obtain a better understanding, a second small test series was conducted for head-on winds only. The test conditions for this second test series were chosen specifically to clear up the areas of uncertainty from the first test series. Wind speeds of 15 and $24 \mathrm{mph}(6.7$ and $10.7 \mathrm{~m} / \mathrm{s})$ were tested to better define the dependence of head-on wind convective heat loss upon wind speed. For the 24-mph wind speed, data were collected for receiver tilt angles at $15^{\circ}$ increments, to better define the dependence of convective heat loss upon receiver tilt angle. In addition, a smaller receiver aperture of 6 inches was also examined for a 24-mph wind, in order to check if the same trends occur for a different aperture size. For this second test series, convective heat loss tests for the no-wind condition were not performed.

\subsection{Test Procedure}

During testing at each wind condition, data were first collected with the aperture facing down and plugged, both with and without wind. Then the various receiver tilt angles were tested with the aperture open, again with and without wind. During each test, 
Figure 2. Receiver-orientation and wind-direction conventions.

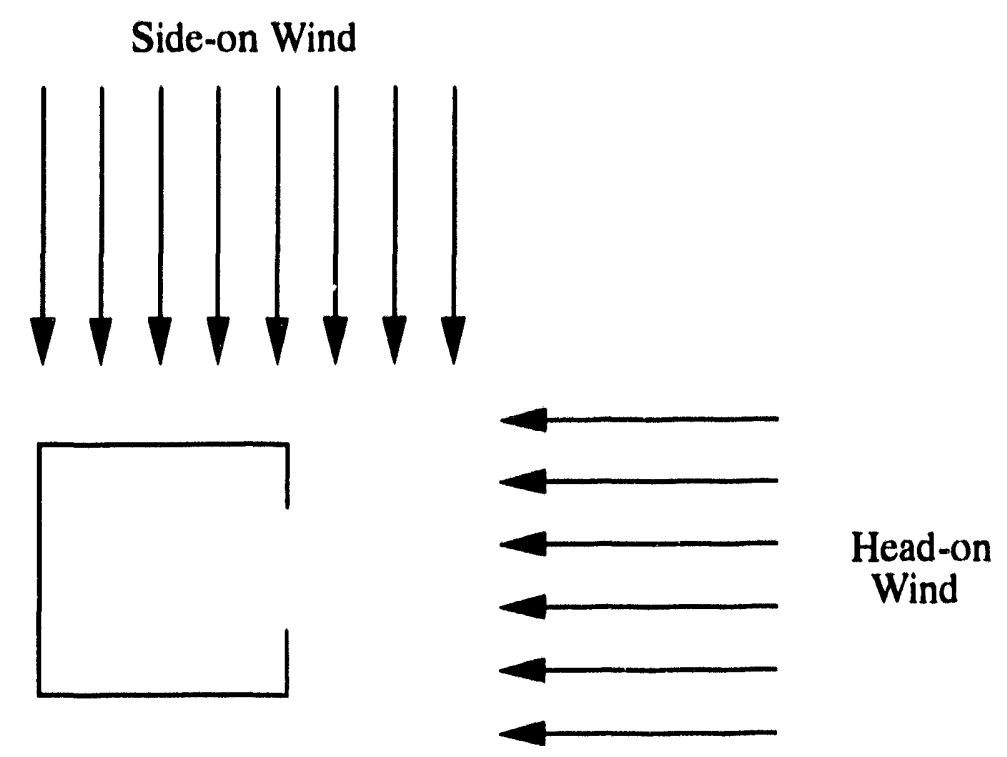

Top View - Looking Down

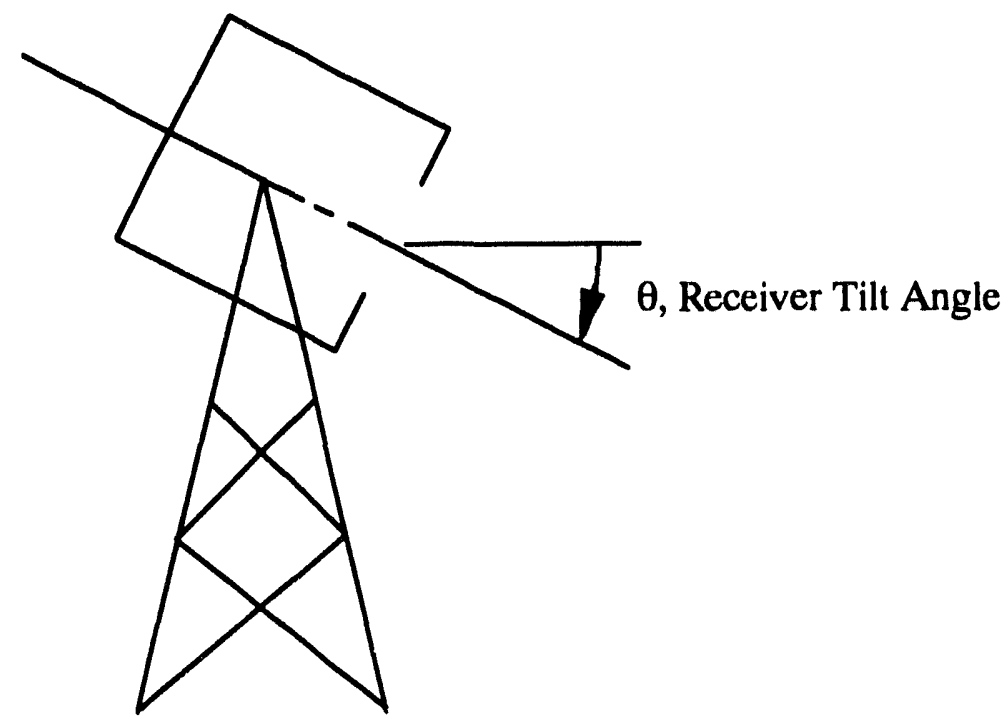

\section{Elevation View}


heat transfer fluid was passed through the receiver until the measured temperatures stabilized. Then pertinent data, such as heat-transfer-fluid inlet and outlet temperatures, inlet-to-outlet temperature difference, ambient temperature, and heat-transfer-fluid flow rate, were recorded. The total receiver heat loss for each test was subsequently calculated using the following equation:

$$
q_{\text {meas }}=\dot{m} c_{p}\left(T_{\text {in }}-T_{\text {out }}\right)
$$

$$
\begin{aligned}
& \text { where } \quad \begin{array}{l}
q_{\text {meas }}=\text { total receiver heat loss rate calculated from measurements } \\
\dot{m}=\text { measured heat-transfer-fluid mass flow rate } \\
c_{p}=\text { heat-transfer-fluid specific heat } \\
\mathrm{T}_{\text {in }}=\text { measured heat-transfer-fluid temperature at inlet } \\
\mathrm{T}_{\text {out }}=\text { measured heat-transfer-fluid temperature at outlet }
\end{array}
\end{aligned}
$$

The thermal properties of Syltherm ${ }^{\circledR} 800$ heat transfer fluid which are required for the evaluation of Eq. (1) are given in Appendix A.

To allow for the comparison of heat losses from one test to another, all of the measured heat losses were normalized linearly to a receiver temperature of $530^{\circ} \mathrm{F}$ and an ambient temperature of $70^{\circ} \mathrm{F}$, according to

$$
q_{\text {total }}=\frac{q_{\text {meas }}\left(T_{\text {rec, norm }}-T_{a m b, \text { norm }}\right)}{T_{\text {rec, meas }}-T_{a m b, \text { meas }}}
$$

where $\quad q_{\text {total }}=$ normalized total heat loss rate $\mathrm{q}_{\text {meas }}=$ total measured heat loss rate defined in Eq. (1)

$\mathrm{T}_{\text {rec, }}$ meas $=$ measured receiver temperature

(average temperature of the heat transfer fluid)

$\mathrm{T}_{\mathrm{amb}}$, meas $=$ measured ambient temperature

$\mathrm{T}_{\mathrm{rec}}$ norm $=$ nominal or normal receiver temperature $\left(530^{\circ} \mathrm{F}\right)$

$\mathrm{T}_{\mathrm{amb}, \text { norm }}=$ nominal or normal ambient temperature $\left(70^{\circ} \mathrm{F}\right)$ 
A nominal receiver temperature of $530^{\circ} \mathrm{F}$ was chosen because it represents the average receiver temperature among the different tests and would therefore require the least amount of normalization. This normalization procedure is justified since the deviation of the measured temperatures from the nominal temperatures is small.

Conduction heat loss from the receiver was calculated as the total receiver heat loss measured with the aperture plugged, minus the calculated amount of conduction through the aperture plug. Radiation heat loss was calculated as the total receiver heat loss with the aperture open, at a receiver orientation of $90^{\circ}$ and without wind, minus the conduction heat loss without wind. According to Stine and McDonald (1988 and 1989), Koenig and Marvin (1981), and Kugath et al. (1979), natural convection from a cavity receiver at $90^{\circ}$ tilt angle is essentially zero; therefore, the calculation of radiation heat loss in this manner is justified. Finally, convective heat loss from the receiver was calculated by subtracting radiation and conduction heat losses from the total receiver heat loss:

$$
q_{\text {conv }}=q_{\text {total }}-q_{\text {rad }}-q_{\text {cond }}
$$

\subsection{Background}

\subsection{Natural Convection Correlations}

Because of the complex natural convection phenomena occurring in cavity receivers, it is very difficult to analytically predict receiver natural convective heat loss. Design correlations for estimating natural convective heat loss from cavity receivers are usually derived experimentally.

Koenig and Marvin (1981) performed one such experiment and developed the following correlation for natural convection from cavily receivers:

$$
\begin{aligned}
& \overline{N u}_{L}=\frac{h \mathrm{~L}}{k}=0.52 \mathrm{P}(\theta) \mathrm{l}_{\mathrm{c}}{ }^{1.75}\left(\mathrm{Gr}_{\mathrm{l}} \mathrm{Pr}\right)^{0.25} \\
& q_{\text {conv }}=\bar{h} A_{T}\left(T_{\text {cavily }}-T_{0}\right)
\end{aligned}
$$


where

$$
\begin{aligned}
& P(\theta)=\cos ^{3.2} \theta \quad \text { when } 0^{\circ} \leq \theta \leq 45^{\circ} \\
& P(\theta)=0.707 \cos ^{2} 2 \theta \quad \text { when } 45^{\circ} \leq \theta \leq 9()^{\circ} \\
& \theta=\text { receiver tilt angle } \\
& I_{c}=R_{\text {aperture }} / R_{\text {cavity }} \\
& L=\sqrt{ } 2 R_{\text {chvily }} \\
& \mathrm{Gr}_{1}=\frac{g \beta\left(\mathrm{T}_{\text {cavily }}-\mathrm{T}_{\mathrm{o}}\right) \mathrm{L}^{3}}{v^{2}} \\
& A_{r}=\text { exposed surface area of receiver heat transfer tubing } \\
& \mathrm{T}_{\text {cavity }}=\text { average temperature of heat transfer lubing } \\
& \mathrm{T}_{\mathrm{o}}=\text { ambient temperature } \\
& B=\text { coefficient of thermal expansion of air }=1 / \mathrm{T} \\
& v=\text { kinematic viscosity of air }
\end{aligned}
$$

where all fluid properties are evaluated at

$$
\mathrm{T}_{\text {prop }}=11 / 16 \mathrm{~T}_{\text {cavity }}+3 / 16 \mathrm{~T}_{0}
$$

Note that the area used in Eq. (5) is the exposed area of the heat transfer tubing inside the receiver.

Stinc and McDonald (1988) found that for the cavity receiver described in this thesis, natural convective heat loss is better predicted if the constant in Eq. (4) is 0.78 , instead of 0.52 , and if the full interior geometric surface area of the cavity is used (i.e., the interior area covered with heat transfer tubing should be considered planar). The resultant equation is referred to in this report as the modified Koenig and Marvin correlation:

$$
\overline{\mathrm{Nu}}_{L}=0.78 \mathrm{P}(\theta) \mathrm{l}_{\mathrm{c}}^{1.75}\left(\mathrm{Gr}_{\mathrm{L}} \mathrm{Pr}\right)^{0.25}
$$

Siebers and Kraabel (1984) reported the following correlation for predicting turbulent natural convection from central receiver cubical cavities, over the range of $10^{5} \leq$ $\mathrm{Gr}_{1} \leq 10^{12}$ :

$$
N u_{L}=0.088 G r_{l}^{1 / 3}\left(\frac{T_{w}}{T_{0}}\right)^{0.18}
$$




$$
\begin{aligned}
& \text { where } \quad \begin{array}{l}
\mathrm{L}=\text { heigist of the interior of the cavity } \\
\mathrm{T}_{0}=\text { ambient temperature, } K \text { or }{ }^{\circ} \mathrm{R} \\
\mathrm{T}_{\mathrm{w}}=\text { average internal wall temperature, } K \text { or }{ }^{\circ} \mathrm{R}
\end{array}
\end{aligned}
$$

This correlation was derived based on the results of a large $2.2-\mathrm{m}$ cubical cavity experiment performed by Kraabel (1983), and experiments of (0.2-m and 0.6-m cubical cavities performed by LeQuere, Penot, and Mirenayat (1981). To account for the effects of receiver tilt angle and the addition of "lips" at both the top and the bottom of the receiver aperture, a method using receiver area ratios is also described by Sichers and Kraabel (1984). In Eq. (7), all fluid properties are evaluated at ambient temperature, and the area to be used for heat transfer calculations is the full interior geometric surface area of the receiver.

Stine and McDonald (1989) performed natural convective heat loss experiments on the cavity receiver described in this report. Their experiments included the effects of different receiver temperatures, tilt angles, and aperture sizes. Using the Sichers and Kraabel correlation [Eq. (7)] as a basis, the effects of different receiver temperatures, orientations, and aperture sizes were included to obtain the following equation:

$$
\mathrm{Nu}=0.088 \mathrm{Gr}_{\mathrm{l}}^{1 / 3}\left(\mathrm{~T}_{\mathrm{w}} \mathrm{T}_{\mathrm{o}}\right)^{0.18}(\cos ) 1^{2.47}\left(\begin{array}{l}
\mathrm{d} \\
\mathrm{L}
\end{array}\right)^{\mathrm{s}}
$$

$$
\begin{aligned}
& \text { where } \quad s=1.12 \cdot 0.982(d / L) \\
& \mathrm{d}=\text { aperture diameter } \\
& \mathrm{L}=\text { receiver internal diameter at cylindrical region } \\
& \theta=\text { receiver tilt angle }
\end{aligned}
$$

In this report, this correlation is referred to as the Stine-McDonald correlation. The heat transfer area to be used with Eq. (8) depends on whether solar insolation is present. For off-sun testing, only the portion of the receiver interior geometric surface area covered with heat transfer tubing should be used. For on-sun situations, the entire receiver interior geometric surface area should be used. 
It is worth noting that in all of the equations above which account for varying receiver tilt angle, natural convective heat loss from the receiver is predicted to be maximum with the aperture facing horizontally $\left(0^{\circ}\right.$ tilt angle) and zero with the aperture facing down $\left(90^{\circ}\right.$ tilt angle).

\subsection{Forced Convection Correlations}

No correlations are available for predicting forced or mixed convection from cavity receivers. Few experimental investigations have been performed in this area, with the results being somewhat contradictory.

Clausing (1981) performed simplified numerical experiments which calculated convective heat losses in a large central cavity receiver based on an energy balance of: (1) the energy transferred from the hot receiver interior walls to the air inside the cavity and (2) the energy transfer across the aperture by the combired influences of flow over the aperture due to wind and the buoyancy-induced flow due to the cold external air. The results of this numerical work show that the influence of wind at $18 \mathrm{mph}$ or less is minimal. This finding is in agreement with the experimental results of McMordie (1984) who examined wind effects on convection from central cavity receivers. McMordie found that for winds of 3 to $15 \mathrm{mph}$, wind-speed and wind-direction effects were indistinguishable.

On the other hand, Kugath et al. (1979) measured the effects of a 10-mph wind on convective heat loss from a cavity receiver from the Shanandoah project (similar to the receiver described in this report) and found convective heat loss to be highly dependent upon receiver orientation. The highest convective heat loss was observed with the wind blowing directly into the cavity, being as much as four times the level of natural convection. They also found that for wind blowing from directly behind the receiver, total convective heat loss was not much higher than pure natural convection.

An experimental investigation conducted by Faust et al. (1981) showed that a noticeable increase in receiver convection occurred with a wind speed of only $2 \mathrm{mph}$. In Faust's experiment, it was observed that winds parallel to the aperture plane result in the highest convective heat loss. It was explained that with wind blowing in this direction, the aperture lies in the separation region and is subjected to the suction pressure of the air flow. 
On the other hand, winds perpendicular to the aperture plane were found to reduce convective heat loss because flow stagnation supposedly decreases the pressure gradient responsible for natural convection.

From the studies referred to above, it is apparent that no conclusions can be made regarding forced or mixed convection from cavity receivers. Wind seems 10 have noticeable effects in small cavity receivers for parabolic-dish solar collectors, but little effect in larger cavity receivers for central receiver systems.

In the absence of a reliable correlation to predict forced convection from cavity receivers, Siebers and Kraabel (1984) suggest that as a first approximation, forced convection from a flat plate the size of the aperture and at the receiver average temperature be used. They also recommend that pure foreed and natural convection from a cavity receiver be simply added logether to obtain the total convective heat loss. However, this recommendation is based on engineering judgement sinee there is no directly applicable information on the subject of mixed convection from cavities.

\subsection{Analysis of Direct Measurements of Convection}

This section discusses the experimental results from both the first and second test series; however, because the majority of the results presented here were obtained from the first test series, the discussions will focus on those results. In the remainder of this thesis, all discussions refer to the first test series unless otherwise noted.

The detailed experimental results and data reduction for all of the tests from both test series are given in spreadsheets in Appendix B. Raw experimental data, intermediate

calculated values, and final heat loss results are included in these spreadsheets. A more concise summary of receiver heat losses, due to convection, conduction and radiation, is given in Appendix C.

\subsection{Convective Heat Loss Without Wind}

Figure 3 presents receiver heat loss as a function of tilt angle for all six of the nowind test sets. The results are given for a nominal receiver temperature of $5.30^{\circ} \mathrm{F}$. Natural 


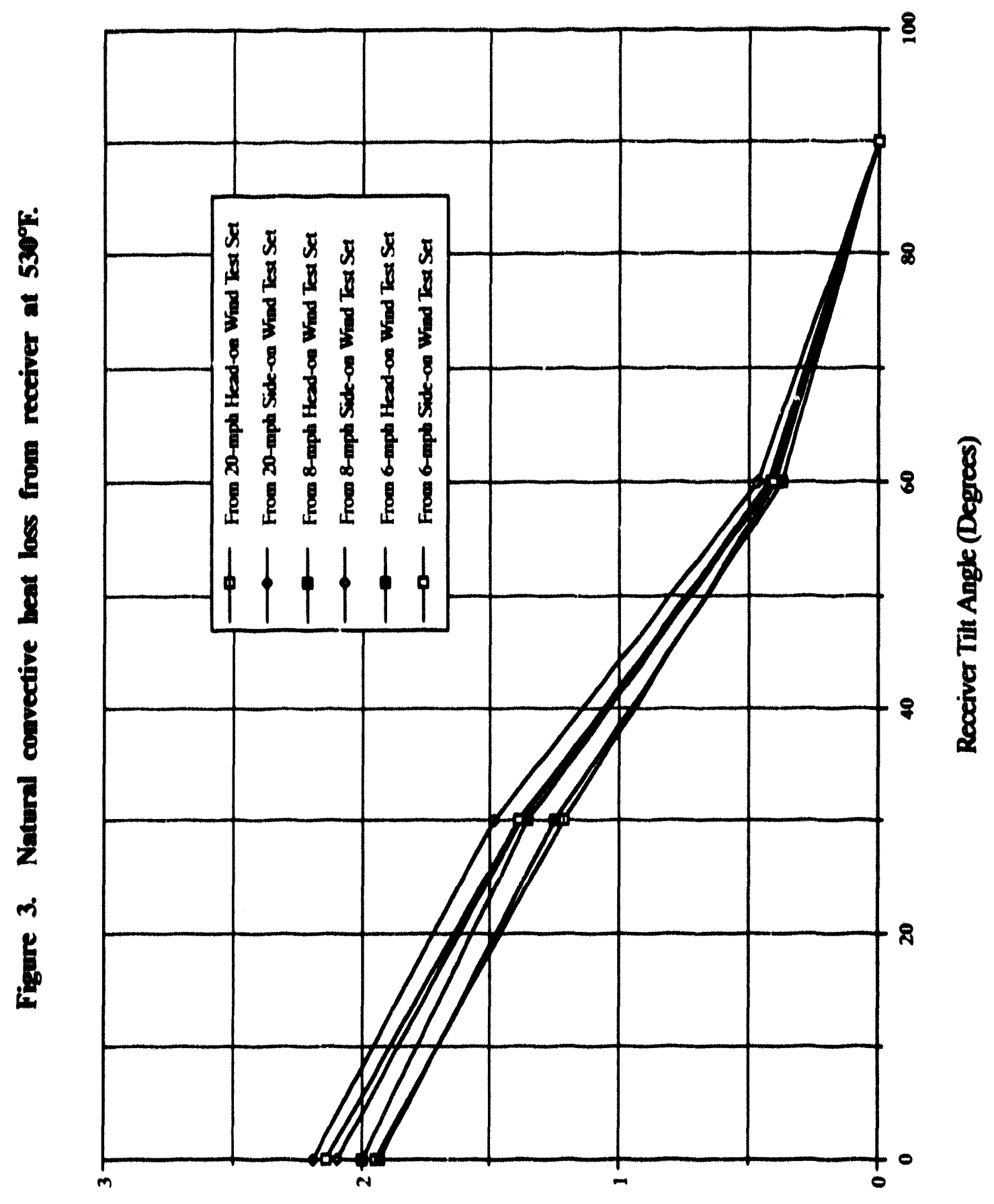

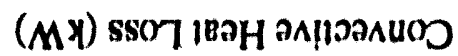


convective heat loss from the receiver is the highest with the receiver facing horizontally ( $\left(0^{\circ}\right.$ receiver tilt angle) and the lowest with the receiver facing straight down $(91)^{\circ}$ receiver tilt angle). With the receiver facing loorizontally, natural convective heil less is approximately $2 \mathrm{~kW}$. With the receiver facing straight down, natural convective heat loss is presumed 10 be zero. From examining Figure 3 , it can be seen that the scatter of convective heat loss data at each receiver tilt angle is reasonably small (about 5-1) percent stundard deviation), which suggests that these experimental results are quite repeatable.

These natural convective heat loss results are qualitatively in agreement with the experimental findings of Stine and MeDonald (1988 and 1989), Kugath (1979), Kocnig and Marvin (1981), and Siebers and Kraabel (1984). The decreased natural convective heat loss as the receiver is tilled downward is due to a larger portion of the receiver volume being in the so-called stagnant zone, where convective currents are virtually non-existent and air temperature is high, and a smaller portion being in the so)-called convective zone, where significant air currents exist. This convective behavior is illustraled in Figure 4. It has been observed by Sichers and Kraabel (1984) and Clausing (1981) that the interior volume above the horizontal plane passing through the uppermest portion of the aperture is relatively stagnant and high-temperature air.

The presumption that natural convective heat loss is zero with the receiver facing straight down was necessary in order to separate heat loss components in data reduction and is supported by observations made in the past by Stine and McDonald (1988 and 1989) and Kugath (1979). Recent flow visualization experiments at this facility, using smoke, have also confirmed the lack of convective flow entering or leaving the cavity when it is tilted facing down. The lack of natural convection with the receiver aperture facing down is reasonable considering that the entire receiver internal volume is in the so-called stagnant zone.

Figure 5 compares the experimental results from the six no-wind test sets 11 predictions obtained using the Stine-McDonald correlation $\mid \mathrm{Eq}$. (8)| and the modified Konig-Marvin correlation [Eq. (6)]. The Stine-McDenald correlation matches the experimental data very well, but the modified Koenig-Marvin correlation is as much as 20 percent low. It is emphasized that great care should be taken to ensure that the correct area is used with these heat transfer correlations. The correct area for Eq. (6) is the full interior 

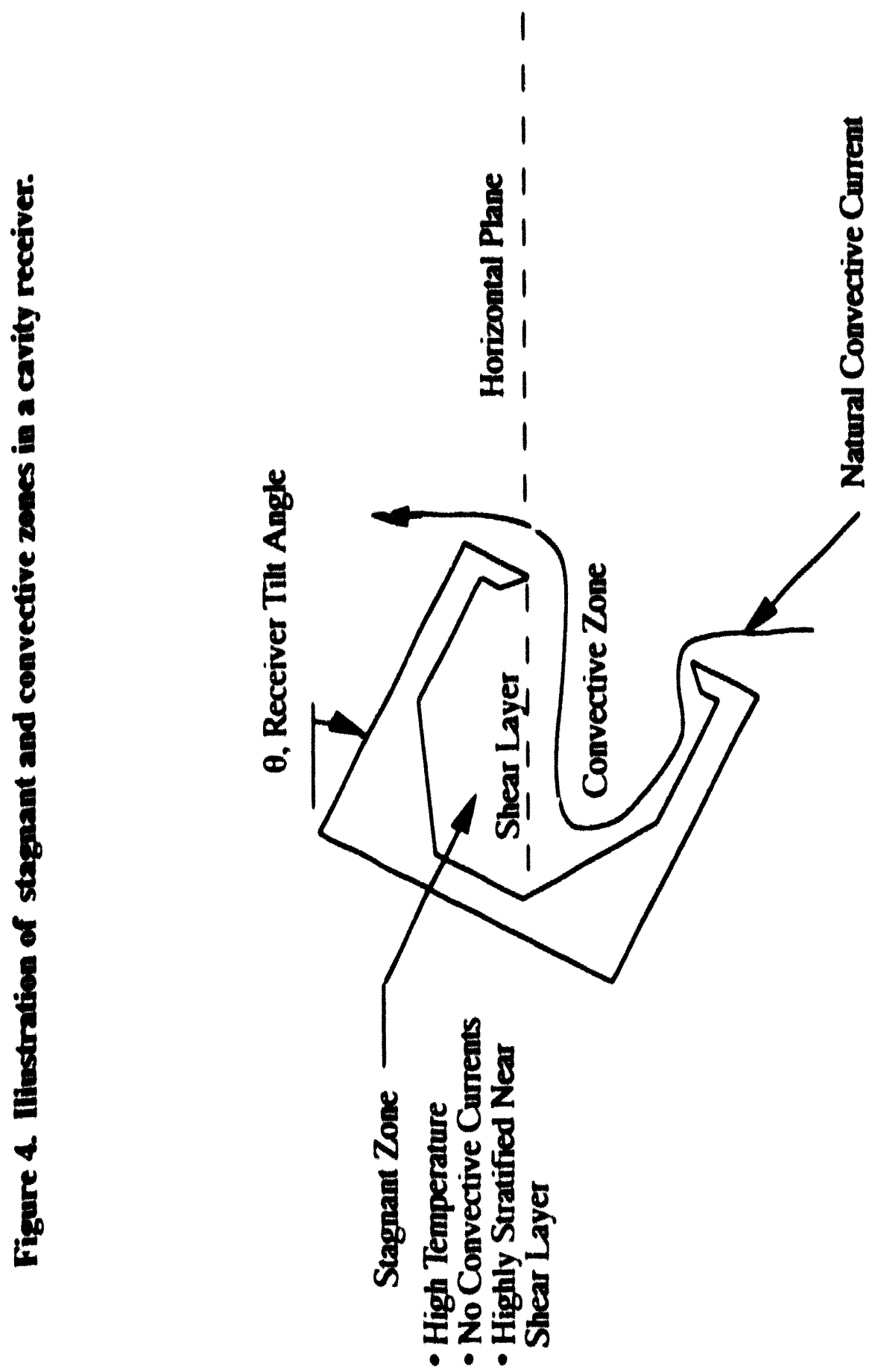


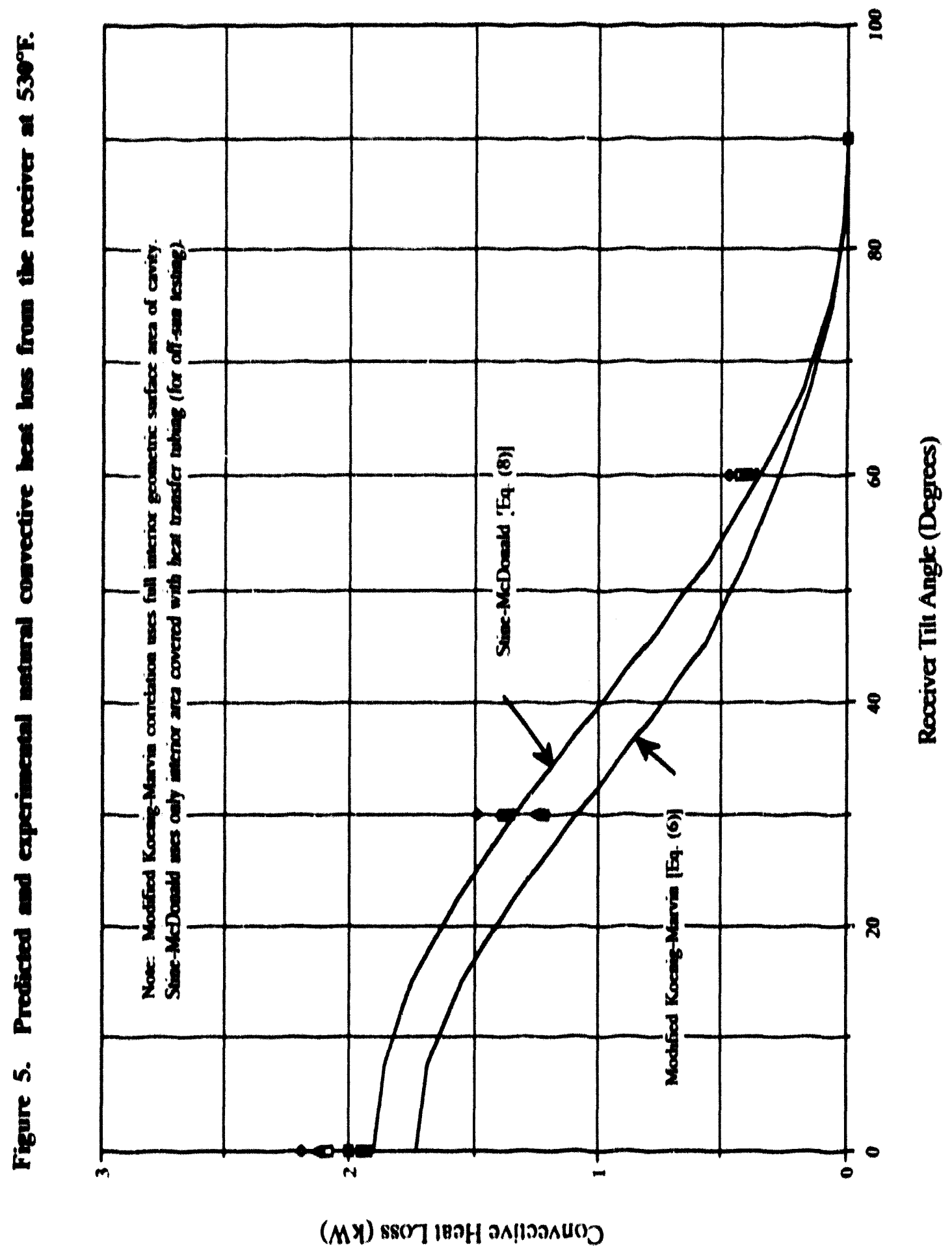


geometric surface area of the receiver, whereas that for Eq. (8) is only the interior area covered with heat transfer tubing (for off-sun testing).

Figure 6 shows the average conduction, radiation, and convection heat losses for the six no-wind tesi sets. While convective heat loss varies as a function of receiver tilt angle, conduction and radiation heat losses are assumed to be independent of tilt angle and are $0.60 \mathrm{~kW}$ and $0.62 \mathrm{~kW}$, respectively. Figure 7 shows the percentage of the total receiver heat loss attributed to the different heat loss modes. At $0^{\circ}$ receiver till angle, natural convection represents about 6.3 percent of the total receiver heat loss. However, at $90^{\circ}$ till angle, natural convection is negligible, and conduction and radiation heat loss percentages are about 50 percent each.

\subsection{Convective Heat Luss With Wind}

Convective heat loss results from the first test series for side-on and head-on winds of 6.8 and $20 \mathrm{mph}(2.7,3.6$, and $8.9 \mathrm{~m} / \mathrm{s})$ are shown in Figures 8 and 9 , respectively. The average of the six no-wind test sets is also shown in each of these figures for reference. For 6- and 8 -mph wind speeds, increases in convective heat loss due to wind are only moderate. The maximum convective heal less for an 8 -mph side-on wind is about 35 percent higher than the maximum natural convective heat loss from the receiver. The corresponding increase for an 8-mph head-on wind is less than 10 percent. However, wind effects at $20 \mathrm{mph}$ are significant, with convective heat loss being as high as 2-3 times the maximum level of natural convection from the receiver.

These experimental results are in sharp contrast to the findings of McMordie (1984) that wind effects on convective heat loss from a cavity receiver are minimal compared to natural convection. A plausible explanation for this discrepancy is that the maximum $\mathrm{Re}^{2} / \mathrm{Gr}$ ratio is about 14 for the lests described here, compared to $\mathrm{Re}^{2} / \mathrm{Grm}$ for McMordie's experiments. It is reasonable that forced convection effects are large in these tests hecause $\mathrm{Re}^{2} / \mathrm{Gr}$ is so large. Nevertheless, $\mathrm{Re}^{2} / \mathrm{Gr}-1$ for McMordie's experiments is large enough that foreed convection should be comparable to natural convection.

By examining Figures 8 and 9 , it is evident that the convective behavior of the receiver is quite different for the different wind directions tested. For side-on winds, 


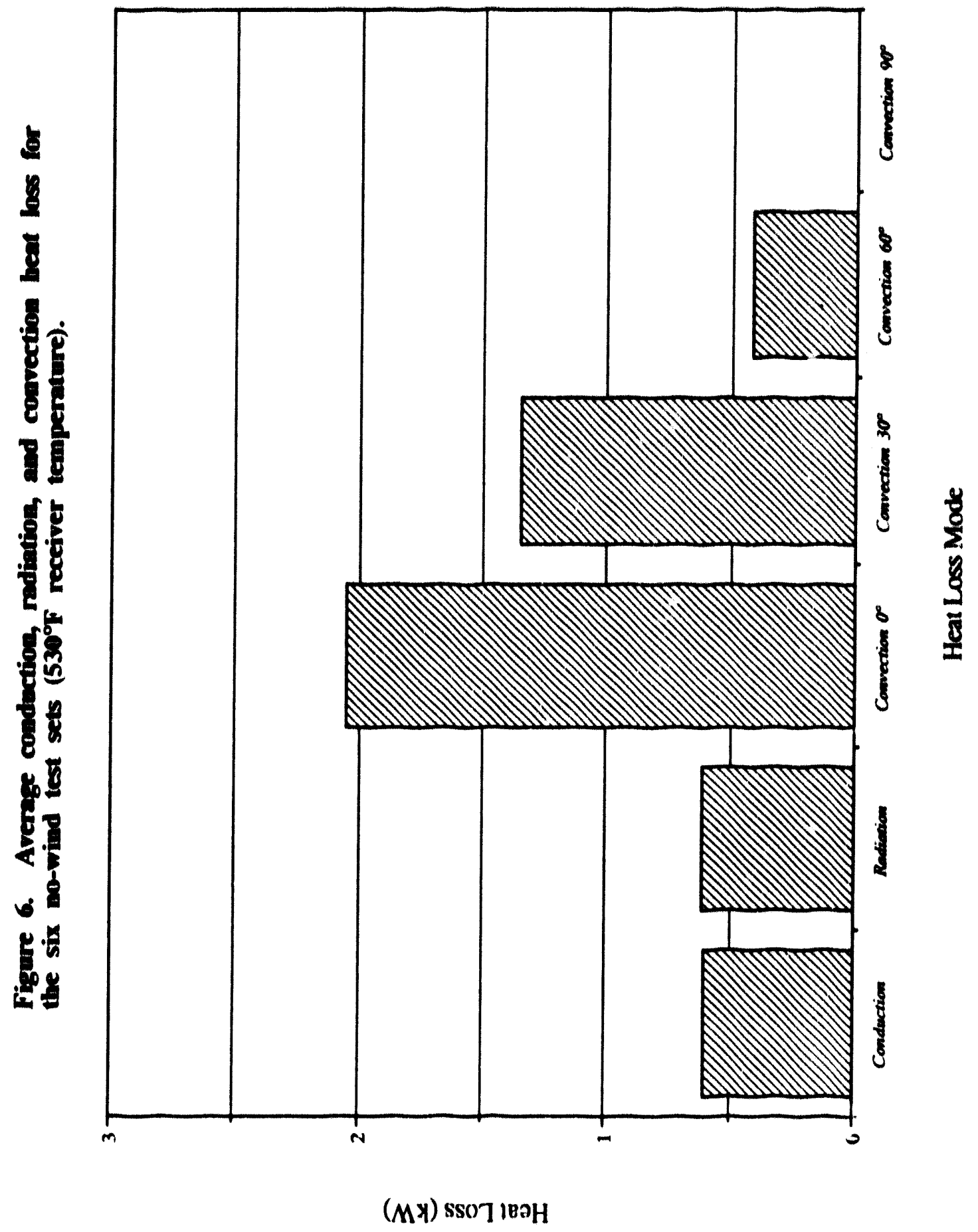




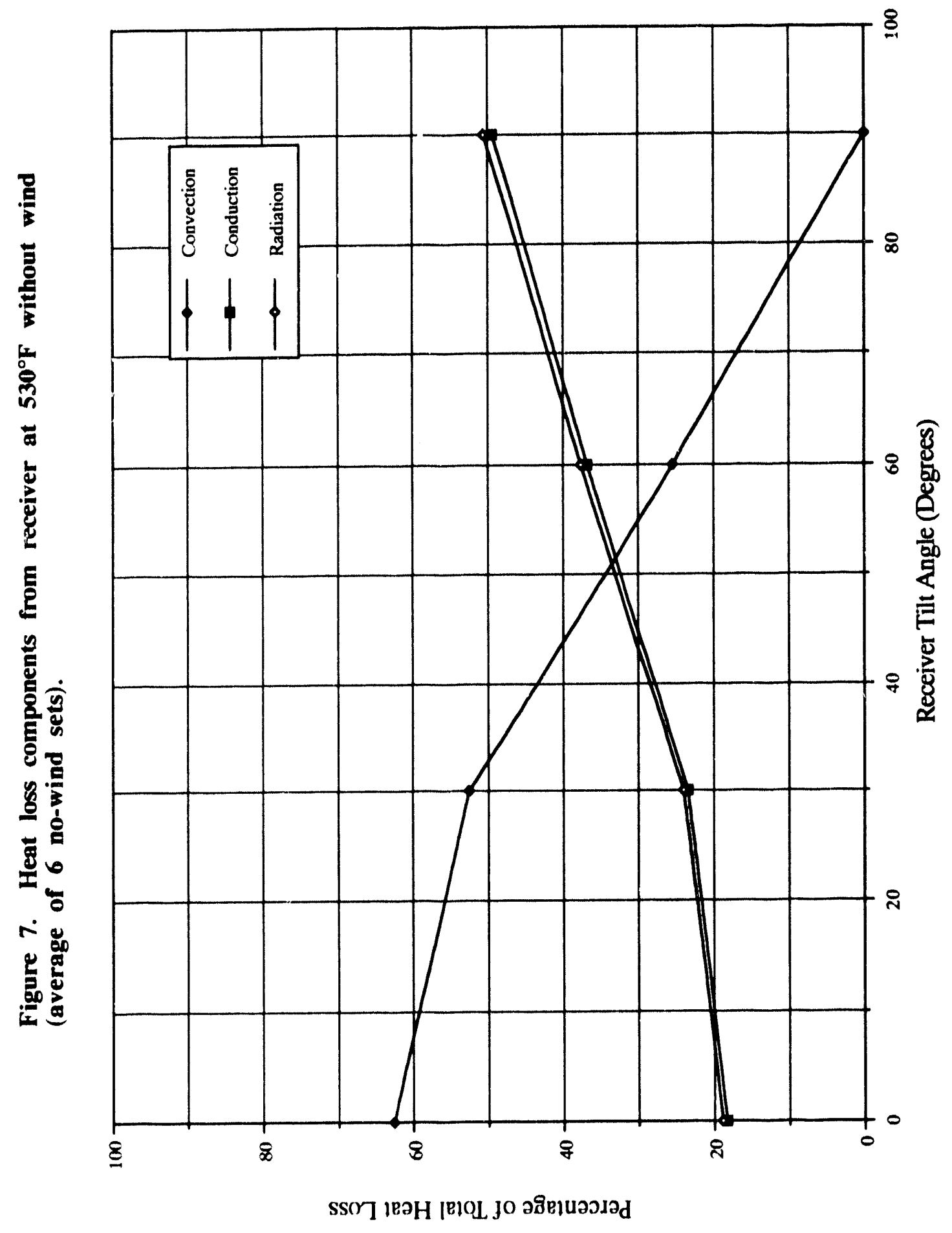


Figure 8. Convective heat loss from receiver at $530^{\circ} \mathrm{F}$ for side-on winds of various speeds.

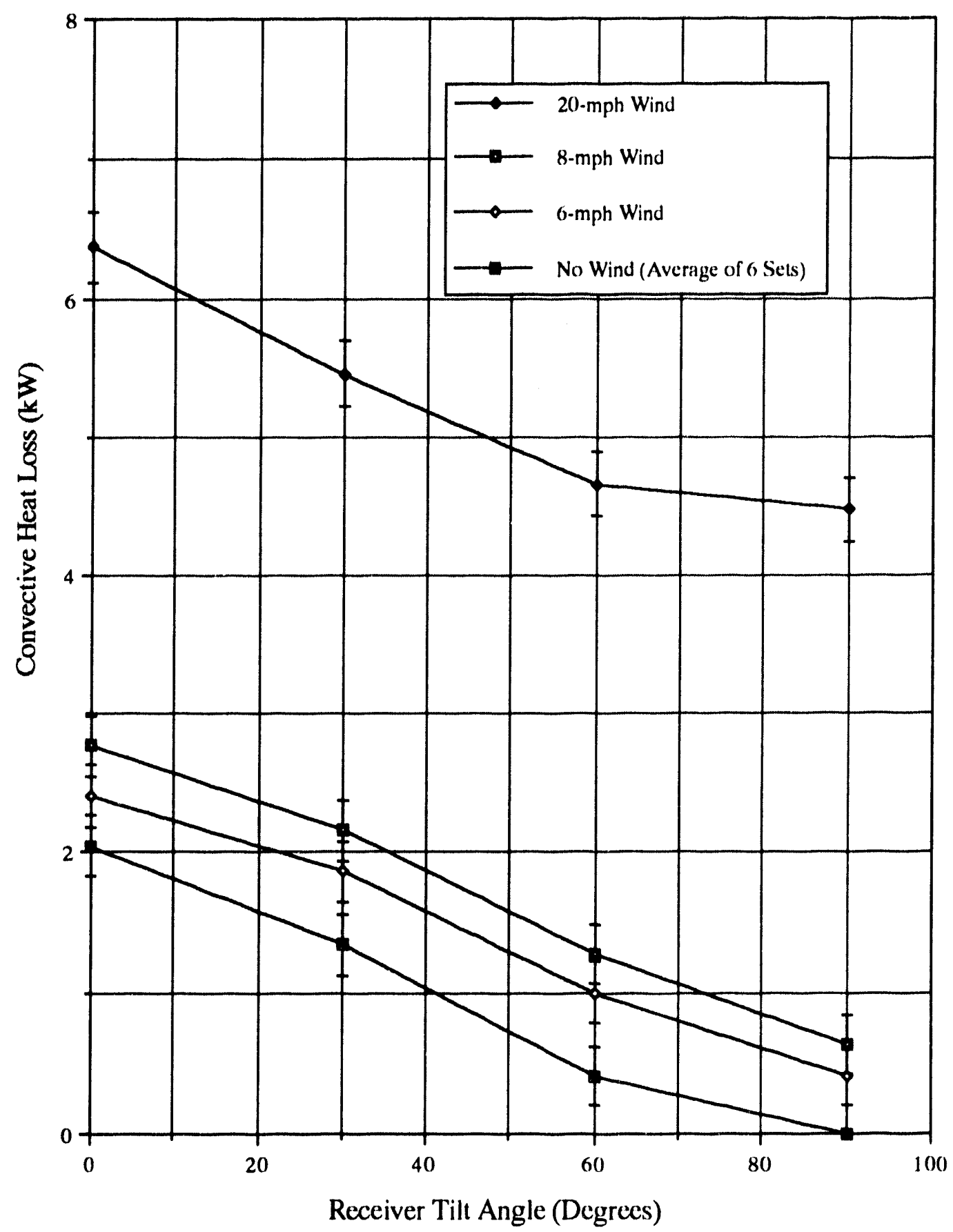


Figure 9. Convective heat loss from receiver at $530^{\circ} \mathrm{F}$ for head-on winds of various speeds.

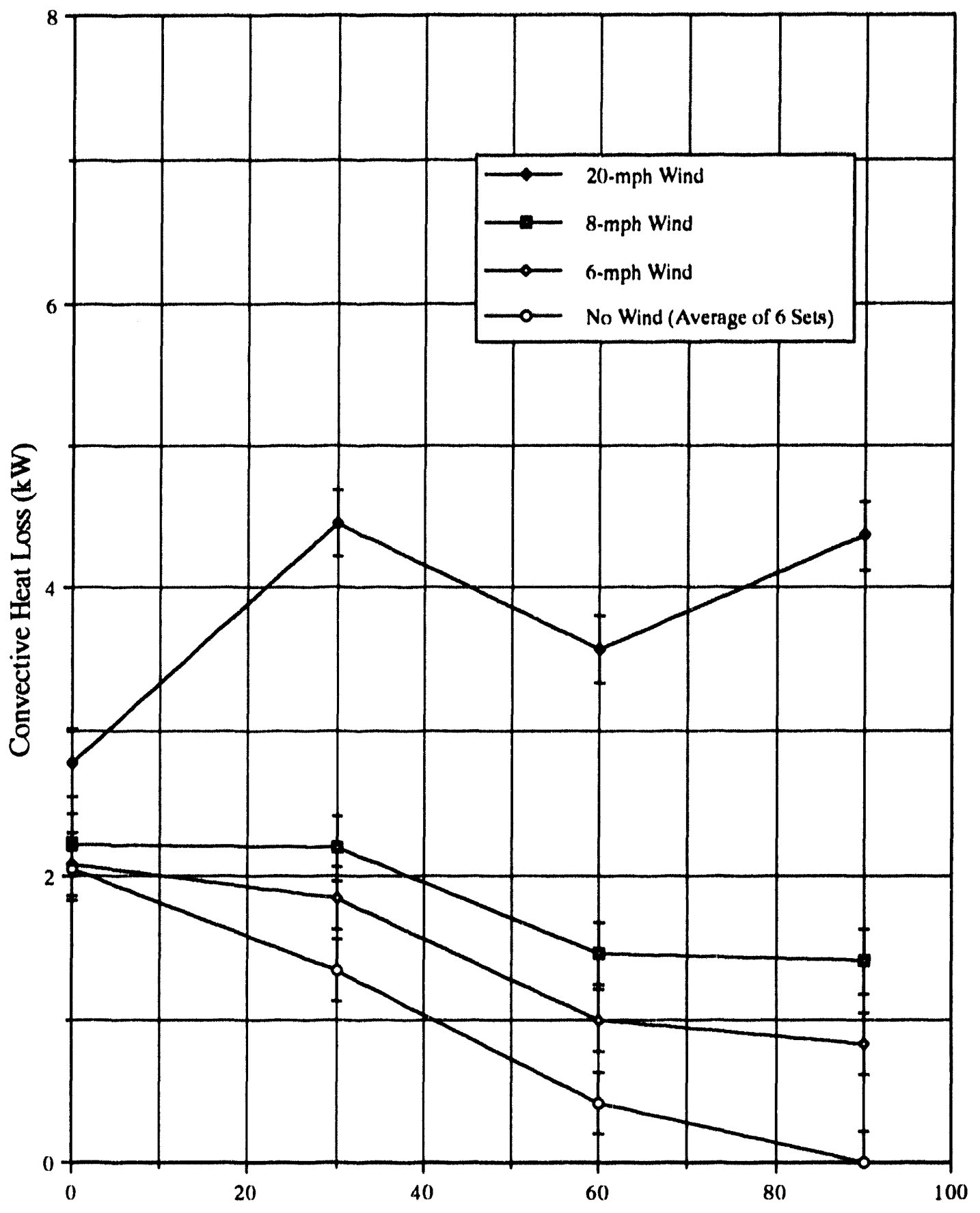

Receiver Tilt Angle (Degrees) 
higher wind speeds result in increases in convective heat loss, above natural convection, which are invariant with tilt angle. In addition, for all of the wind speeds examined, the highest convective heat loss for side-on wind occurs with the receiver facing horizontally, and the lowest occurs with the receiver facing down. For head-on winds, however, the amount of increase in convective heat loss varies as a function of receiver tilt angle. Increases in convective heat loss due to wind are minimal with the receiver facing horizontally; however, with the receiver facing down, convective heat loss increases are large.

Figures 10 and 11 present the convective heat loss results as a function wind speed, for side-on and head-on winds, respectively. Convective heat loss versus wind speed appears to be well behaved for side-on winds, but is more erratic for head-on winds. In an attempt to obtain a better understanding of the effects of wind, natural convective heat loss was subtracted from the total convective heat loss at each condition ( sec Figures 12 and 15). The resultant curves, discussed in detail below, represent the increase in convective heat loss due to the presence of wind. It is believed that with the data presented in this fashion, insight into the forced convection problem may be more easily obtained.

\subsubsection{Analysis of Forced Convection Due to Side.On Wind}

Generally speaking, natural convective currents flow inside the receiver from bottom to top, in a vertical plane. For side-on winds, forced convective currents are generally in a direction normal to the plane of natural convective currents. Because of this orthogonal relationship between natural and forced convective currents, it is reasonable to hypothesize that forced convection from the receiver is independent of natural convection. In addition, pure foreed convection should not change at all as the receiver tilt angle changes. Indeed, in the absence of gravity, side-on wind convective heat loss would be the same for any receiver tilt angle. The result of this hypothesis is that natural and forced convection should be additive for side-on wind:

$$
q_{\text {conv overall }}=q_{\text {natural }}+q_{\text {forced }}
$$

or 


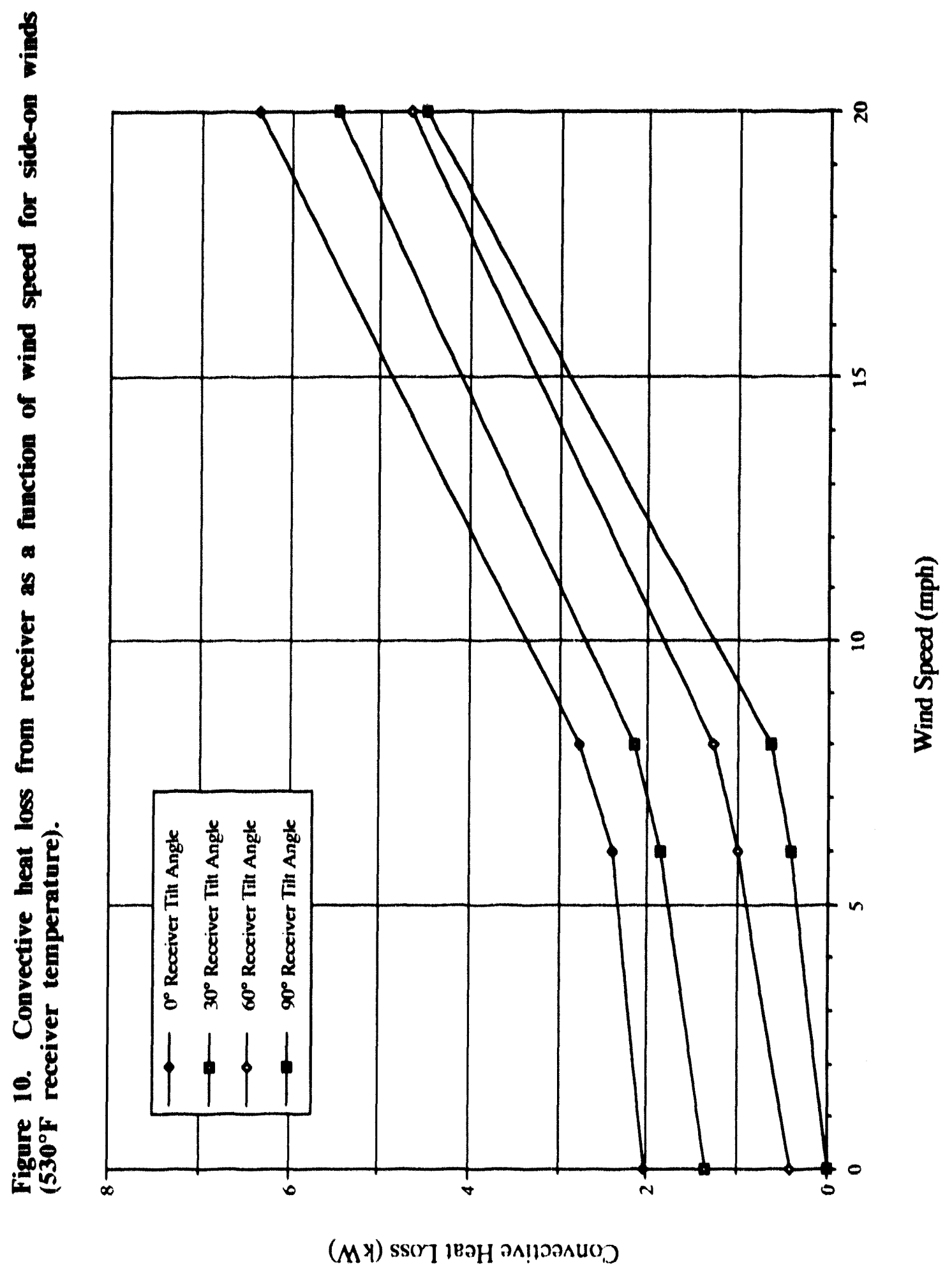




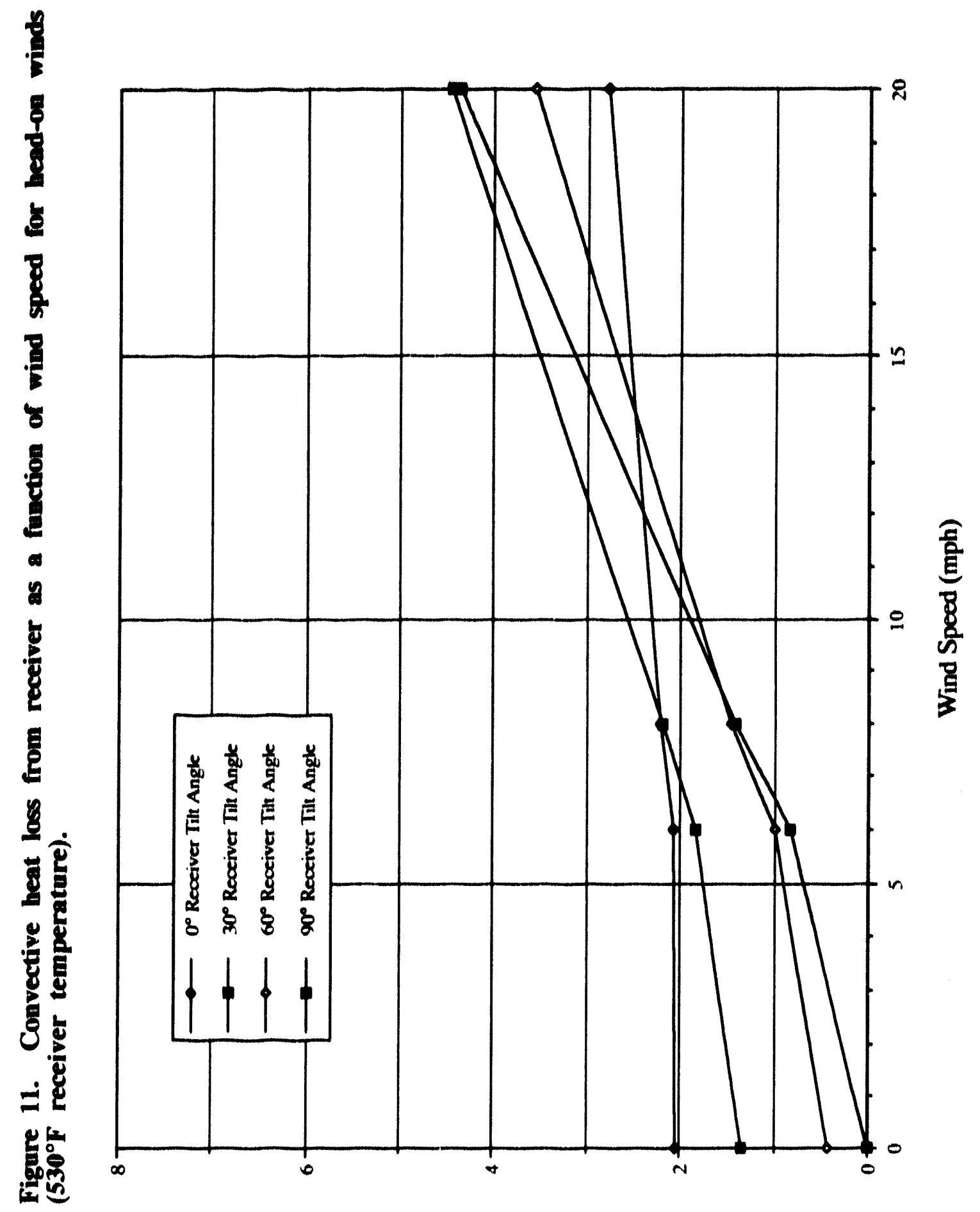

(M 


$$
h_{\text {overall }}=h_{\text {nalural }}+h_{\text {forced }}
$$

In addition. the foreed convection component should be a function of wind speed only. Equations (9) and (10) are in agreement with the recommendation given by Sichers and Kraabel (1984) for predicting mixed convection from cavity receivers.

Figure 12 shows the increase in measured convective heat loss from the receiver due (o) side-on wind. These experimental results confirm that the increase in convective heat loss due to side-on wind follow's the same trend regardless of receiver tilt angle. For a 20-mph side-on wind, the convective heat less increases for the different receiver tili angles vary by only about 3-percent standard deviation. Indeed, it appears that the increase in convective heat loss due lo side-(on wind is a function of wind speed only, and that natural and forced convection are additive according to Equations (9) and (10) ahove.

A curve fit of the data shown in Figure 12 gives the pure foreed convection heat transfer cocflicient as a function of wind speed for side-(1)n wind:

$$
h_{\text {forwed }}=0.1967 \mathrm{~V}^{1.844}
$$

where $h_{\text {fored }}=$ forced convection heat transfer coefficient, $W /\left(m^{2} \cdot K\right)$ $\mathrm{V}=$ side-on wind velocity, $\mathrm{m} / \mathrm{s}$

This equation is hased on the full interior geometric surface area of the receiver, which is $1.472 \mathrm{~m}^{2}$. Comparison of this curve-fit to the experimental data from all of the side-on wind tests is shown in Figure 13. It can he seen that the experimental data are represented very well by this single curve-fit.

It is interesting to note that the exponent of 1.849 in the velocity term of $\mathrm{Eq} .(11)$ is much larger than that usually associated with convective heat transfer. For example, for turbulent heat transfer from a flat plate, the Nusselt number relationship is

$$
N u_{1}={ }_{k}^{h L_{1}}=0.037 \mathrm{Re}_{1}^{0.8} \mathrm{Pr}^{1 / 3}
$$




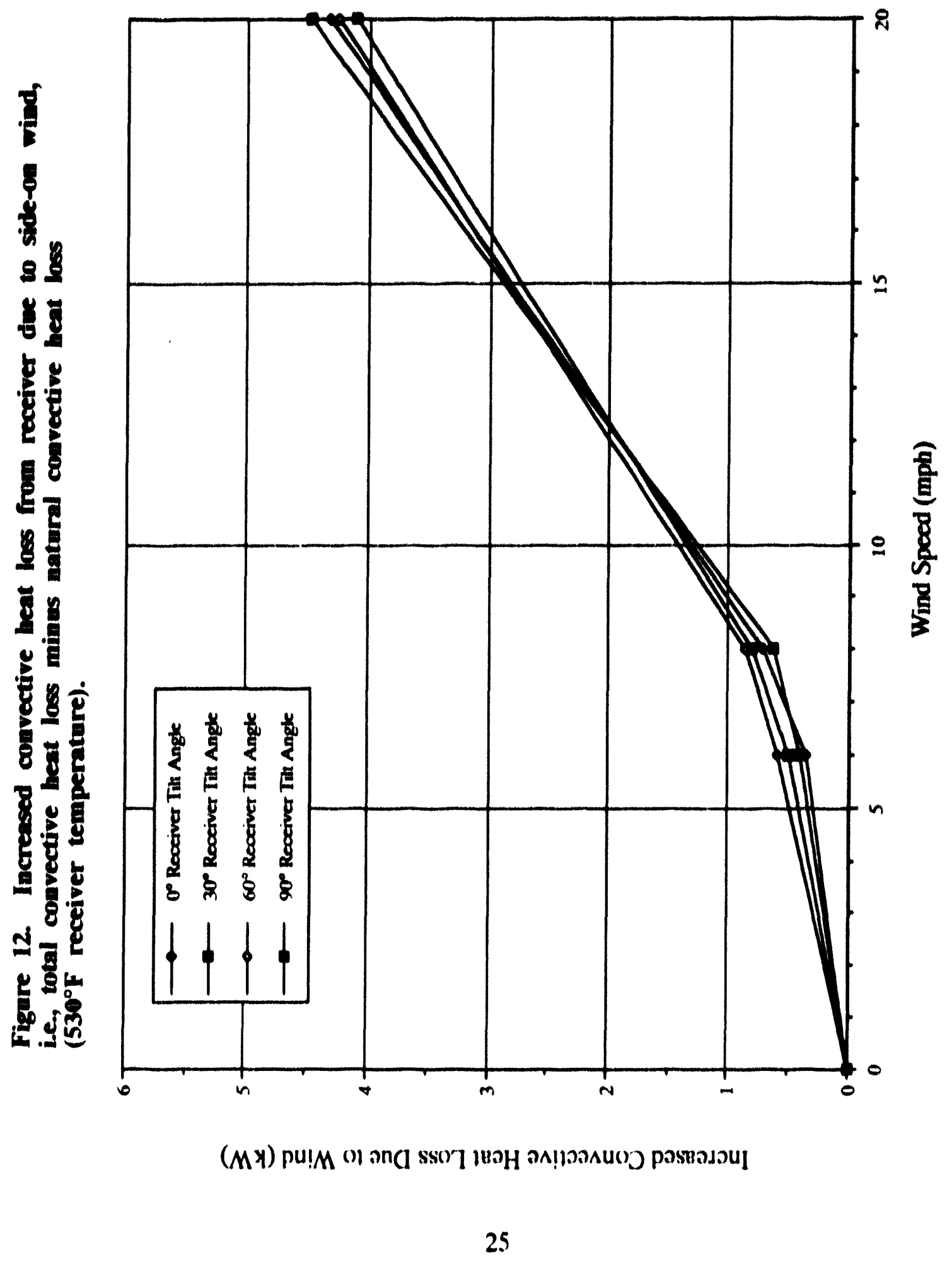




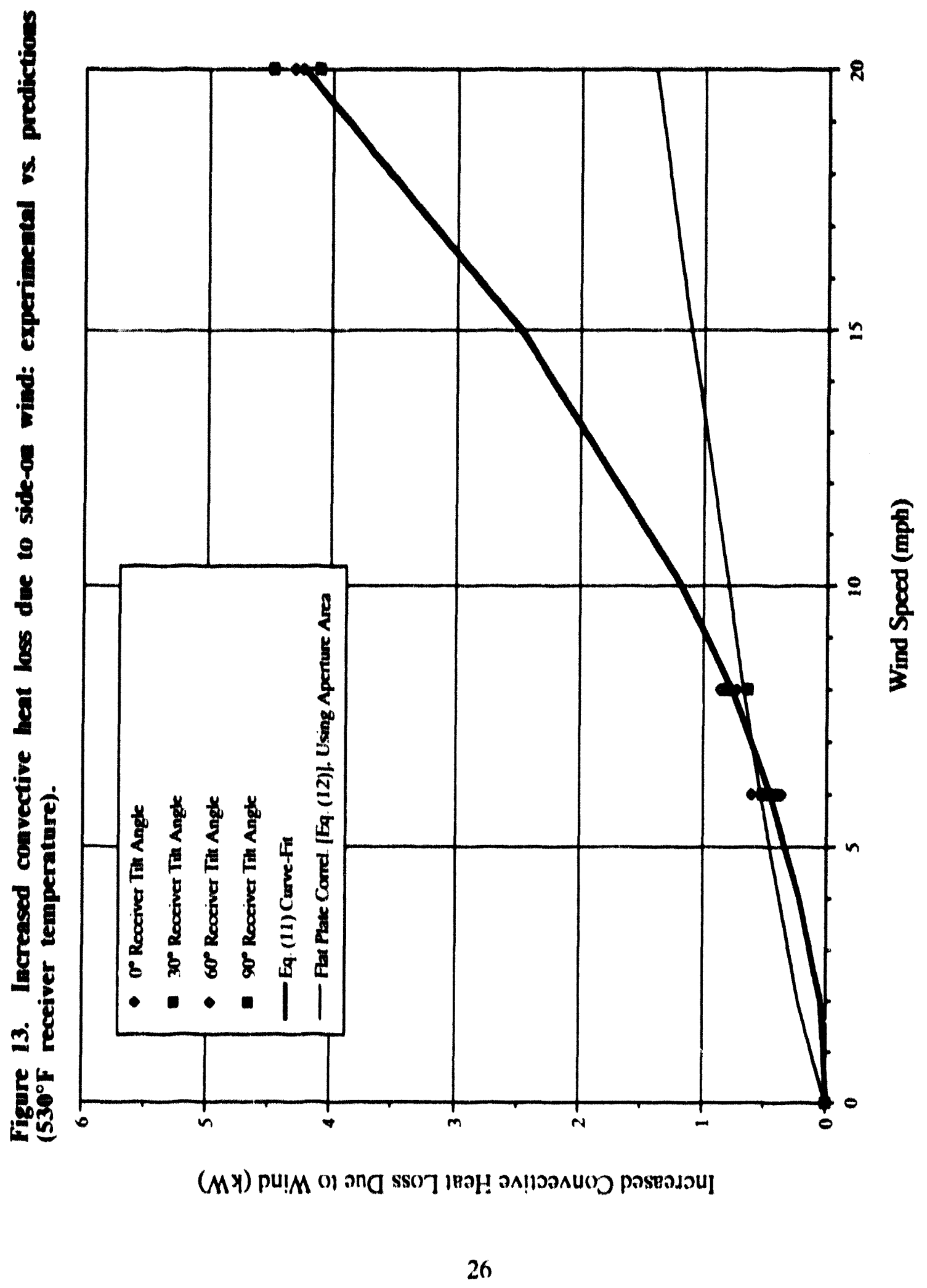


with the heal transfer coefficient being proportional to velocity raised to the $(1.8$ peower. The exponent of 1.849 in Eq. (11) is closer 10 that normally associaled with shear stress. For example, for turbulent flow over a flat plate, shear force is proportional lo velexily raised to the 1.8 power. The fact that the heal transfer cosefficient in ley. (11) varies about the sume as for shear forec suggessts that the delermining facter for heat fransfer from the cavity may be the ability of wind Io transfier mass and encrgy across the aperture vin lluid shear, net the ahility of the receiver walls to transfer energy to the air inside the cuvily. This argument is consistent with that given hy Clausing ( $\mid 981$ ).

As previously mentioned, Sichers and Krumbel (1984) recommended that in the absence of a reliable correlation for predicting forced convective heat loss from a cavily receiver, the hent loss from a flat plate the siae of the recciver aperture and at the receiver average lemperalure be lised. Following this recommendalion. Fy. (12) was used (1) predict receiver force convection. The resullant heut loss curve is shown in Figure 1.3. Note that Eq. (12) matches the experimental dalu adcqualely for low wind speceds, hut grossly underpredicts corivective hent loss al wind speeds uhove $10 \mathrm{mph}$. II is obvious that the curve of Fy. (12) is not representative of the experimental data, and that the curve-fil of Eq. (11) is a beller malch.

As a side-note on convective heal loss due (o) side-(1) wind, let us examine the percentage of tolial receiver heal loss altribuled lo convection, conduction, and radiation. for a 20)-mph side-(on wind. These dala are shown in Figure 14. Il can be seen that for a 2(). mph side-on wind, convective heal loss is over 75 percent of the tolal receiver heal loss for all receiver tilt angles. This is in sharp contrast to the no-wind condition (Figure 7) where natural convection accounts for 6.3 percent of the total receiver heat loss at ()$^{\circ}$ till angle and is negligible at $(x)^{\circ}$ tilt angle.

\subsubsection{Analysis of Forced Convection Due to Head.On Wind}

Comparison of Figures 8 and 9 shows that receiver convective heal loss characteristics are very diflerent for head-en and side-on winds. For side-()n winds, the heat loss curves as a function receiver tilt angle are shaped the same regardless of wind speed. However, for head-on winds, the heat loss curves versus receiver till angle do not all follow the same trend. 


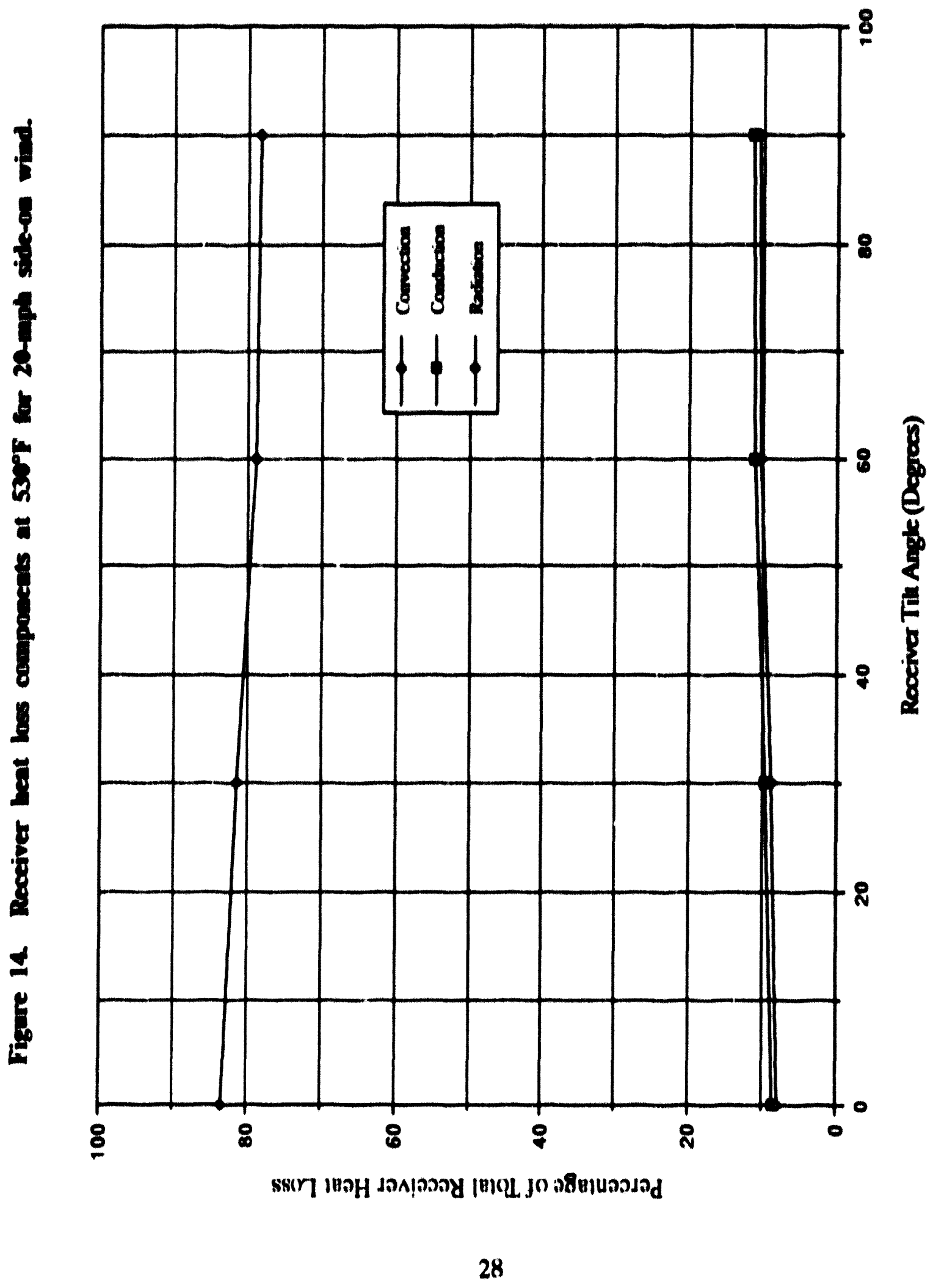


Figure 15 shows the increase in convective heat loss due to head-on wind. Different receiver lilt angles result in different curves as a function of wind speed. With the

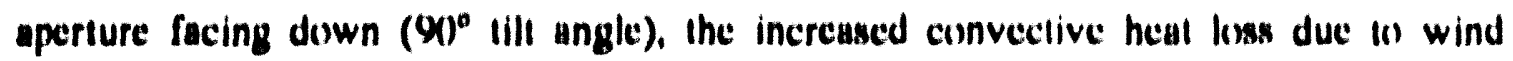
increases rapidly with wind speed. Al receiver tilt angles of 3()$^{\circ}$ and 6()$^{\circ}$, increased convective heat loss due 10 wind are similar to each other. Al a receiver till angle of $0^{\circ}$. increased convective heat loss due to wind is very small, even for high-speed wind. These resules show that, in general, wind eflects diminish as the receiver is tilled upward from xpo $^{\circ}$ till angle $1000^{\circ}$ illt angle.

Because the convective heat loss results from these head-on wind tests behave much differently than these for side-on winds, a second smill lest scrics consisting of several additional head-en wind lests was conducted (1) confirm the results and also II) provide a beller understanding of the phenomena. In these additional lests, the primary objective was to validate the convective heat loss trends, hoth versus wind speed and receiver lill angle. To verily the dependence of eonvective heat loss upon wind speted. lests were conducted at wind speeds of 15 and $24 \mathrm{mph}$, which were wind speeds nest previously examined. Th verify the dependence of eonvective heat loss upen receiver till angle, the 24-mph tests were conducted for receiver till angles from 1$\left.)^{\circ} 1190\right)^{\circ}$ al $15^{\circ}$ increments, instead of the $30^{\circ}$ increments previously exumined. Addilional lests were also conducted with a 24-mph wind using a 6.inch aperlure, instead of the neminal 18 -inch aperture, in order to delermine if the sume trends occur for a different uperture size.

The results from these three additional lest sets are shown in Figure 1h, along with the results from head-on wind lests from the first lest series. The results from the additional lests are shown as bold lines whereas the original head-on lest results are shown as plain lines. By exumining this figure, it can be seen that the results from the additional tests follow the same trends as the original lest dala. The curvalures of all of the curves are negative at $30^{\circ}$ receiver till angle and positive at $60^{\circ}$ till angle. The trend is hest seen in the 24-mph, 18-inch-aperture curve, where data are plotled at $15^{\circ}$ increments. The consistency of these additional data to the original data suggests that the measured convective heat lesses for head-on winds are representative of the physical phenoniena and are not gross experimentul crror. 


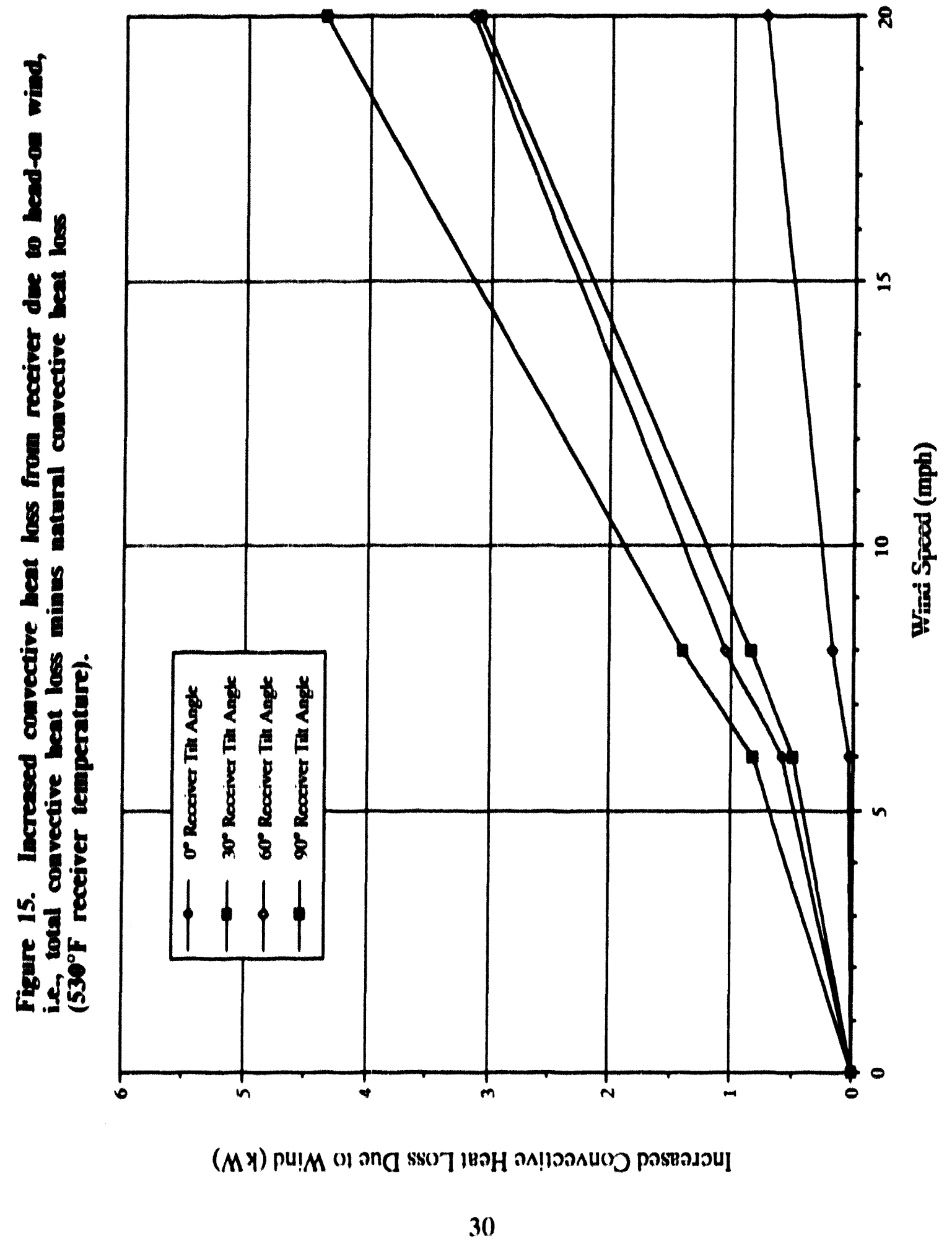




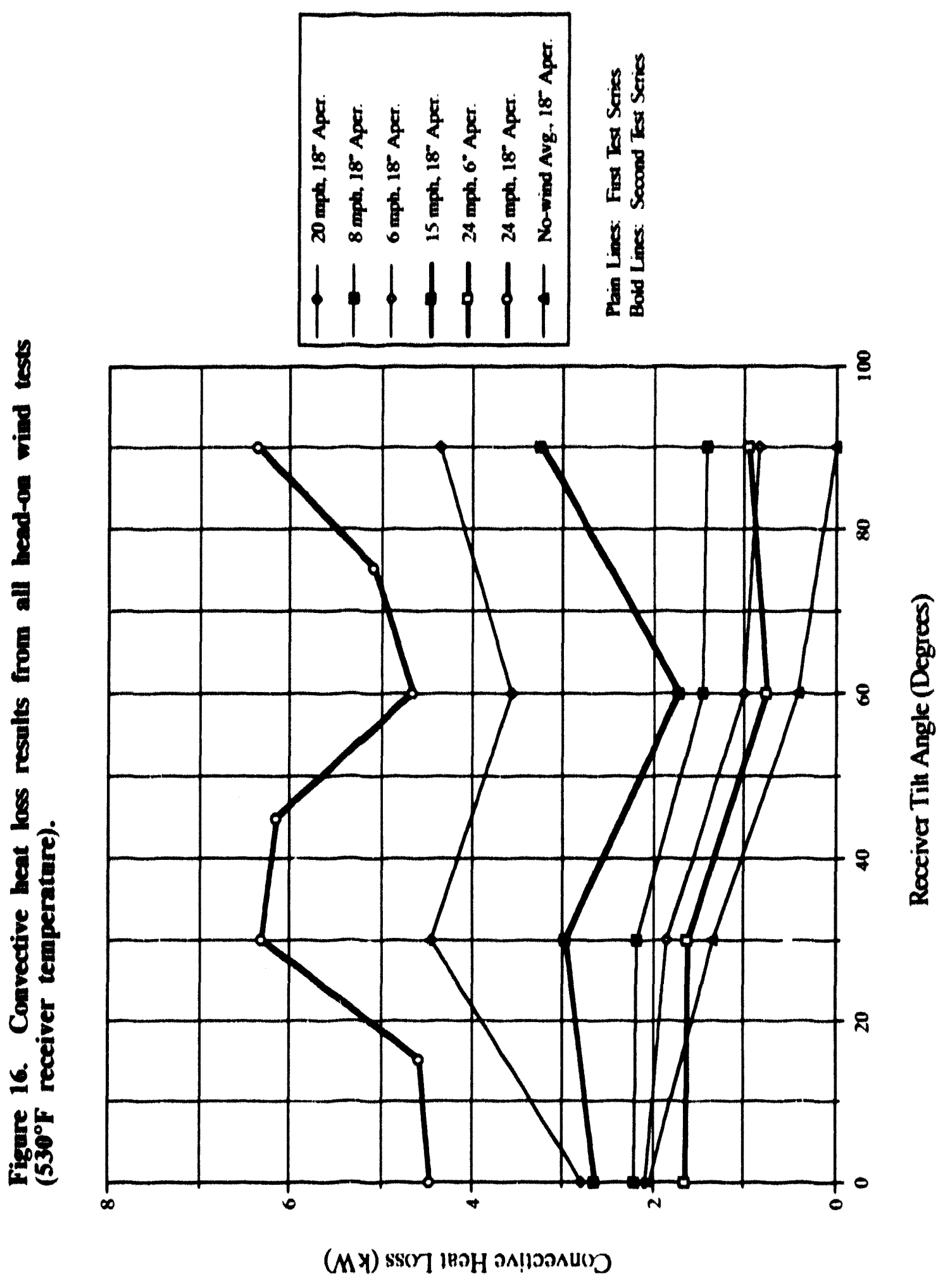


For head-on winds, it is a more difficult problem to separate natural and forced convection components. The natural and forced components are aiding since the total convective heat loss is greater than natural convection alone, hut the forced and natural components are probably not additive. However, a correlation of the form

$$
\overline{\mathrm{h}}_{\text {overall }}=\overline{\mathrm{h}}_{\text {natural }}+\overline{\mathrm{h}}_{\text {forced }}
$$

is a convenient form for a design correlation, especially considering the modest level of understanding that currently exists. With the assumption that natural and forced components are additive, a curve-fit of the increased convective heat loss due to head-on wind is

$$
\overline{\mathrm{h}}_{\text {forced }}=f(\theta) \mathrm{V}^{1.401}
$$

where

$$
\begin{aligned}
& f(\theta)=0.1634+0.7498 \sin \theta-0.5026 \sin 2 \theta+0.3278 \sin 3 \theta \\
& \bar{h}_{\text {forced }}=\text { forced convection heat transfer coefficient, } \mathrm{W} /\left(\mathrm{m}^{2} \cdot \mathrm{K}\right) \\
& \mathrm{V}=\text { head-on wind velocity, } \mathrm{m} / \mathrm{s} \\
& \theta=\text { receiver tilt angle }
\end{aligned}
$$

Comparison of this correlation to the experimental data is given in Figures 17 and 18 . The agreement between the predicted and experimental values is considered fair. This equation and Eq. (11) for side-on wind represent a relatively accurate correlation of wind effects on convective heat loss from the cavity receiver tested. They are not intended to be general equations for predicting convective heat loss from all cavity receivers since they are based on a limited number of data points. When more heat loss data become available, the correlations can be revised for broader application. 


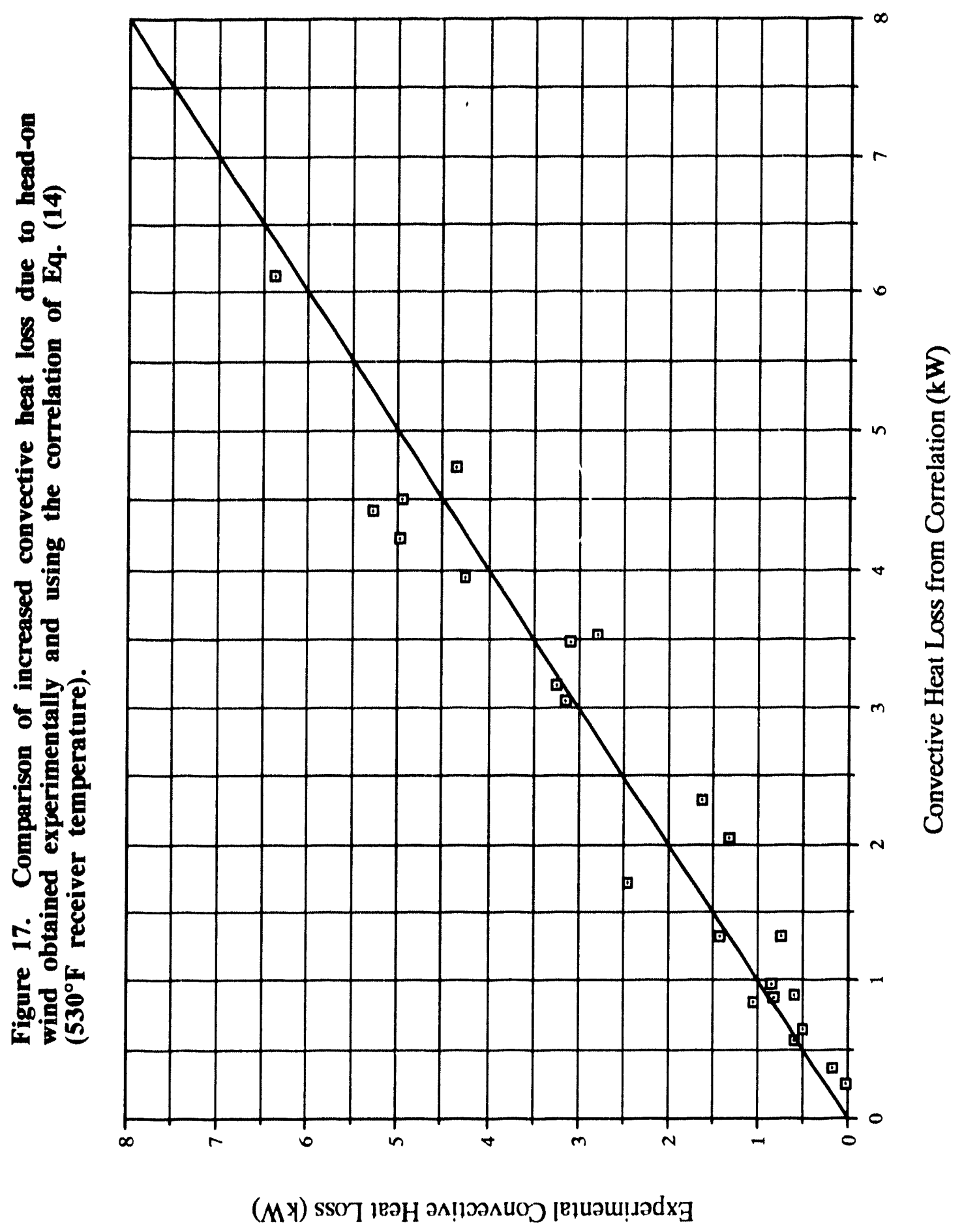




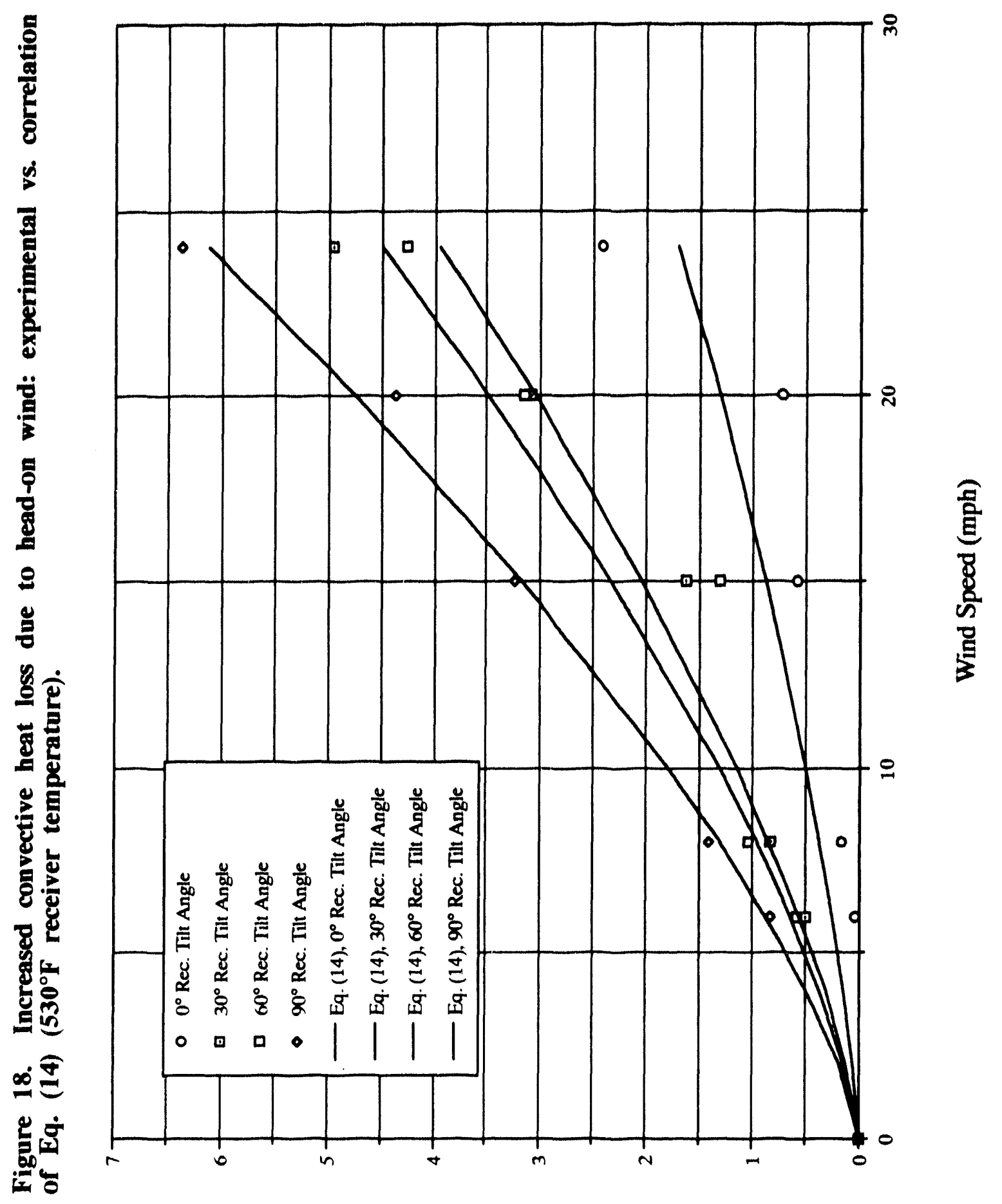

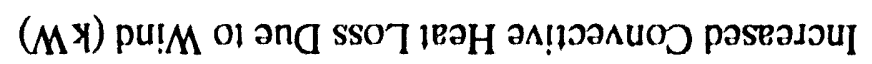




\subsection{Analysis of Measured Air Temperatures and Average Internal Heat Transfer Coefficients}

\subsection{Measured Air Temperatures Inside Receiver}

During each of the tests from the lirst test series, temperature measurements were made at various locations on the receiver in hope that they would provide useful information for the interpretation of convective heat loss results. The localtions at which the temperature measurements were made are shown in Figure 19. A tetal of 26 thermocouples were used, most of which were located in representative forward and aft planes in the receiver. Twelve thermocouples were localed in each plane, with three each being located at clock angles of 12,3,6, and 9. At each clock-angle location, ihree thermocouples were installed: one on the receiver outer surface, one on the heal transfer tubing facing the interior of the cavity, and one in the cavity airspace 1 in. $(2.5 \mathrm{~cm})$ from the heat transfer tubing. Two thermocouples were localed at the receiver aft end.

Measured receiver temperatures from all of the lests are tabulated in Appendix D. Of particular interest are the air temperature measurements because they give special irisgy.. into some of the fluid and convective heat transport phenomena occurring for the different test conditions. The next several sections will discuss in detail these air temperature measurements. In all of the air temperature plots presented helow, a vertical coordinate system is used as the independent variable becausc it was deemed most appropriate considering the fact that without wind, natural convective effects result in temperature gradients in this direction. A vertical location of zero corresponds to the horizontal plane passing through the top of the receiver aperture. This coordinate system is illustrated in Figure 20.

\subsubsection{No-Wind Tests}

Figures 21 through 24 show measured receiver air temperature versus vertical location within the receiver for all of the no)-wind lests. The dependency of air temperature to vertical location inside the receiver, and the existence of a stagnant zone within the receiver, are clearly shown. With the receiver facing horizontilly ( ()$^{\circ}$ tilt angle), air temperatures are only about $175^{\circ} \mathrm{F}$ at the hottom of the receiver, due to natural convective 


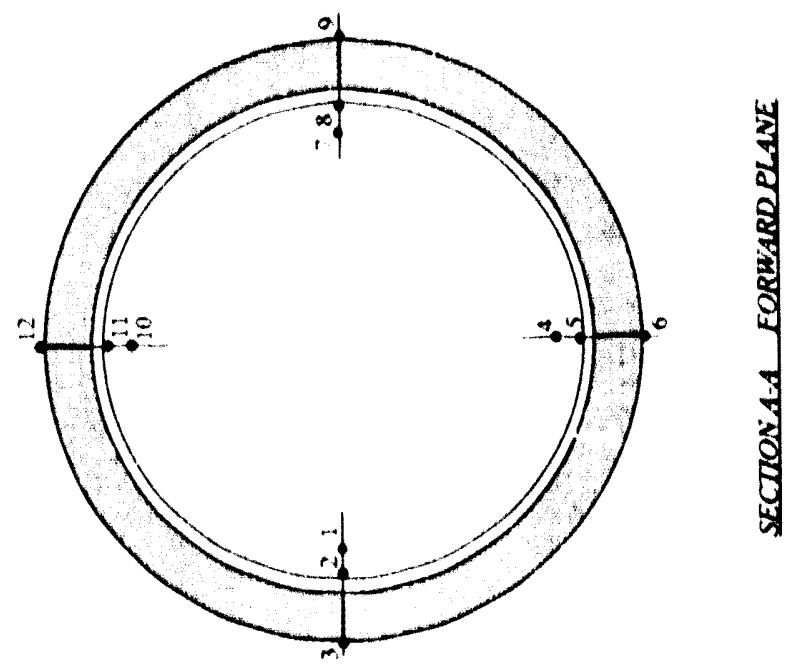

䓪

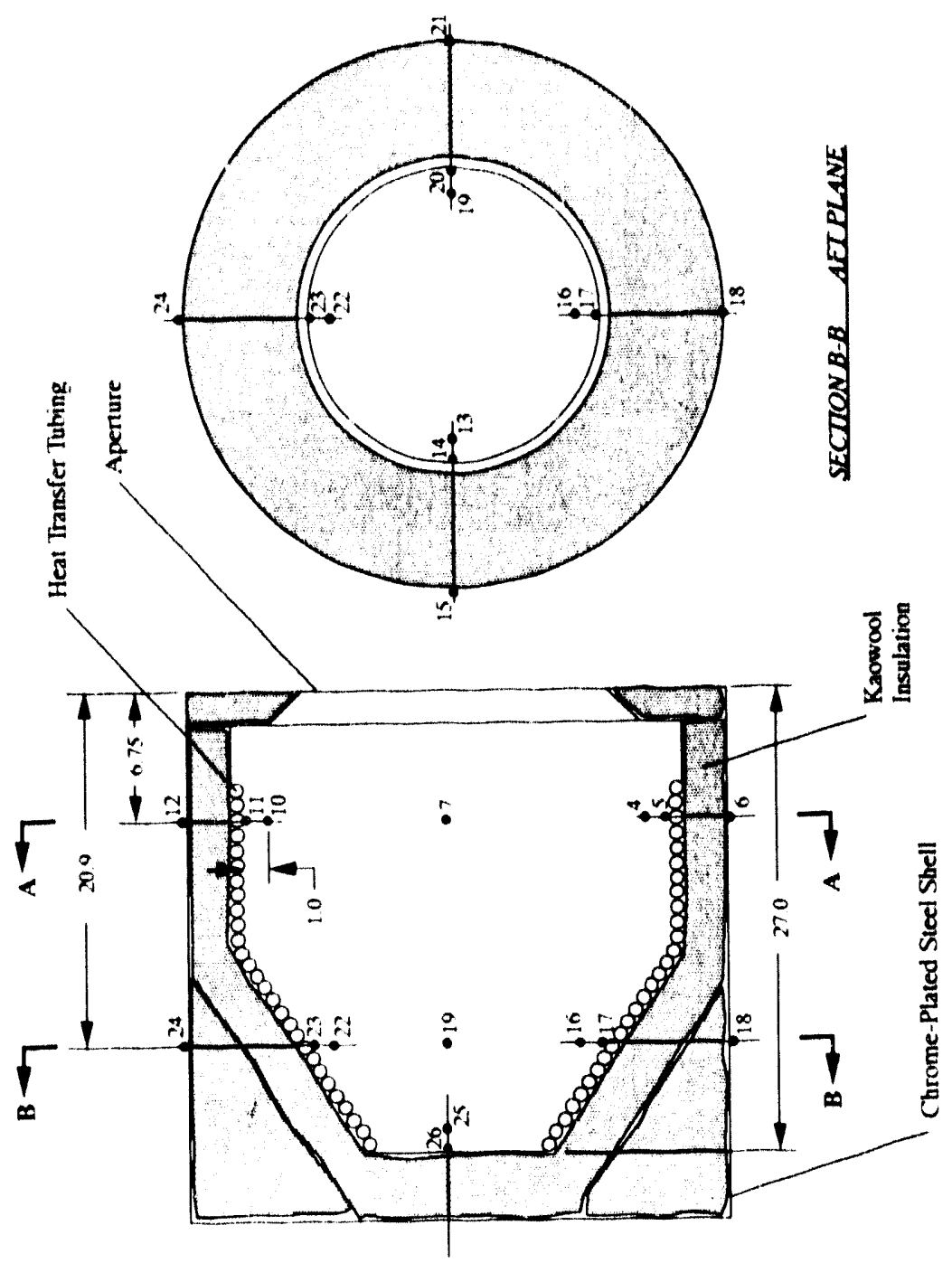



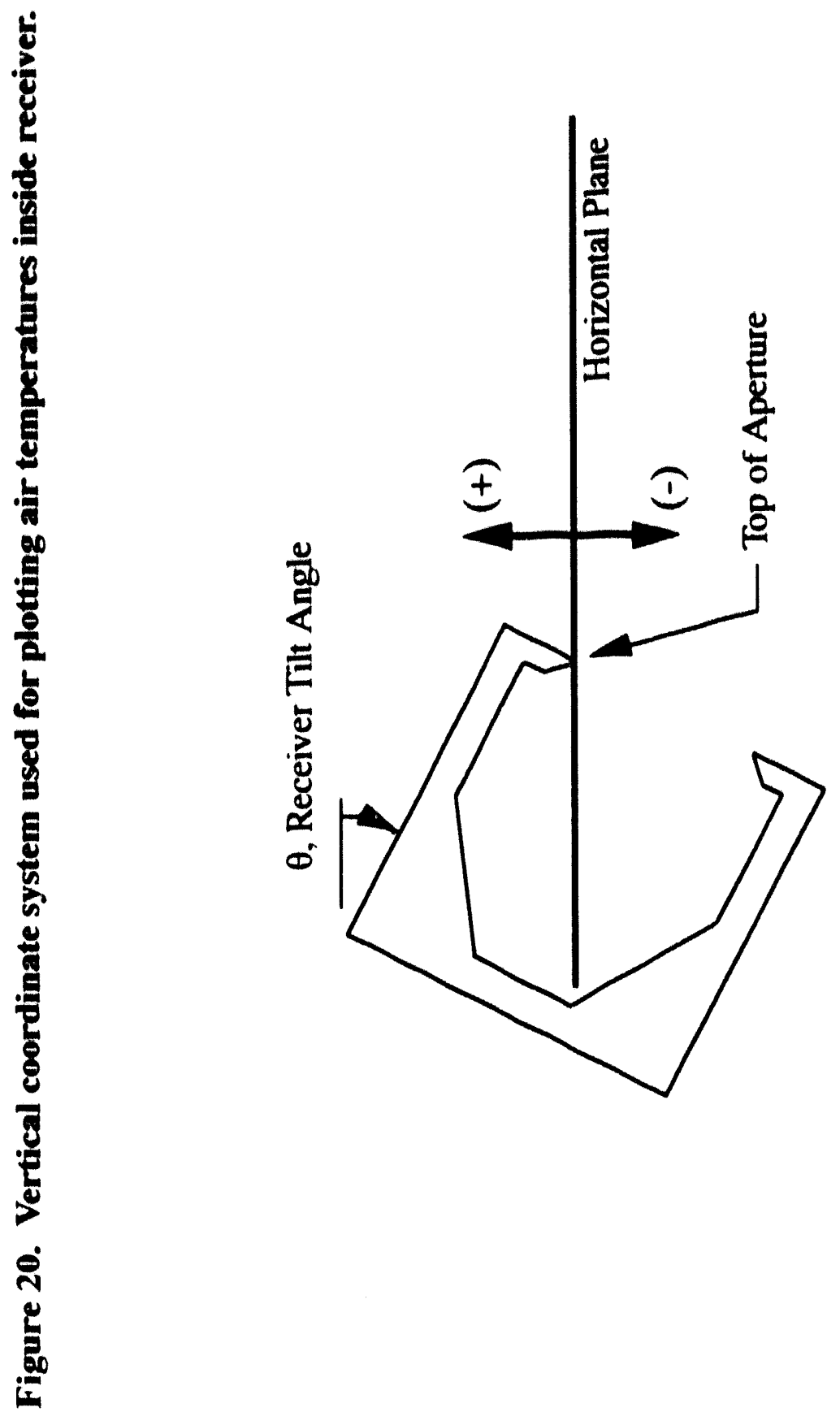


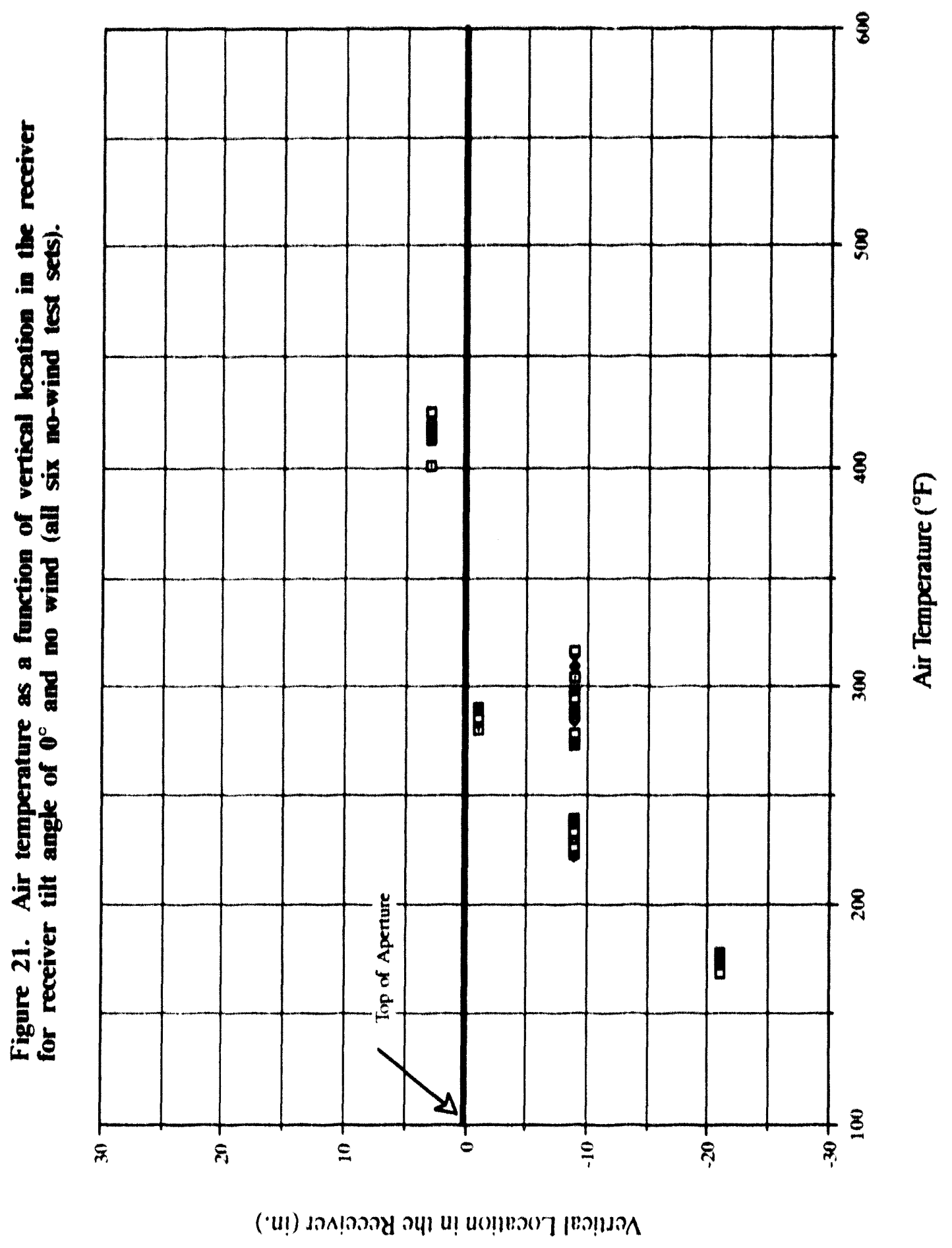




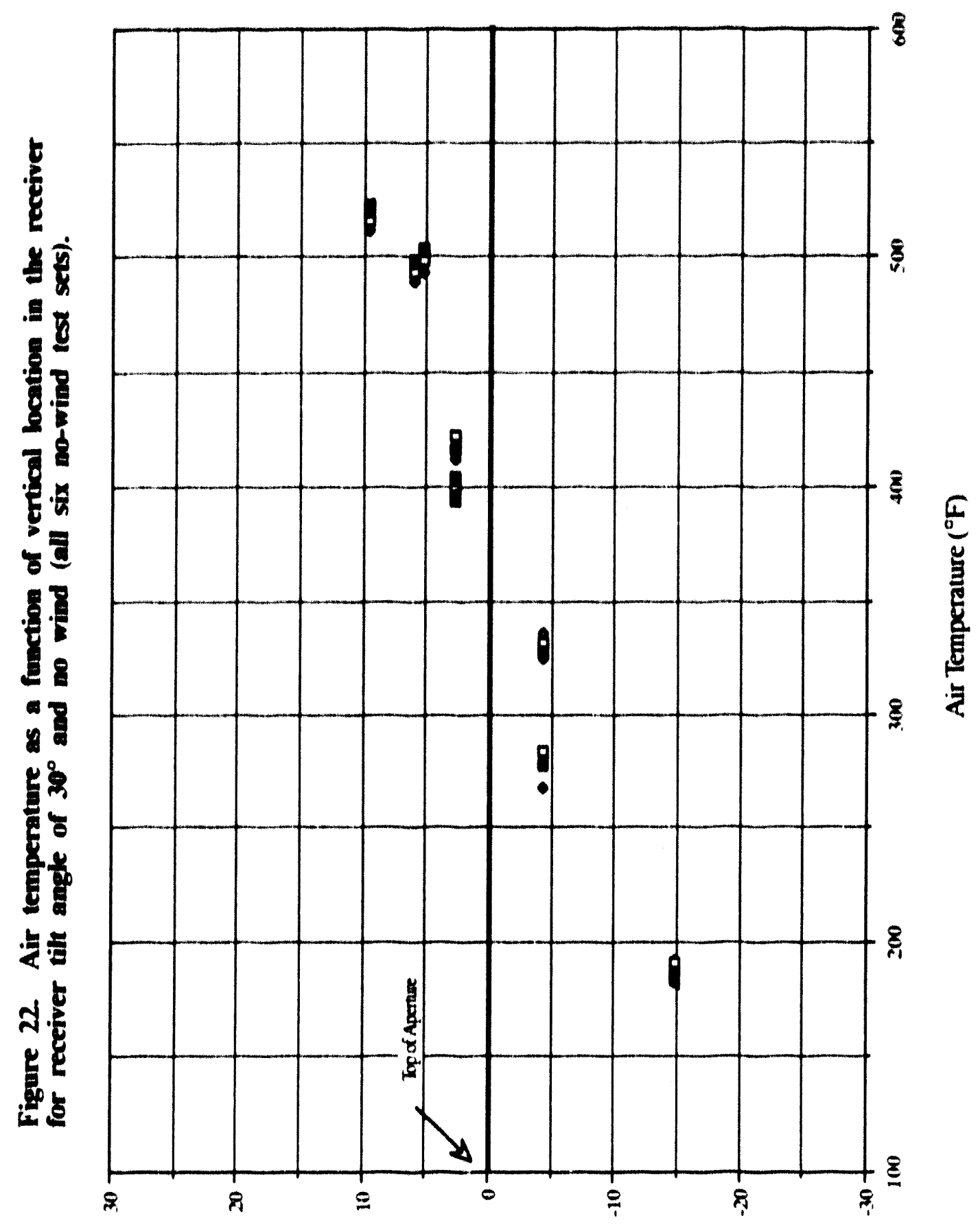

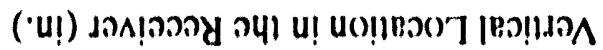




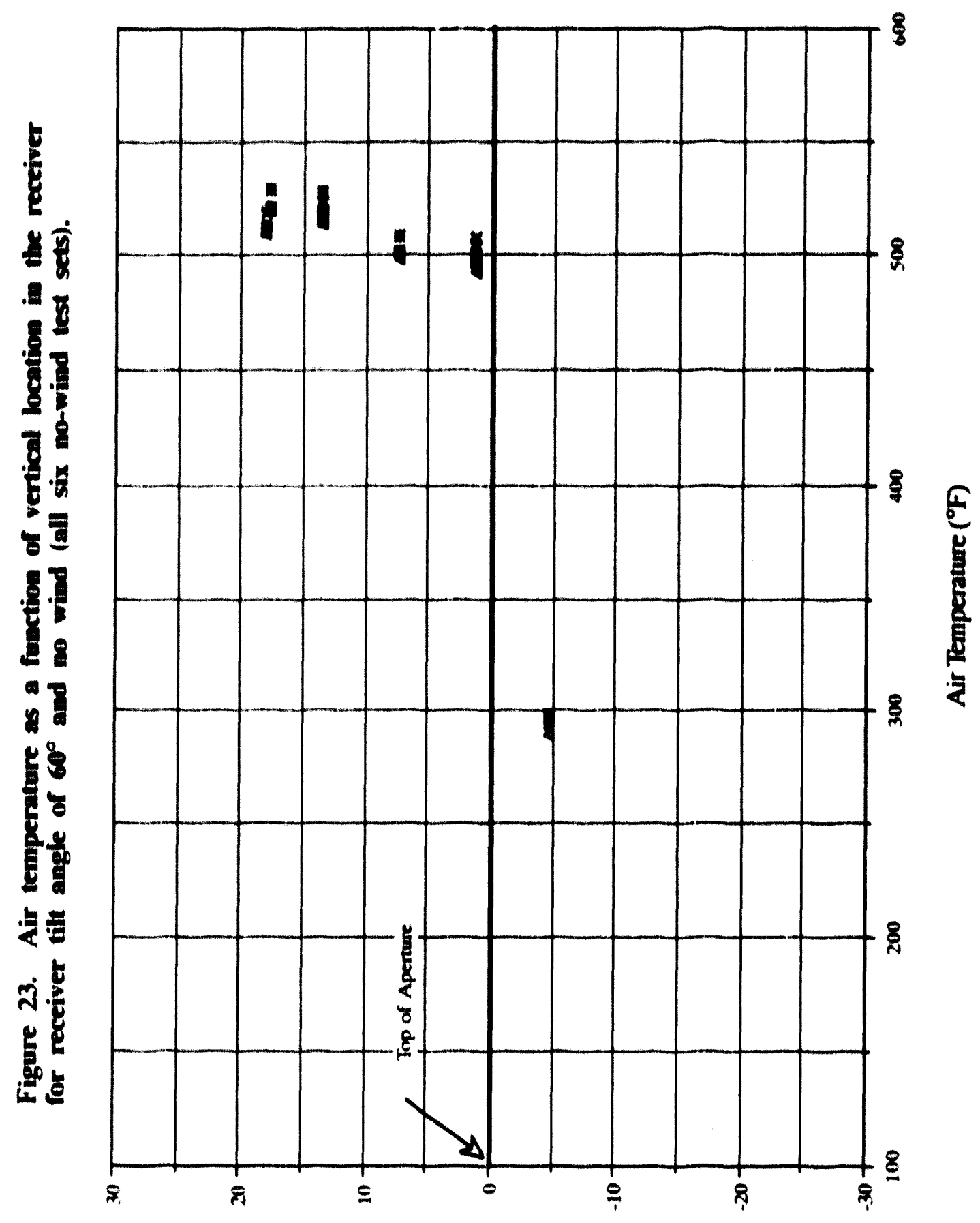

ג 


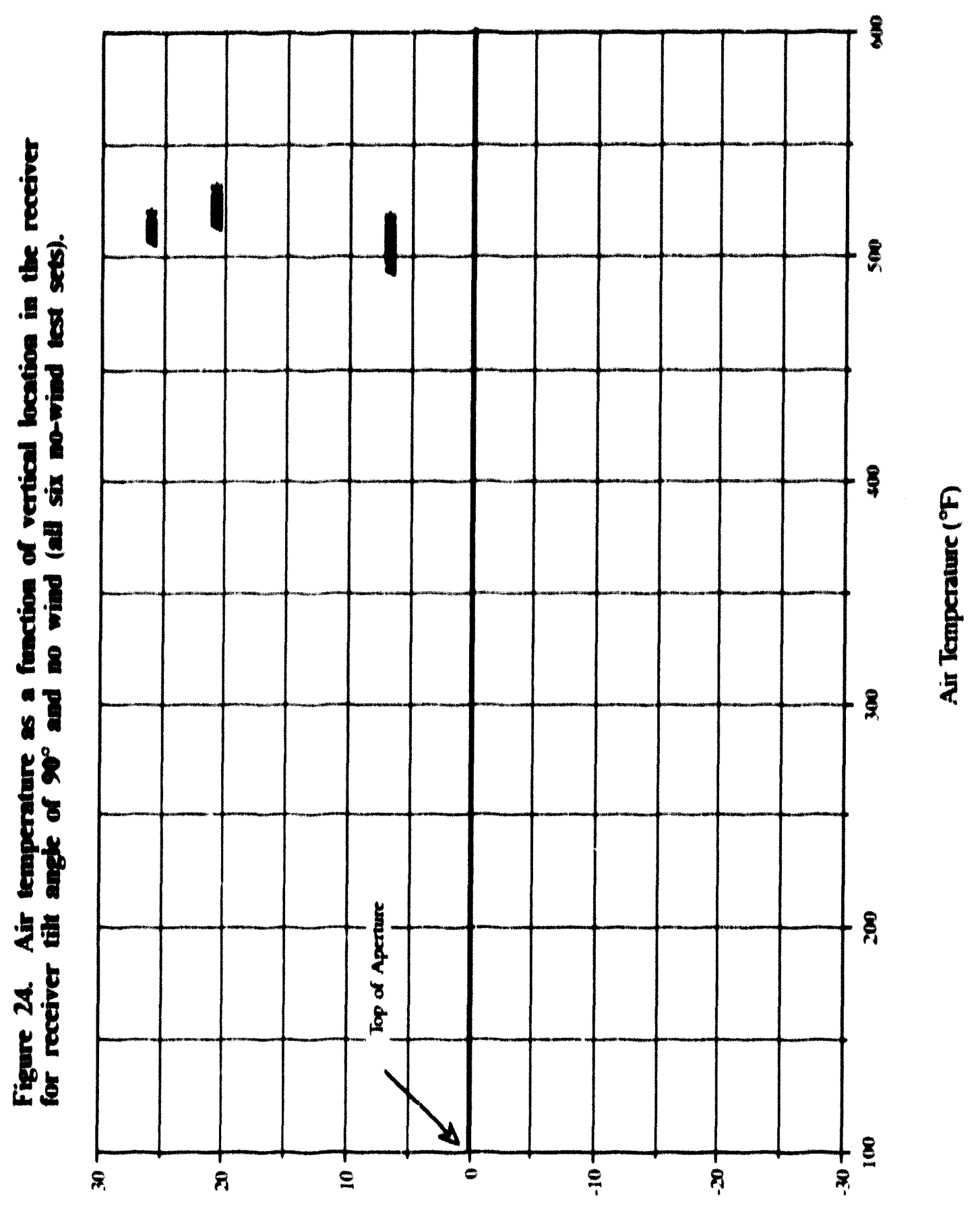

ג 
currents supplying cowel outside air into the chvily. As the uir is healed, it rises and hecomes holler as it absorbs more heat from the hot receiver internal surfaces. Above the IIp of the aperture plane (ubuve $y=(1)$ ), the air is the hollest hecause it is stugnant since it has nowhere to excupe (i.c., it is in the stugnunt anne).

Al $31^{\circ}$ till angle, the lemperalure difference between the hellem and top of the receiver is larger than $310^{\circ}$ lilt angle hecause the lemperatures in the stagnant ane are higher. The lemperalures are less than $2(x)^{\circ} \mathrm{F}$ at the bellem of the receiver, hut are grealer than $5(x)^{\circ} \mathrm{F}$ al the lop. The higher temperatures in the l(1) pertion of the receiver is most likely duc of the fact that at this receiver tilt angle, the stagnant aune is larger than at $0^{\circ}$ till ungle. The larger stagnant zone is believed to result in less mixing heiween the relatively coxsler air in the convective aone and the holler air inside the stagnant aone, thus resulting in "higher-lemperalure stugnant ane.

As $(x)^{\circ}$ tilt angle, the presence of the slagnant eone is very nesticeable. Five inches helow the plane passing through the lop of the aperture, air lemperalures are less than $3(x)^{\circ} \mathrm{F}$. Hewever, at all of the vertical lecutions above the aperlure plane, lemperatures are generally ubove $\mathbf{s ( k )})^{\circ} \mathrm{F}$. This highlights the very strong verticul lemperulure gradients in the vicinity of the aperlure plane. On the other hand, it shows that the temperatures in the bulk of the stugnant anne are essentially constant.

Al $9\left(1^{\circ}\right.$ lilt angle, temperatures everywhere in the receiver are $5(x)^{\circ} \mathrm{F}$ or above. because the entire cavity is in the so)-called stagnant anne. Similar to the results at 6()$^{\circ}$ tilt angle, air lemperatures within the stugnant eone are essentially constant. Although no measurements were niade near the aperture planc, if is reasonuble 16 expect that very large verticul temperature gradients would exist there.

\subsubsection{Side-in Wind Tests}

Measured air lemperalures for the side-on wind lests are shown in Figures 25 through 28. These lemperatures are quile different than thesse for the no-wind condition. Al a receiver till angle of ()$^{\circ}$, the vertical lemperature variation caused by natural convective effects is all but eliminated hy the presence of side-on wind. The effects of wind are greatest for higher wind speeds, but are still significant at all wind speeds. For this 


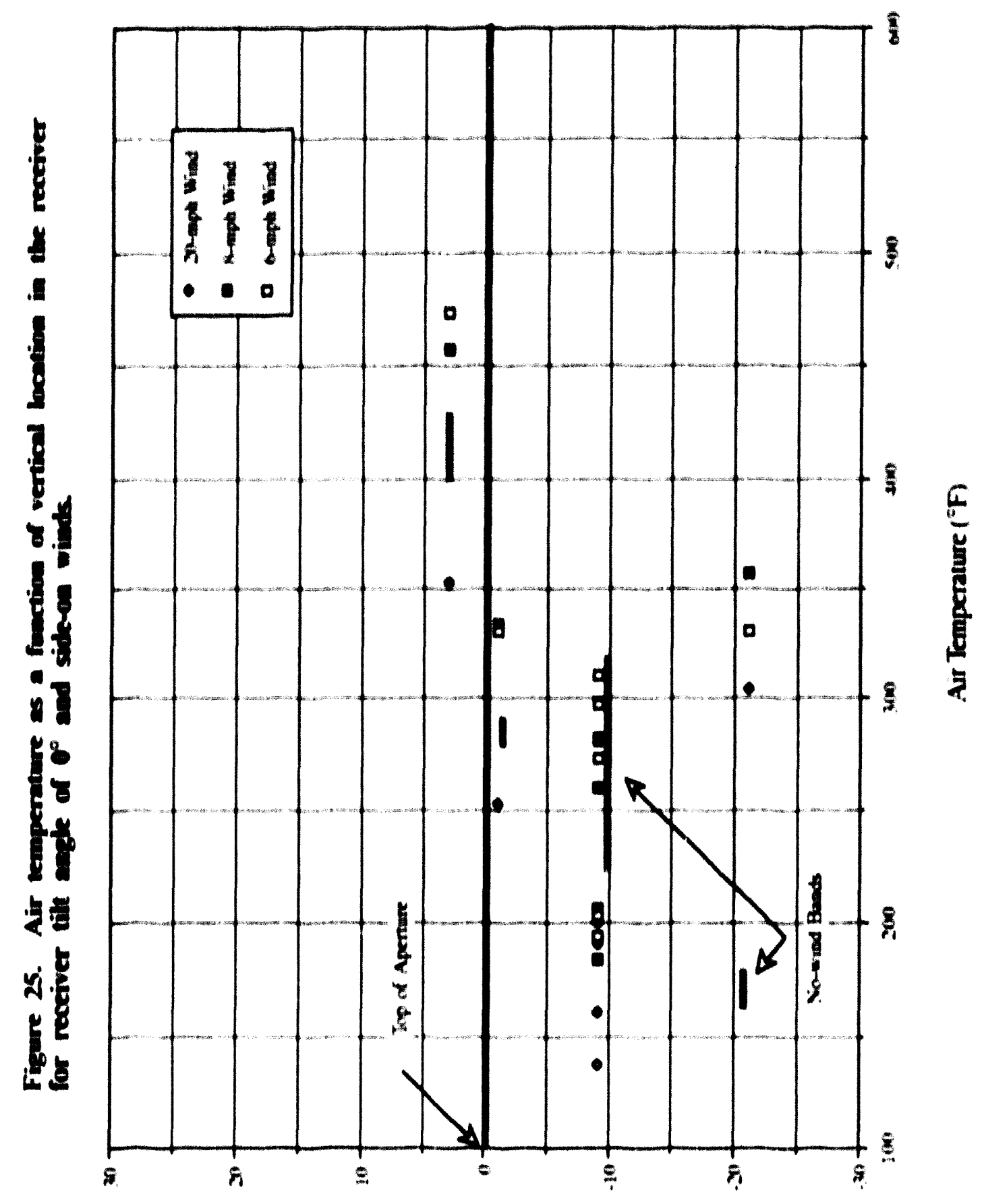

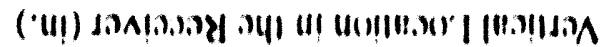




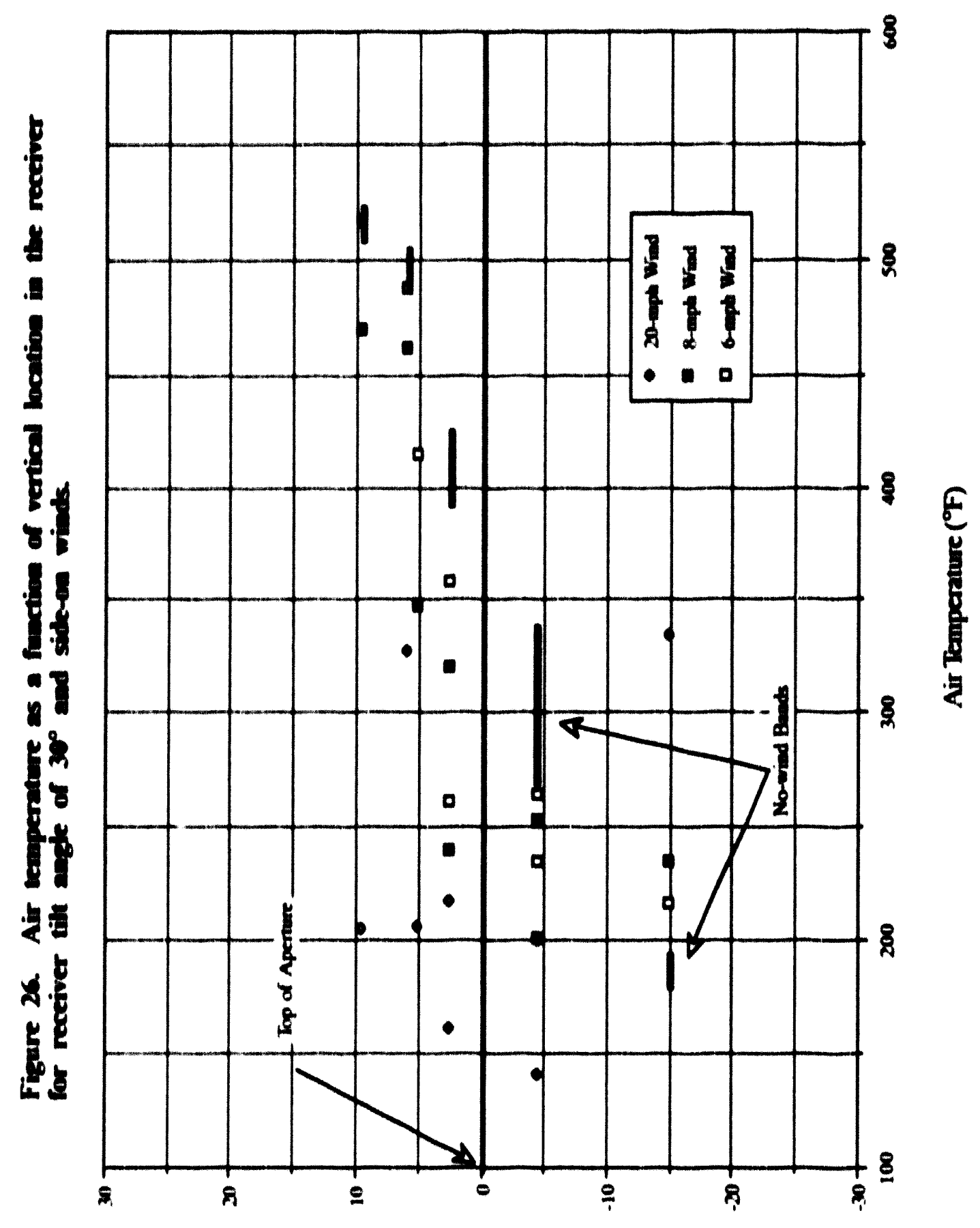

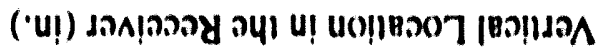




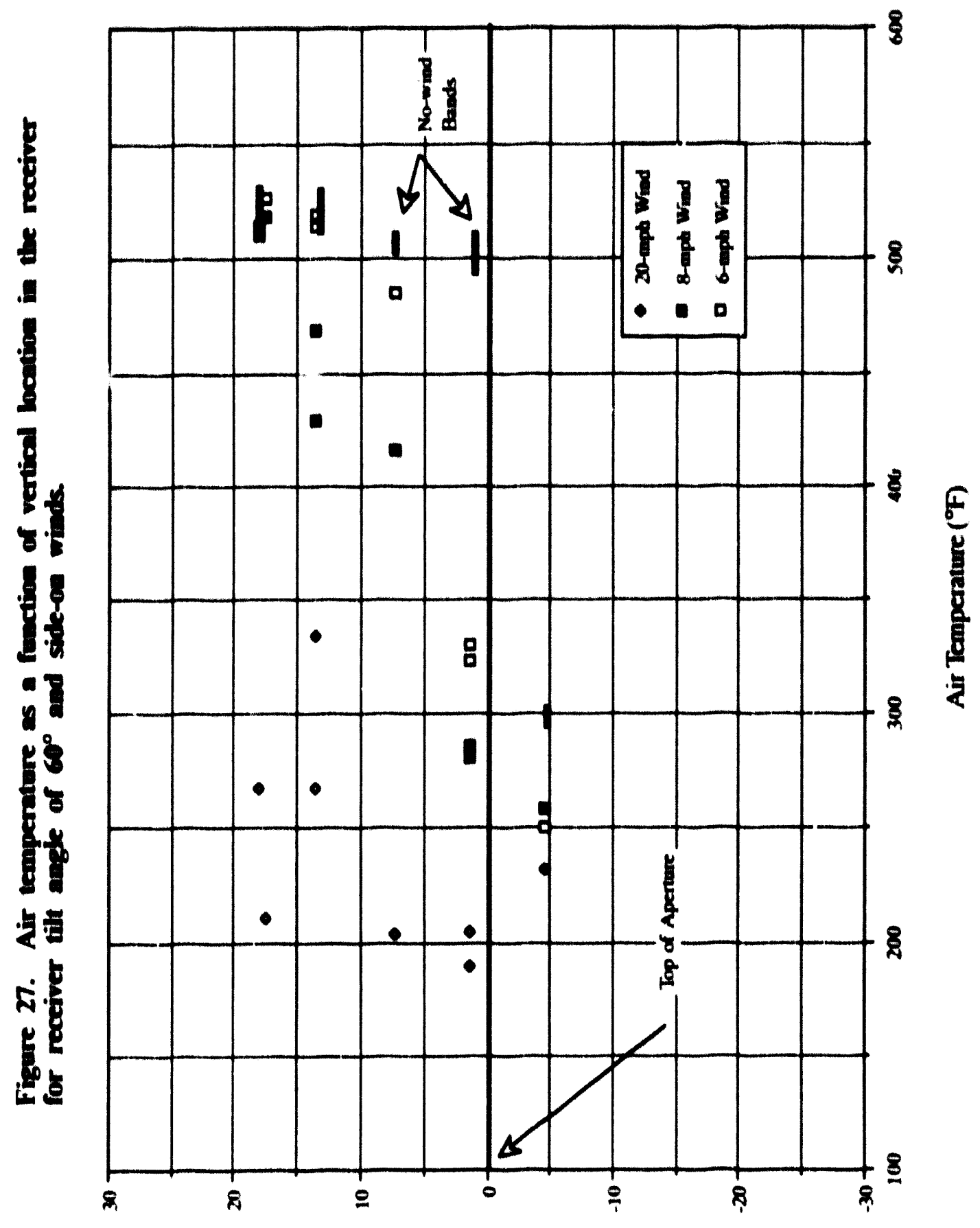

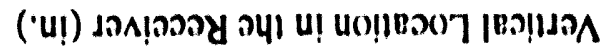




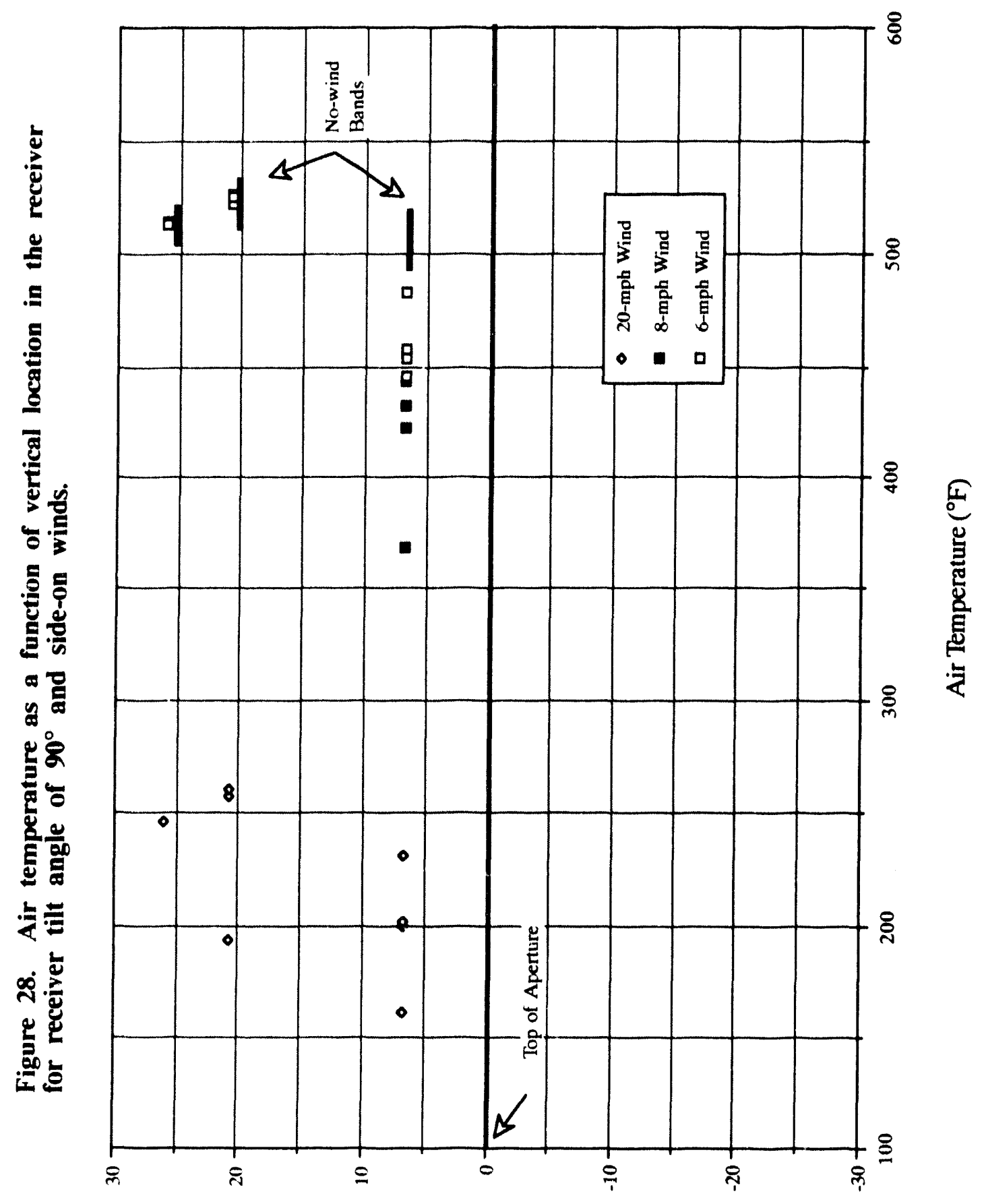

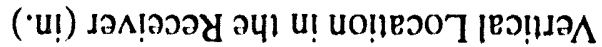


receiver tilt angle, it seems that the presence of side-on wind results in lower air temperatures at vertical locations the same as the aperture. This suggests that side-on wind causes forced convective currents in the mid-section of the receiver. It is interesting to note that although the temperatures in the receiver mid-section are lower than those oceurring without wind, the temperatures in the top and bottom portions of the receiver are generally higher for side-on winds than for no wind at all. This is thought to be a result of forced convective currents within the receiver mid-section actually impeding the natural convective currents normally present in the lower and top portions of the receiver.

At $30^{\circ}$ tilt angle, the effects of wind are noticeable, but are harder to interpret due 10 the more complicated receiver-orientation/wind-direction geometric relationship. Lower temperatures in the receiver vertical mid-section can be seen, but are not as distinct as those occurring for $0^{\circ}$ tilt angle. For lower wind speeds, the air temperatures are not too far from those occurring without wind. Vertical temperature gradients can be seen and it appears that stagnant zones are being formed near the top of the receiver. However, for 20-mph wind, air temperatures virtually everywhere in the receiver are much lower than those occurring without wind.

At $60^{\circ}$ tilt angle, the extent to which the air temperatures are lower than those without wind is dependent upon wind speed. For a 6-mph wind, temperatures in the top 10 inches of the receiver are $480-530^{\circ} \mathrm{F}$, indicating that the air in that region is stagnant. At the same time, air temperatures nearer to the aperture plane are much lower, indicating that forced convective currents are present. For a $20-\mathrm{mph}$ wind, forced convective currents are present everywhere in the cavity, as is evident by the low air temperatures and the lack of any distinct vertical temperature gradients.

Al $90^{\circ}$ tilt angle, the effects of wind are obvious. Al wind speeds of 6 and $8 \mathrm{mph}$, wind effects are only seen near the aperture. Air temperatures slightly above the aperture plane are about $100^{\circ} \mathrm{F}$ less than the temperatures in the stagnant zone. However, for a 20 mph wind, air temperatures are low everywhere in the receiver, which indicates that higherspeed wind induces strong air circulation everywhere in the receiver. 


\subsubsection{Head-on Wind Tests}

Measured air temperatures from the head-on wind lests are shown in Figures 29 through 32. For a receiver tilt angle of $90^{\circ}$, air temperatures are fairly similar to those for side-on winds. This is reasonable considering that head-on and side-on winds are essentially the same for this receiver tilt angle. The only significant difference in the air temperatures for the two wind directions is that it appears as though low-speed head-on wind has a larger effect in reducing air temperatures near the aperture plane. This effect may be caused by the fact that the receiver mount acts as a flow obstruction for side-on wind, but not for head-on wind.

For receiver tilt angles of $30^{\circ}$ and $60^{\circ}$, the effects of wind are again dependent upon wind speed. It can be seen that the effects of low-speed winds are only moderate, with vertical temperature gradients still apparent. For a wind speed of $20 \mathrm{mph}$, however, air temperatures are much lower than those occurring without wind, and no distinct temperature gradient can be seen.

For a receiver tilt angle of $0^{\circ}$, the air temperatures are very similar to those occurring without wind. This is probably due to the fact that wind blowing directly into the aperture of the receiver, although creating a high pressure region near the aperture, does not create any asymmetrical flow which seems to be the most efficient for transporting air into and out of the receiver. In addition, this type of head-on flow does not appear to induce significant air currents inside the cavity. These reasons are a likely explanation for why head-on wind convective heat loss at $0^{\circ}$ tilt angle is not much higher than that occurring without wind.

\subsection{Average Air Temperatures and Internal Heat Transfer Coefficients}

To gain additional insight into receiver forced convection, it is useful to examine average air temperatures within the cavity and to calculate an average internal heat transfer coefficient for each of the tests. These average internal heat transfer coefficients are based on the difference between the receiver inner wall temperature and the average air temperature inside the receiver. As such, they are only for the purpose of analyzing the convective heat loss phenomena and should not to be used for design purposes. The average air temperature is a straight numerical average of all temperature measurements in 


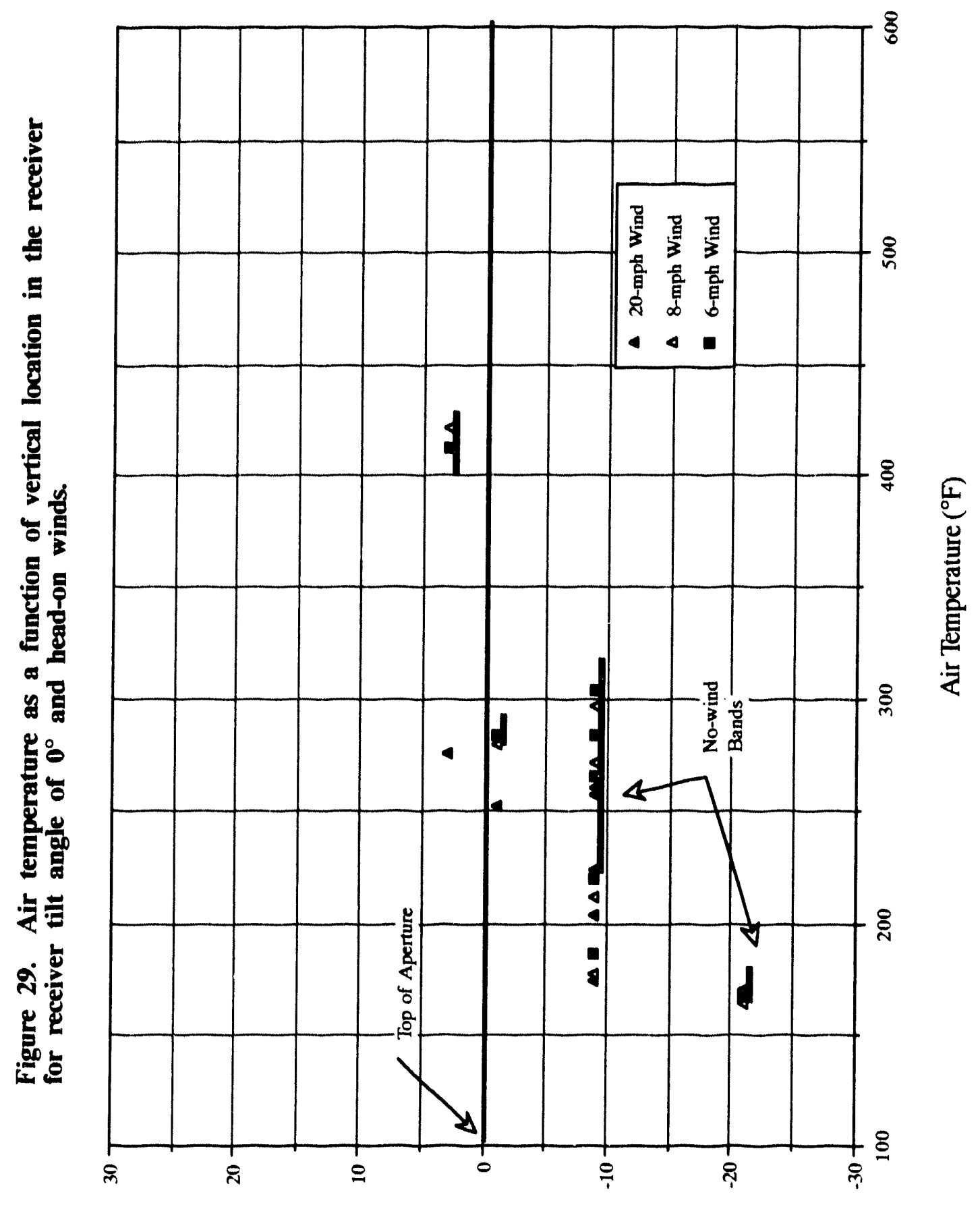

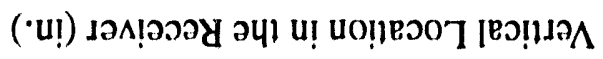




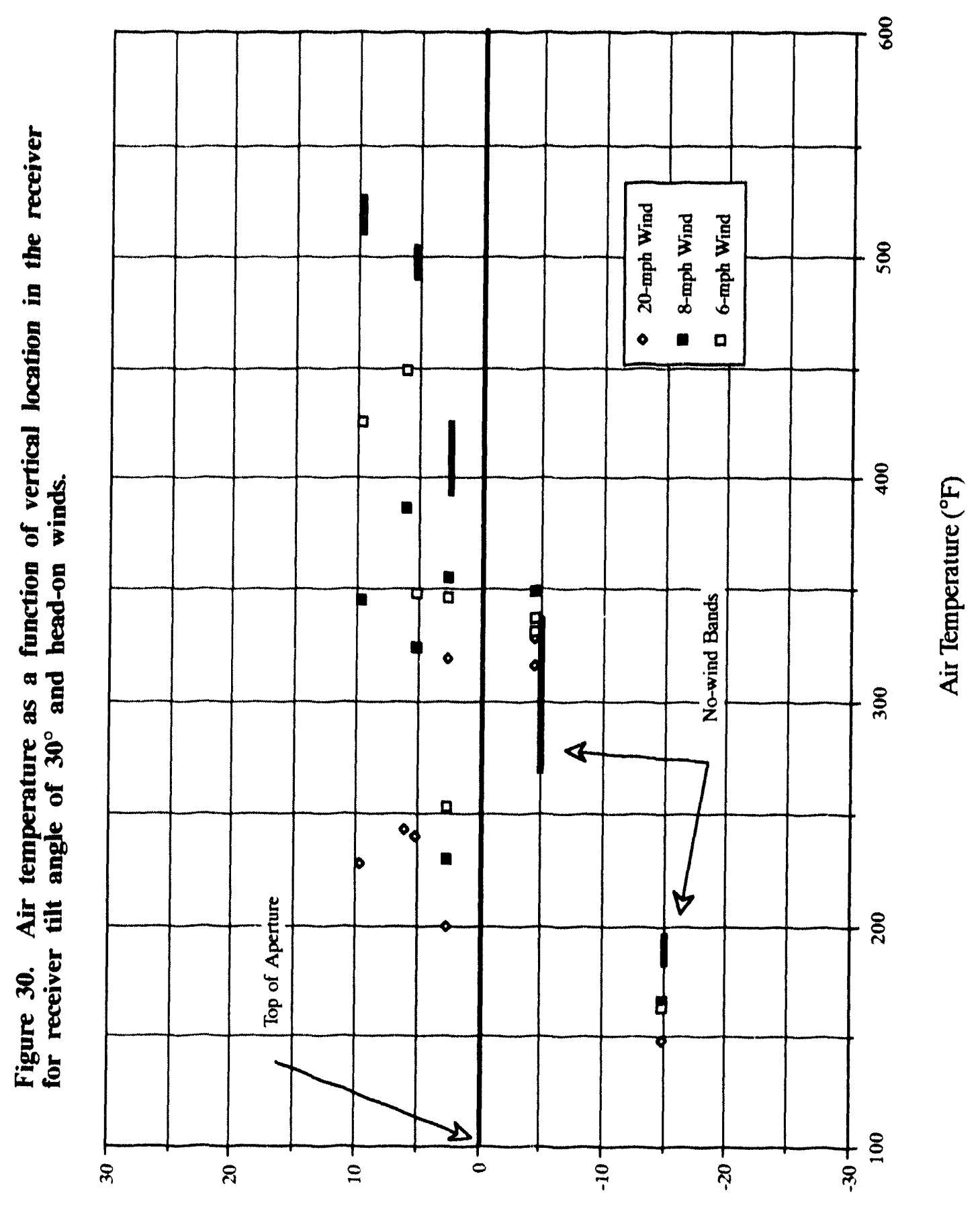

( 


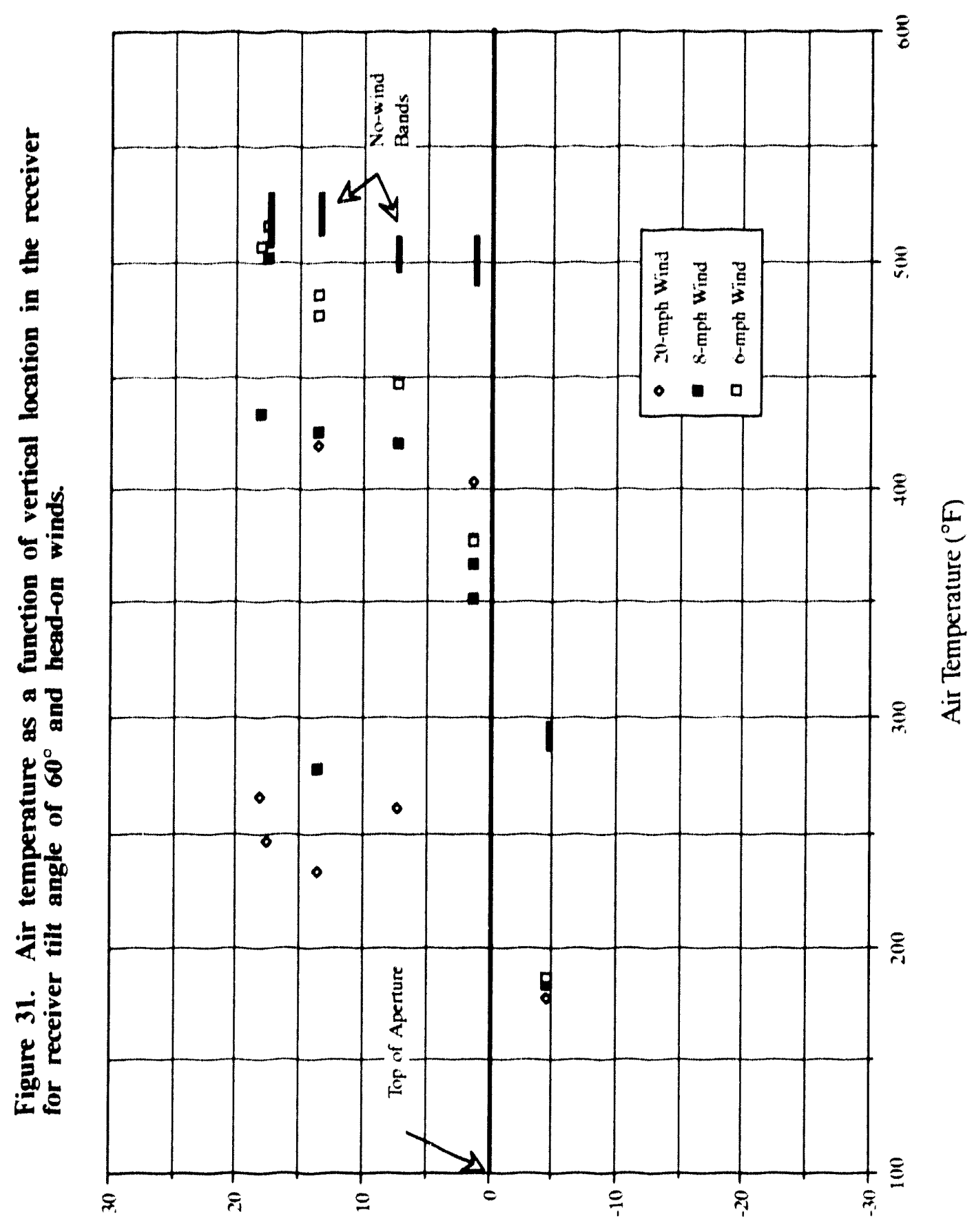

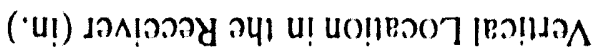




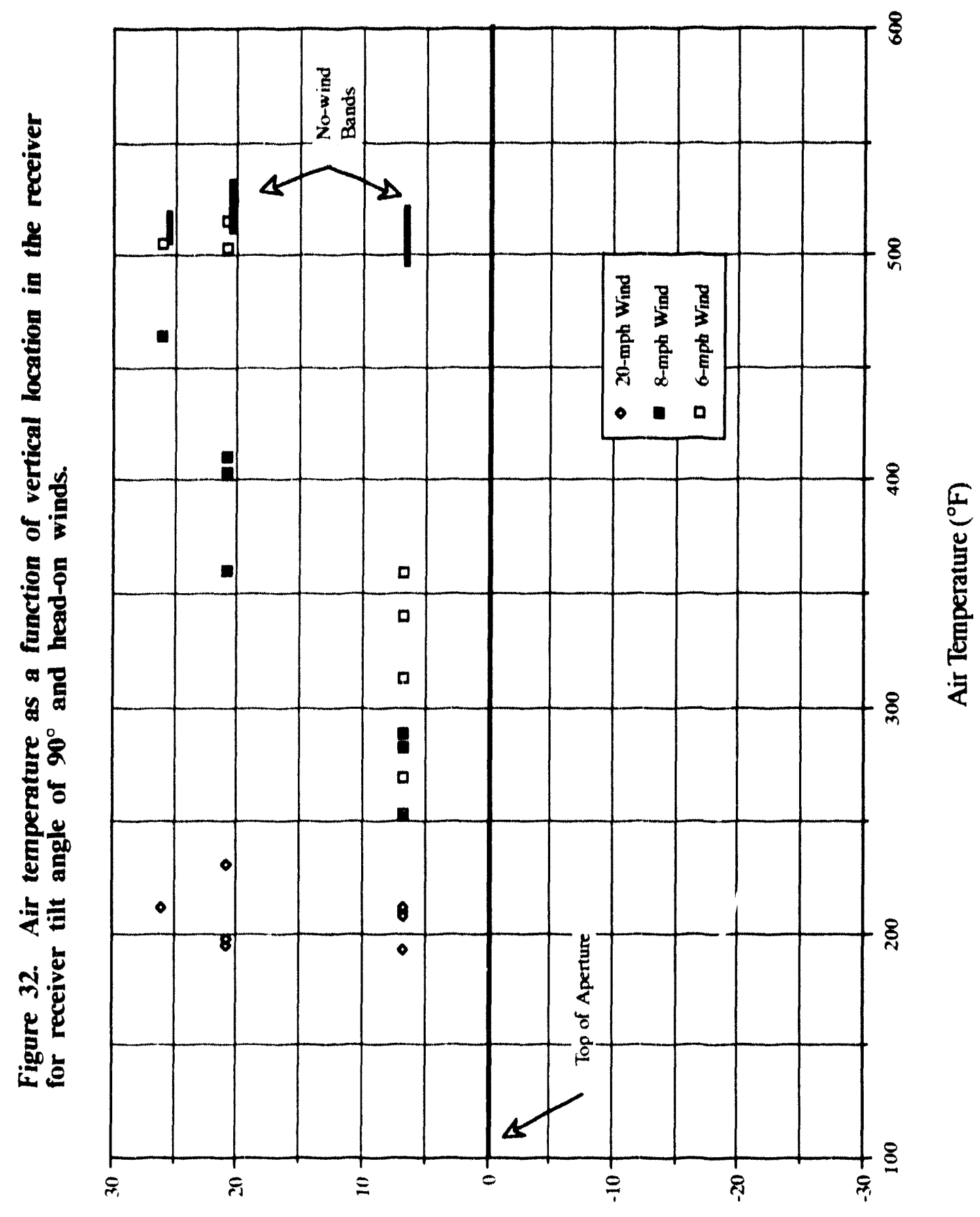

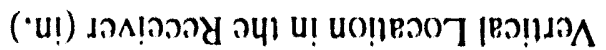


the receiver cavity airspace. It is neither an area-average nor a volume-average because the area or volume associaled with a particular thermocouple measurement is undelined. However, the calculated average temperature is considered representative since the thermocouples are spaced fairly evenly.

The average internal heat transfer coefficient is based on the receiver convective heal loss and the difference between the average inner-wall temperature and average air temperature inside the cavity:

$$
h_{a v g \text { internal }}=\frac{\varphi_{\text {conv }}}{A\left(T_{\text {avg is }}-T_{\text {avg air }}\right)}
$$

where

$$
\begin{aligned}
& h_{a v g} \text { internal = average internal heat transfer cocflicient } \\
& q_{\text {conv }}=\text { receiver convective heal loss rate } \\
& A=\text { full interior geometric surface area of receiver } \\
& T_{\text {avg i.s. }} \text { average inner-surface temperalture from measurements } \\
& T_{\text {avg air }} \text { average cavily air temperature from measurements }
\end{aligned}
$$

In a broad sense, the average air temperature inside the cavity is an indication of how well fresh air is replenished inside the receiver. The average internal heal transfer coefficient is an indication of how well heat is transferred from the receiver inner surfaces to the air inside the receiver, i.e., the extent of air circulation inside the receiver.

\subsubsection{No.Wind Tests}

Figure 33 shows the average air lemperature inside the receiver plotled against receiver tilt angle for all six of the no-wind test sets. The temperatures from the six sets agree very well with one another, indicating that the repeatability of the no-wind tests is good. As the receiver is tilted downward (as tilt angle increases), the average air temperature inside the receiver increases. This trend is consistent with the hypothesis that a stagnant zone exists inside the receiver, increasing in size as the receiver is lilted downward. The increase in receiver average air lemperalure corresponds to a decrease in the temperature differential between the receiver inner wall and the average air temperature, i.e., the driving potential for convective heat transfer decreases. 


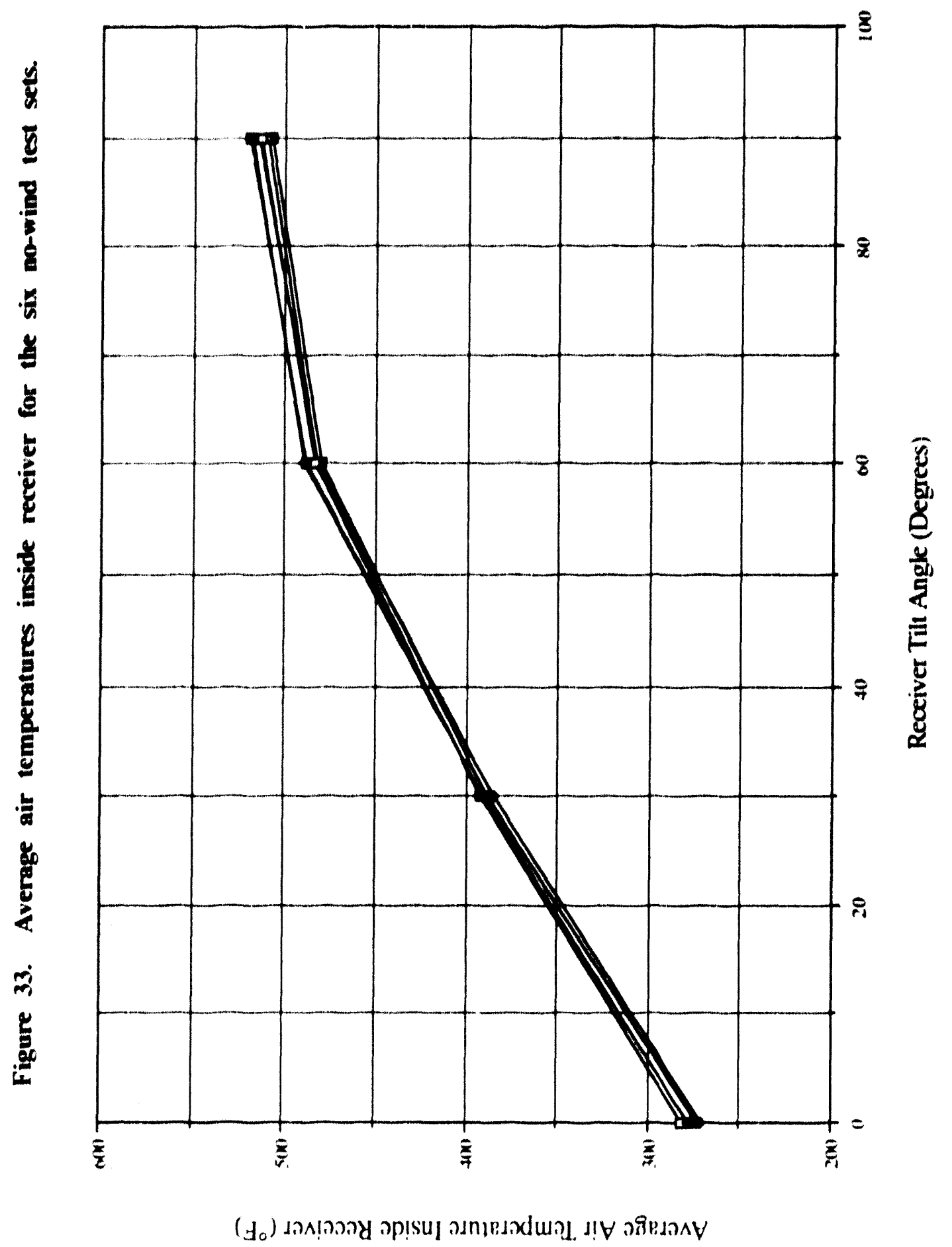


Figure 34 shows the average internal heal trunster cocllicients for the no)-wind tests. The heat transfer cocflicients are approximately constant for all receiver till angles, except lor a till angle of 9()$^{\circ}$, where nalural convective heal transfier is presumahly equal (I) acro. The high value of heat transfier cocflicient al $60^{\circ}$ till angle for one of the est sets appears to be anomalous, due 10 the face that as convective heat loss and lemperature difference become small, the quentient of these values becomes sensitive to dati uncertaintiss.

The results shown in Figures 3.3 and 34 imply that between $\left(1^{\prime \prime} \text { and } 60\right)^{\circ}$ lill angle, nalural convective heal loss decreases with increasing lill angle becaluse the slagnant anne within the receiver becomes larger and the average nir temperalure increases, not because of a decrease in the ability of heat lo be transferred from the receiver inner wall to the air inside: the receiver.

\subsubsection{Side-on Wind Tests}

Figure 35 shows the average air temperature inside the receiver versus receiver tilt angle for side-on winds. Increased wind speed generally results in decreased average air temperature. For wind speeds of 6 and $8 \mathrm{mph}$, the dependency of air temperature 10 receiver tilt angle still exists. This indicates that low-speed winds are not strong enough $(1)$ overeome the existence of the stagnant anne and verlical lemperature gradients. However, with a 20 -mph wind, the average air temperature is independent of receiver till angle, which indicates that a stagnant zone no longer exists.

Nole that the average air temperatures at low wind speeds and at a receiver till angle of $0^{\circ}$ are actually higher than that occurring without wind. This is consistent with the observation made in the previous section that at this receiver tilt angle, side-en winds actually impede air circulation in the bottom and top portions of the receiver, thus resulting in relatively high air temperatures at those lecations.

Figure 36 shows the average internal heat transfer coeflicients for the side-on wind tests. The heat transfer coefficients increase as wind speed increases and as the receiver is tilted upward (from $90^{\circ} 100^{\circ}$ ). The increased heat transfer coefficient as wind speed 


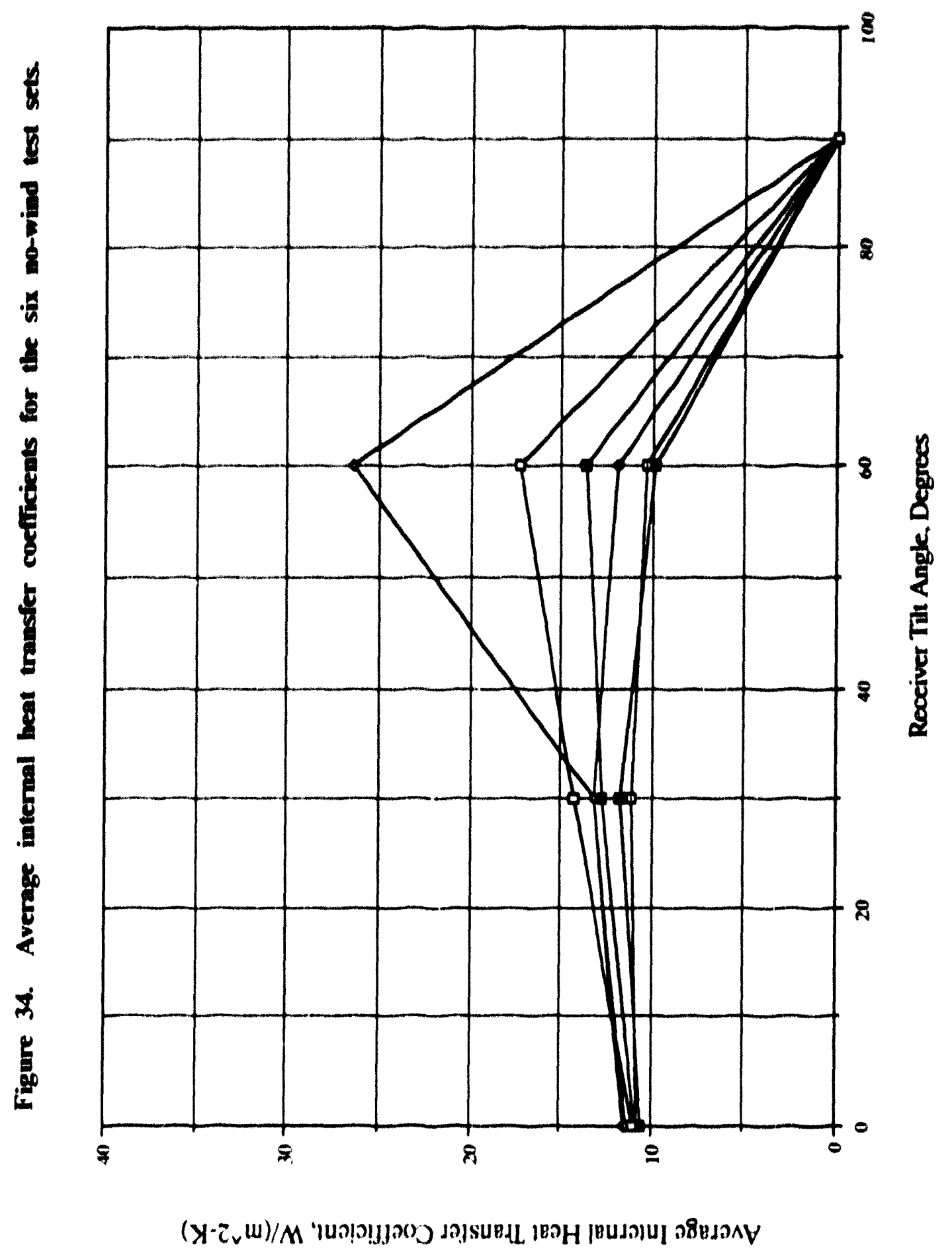




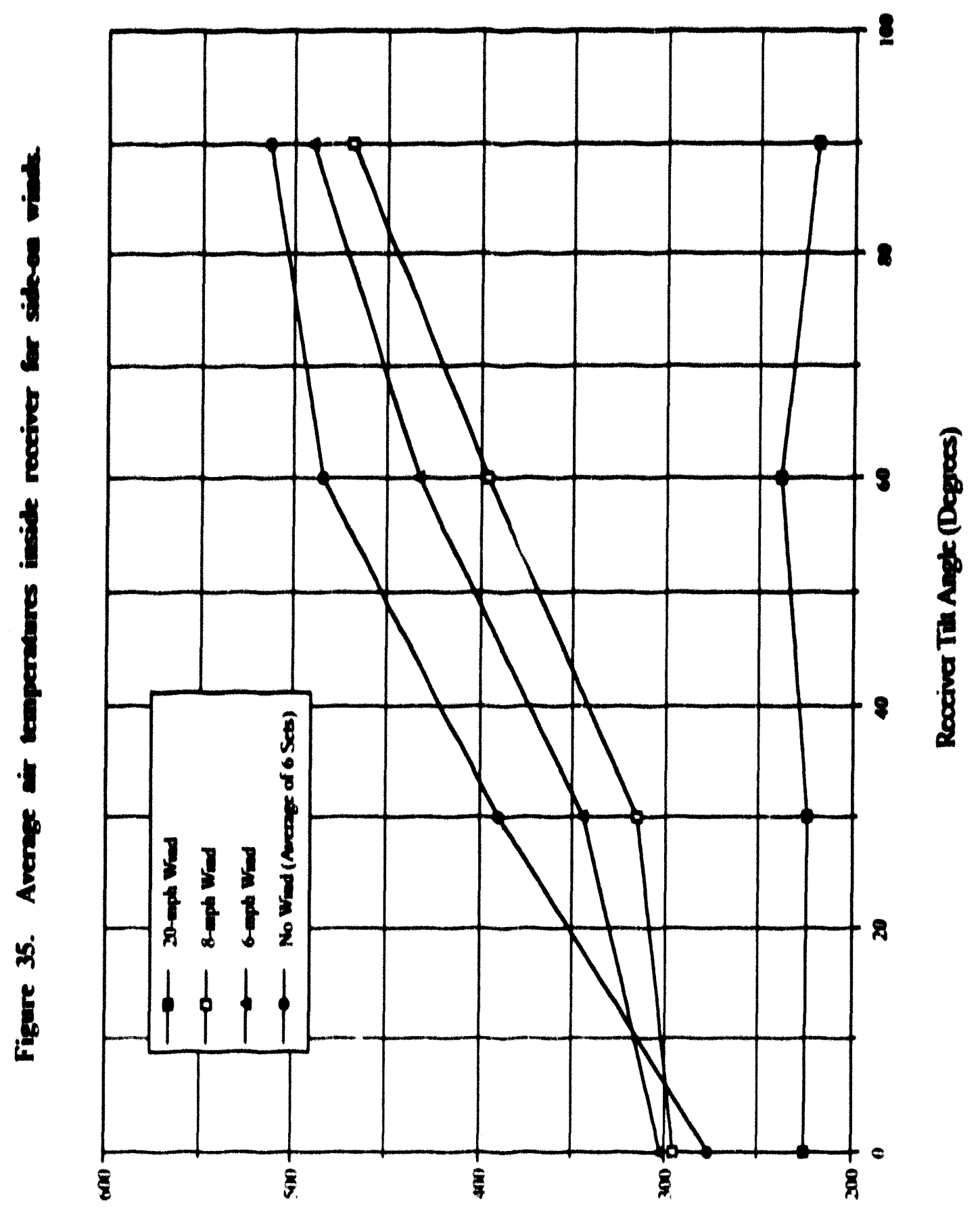

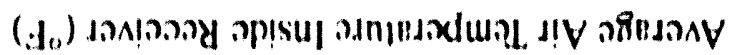




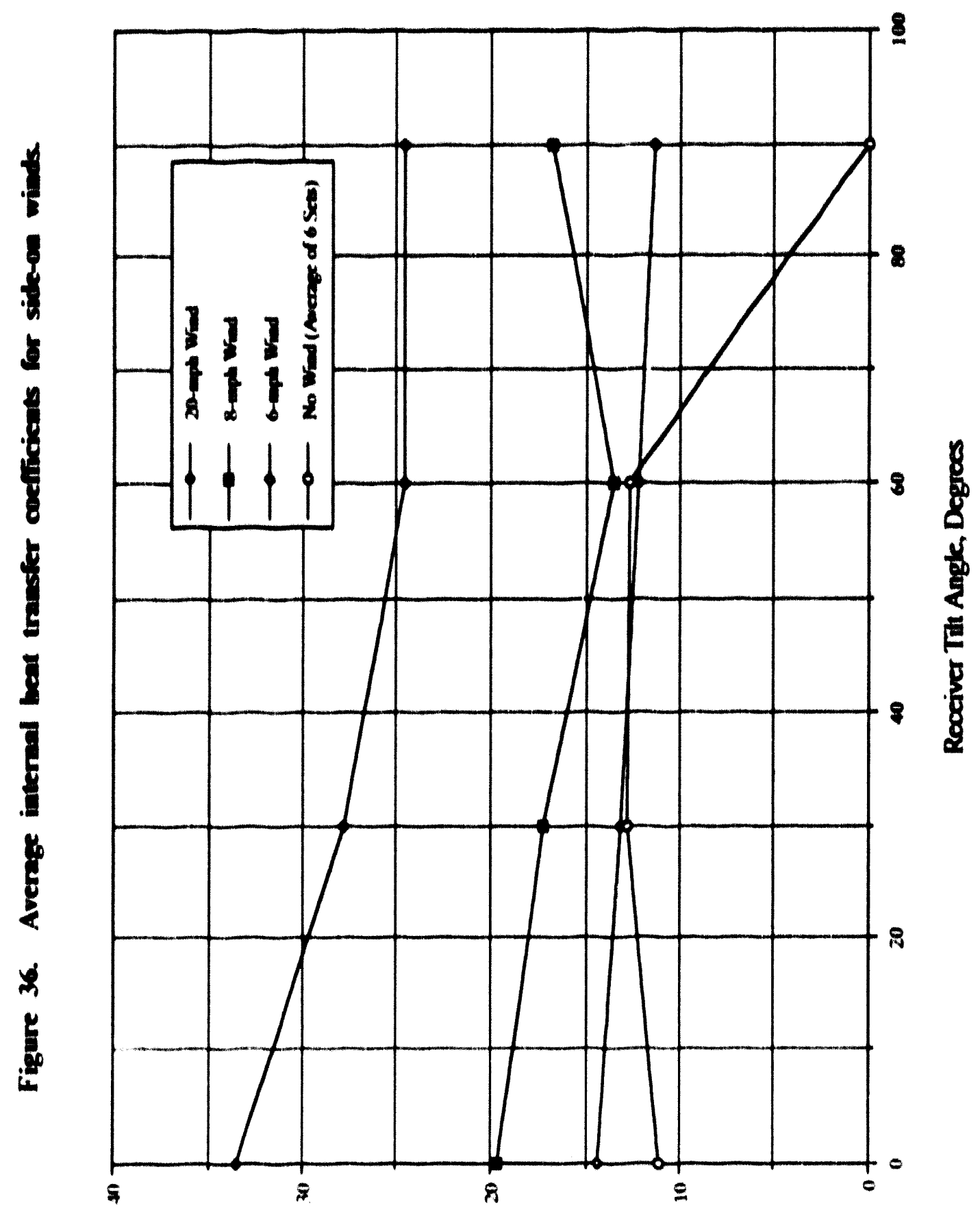

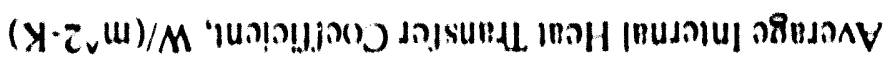


increases is a result of more vigorsus air circulation whin the receiver as the wind speed increases. The increased heat transfer coeflicient as the receiver is tilled upward is somewhat surprising since it was shown previously that the average internal heal transfer coefficient without wind is essentially invariant with till angle, and hechusc one would expect forced convection duc (o) side.()n wind 10 also he invariant with till angle.

\subsubsection{Head-on Wind Tests}

Figure 37 shows the average air lemperatures for all of the hend-(on wind lests. Similar to side-on winds, higher wind speeds result in liwer average air lemperatures. For receiver till angles from $0^{\circ}$ to $60^{\circ}$, the average air temperature increases fiof all wind speeds, because of stagnant zone effects. However, going from 6()$\left.^{\circ} 11\right) 900^{\circ}$ till angle, the average air temperature inside the receiver decreases. This shows that wind hlowing parallel io the aperture plane is relatively effective in replenishing the air inside the receiver.

The average internal heat transfer coefficients for the head-on wind lests are shown in Figure 38. Heat transfer ceefficients increase slightly as the receiver is tilted upward from $90^{\circ}$ to $30^{\circ}$ till angle. However, as the receiver approaches $0^{\circ}$ till angle (wind blowing directly into the receiver), the heal transfer coefficients decreasc, especially at 20-mph wind speed. This shows that wind blowing directly into the receiver aperture does not cause strong convective currents within the receiver, which explains why convective heat loss is so low for this receiver-tilt-angle/wind-direction combination.

\subsection{Hypothesized Flow Patterns In and Around the Receiver}

The air temperature measurements and calculated internal heat transfer coefficients have provided insight into the physical nature of convective now inside and near the receiver. Based on these results and overall convective heat iesses, it is possible to hypothesize flow patterns for several of the different wind conditions and receiver till angles.

For the no-wind condition, the flow patterns for the different receiver lilt angles lested are shown in Figure 39. These flow pallerns are consistent with past experimental findings for natural convection from cavity receivers. Al $0^{\circ}$ till angle (receiver laceing 


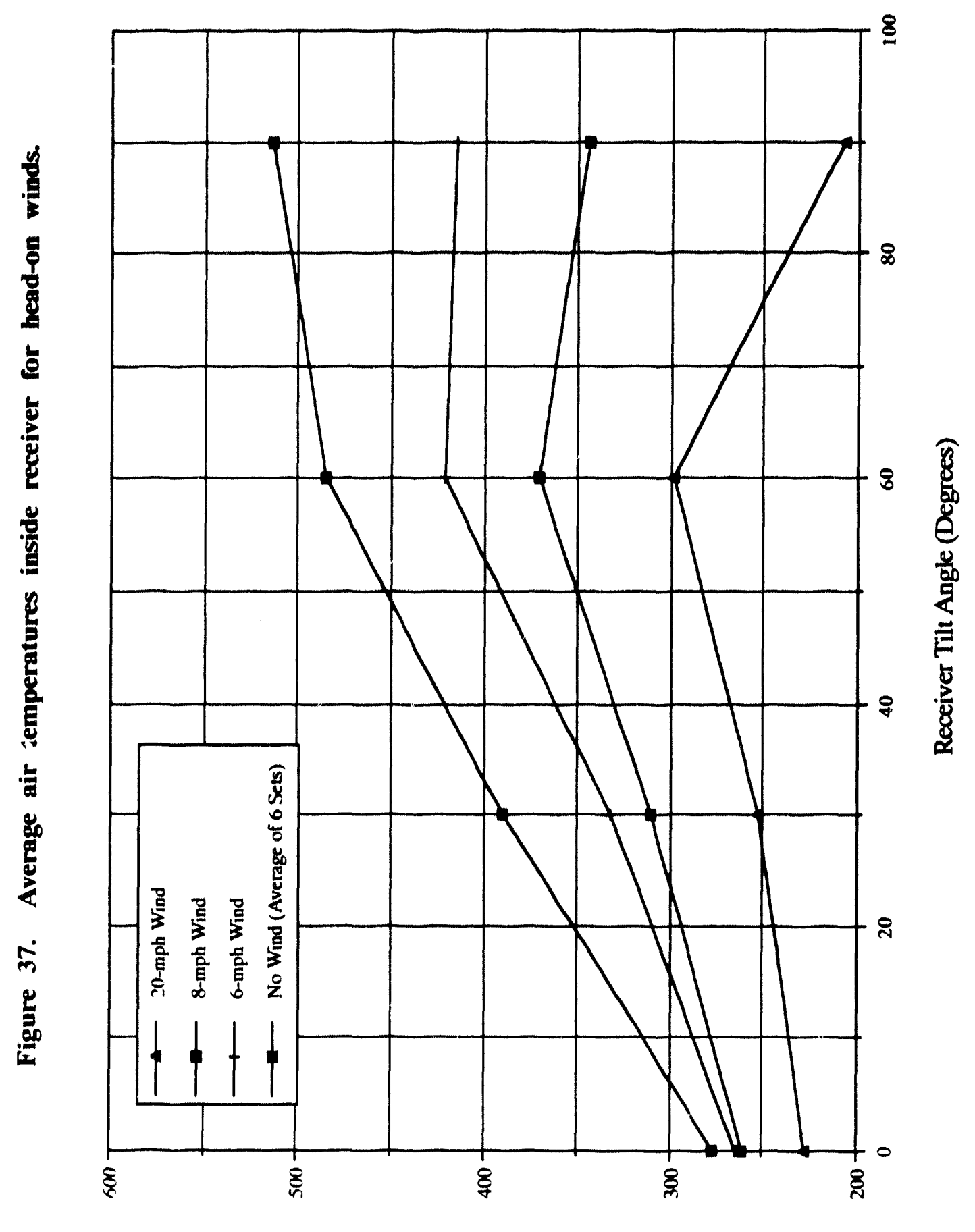

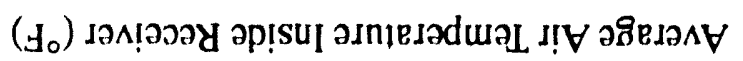




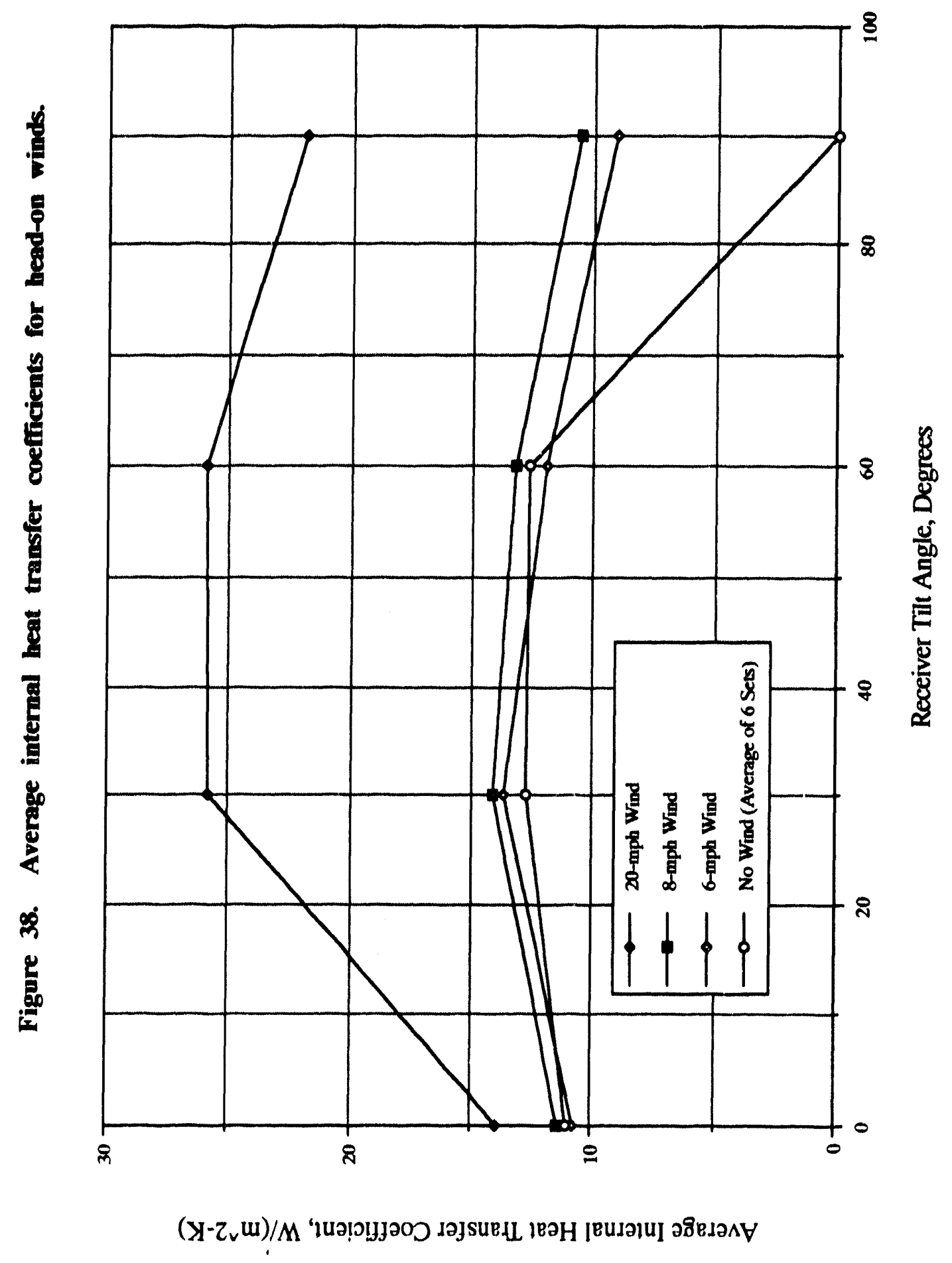




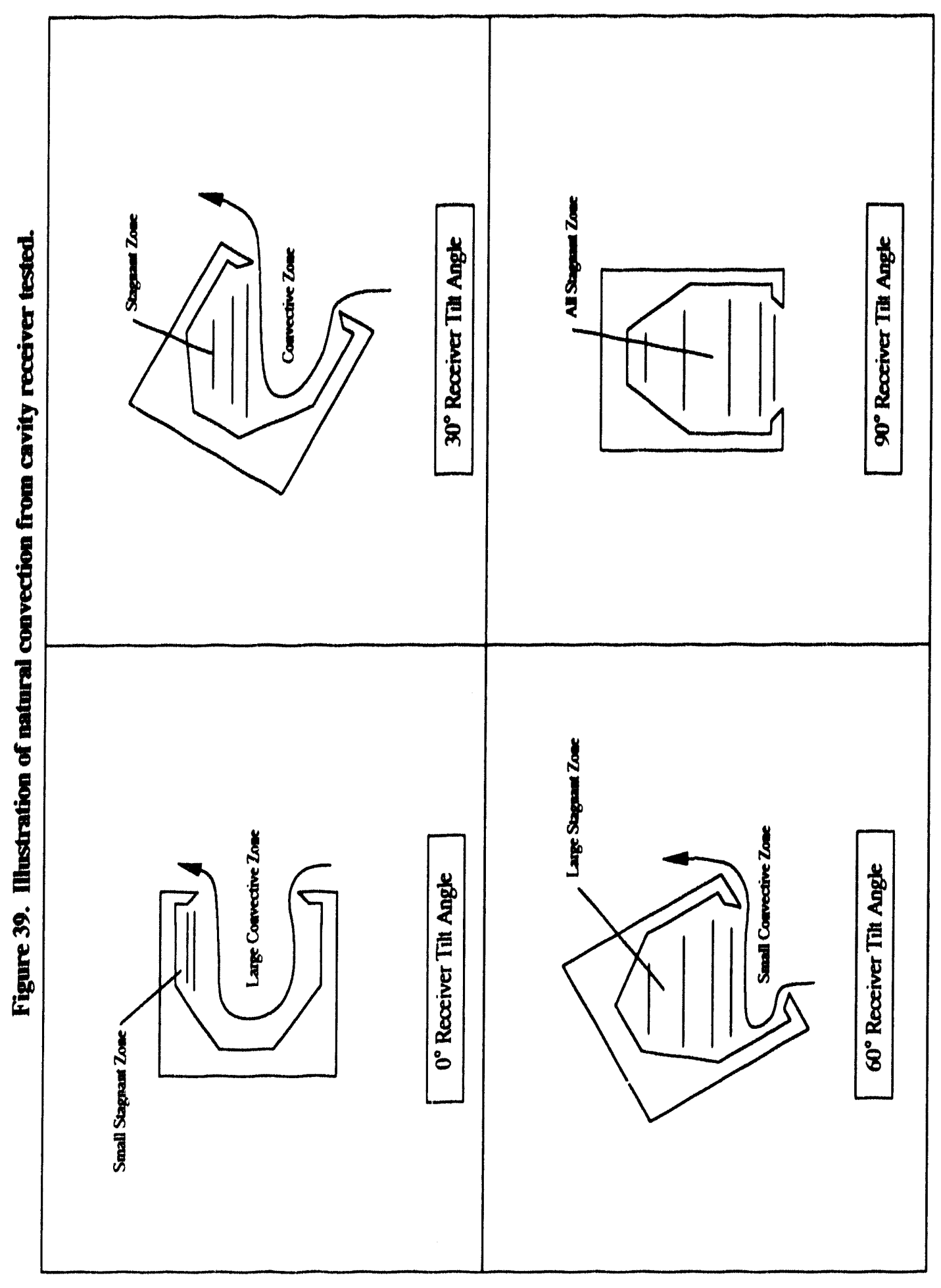


horizontally), natural convective currents occupy most of the receiver, with air temperature being lowest at the bottom and hotter as it rises and picks up heat. The hottest air is in the stagnant zone above the top of the receiver aperture sinee the air there has nowhere to escape. As the receiver is tilted downward, the stagnant zone becomes larger, which results in an overall increase in receiver average air temperature. With the aperture facing straight down, the entire cavity is a stagnant zone, resulting in the highest receiver average air temperature. It is the increase in the size of the stagnant zone and the resultant increase in average air temperature that causes natural convective heat loss to decrease as the receiver is tilted downward.

Presence of wind significantly alters the flow patterns within the receiver. Although many of the conditions tested result in very complex flow patterns, it is possible to hypothesize flow patterns for several of the less complicated conditions. Figure 40 shows hypothesized flow patterns for several head-on and side-on wind conditions.

At a receiver tilt angle of $0^{\circ}$, a head-on wind does not alter internal air temperatures very much from that resulting from natural convection. It seems that wind blowing directly into the aperture does not induce significant air currents inside the receiver, nor does it augment air flow into and out of the receiver through the aperture. As a result, convective heat loss for this receiver-tilt-angle/wind-direction condition is relatively low.

For a receiver tilted partially downward, but not straight down, the effects of headon wind appear to be dependent upon wind speed. Low-speed head-on wind appears to result in air circulation mainly in the lower portion of the receiver, while higher-speed wind results in air circulation throughout a larger portion of the receiver. This circulation within the receiver is thought to be a result of a shear forces at the aperture due to the tangential component of wind velocity.

At a receiver tilt angle of $90^{\circ}$, head-on and side-on winds are essentially the same. The wind velocity is parallel to the receiver aperture. At low wind speeds, the effects of wind are only felt in the lower portion of the receiver. Air temperatures in the lower portion of the receiver are much lower than those occurring without wind. However, temperatures in the top portion of the receiver are high, being about the same as those occurring without wind; i.e., momentum transport due to low-speed wind is not strong 


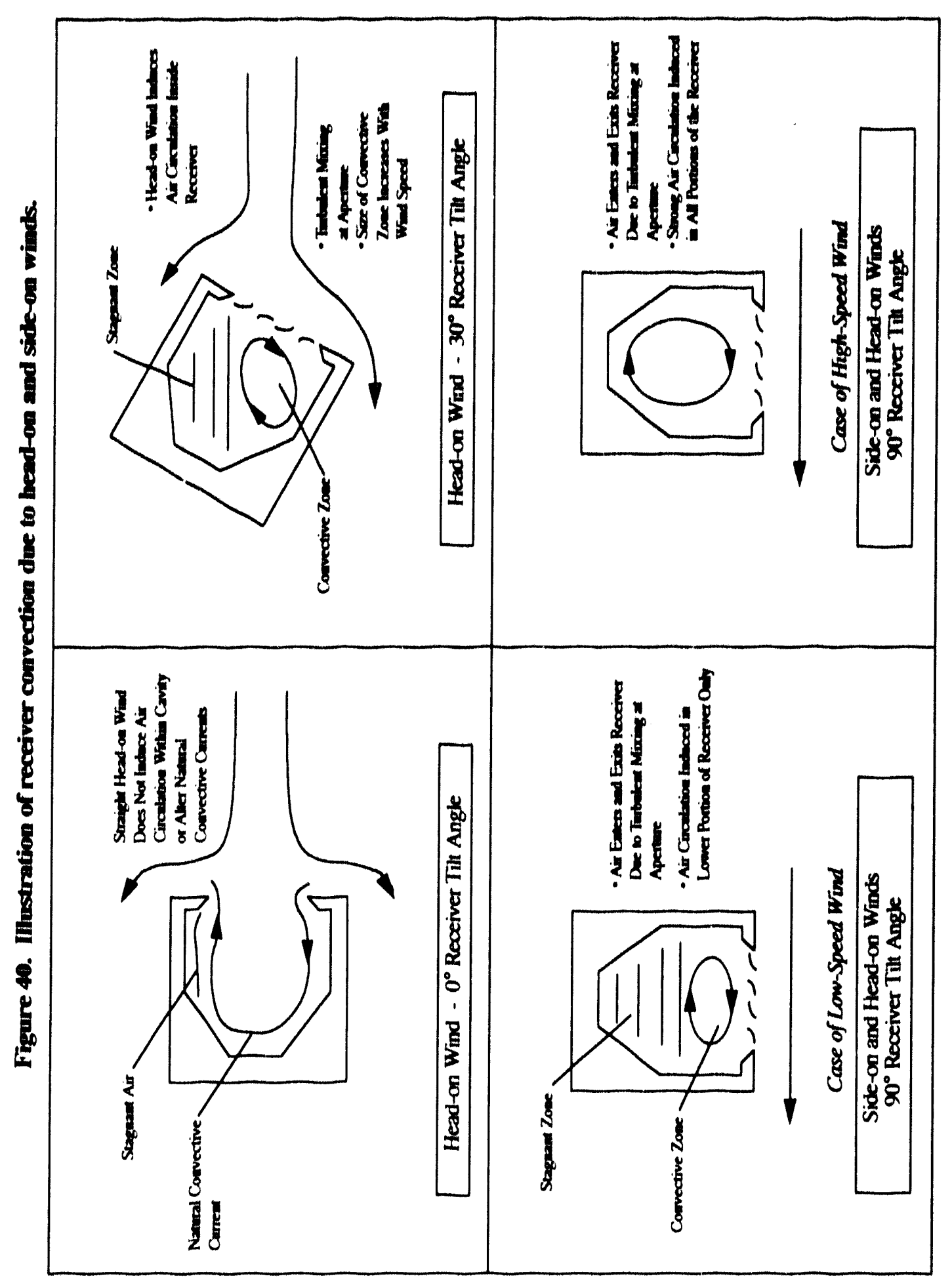


enough to overcome buoyancy forees. However, at high wind speeds, wind effects are felt everywhere in the receiver. The effects of high-speed wind are so strong that vertical temperature gradients due to buoyancy forces are completely eliminaled.

For side-on wind at other than $90^{\circ}$ tilt angle, receiver flow patterns are similar 10 those shown for $90^{\circ}$ tilt angle. However, the presence of additional natural convective currents, oriented orthogonally to wind-induced currents, decreases the extent of the stagnant zone and results in higher overall convective heat loss.

\subsection{Reliability of Test Results}

The reliability of the results from these tests is dependent upon the accuracy of the measurements taken during the test and the algorithms used in data reduction. Accurate measurements of temperature difference between the heat-transfer-fluid inlet and outlet, and of the heat-transfer-fluid flow rate, are important because overall receiver heat loss is proportional to these quantities. With respect to the algorithms used in data reduction, each additional step that is required to derive the final convective heat loss value induces more uncertainty. This is because each component used in the data reduction algorithm has associated uncertainties, and these uncertainties are propagated and magnified with each additional mathematical step. The uncertainty in temperature measurements and an overall uncertainty analysis are presented in the next two sections.

\subsection{Uncertainty in Temperature Measurements}

The accuracy of temperature-difference measurements is important since total receiver heat loss is proportional to it. In the measurement of convection heat loss for these tests, temperature difference was measured two different ways. First, two junctions of a thermocouple were place at the receiver inlet and outlet to obtain a direct temperaturedifference measurement. Second, temperature difference was obtained indirectly by measuring absolute temperatures at the receiver inlet and outlet, and then calculating the difference.

Figure 41 shows the comparison of temperature differences measured directly and indirectly, for all of the tests conducted. It can be seen that these two methods for 


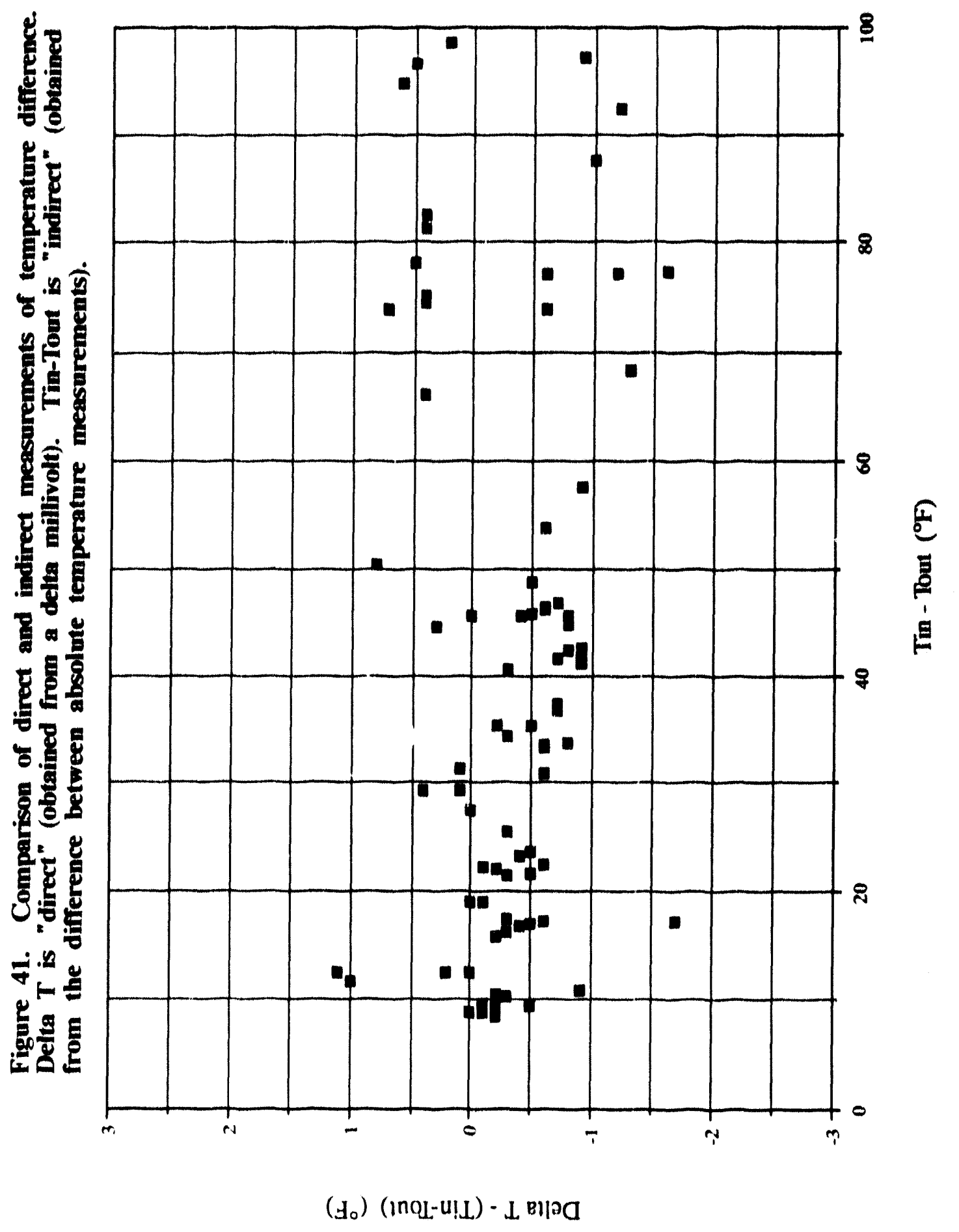


measuring temperature difference agree to within $\pm 1.4^{\circ} \mathrm{F}$, except for two data points. This comparison indicates that the two methods agree well with one another; however, it does not say anything about thermocouple accuracy. Nevertheless, in dala reduction, a temperature-difference uncertainty of $\pm 1,4^{\circ} \mathrm{F}$ was used because it was folt that the direct temperature-difference measurements were at least good 10 within this value. This is thought to be acceptable since each junction of a thermocouple for a direct lemperature. difference measurement should have essentially the same characteristics, thereby minimizing temperature-difference uncertainties. The assumed temperature-difference uncertainty of $\pm 1.4^{\circ} \mathrm{F}$ corresponds to absolute temperature uncertainty in each of the thermocouple junctions of $\pm 1^{\circ} \mathrm{F}$.

For situations where absolute lemperature measurements were required, an uncertainty of $\pm 2^{\circ} \mathrm{F}$ was used. However, this level of uncertainty has very little effect on the overall uncertainty of the lest results because the only parameters that depend on absolute temperature are heal-transfer-fluid thermal properties and thermocouple characteristics (c.g., Secheck coefficient), and these parameters are only weak functions of temperature. (The thermal properties of Syltherm 800 heat transfer fluid are given in Appendix $A$, and the thermoelectric characteristics of type-K thermocouples are given in Appendix E.)

\subsection{Overall Uncertainty Analysis}

A complete uncertainty analysis was performed so that the confidence level of these experimental data could be assessed. The analysis takes into account uncertainties in measured temperatures, heat-transfer-fluid flow rate, and material thermal properties. I also accounts for the propagation of uncertainty resulting from data manipulation during the separation of conduction, radiation, and convection heat loss components. The individual parameter uncertainties used to perform the analysis are given below. The details of the uncertainty analysis procedure are given in Appendix F. Tabulated uncertainty analysis results are given in Appendix $C$, and error bars for receiver convective heal losses are also shown in Figures 8 and 9. 
Parameler

Direct Measurement of Temperature Difference

Absolute 'Temperalure

Heal-Transfer-Fluid

Flow Rate

Heat-Transfer-Fluid

Specific Heat

Heat-Transfer-Fluid

Density
Uncertainty

$\pm 1.4^{\circ} \mathrm{F}$

$\pm 2^{\circ} \mathrm{F}$

$\pm 0.5 \%$ of meler reading

$\pm 1 \%$ of value

$\pm 1 \%$ of value

Figure 42 illustrates some typical results from the uncertainty analysis. For no wind, heat loss uncertainties are about $0.1 \mathrm{~kW}$ for conduction, $0.15 \mathrm{~kW}$ for radiation, and 0.21-0.22 kW for convection. The uncertainties are similar for the 20-mph side-on wind condition, except those for convective heat loss are slightly higher at $0.23-0.25 \mathrm{~kW}$. The (0.1 kW uncertainty in conduction heal loss, shown for both conditions, is essentially equal to the uncertainty in overall receiver heat loss with the aperture plugged. The radiation heat loss uncertainties are higher than those for conduction hecause the calculation of radiation heat loss requires one additional step. Convective heat loss uncertainties are even higher because its calculation requires yet another step.

Although convective heat loss uncertainties do not vary much with receiver tilt angle, the uncertainty percentages vary greatly. Al the highest convective heat loss condition, the uncertainty is only about 4 percent of the total convective heat loss. On the other hand, the uncertainty percentage can approach infinity as the heat loss level approaches zero. Fortunately, at low heat loss levels, the accuracy of the experimental results has litlle effect on overall system efficiency.

At this point, it is worthwhile to discuss the effects of uncertainties in temperature difference and heat-transfer-fluid flow rate, specific heat, and density. Overall receiver heat loss uncertainty is a result of uncertainties in material properties and in measured parameters. It is quantified by Eq. (F4) in Appendix F and repeated here as follows: 


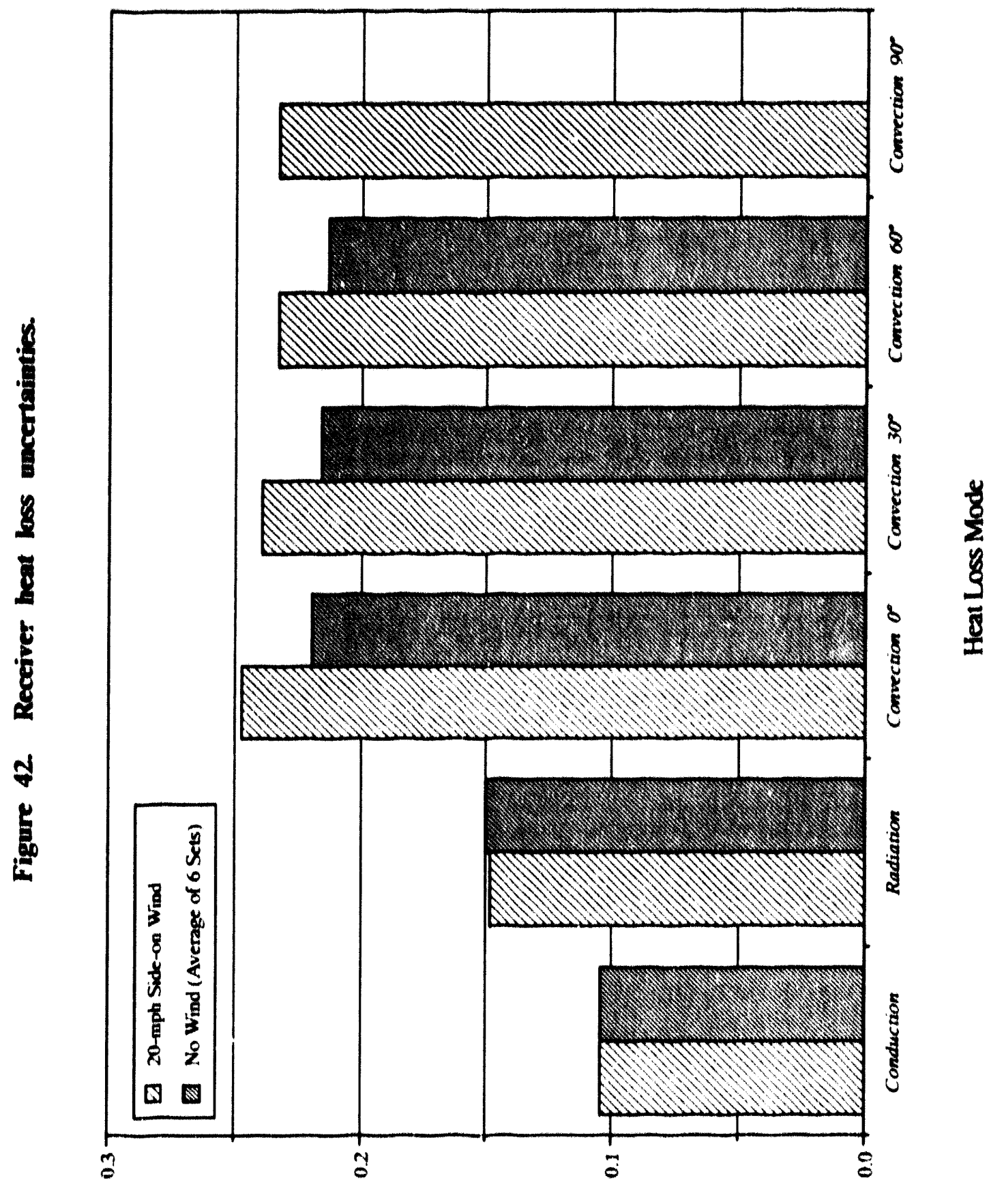

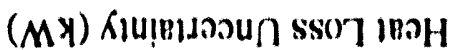




$$
w_{\text {meat }}=2.25 \times 10^{-4} 4_{\text {mens }}{ }^{2}+2.0 \frac{q_{\text {meas }^{2}}^{2}}{(\Delta T)^{2}}
$$

where $y_{\text {meas }}=$ lotal receiver heal loss rate derived from measurements

$w_{\text {ymeas }}=$ uncertainty in total receiver heal loss rate

$\Delta \mathrm{T}=$ temperature difference between the heat-transfer-fluid inlet and outlet

The first term on the right-hand side of Eq. (16) is the due to uncertainties in heat-transferlluid flow rate, specific heat, and density, and increases as receiver heat loss increases. The second term on the right-hand side is due to uncertainty in the measured temperature difference between the receiver inlet and outlet, and is approximately proportional to the heal-Iransfer-fluid flow rale. In these tests, the heal-Iransfer-fluid flow rate was held nearly constant, so that the uncertainty due to the second term on the right (temperature uncertainty) is essentially constant. At low heat loss rates, most of the uncertainty in overall receiver heat loss was found to be due to uncertainty in temperature difference. However, at higher heat loss levels, the effects of uncertainty in flow rate and fluid material propertics become comparable to that due lo lemperature difference.

It is interesting 10 note that given a particular receiver heat loss level and the parameter uncertaintics used in this analysis, that the overall heat loss uncertainty can be reduced by reducing the heat-transfer-fluid flow rate. This is because the temperature difference term (the second term on the right) is equal $102.0\left(0 \mu c_{p}\right)^{2}$. This method appears as though it could be used to reduce heat loss uncertainties without costs. However, at some point, the advantage of reducing heat loss uncertainty would be overshadowed by the disadvantage of a non-isothermal receiver, because low thuid llow rates would result in large temperature differences between the receiver inlel and outlet.

\subsection{Comparison of Analytical Predictions to Experimental Results}

In order to increase conlidenec, it is desirable to compare the experimental data and analyses wherever possible. Therefore, an effort was made 10 predict radiation and conduction heat losses by using a combination of computer modeling and hand 
computations. A discussion of these analyses and the comparison of predicted 10 experimental results are given in the next Iwo sections.

\subsection{Radiation Heat Loss}

To predict radiation heat loss from the receiver, a compuler model was generated using PATRAN (PDA Engineering) which is a model generator for finite-diflerence und finite-element analysis. This thermal network is shown in Figure 43. The radiution analysis was based on an electrical analogy, which incorporates surfuce resistances duc Io gray surfaces, shape resistances associaled with the ahility of one surface on "sec" other surfaces, and radiosily nodes.

A program called VFAC (PDA Engineering) was used to set up the detailed radiation network for the computer model by calculating shape lactors and shape and surface resistances, and by defining radiosity nodes. A sel of ulgebraic equations is obtained by setting the summation of heal rate into each radiosity node equal to ecro. The general matrix formulation for the sel of algebraic equations is " t.dlows:

$$
J_{i} \cdot\left(1 \cdot \varepsilon_{i}\right) \sum_{i=1}^{N} F_{i \rightarrow j} J_{j}=\varepsilon_{i} E_{h i}
$$

$$
\text { where } \quad \begin{aligned}
& J=\text { surface radiosity } \\
& F=\text { radiation shape factor } \\
& E_{h}=\text { lotal hlackhody emissive power } \\
& E=\text { surface cmissivity }
\end{aligned}
$$

The radiation network was subsequently solved using P.Thermal, which is the PDA thermal analysis compuler code.

In the analysis, the receiver internal surfiaces were assumed to be gray (emissivity which is constant, i.e., independent of temperature and wavelength). An emissivity of (1.9 was used for the receiver luhing area since it was painled with Pyromark paint. An 

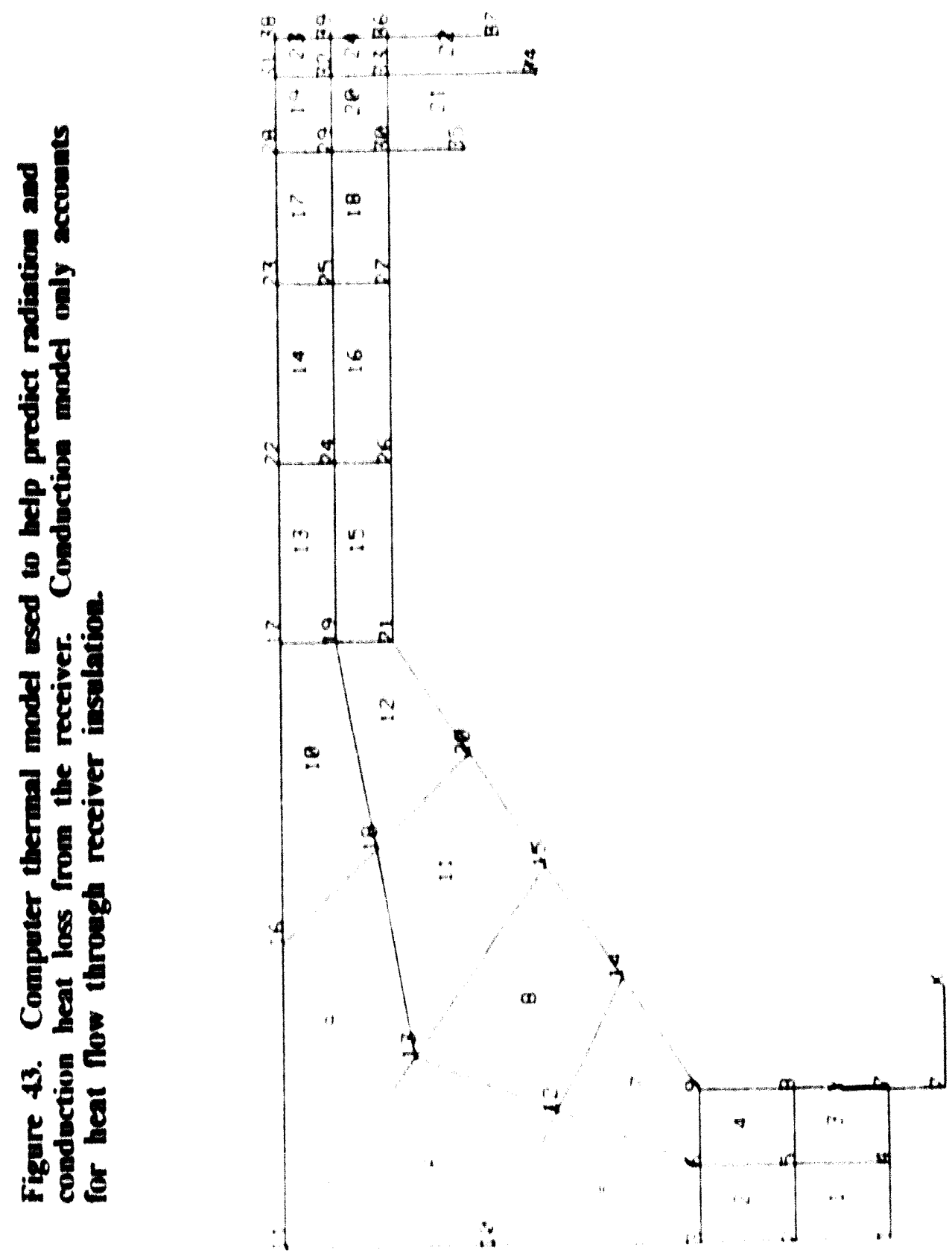
emissivity of (0.3 was used for the chrome-plated-stecl surfices at the forward and alt ends of the receiver lubing areu.

For the $5.300^{\circ} \mathrm{F}$ nominal receiver lemperafure in thesc lests. the predicted radiation heal less from the receiver is $0.74 \mathrm{~kW}$, which is slightly higher than the $10.62 \mathrm{~kW}$ obtained experimentally. Some of this deviation may be dae to the chrome-plated-sted pertion of the receiver, forward and aft of the heat transfer lubing, heing lower in temperalture than the average lemperalure of the heal transfier fluid.

Figure 44 shows measured receiver inner wall lemperalures which are typical of the temperutures from tests used on calculate radiation heal loss. $A$ line is drawn in this ligure lo represent the average heal-Iransfer-fluid temperalure for this case. Recall that the aclual average temperature of the heat transfer fluid is slightly dilferent than the nominul receiver lemperature of $530^{\circ} \mathrm{F}$ for which radiation heul loss is given. The datu shown in Figure 44 show that the average heat-transfire-fluid lemperature is an acecplable representation of the temperatures occurring on the heal-transfer-lubing surfuces ?al receiver forward and alt planes). The measured cemperalures on the surfince of the heil transfer lubing range from $536^{\circ} \mathrm{F}$ (1) $946^{\circ} \mathrm{F}$, compared to the heul-transfer-fluid average lemperulure of $541^{\circ} \mathrm{F}$ However, the temperature of the chrome-plated-steel area aft of the heut transfer lubing is somewhat lower in temperature at $5\left(59^{\circ} \mathrm{F}\right.$. Moreover, it is highly likely that the chromeplated-stecl area forward of the heat transfier luhing is also lower in temperature than the average temperature of the heat transfer lluid; however, the actual temperatures in this region ure unknown since no lemperature measurements were taken there.

In light of the receiver lemperatures shown in Figure 44, the radiation heal loss was predicted with the aforementioned compuler thermal model using a receiver aft-section temperature of $5(x)^{\circ} \mathrm{F}$ and an estimated temperature of $3(1)()^{\circ} \mathrm{F}$ in the area forward of the heat transfer lubing. The $50(0)^{\circ} \mathrm{F}$ lemperature in the alt sedtion takes into account the fact that the normalieed receiver temperature is $5.30^{\circ} \mathrm{F}$, not $541^{\circ} \mathrm{F}$. The resultant predicted radialion heat loss is $0.71 \mathrm{~kW}$, which is closer 10 , but still about 1.5 percent above, the experimental valuc. 


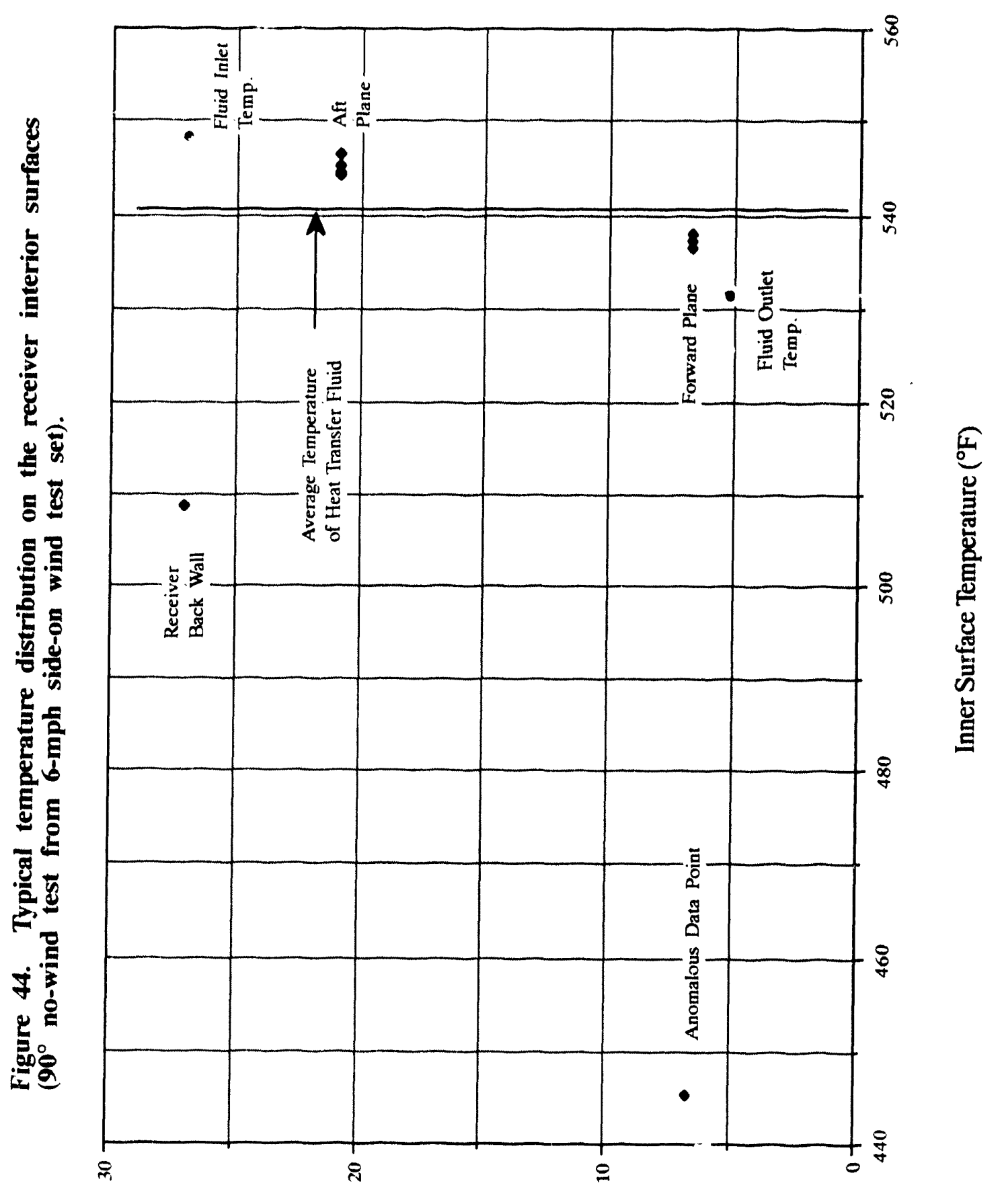

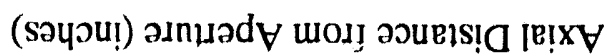


It is interesting to note that a first-order prediction of radiation heat transfer from the receiver can be obtained by using the aperture area and an effective aperture emissivity. The effective emissivity for the cavity receiver tested is 0.94 based on the isothermal radiation model, 0.91 based on the non-isothermal radiation model, and 0.79 based on the experimental results. Thus, it appears that a relatively conservative value of radiation heat loss can be obtained by simply using the emissivity of the receiver tubing (of (0.9. To be more conservative, an upper bound for radiation heat loss can be oblained by simply using an effective emissivity of 1.0. Predicted radiation heat loss curves using these effective emissivities are shown in Figure 45.

Another interesting fact to note is that the receiver cavity has radiation characteristics that are similar to that of a hohlraum, which is a large cavity with a very small opening through which radiative heat is transmilted. The unique characteristic of a hohlraum is that the amount of radiation transmitted through the small hole is independent of the emissivity of the interior surfaces. Using the computer radiation model, it was found that a 50 pereent reduction in the emissivity of the interior surfaces of the receiver only decreased radiation heat loss by about 10 percent. Thus, an effort to reduce radiation heat loss from the receiver by lowering the emissivity of the cavity surfaces would probably not be productive.

\subsection{Conduction Heat Loss}

In order to analytically predict conduction heat loss from the receiver, a combination of finite-element heat-transfer modeling and hand computation was performed. The axisymmetric finite-element model was the same basic model as that used for calculating radiation heat loss (Figure 43) and only accounts for conduction heat loss through the receiver-wall insulation. In this model, the receiver inner surface was constrained at $5.00^{\circ} \mathrm{F}$, and the receiver outer surface was constrained at $85^{\circ} \mathrm{F}$ for the 2() -mph wind condition and $115^{\circ} \mathrm{F}$ for the no-wind condition. These outer surface temperatures were chosen based on actual average outer-surface temperature measurements given in Appendix D.

The hand computation took into account heat conduction through the receiver tubing support structure, which consists of forward and aft supports at hree circumferential locations, and a receiver forward-end structure. These structures are depicted in Figure 46. 


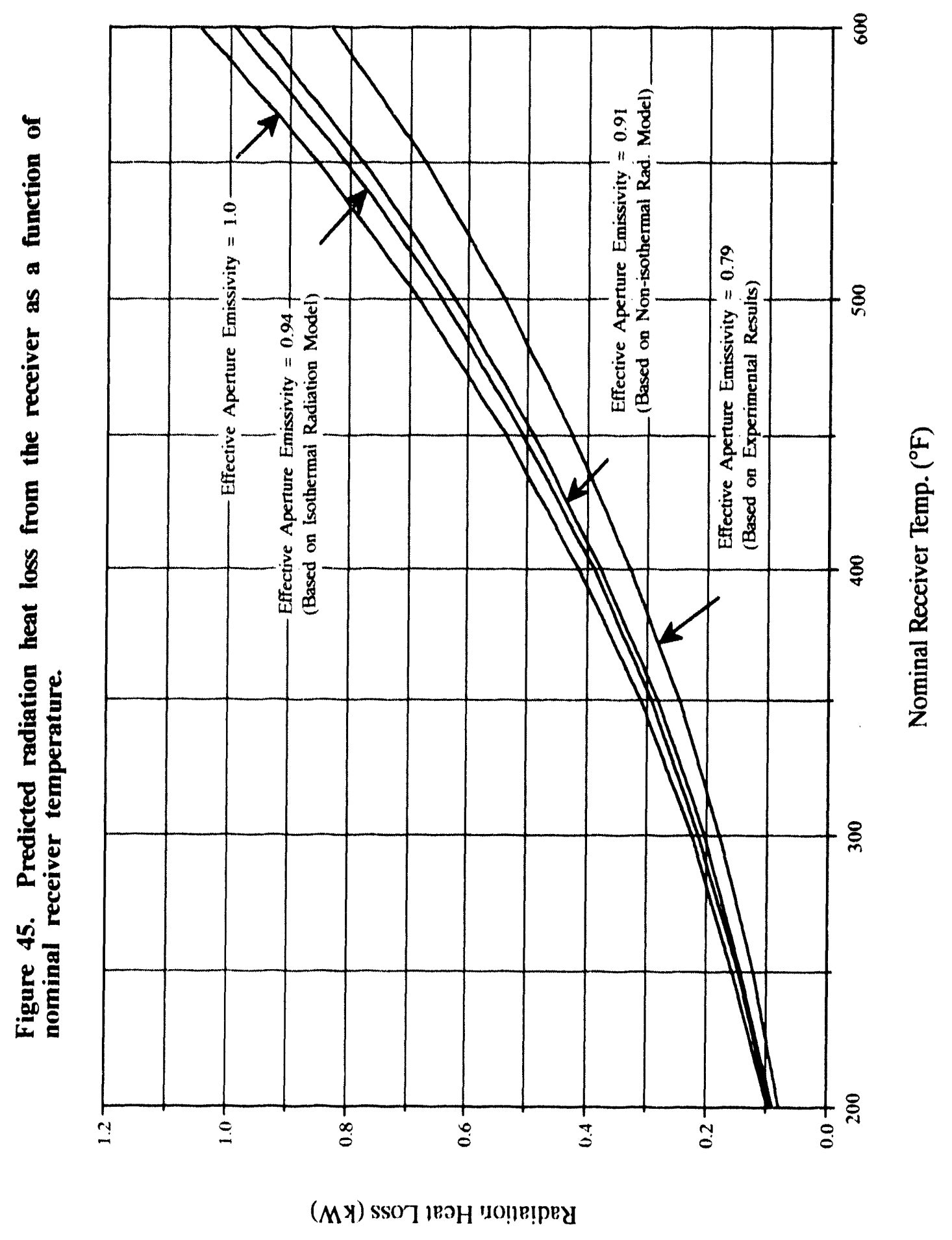



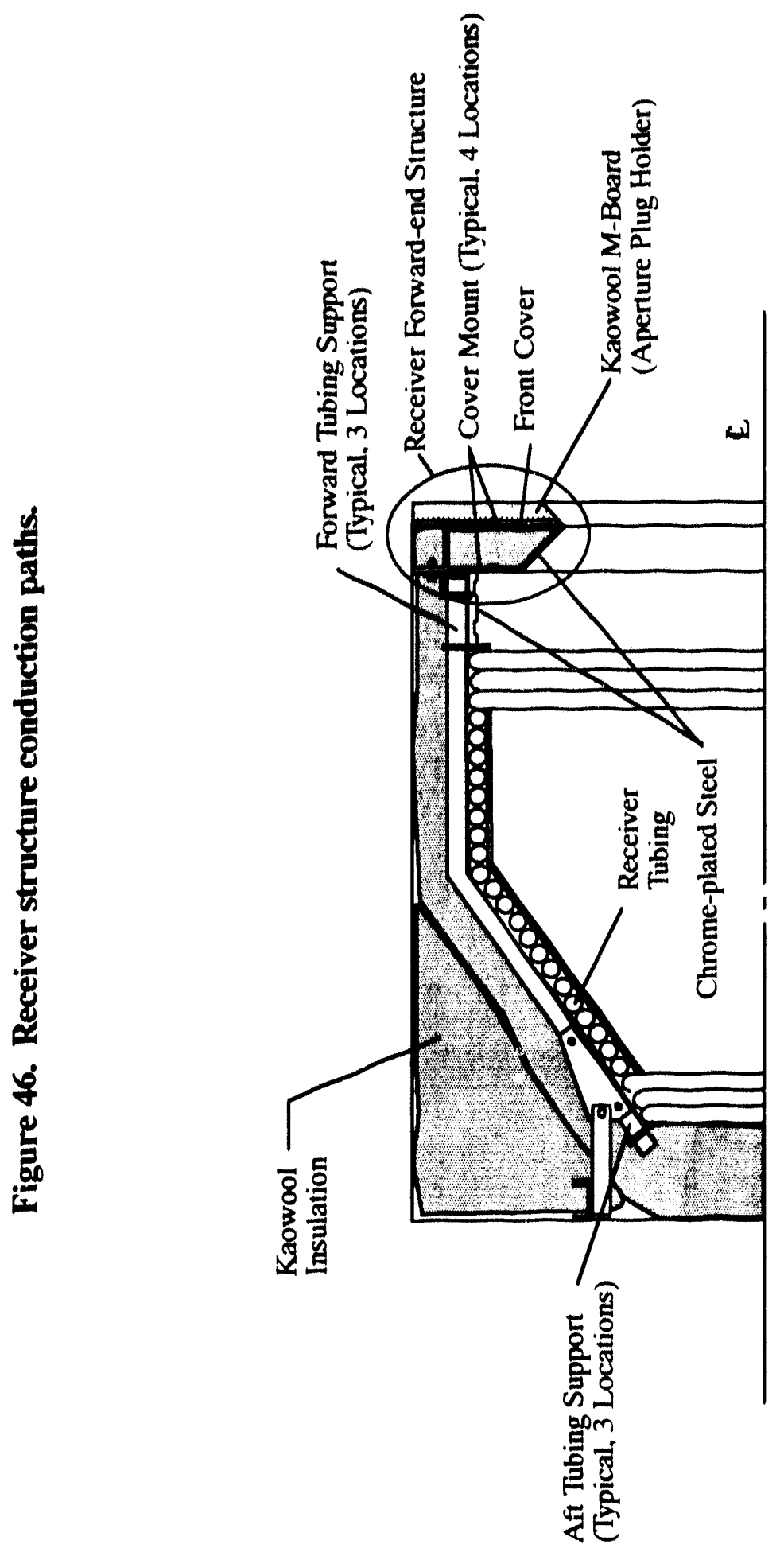
The inner and outer surface lemperatures used in these computations are the same as those used in the computer model.

The table below summarizes the amount of conduction heat loss predicted through each conduction path. Values are given for the case of no wind and for a 20 -mph wind. The only difference between these two cases is the small difference in receiver outer surface temperature.

Conduction Heat Losses Through Various Receiver Conduction Paths

\begin{tabular}{|c|c|c|c|c|}
\hline \multirow[t]{2}{*}{ Conduction Path } & \multicolumn{4}{|c|}{ Estimated Conjuction Heal Loss } \\
\hline & $\begin{array}{r}\mathrm{N} \\
(\mathrm{kW})\end{array}$ & (\%) & $\begin{array}{l}2(1)-m \\
(k W)\end{array}$ & $\begin{array}{l}\text { Nind } \\
\text { (\%) }\end{array}$ \\
\hline Receiver Insulation & 0.217 & 30.3 & 0.232 & 30.3 \\
\hline $\begin{array}{l}\text { Aft Tubing Support } \\
\text { (Total of } 3 \text { Locations) }\end{array}$ & 0.014 & 2.0 & 0.01 .5 & 2.0 \\
\hline $\begin{array}{l}\text { Forward Tubing Support } \\
\text { (Total of } 3 \text { Locations) }\end{array}$ & $(0.010$ & 1.4 & 0.011 & 1.4 \\
\hline Receiver Forward-end Siructure & 0.474 & 66.3 & 0.508 & 66.3 \\
\hline T(u)al & 0.71 .5 & $1(x)$ & 0.766 & 100 \\
\hline
\end{tabular}

About 66 percent of the conduction heat loss from the receiver is attributed to conduction through the receiver forward-end structure (see Figure 46). Another 30 pereent is due to conduction through the receiver insulation. Surprisingly, conduction through the forward and aft tubing supports is very small, being less than 4 percent of the total conduction heat loss.

The conduction heat losses found experimentally are generally lower than the predicted values. Experimental conduction heat loss is $0.60 \mathrm{~kW}$ average for the no-wind condition and $0.66 \mathrm{~kW}$ for $20-\mathrm{mph}$ side-en wind condition. However, experimental conduction heat loss from the 20-mph head- wind test is $1.09 \mathrm{~kW}$, which is much higher than the predicted values above. It is believed that the $1.09 \mathrm{~kW}$ experimental conduction heat loss is anomalously high, since it is higher than all of the other measured conduction 
heat losses from the first test series, which are in the range of $0.5-(0.7 \mathrm{~kW}$. In general, analytical conduction heat losses are $15-20$ percent higher than experimental values.

A plausible explanation for the difference between the measured and estimated conduction heat loss values (except for the $1.09 \mathrm{~kW}$ for the 20 -mph head-on wind) is that the actual difference in temperature between the inner and outer surfaces of the receiver at the forward-end structure is probably less than the value used in the conduction analysis. The temperature difference used in the analysis was based on average inner and outer wall temperatures derived from actual measured temperatures. In these measurements, almost all of the thermocouples on the interior surface of the receiver were on the hot heat transfer lubing. In addition, the outer surface thermocouples were located where here is 3 inches of Kaowool insulation in the receiver wall. The high conductive resistance provided by this insulation is a major reason why measured ouler surface lemperatures are not much higher than the ambient air temperature. For the forward-end structure area, however, the inner surface temperature is probably lower than $5.30^{\circ} \mathrm{F}$, since it is somewhat removed from the heat transfer tubing, and the outer surface temperature is probably slightly higher than that measured on the receiver wall, hecause of the higher thermal conductivity of steel.

If it is assumed that the inner surface of the forward structure is at $30\left(0^{\circ} \mathrm{F}\right.$, as was done in the radiation analysis, the estimated levels of conduction through the forward-end structure would then be $0.21 \mathrm{~kW}$ and $0.25 \mathrm{~kW}$ for the no-wind and $2(1)-\mathrm{mph}$ wind conditions, respectively. The corresponding total conduction heat loss levels would then be $0.45 \mathrm{~kW}$ and $0.51 \mathrm{~kW}$, respectively, which are about 25 pereent lower the measured conduction heat loss values. The actual inner surface temperature at the receiver forward end, during the tests in which conduction heat loss was measured, was probably less than $530^{\circ} \mathrm{F}$, but not as low as $300^{\circ} \mathrm{F}$ since the aperture was plugged during these tests.

A more representative conduction analysis might be obtained by modeling the convective and radiative boundary conditions on the inner and outer surfaces of the receiver forward-end structure. In this way the inner and outer surface temperatures are obtained analytically. However, the determination of local boundary conditions on the interior of the forward-end structure would involve some uncertainties. 
A possible explanation the high conduction heat loss value for the 20-mph head-on wind is that air leakage may have occurred through the receiver joint areas. In fact, during some of the receiver tests in which smoke visualization was used, a small amount of smoke was seen escaping through joints in the receiver walls, indicating that at least some air leakage oceurred. However, it is impossible to predict quantitatively the heat loss due to this air leakage. In future testing using this receiver, an effort should be made to seal the receiver as best as possible.

\subsection{Conclusions}

The convective heat loss characteristics of a cavity receiver for a parabolic-dish concentrating solar collector have been determined experimentally for the no-wind condition, side-on winds of up to $20 \mathrm{mph}$, and head-on winds of up to $24 \mathrm{mph}$. Natural convective heat loss from the receiver was found to be the highest with the receiver aperture facing horizontally and negligible with the aperture facing straight down.

For side-on wind, convective heat loss is also the highest with the aperture facing horizontally and decreases as the receiver is tilted downward, but the magnitudes are much higher than those resulting from natural convection. For head-on wind, convective heat loss is gencrally lower than those for side-on wind. Head-on wind blowing directly into the receiver aperture does not increase convection significantly above natural convection. This is believed to be a result of this type of low inducing little convective current in the receiver, and generating little convective trausport into and out of the receiver. Overall, the effects of wind on convective heat loss from the receiver are the greatest for wind blowing parallel to the aperture and the smallest for wind blowing directly into the aperture. It was found that for wind speeds of $20-24 \mathrm{mph}$, the total convective heat loss from the receiver can be as much as three times the maximum level of natural convection.

It was found that the lotal convective heat loss could be expressed as a sum of the natural and forced convection. For side-on wind, a curve-fit is presented in Eq. (11) for determining the forced convection heat transfer coefficient as a function of wind speed only. For head-on wind, a curve-fit is presented in Eq. (14) for determining the forced convection heat transfer coefficient as a function of both wind speed and reciver tilt angle. 
The results of the uncerlainty analysis indicate that convective heat loss uncertaintics are between $(0.21-() .26 \mathrm{~kW}$. Altheugh convective heat loss uncertainly only varies slighily from lest lo lest, uncertainty as a percentage of convective heat loss varies greatly. At the highest convective heat loss level, the uncertainty percentage is only about four percent, but for low heat loss rates, uncertainty percentage approaches infinity. Forlunalely, at low heal loss rates, the accuracy of the measurements is not critical. The small uncertainty percentages for the higher heat loss rates associated with the different wind conditions indicate good data reliability.

Air temperalure measurements made inside the receiver provided useful insight into the receiver convective phenomena. These measurements confirm the presence of the stagnant zone for the no-wind condition and clearly indicale the extent to which head-on and side-on winds affect convective flow within the receiver. Analyses were also performed to predict radiation and conduction heat losses from the receiver for comparison to measured values. Measured and analytical radiation heat loss levels agrec lo within about 15 percent. Measured and analytical conduction heal loss levels agree to within 15 25 percent.

The correlations presented in this report for predicting forced convective heat loss are only for this particular receiver. It is desirable to have a correlation which lakes into account different receiver geometries, temperatures, and aperture sizes. It is therefore recommended that future testing be performed first on this receiver, with different aperture sizes and temperatures, then with different receiver geometries. With a compilation of data from future receiver testing performed at this or any other facility, the curve-fits presented in this thesis can be refined and modified to be more general. 


\section{References}

Clausing, A. M., 1981, "An Allalysis of Convective Lesses From Cavity Solar Contral Receivers," Solar Energy, Vol. 27. No. 4, pp. 295-300.

Faust, K. M., E. J. Plate, and M. Kuce:ra, 1981, "Experimental Investigation of the Convective Losses from the Cavity Receiver of the Project CAST," In SAND81-8014 (P. Falconc), Sandia National Laboratories, pp. 143-164.

Haddad, G., 1991, "Cavity Receiver Heat Loss Tests in Wind," Master's Project, California State Polytechnic University, Pomona.

Holman, J. P., 1984, Experimental Methods for Engineers, 4th ed., McGraw-Hiil, New York.

Koenig, A. A., and M. Marvin, 1981, "Convection Heat Loss Sensitivity in Open Cavity Solar Receivers," Final Report, DOE Contract No. EG77-C-(14-3985, Department of Energy, Oak Ridge, Tennessee.

Kraabel, J. S., 1983, "An Experimental Investigation of Natural Convection from a Side-Facing Cubical Cavity," ASME-JSME Thermal Engineering Joint Conference Proceedings, Vol. 1, pp. 299-306, Honolulu, Hawaii, March 20-24.

Kugath, D. A., G. Drenker, and A. A. Koenig, 1979, "Design and Development of a Paraboloidal Dish Solar Collector for Intermediate Temperature Service," Proc. ISES Silver Jubilee Congr., Vol. 1, pp. 449-453.

LeQuere, P, F. Penot, and M. Mirenayat, 1981, "Experimental Study of Heat Loss Through Natural Convection from an Isothermal Cubic Open Cavity," In SAND81-8014 (P. Falcone), Sandia National Laboratories, pp. 165-174.

McDonald, C. G., 1992, "Cavity Receiver Heat Loss Tests Without Wind," Master's Thesis, California State Polytechnic University, Pomona. 
McMordic, R. K., 1984, "Convection Heal Loss From a Cavity Receiver," ASME: Journal of Solar Energy Enginecring, Vol. 106, pp. 98-1010.

PDA Engineering, Costa Mesa, CA.

Sichers, D. L., and J. S. Kraabel, 1984, "Estimating Convective Encrgy Loisses From Solar Central Receivers," SAND84-8717, Sandia Nattional L aboraturies.

Stine, Wm. B., and C. G. McDonald, 1988, "Civity Receiver Heat Losss Measurements," 1988 ASME Solar Energy Division Comference, Denver, Colorado, 10.14 April.

Stine, Wm. B., and C. G. McDonald, 1989. "Cavity Receiver Convective Heat Loss," Proceedings of International Solar Energy Society Solar World Congress 1989 Kobe, Kobe, Japan, 4-8 September. 


\section{List of Symbols}

A full interior geonelric surfice area of receiver

$A_{1}$ exposed surfice area of receiver heal trasisfer lubing in ly. (5)

$c_{p}$ heal-transter-fluid specific heal

d aperlure diameter

E total blackbody emissive power

F radiation shape factor

g gravitational acceleration

Gr. Grashol number $=$ gBATL $\mathrm{L}^{3} / \mathrm{N}^{2}$

h convective heal transfer coefficient

$h_{\text {avg incenal average inlernal heal transfer cocflicient }}$

hereed heal transfer coeflicient fior forced convection

$h_{\text {natural }}$ heal transfer coefficient for natural convection

hoverall overall heat transfer coeflicient for mixed convection

$\mathrm{J}$ radiosily

k thermal conductivity

l. $R_{\text {aperture }} / R_{\text {cavily }}$

1. characteristic length

m heal-transfer-fluid mass flow rate

$\mathrm{Nu}$. Nusselt number $=\mathrm{hl} / \mathrm{k}$

$P(\theta) \quad$ constant in Eq. (4)

Pr Prandil number

qcond conduction heat loss rate

qoonv convective heal loss rate

$q$ conv overall overall convective heat loss rate for mixed convection

qforced convective heat loss rate due to forced convection

4meas total receiver heat loss rate derived from measurements

Ynatural convective heat less rate due to natural convection

Uplugged lotal heat loss rate with the aperture plugged

$4_{\text {mid }}$ radiation heal loss rate

Gtotal normalized total heat loss rate

Q heal-transfer-fluid volume flow rale

$\mathrm{R}_{\text {aperture }}$ radius of aperture 


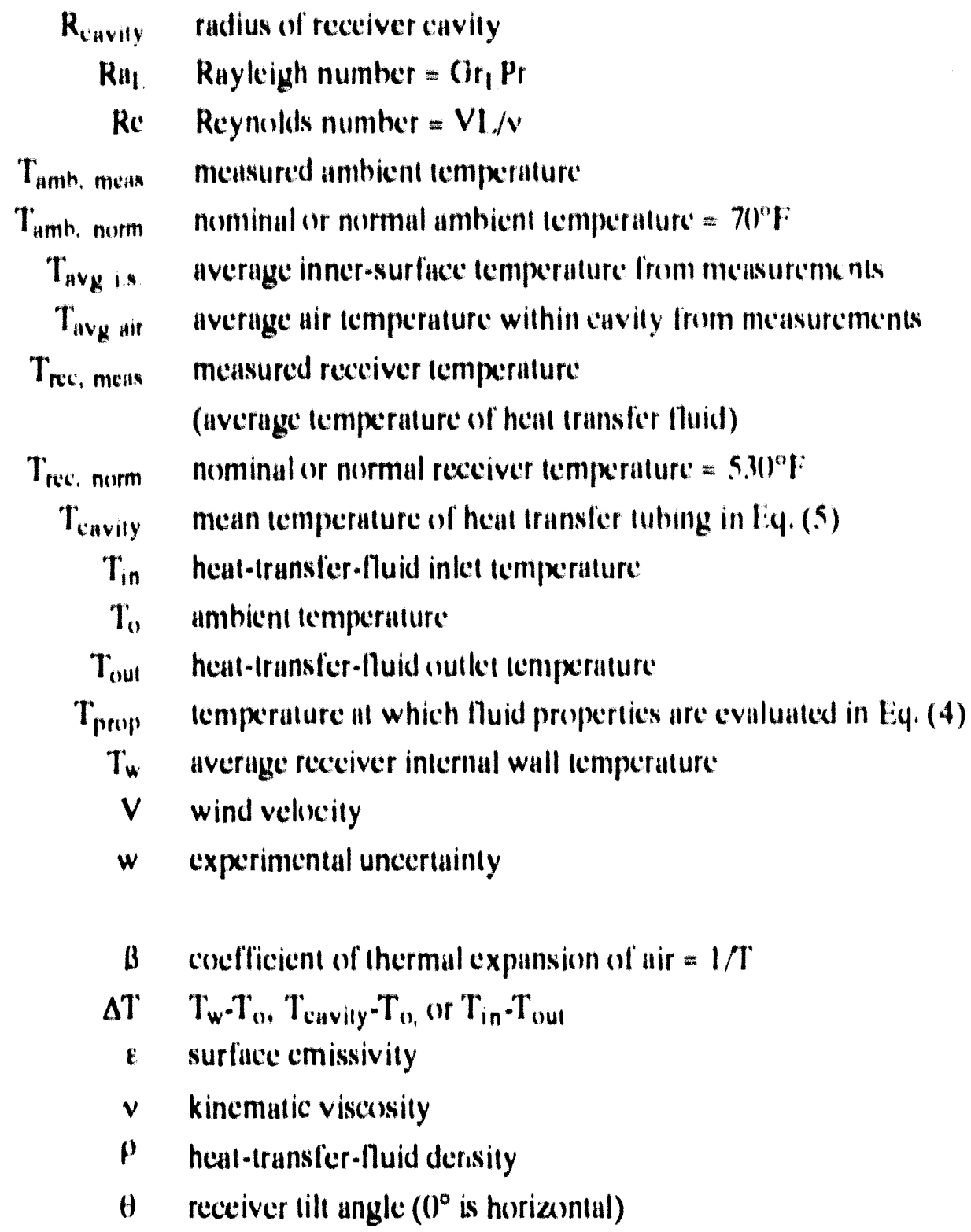


Appendix A

Material Properties 
Figure Al. Specinc heat of Syltherm 800 heat transfer nuid.

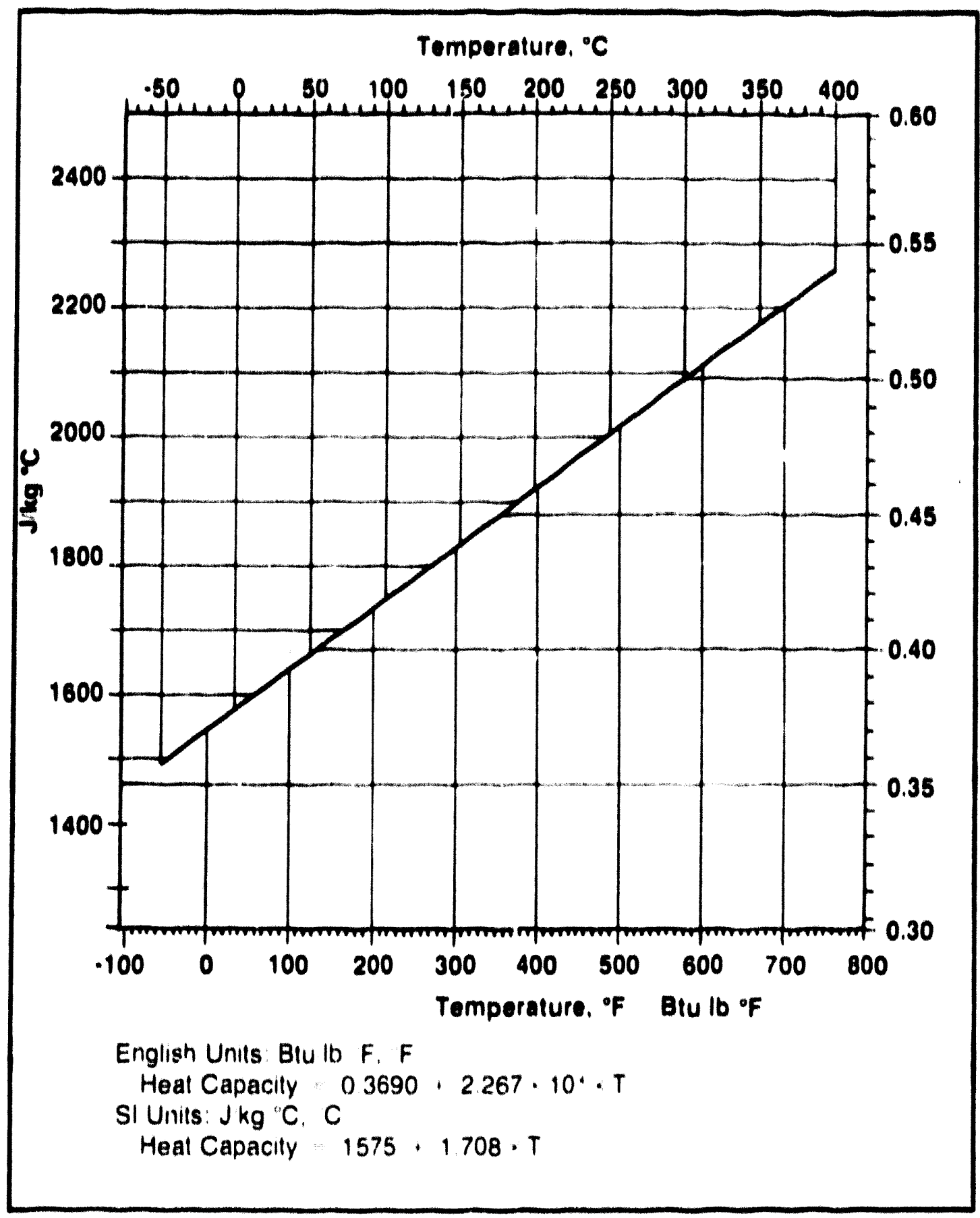




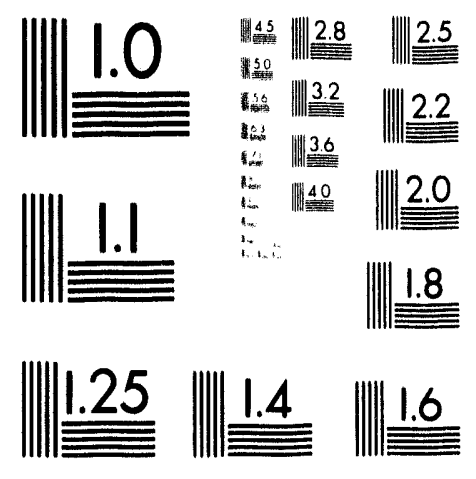



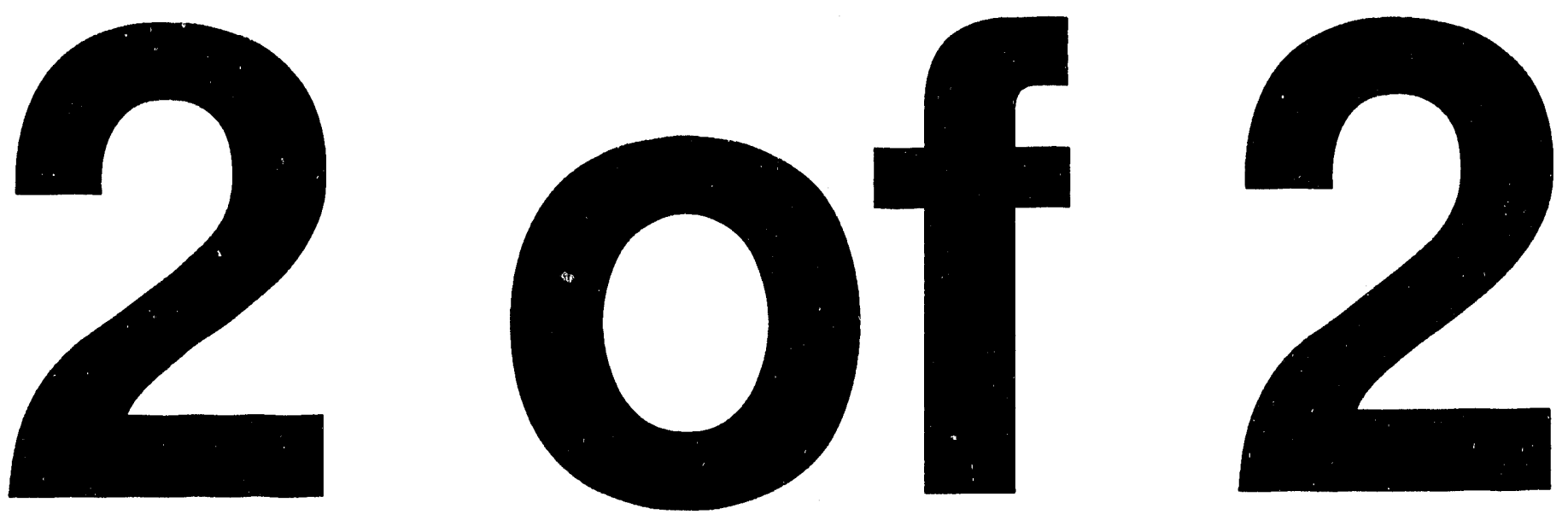
Figure A2. Density of Syltherm ${ }^{\circledR} 800$ heat transfer fluid.

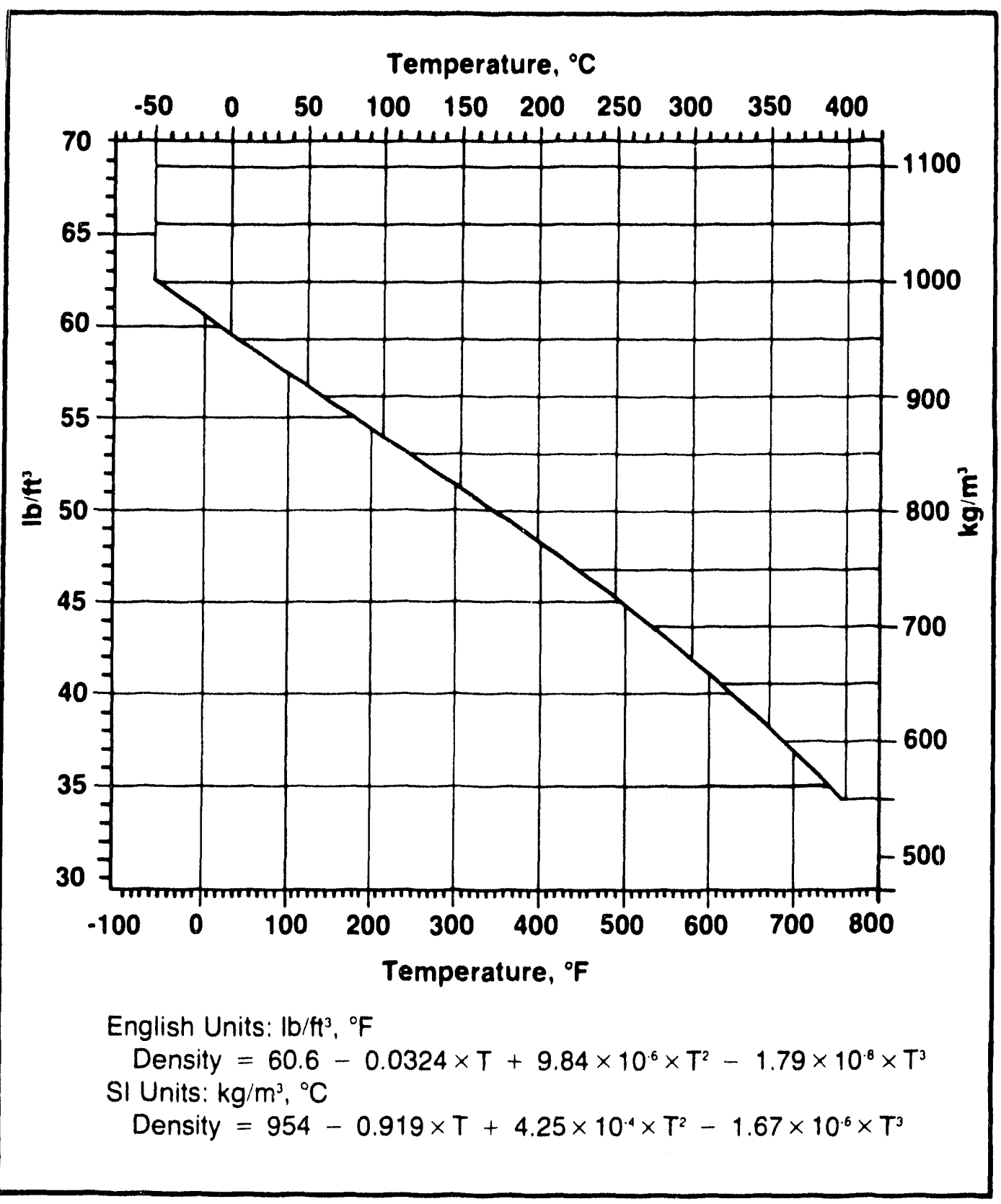


Figure A3. Thermal conductivity of Kaowool insulation.

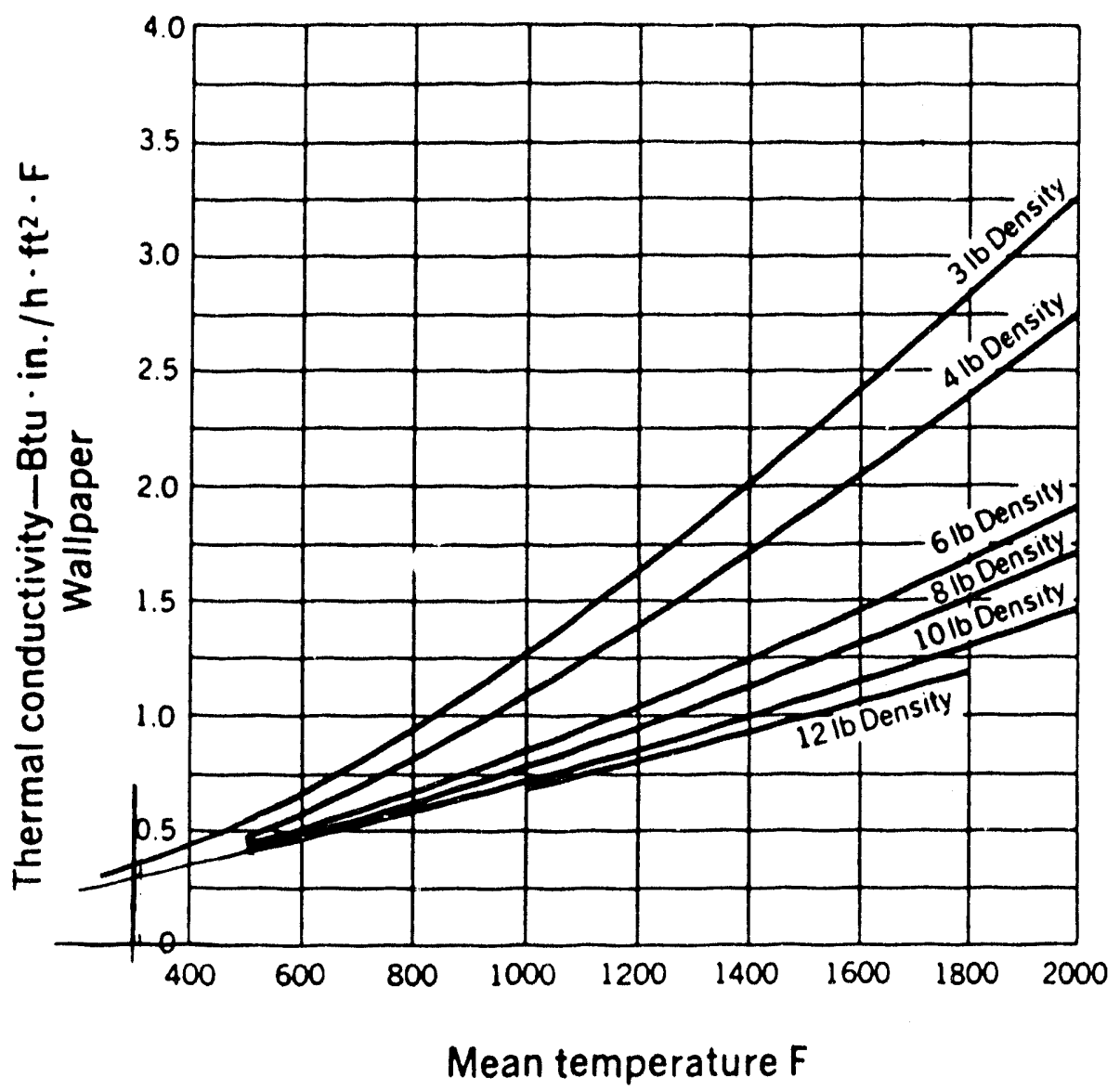


Appendix B

\section{Data Analysis Spreadsheets}




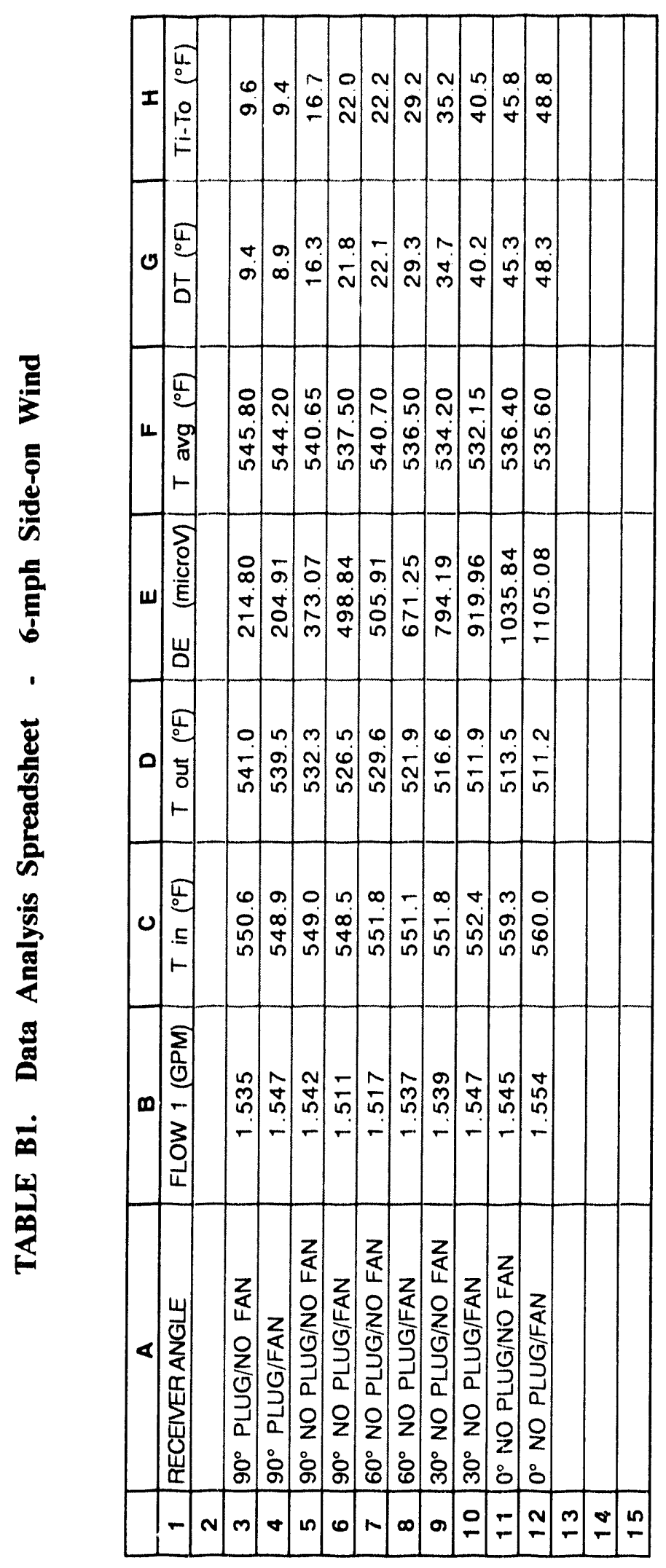




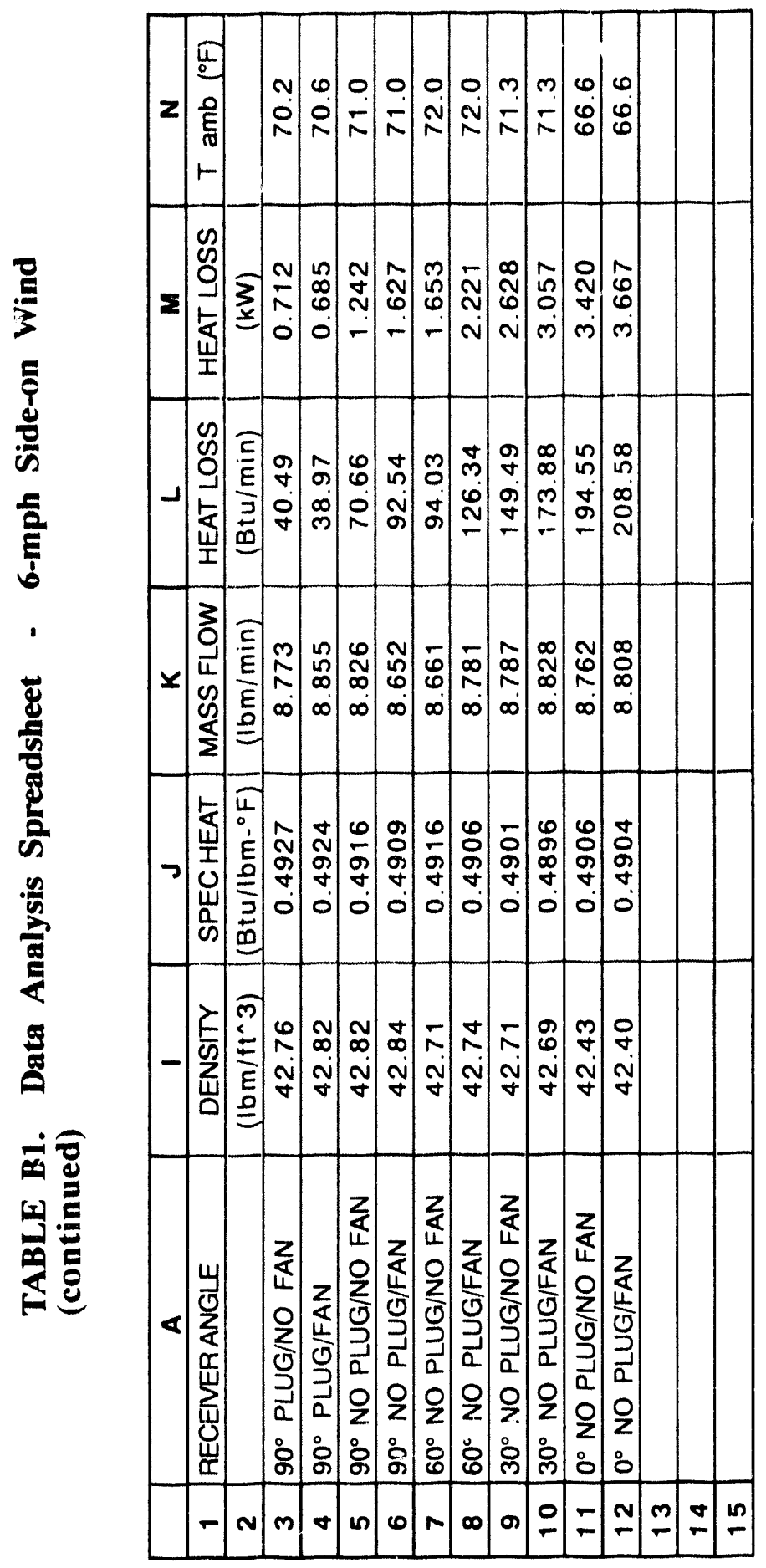




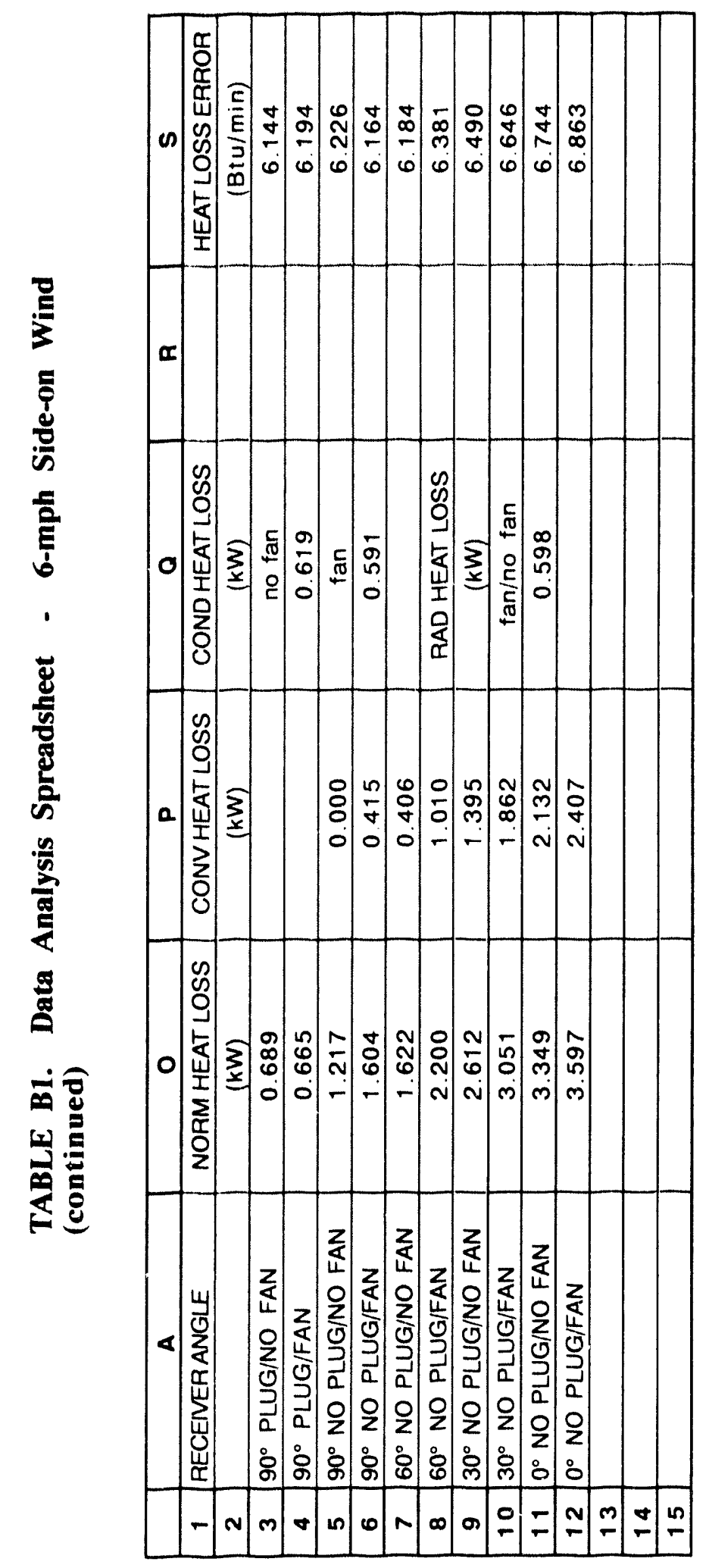




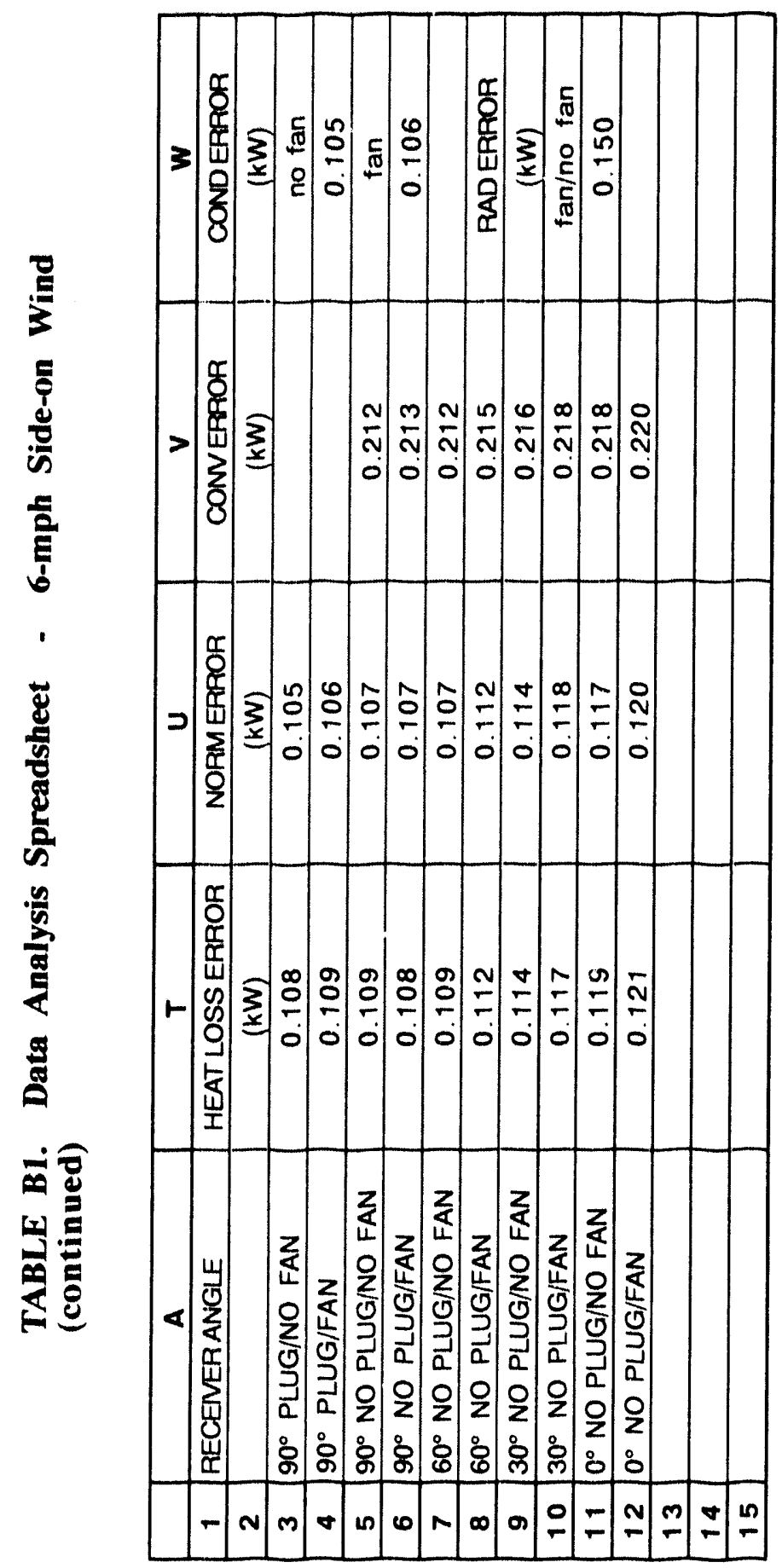




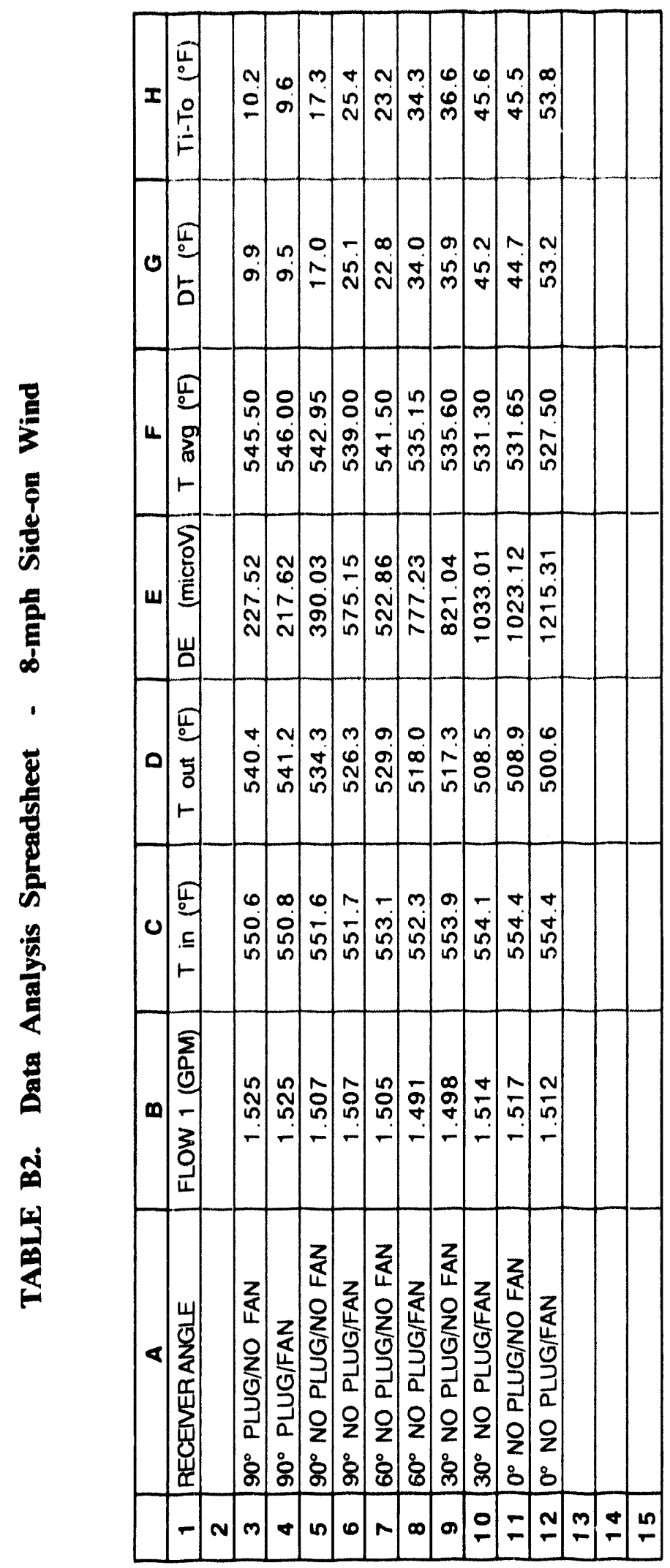




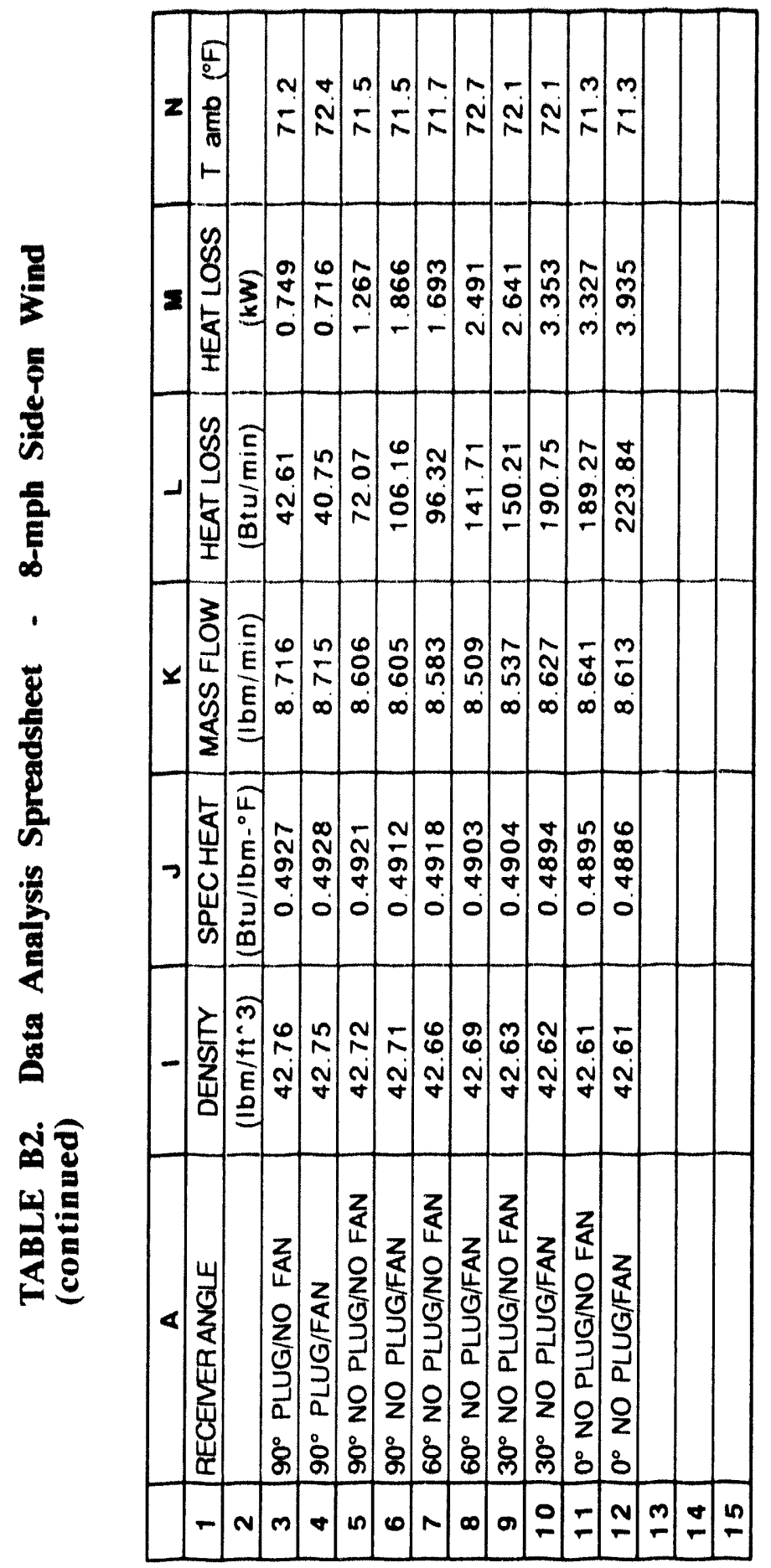




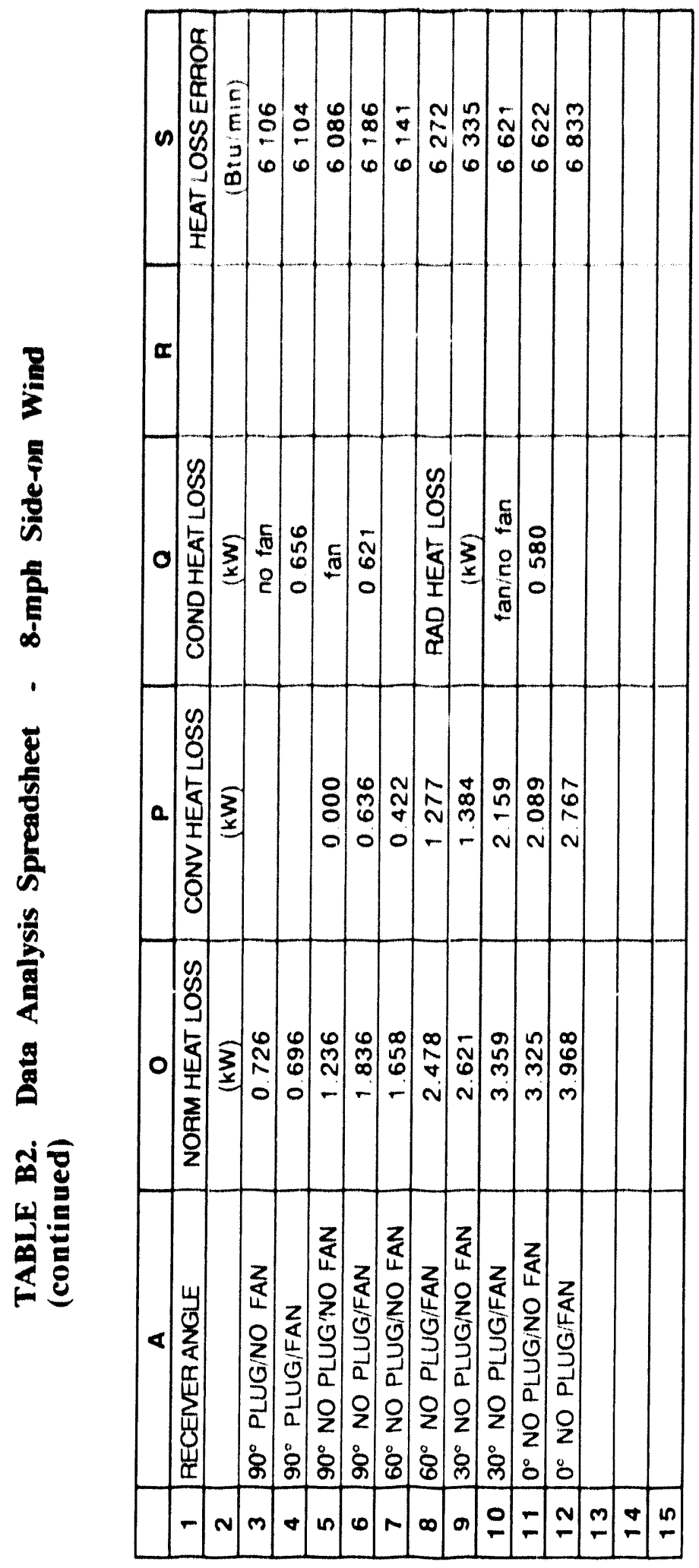




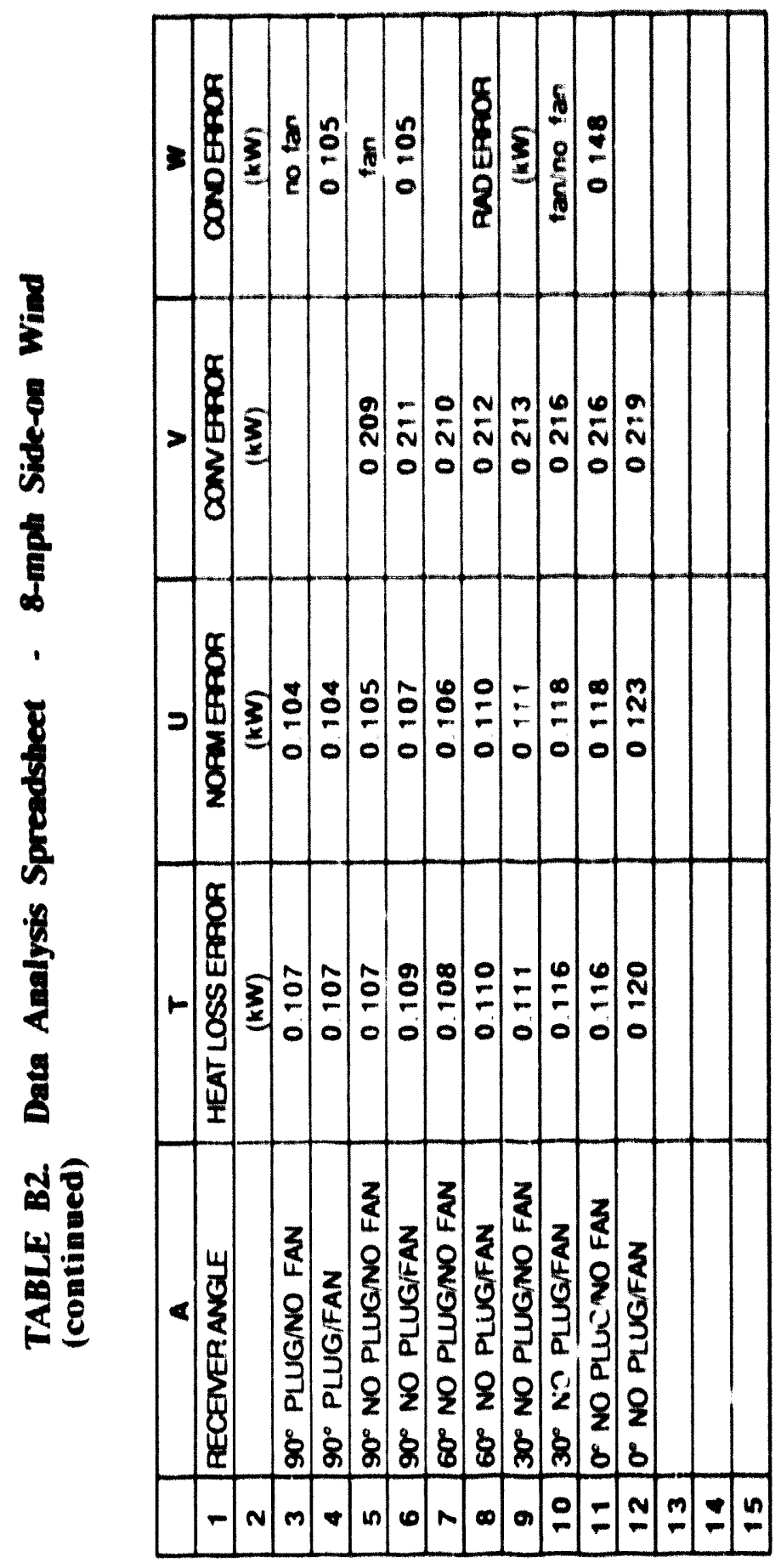




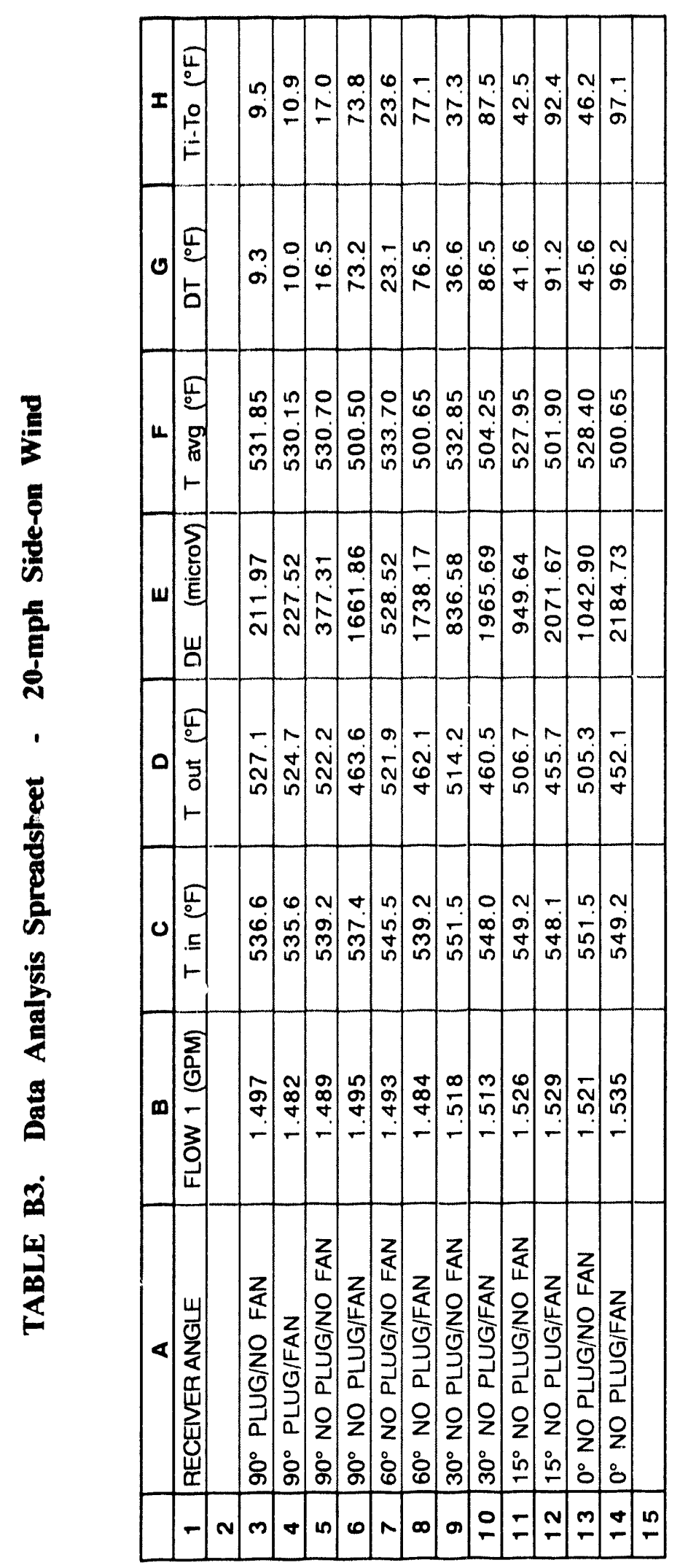




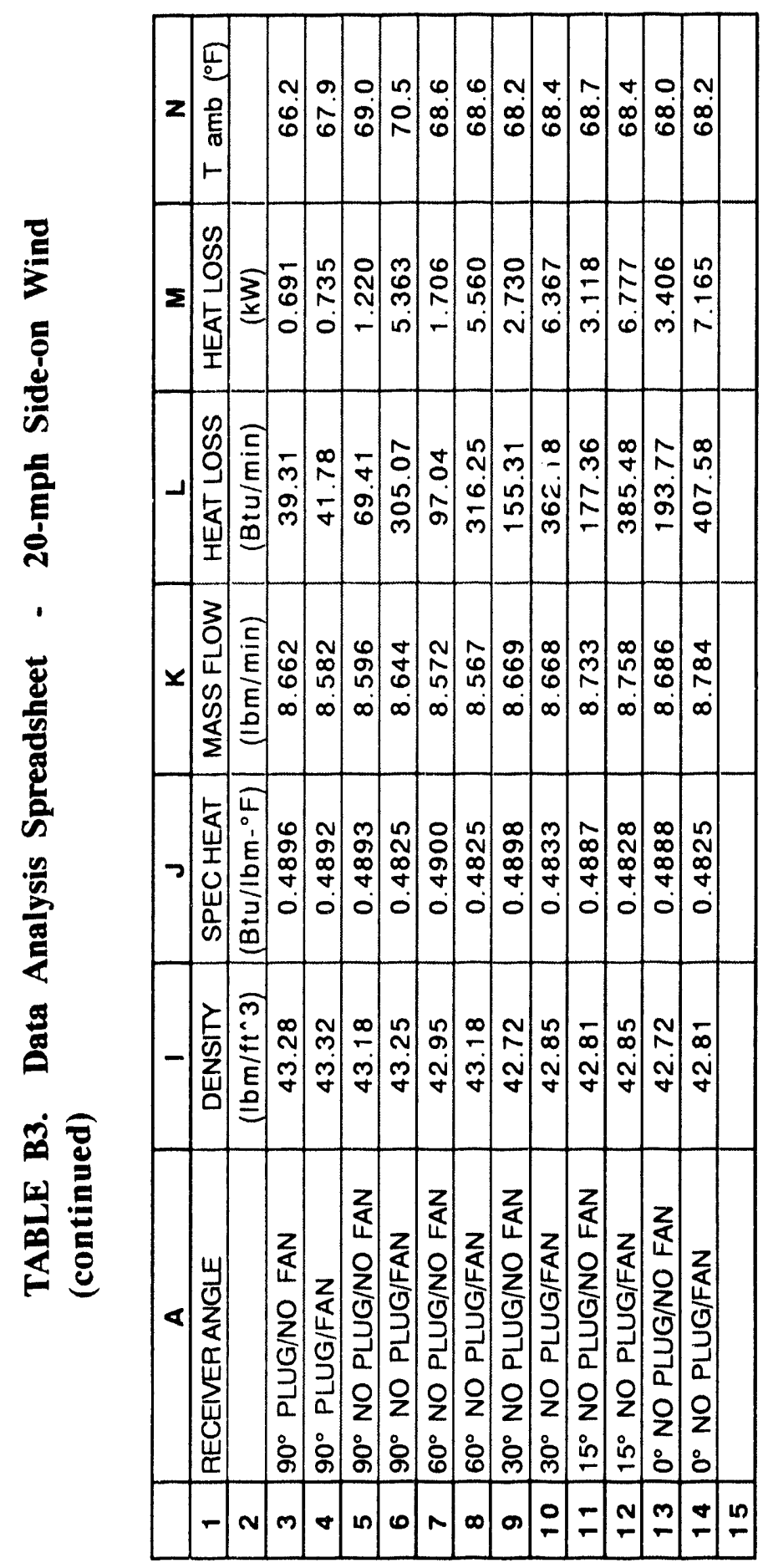




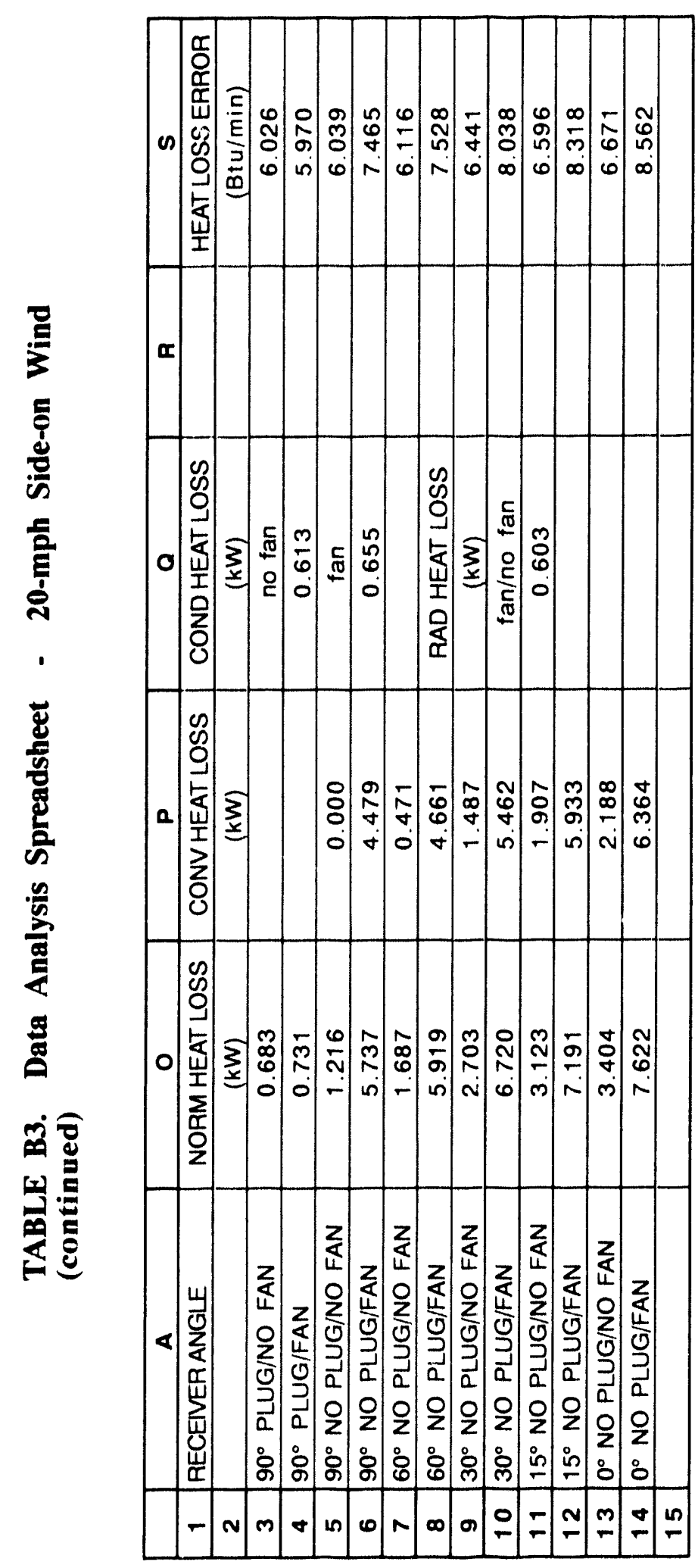




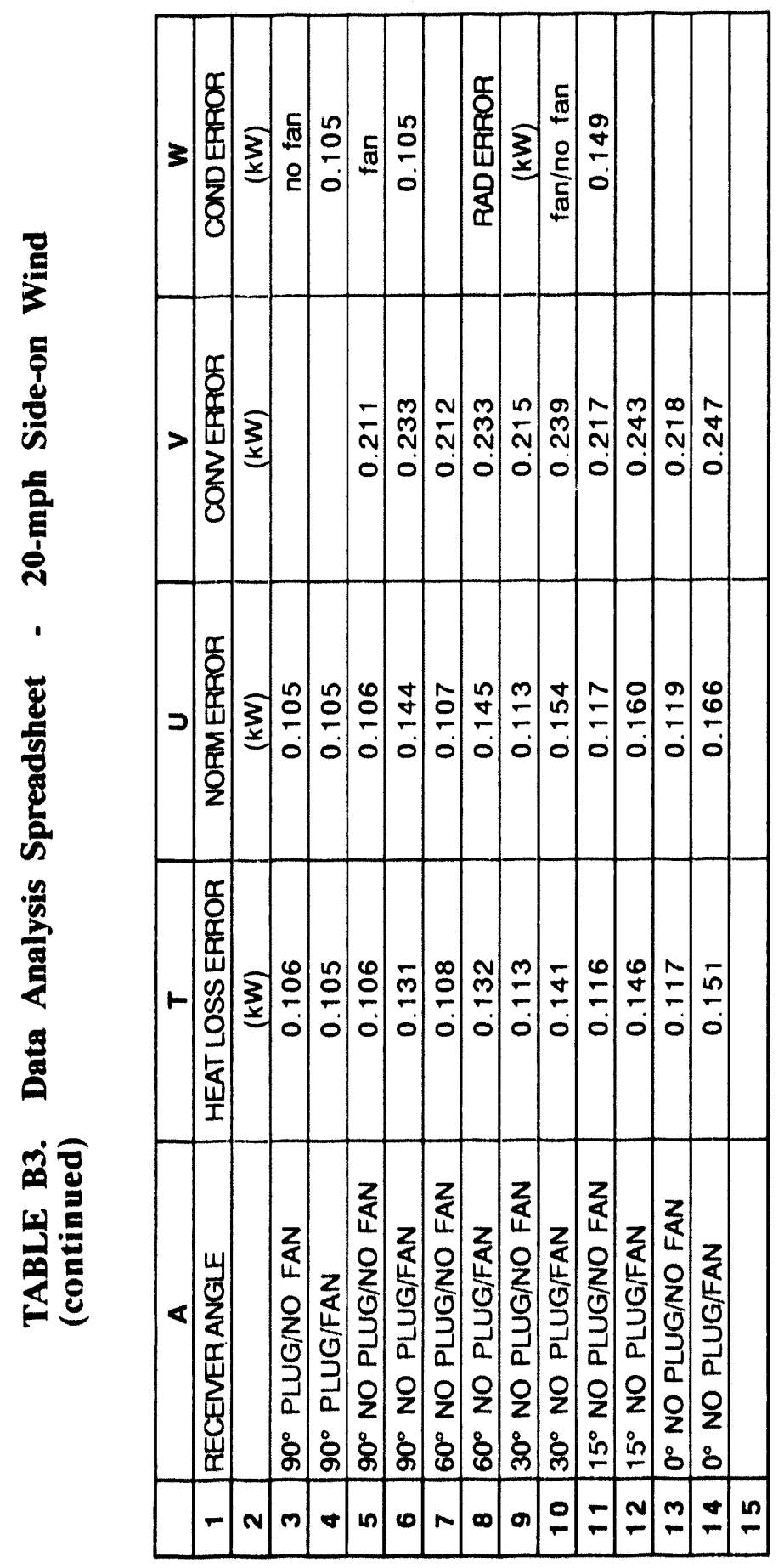




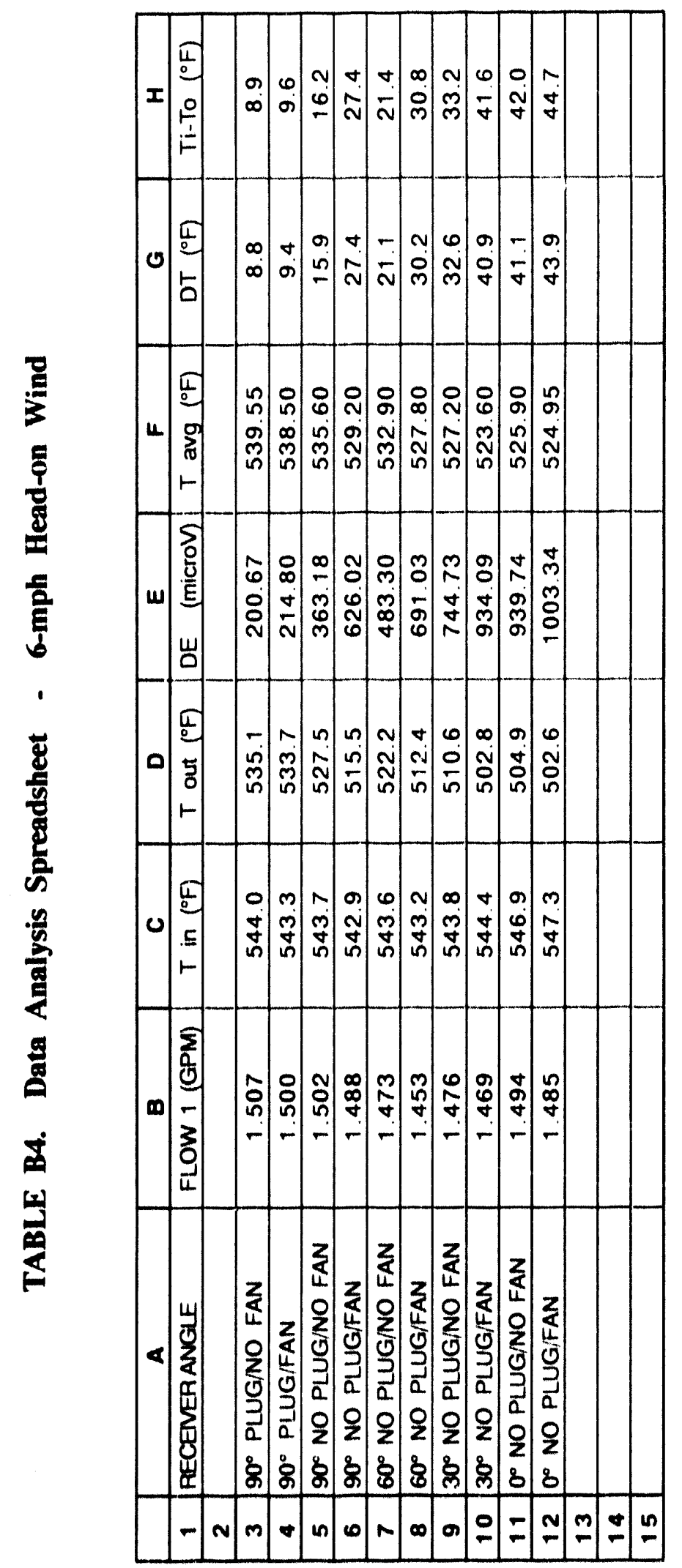




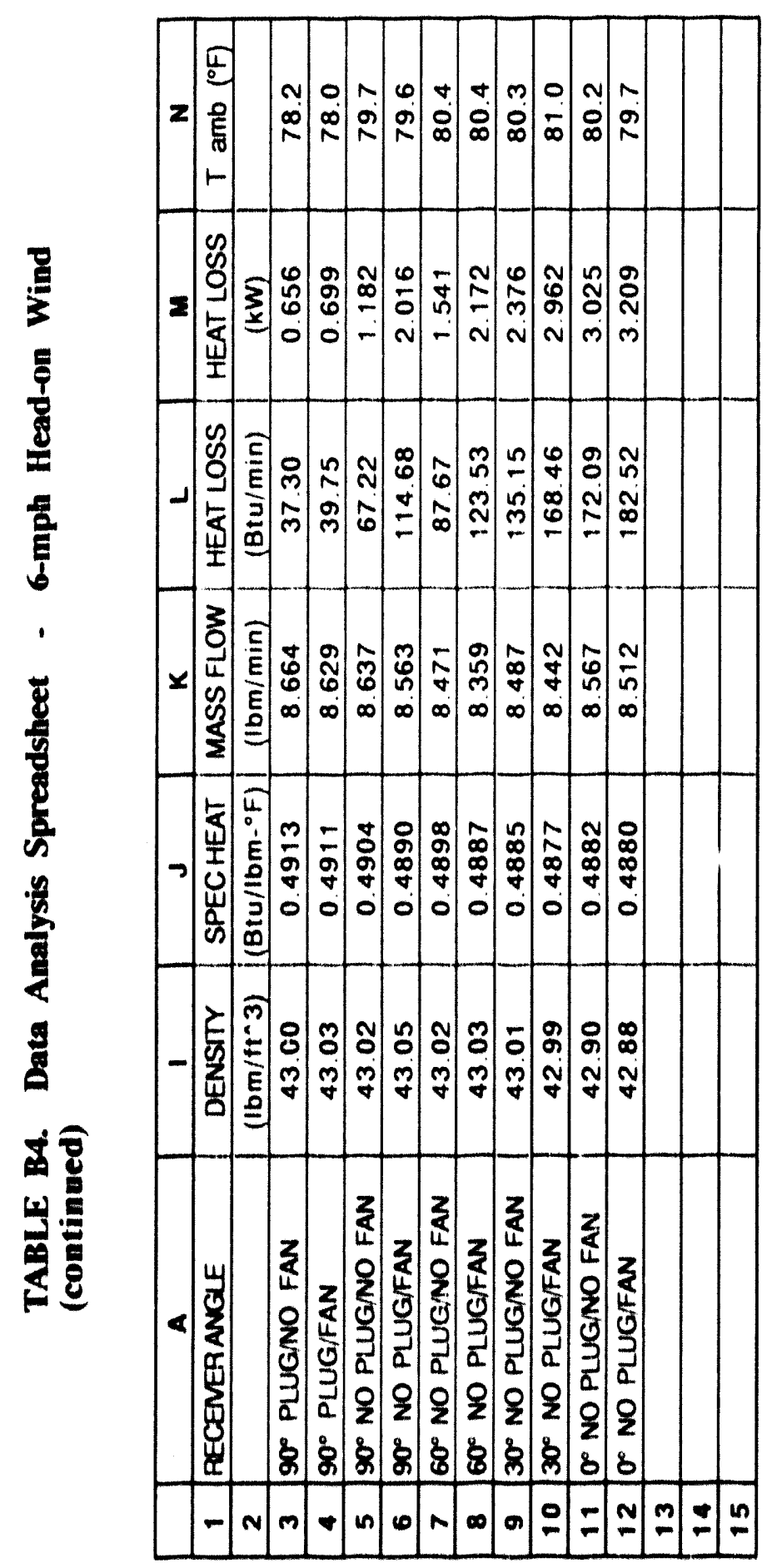




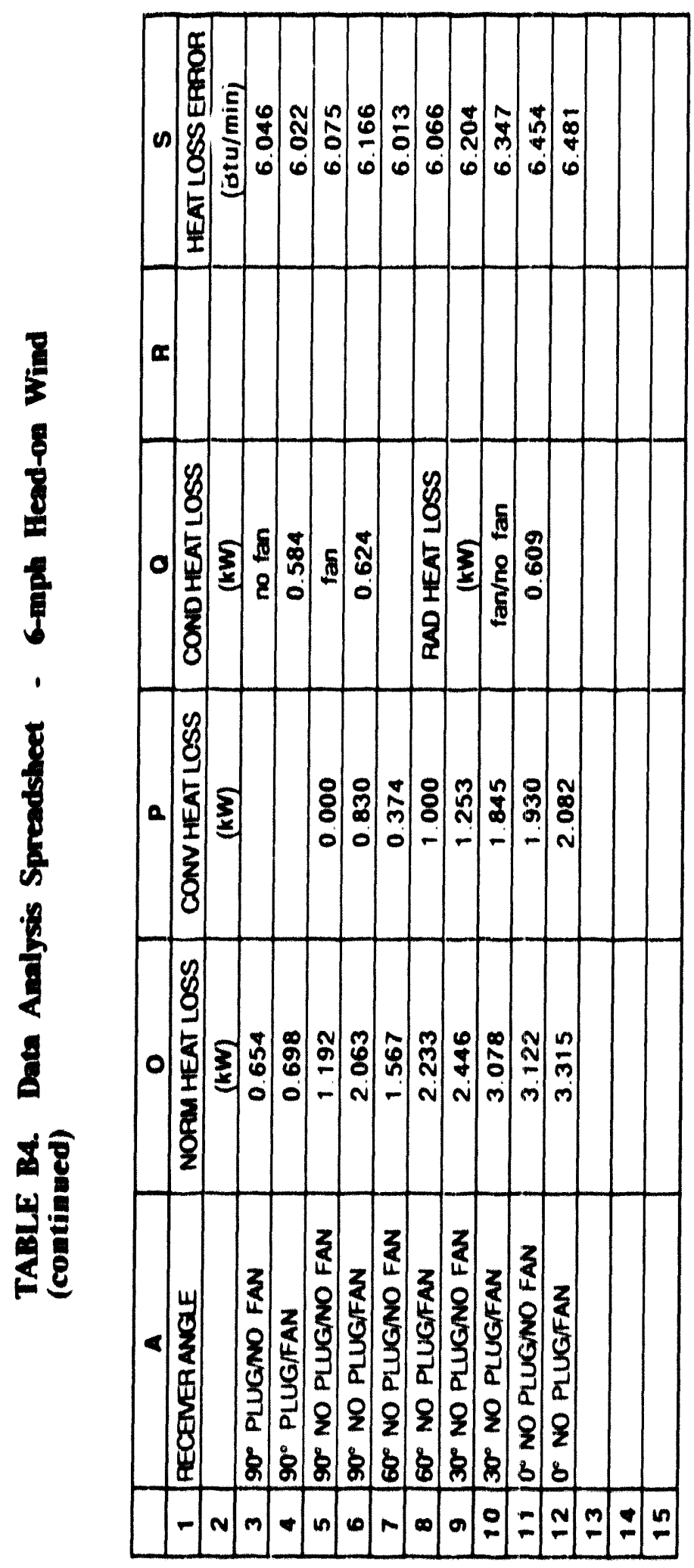




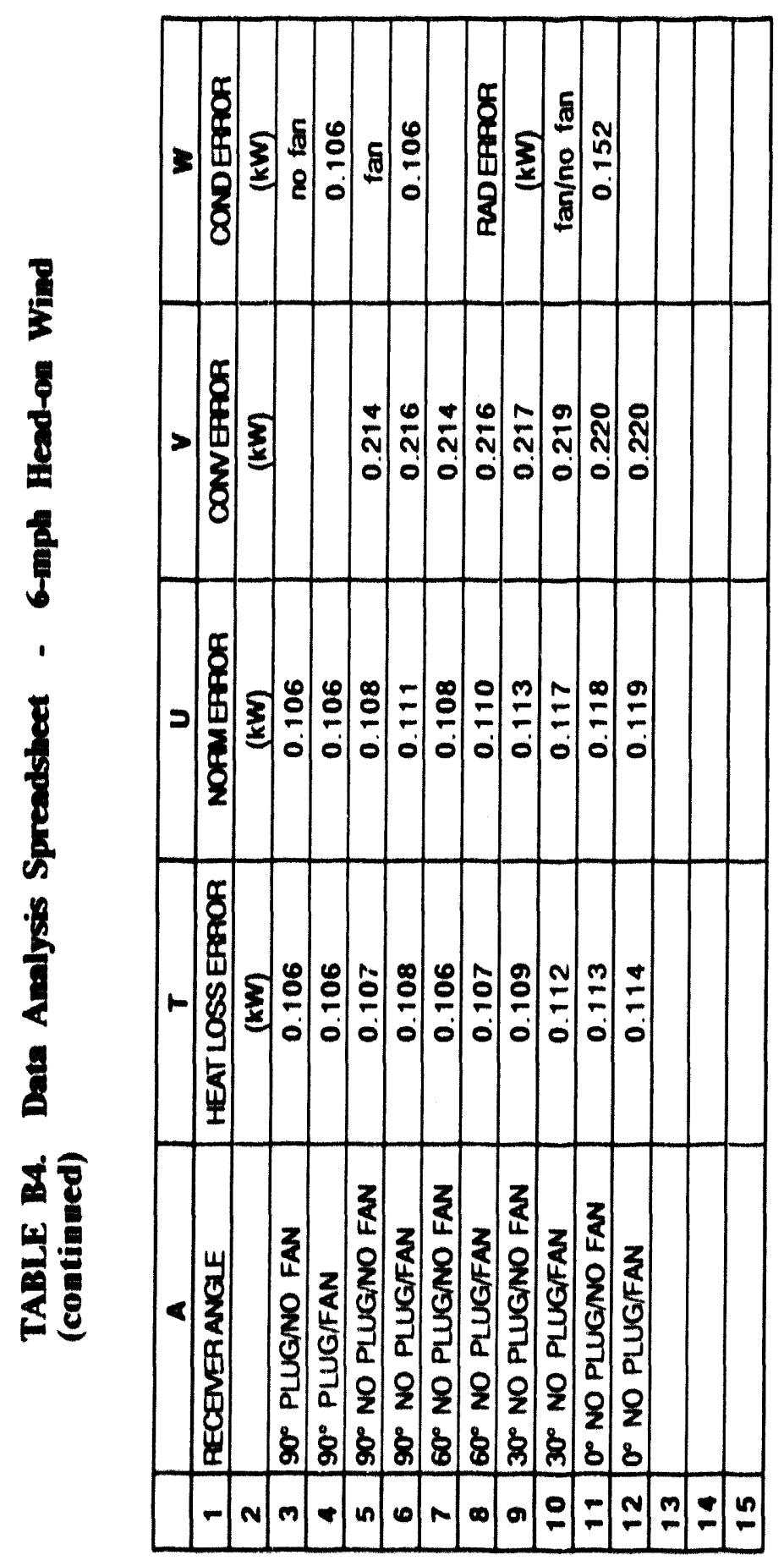




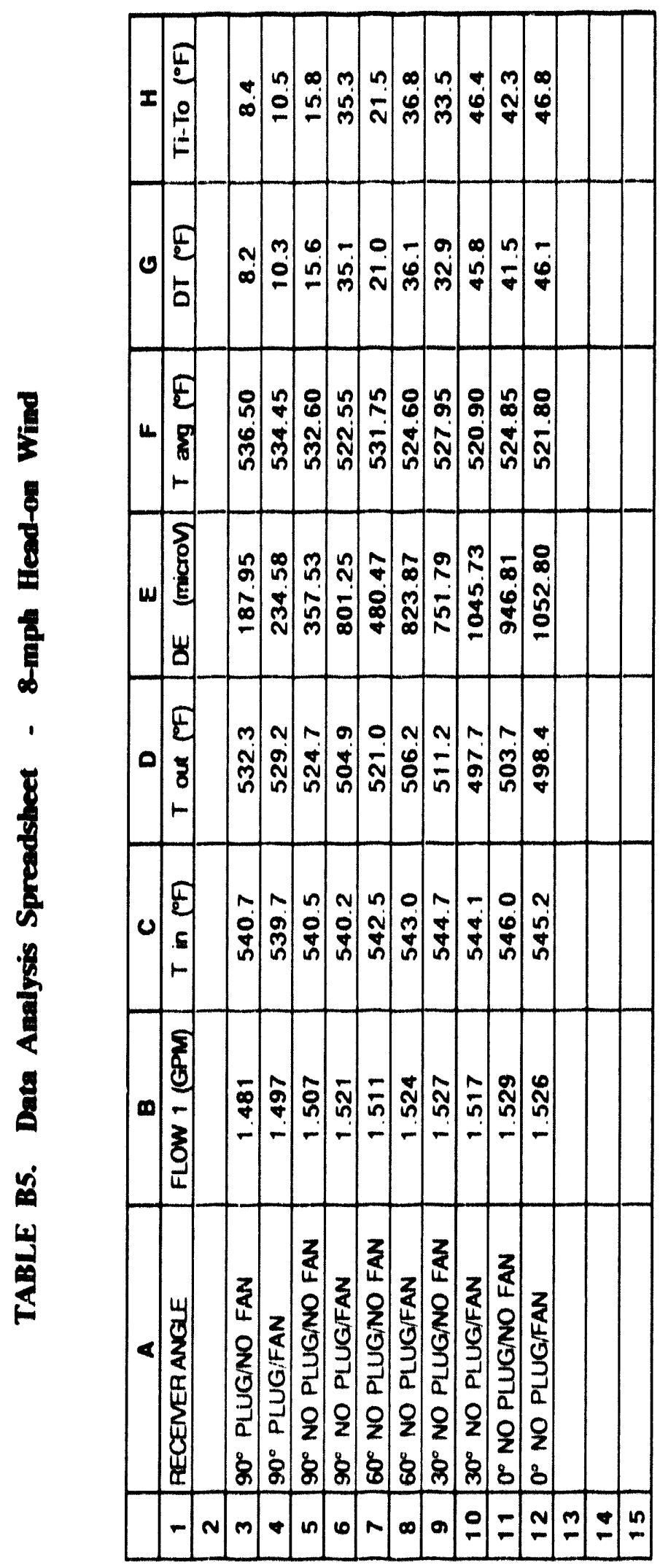




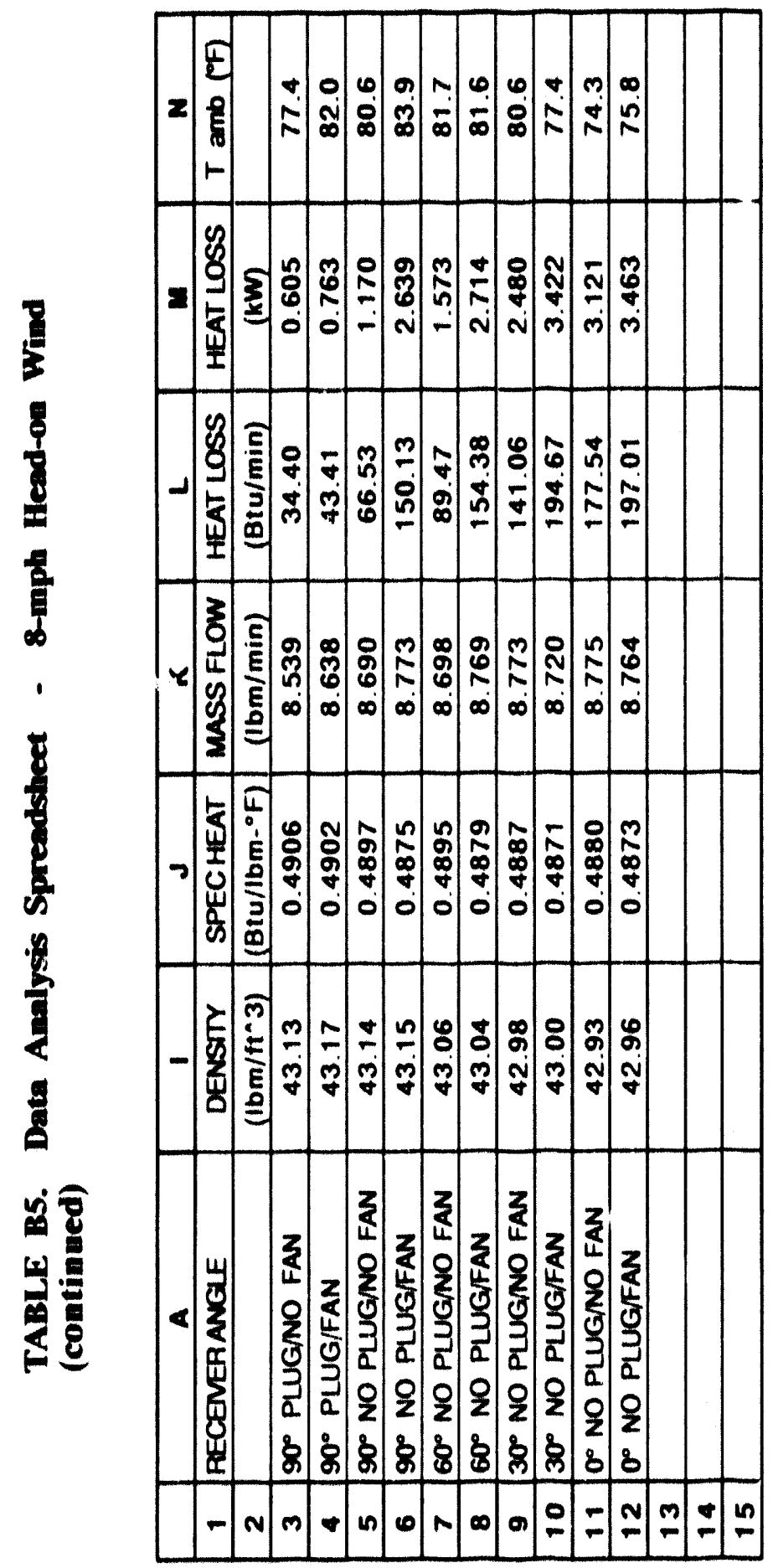




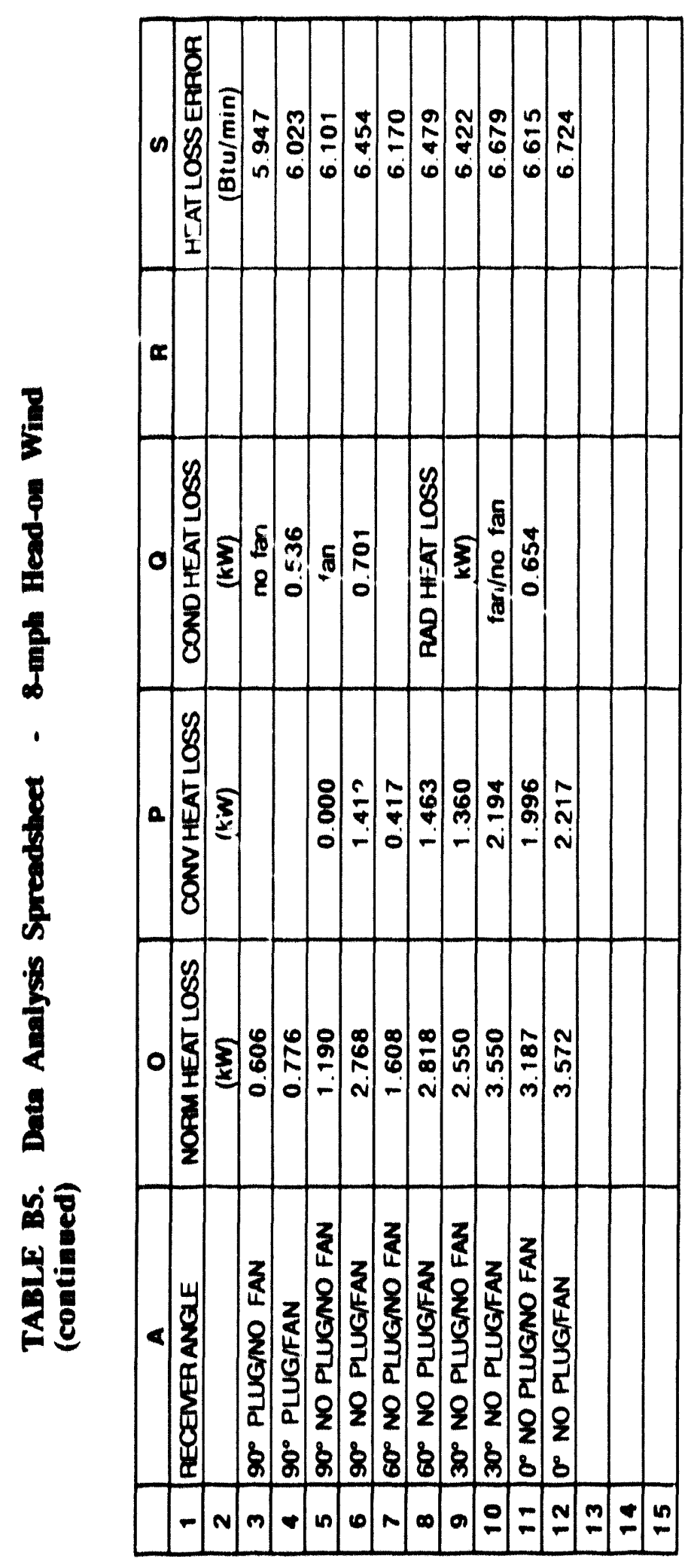




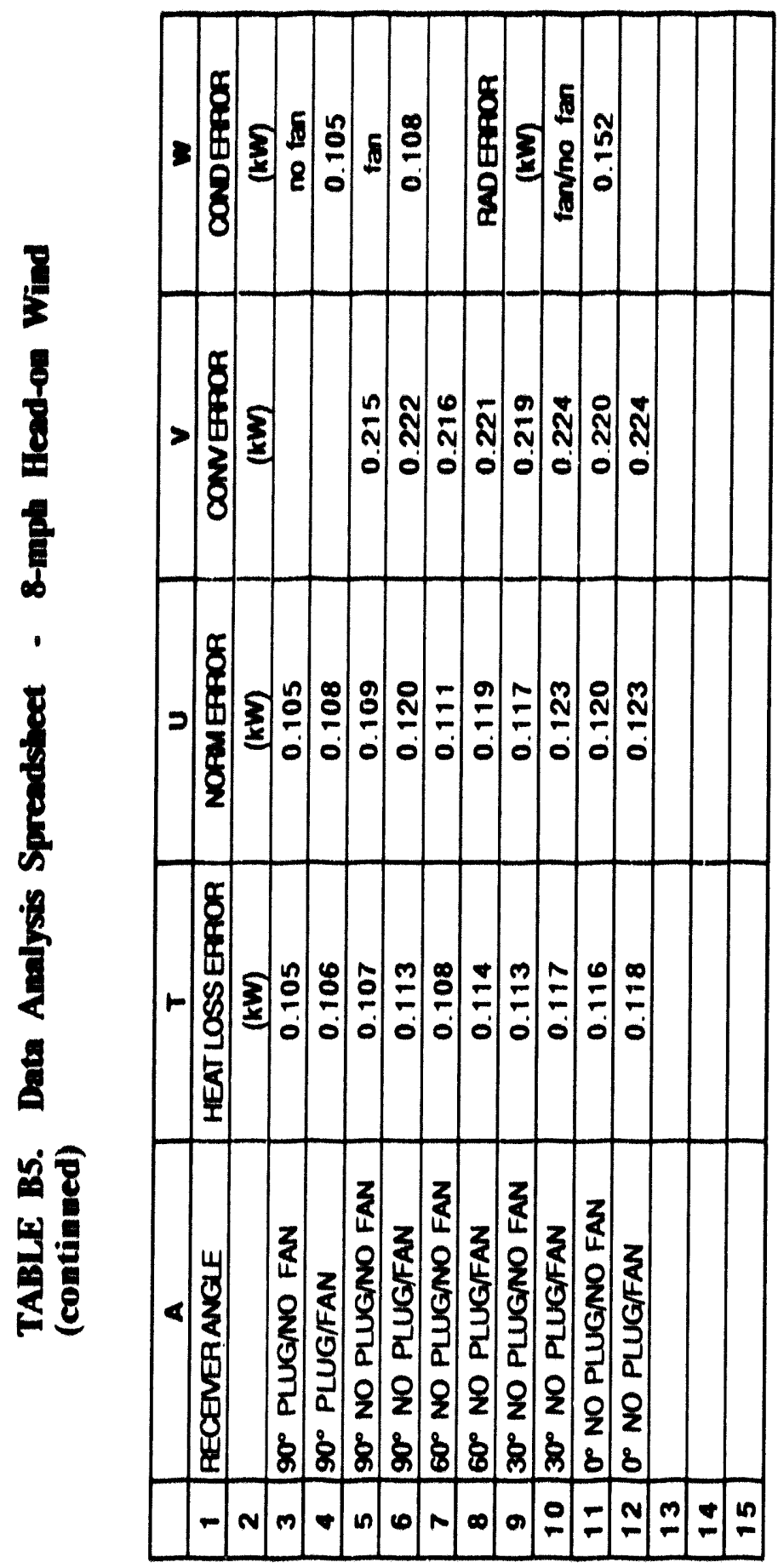




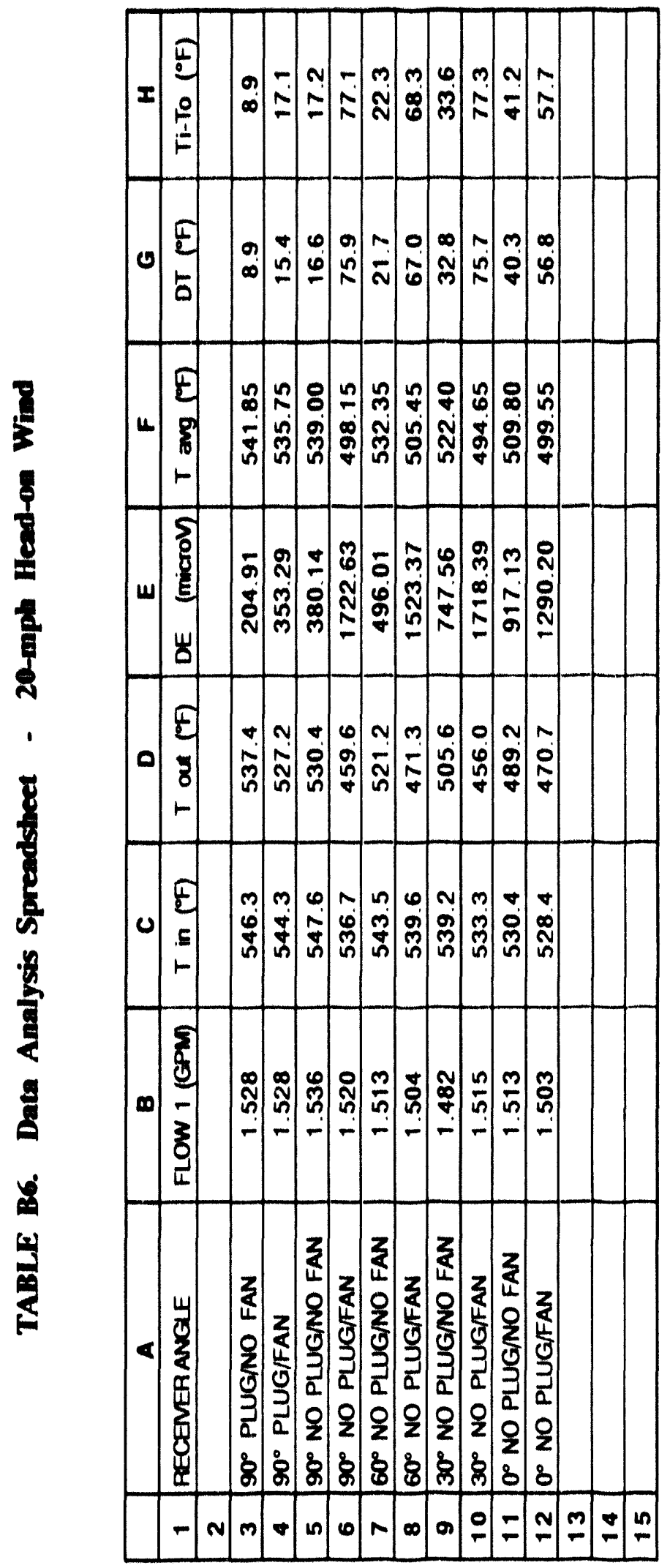




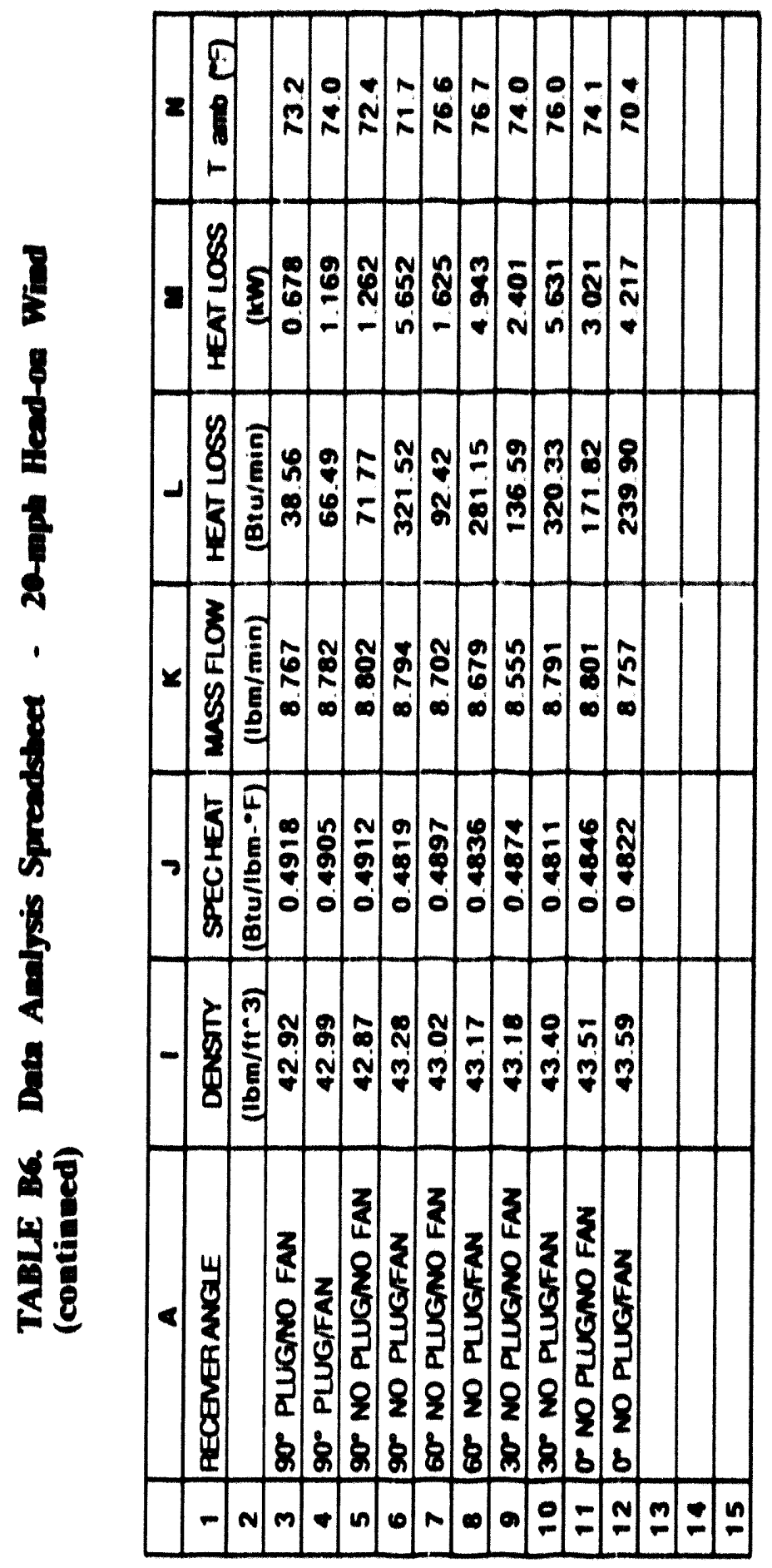




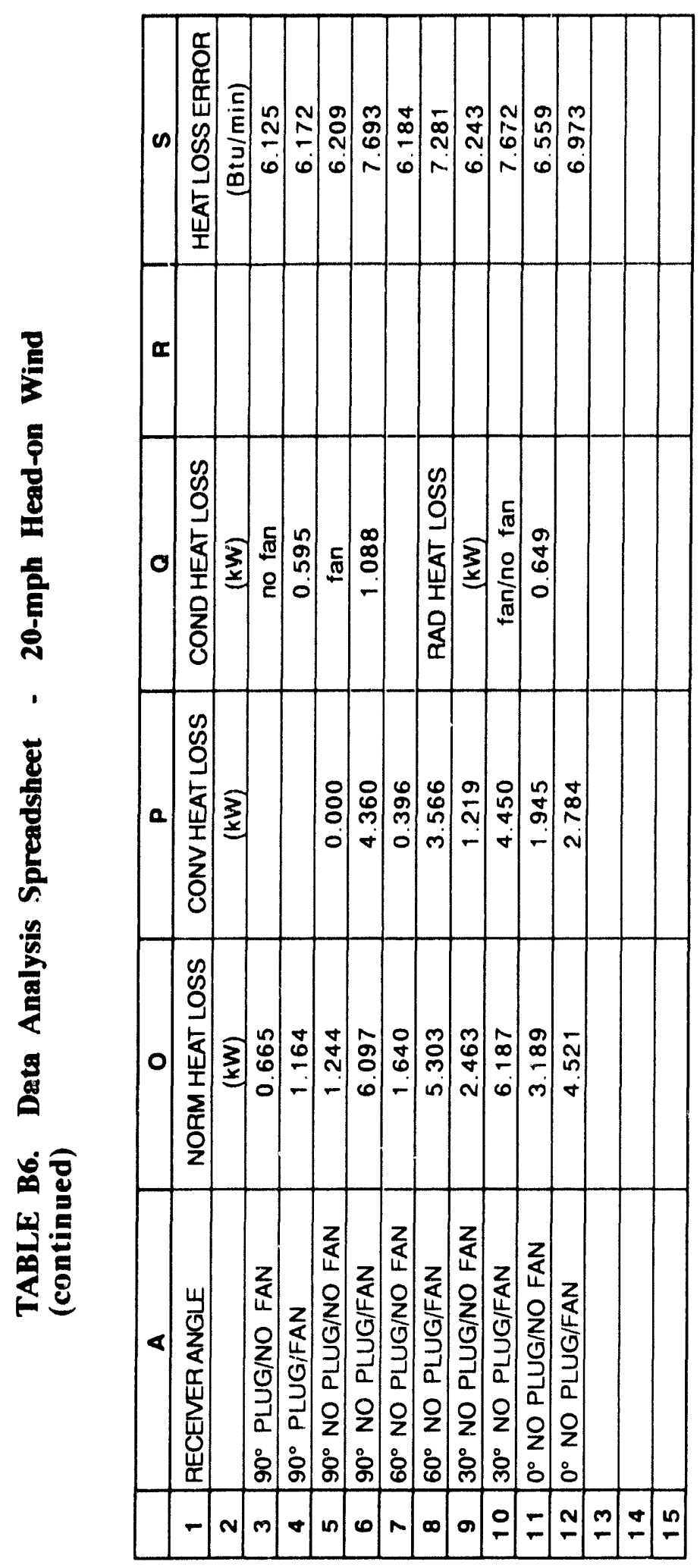




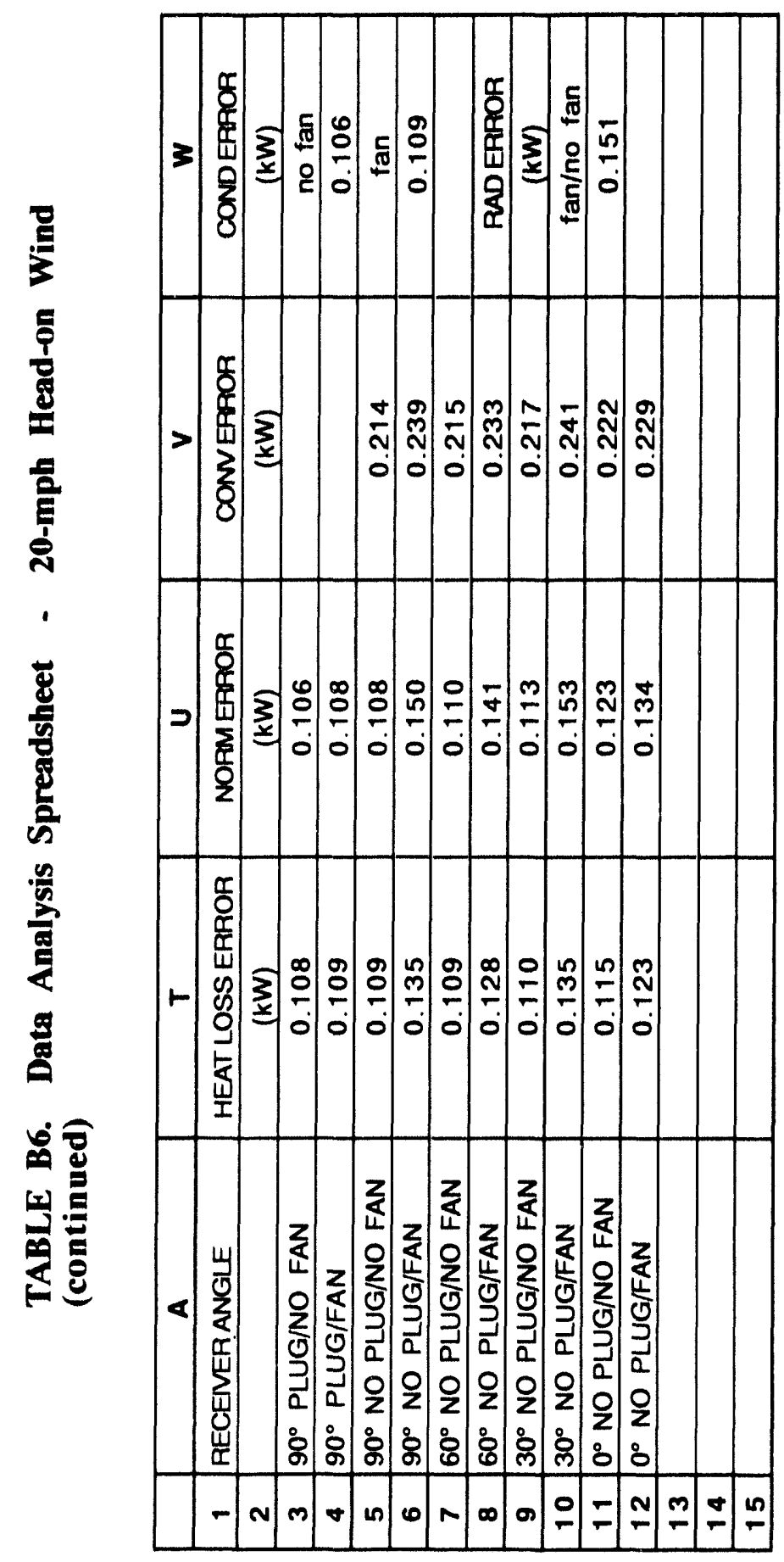




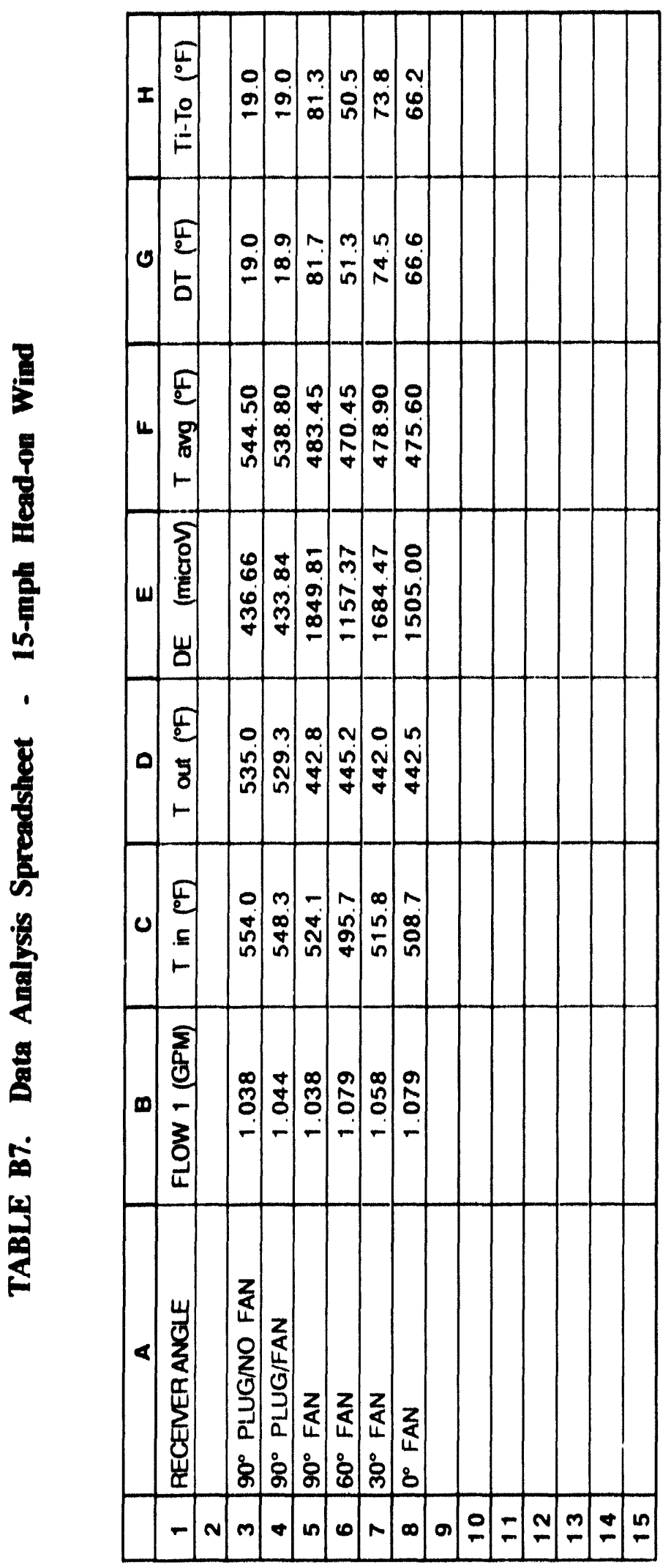




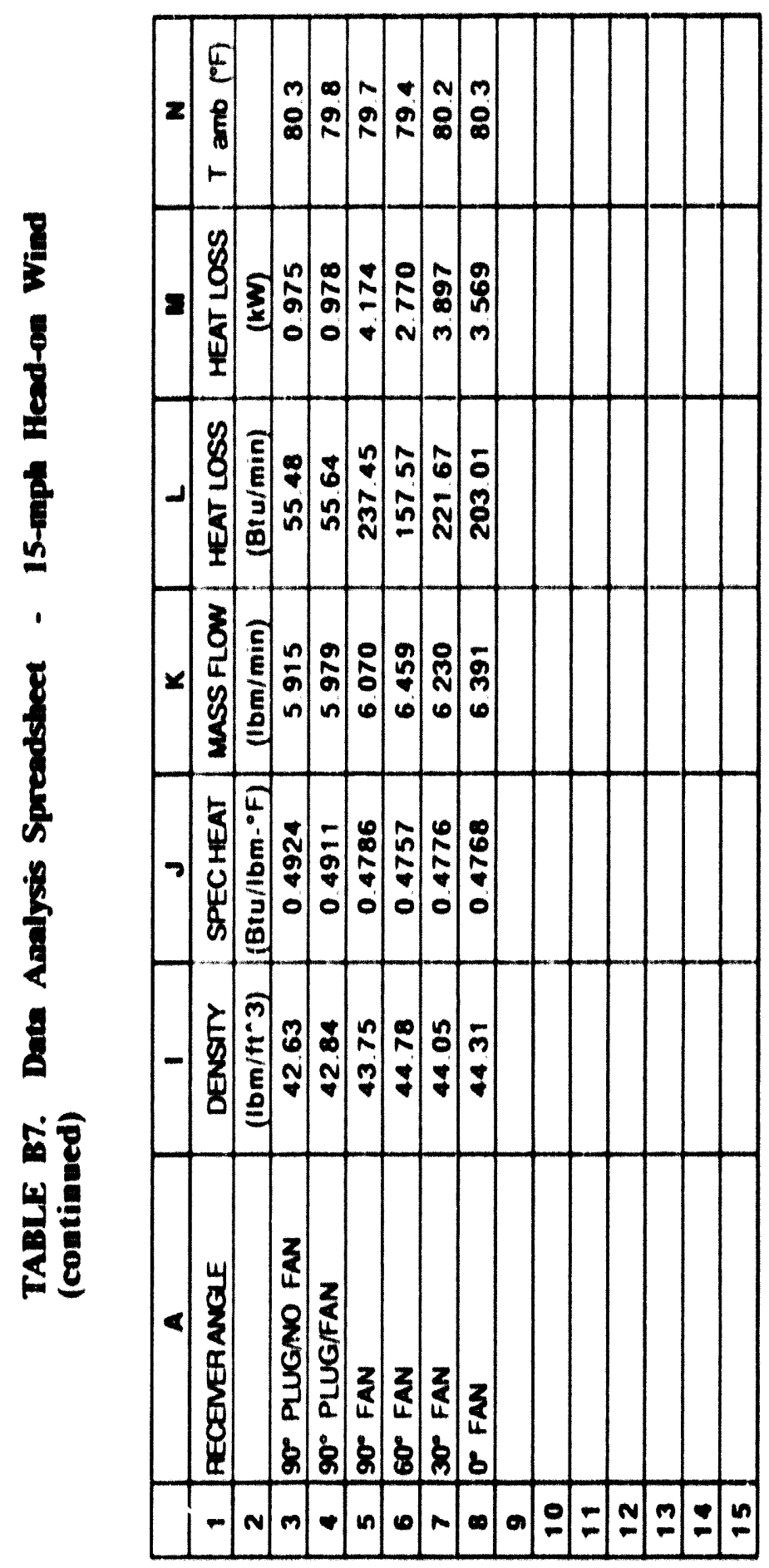




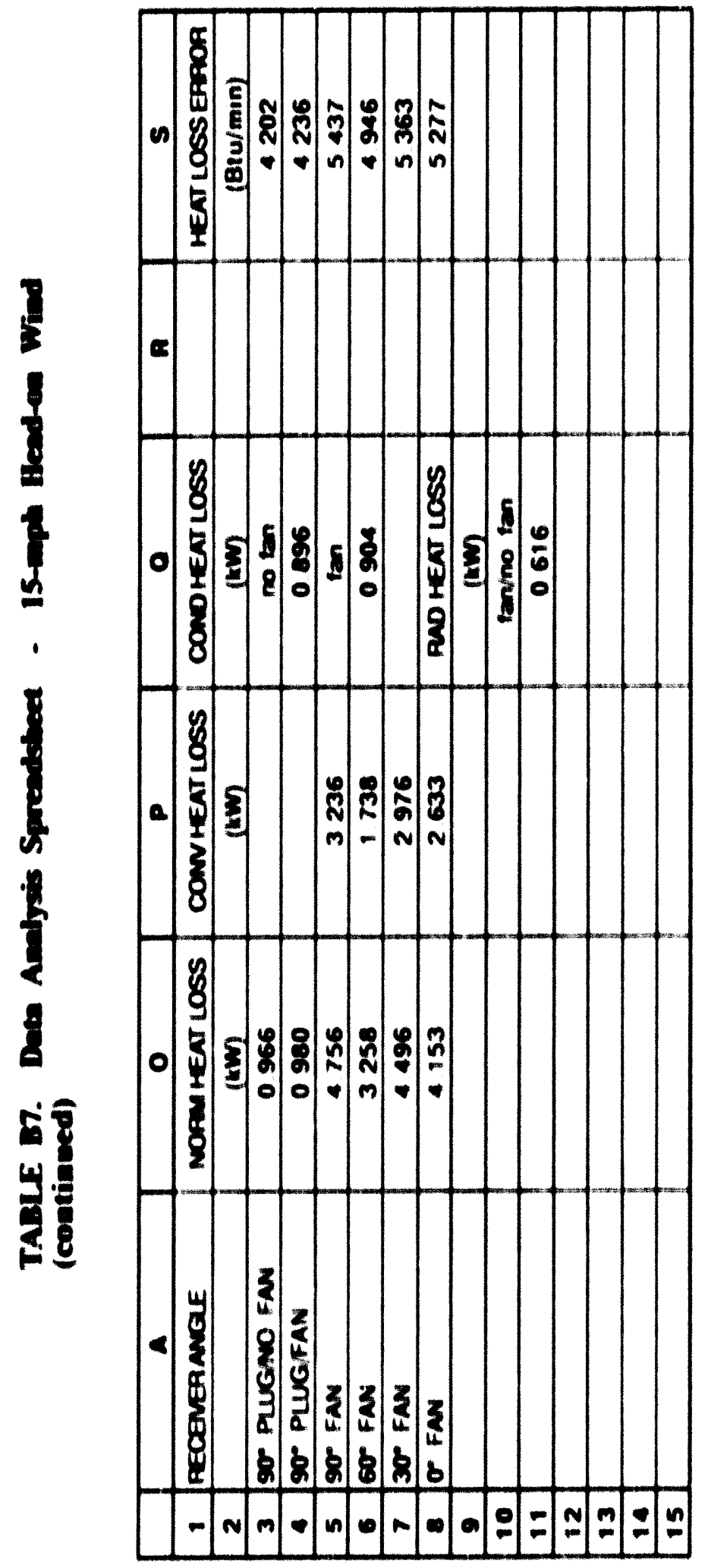




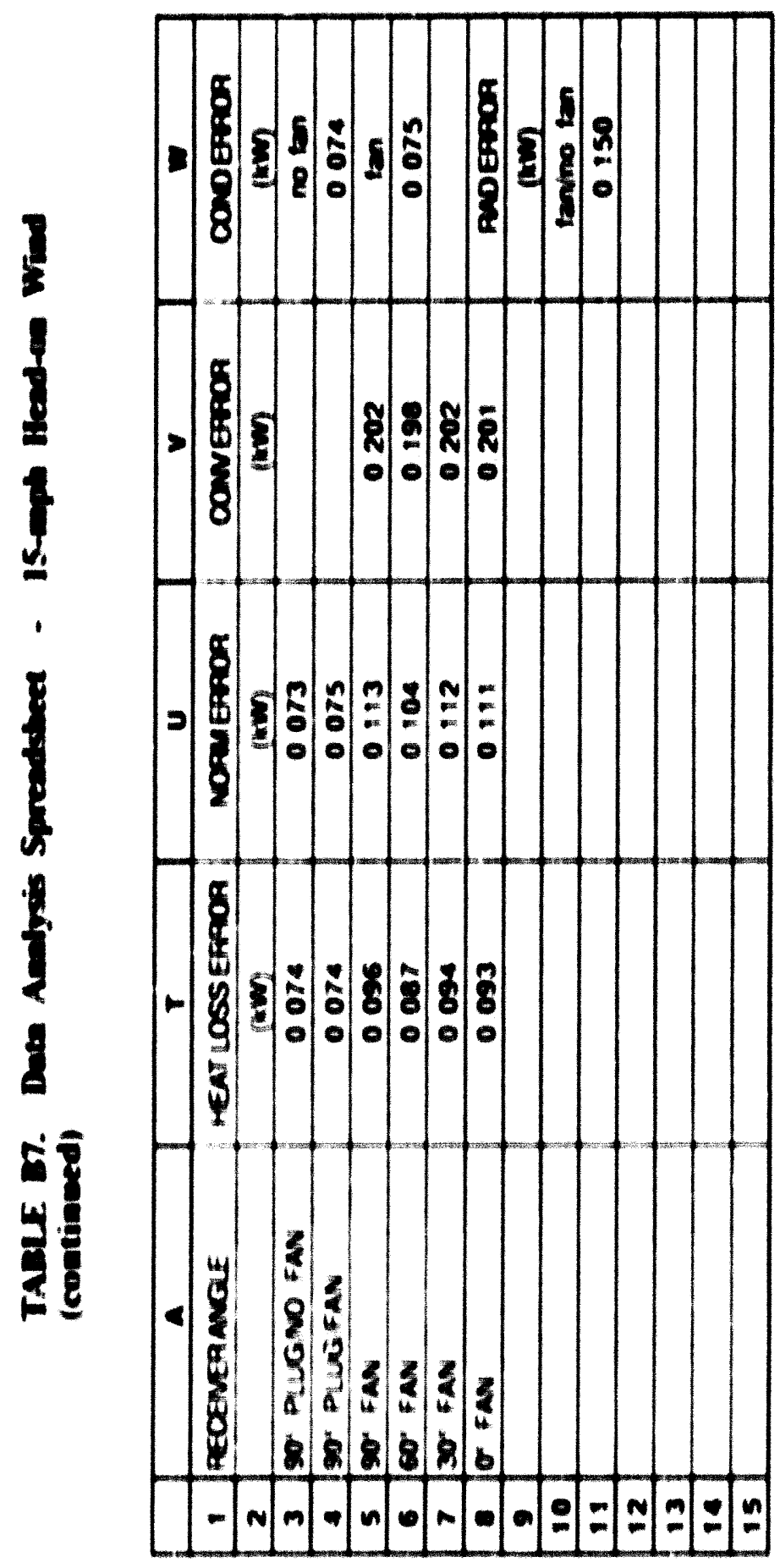




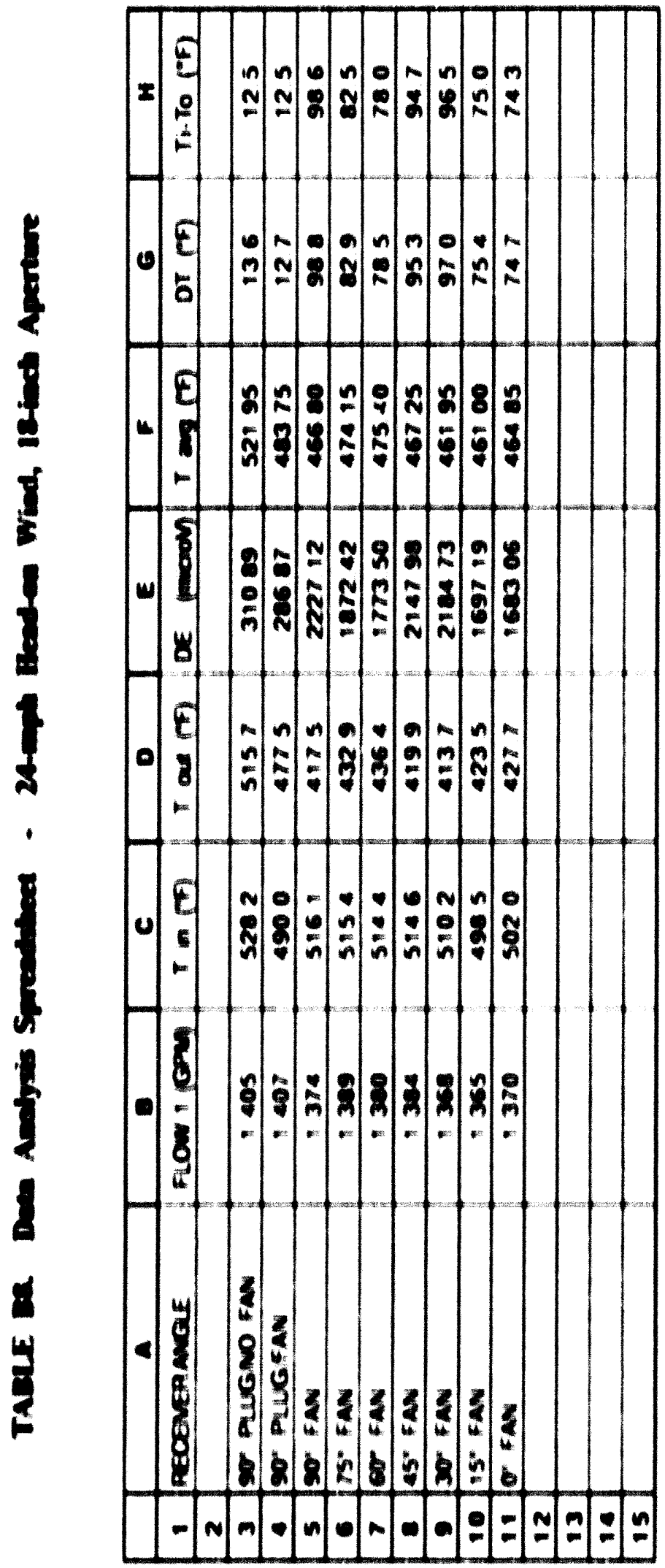




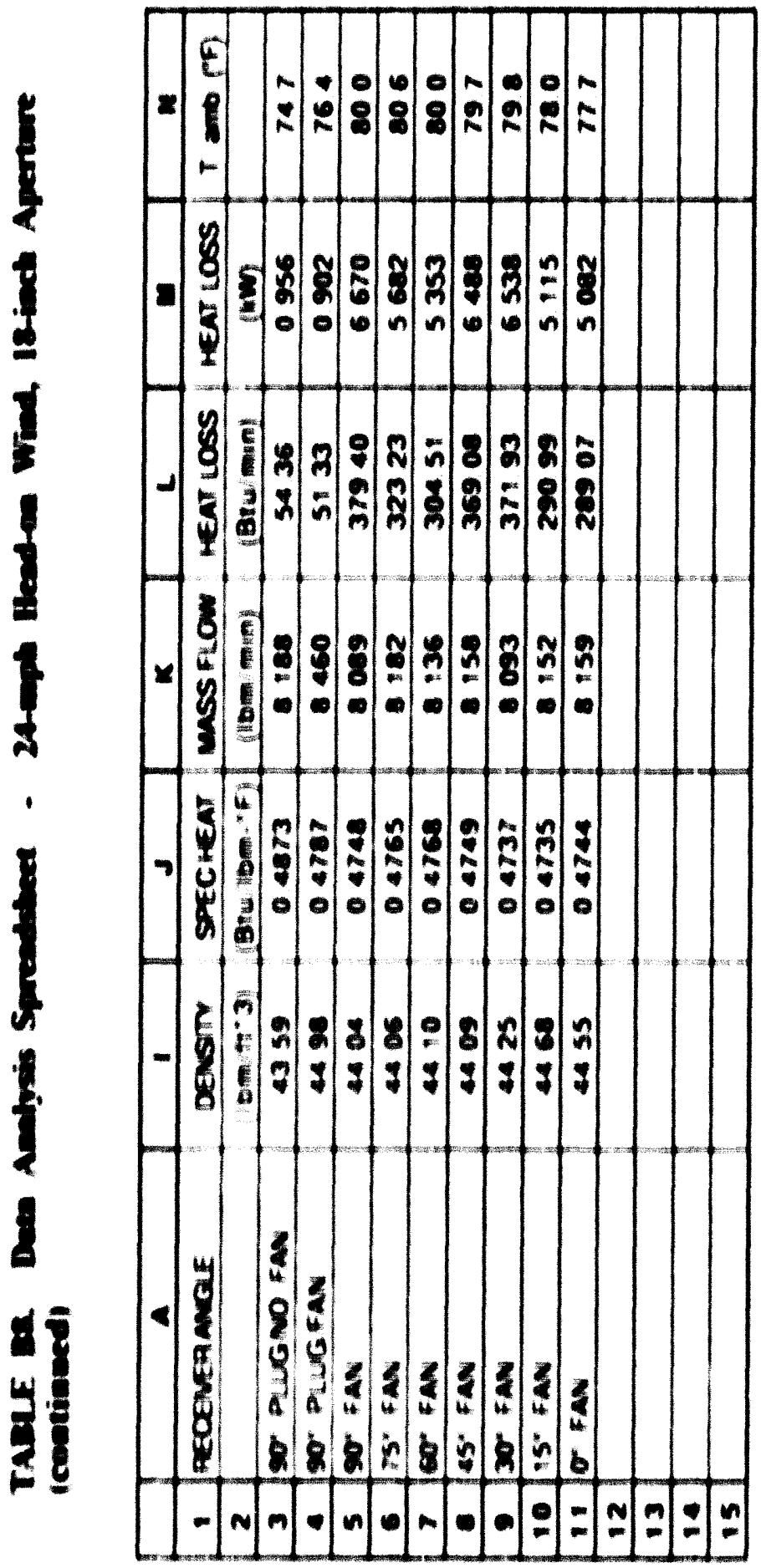




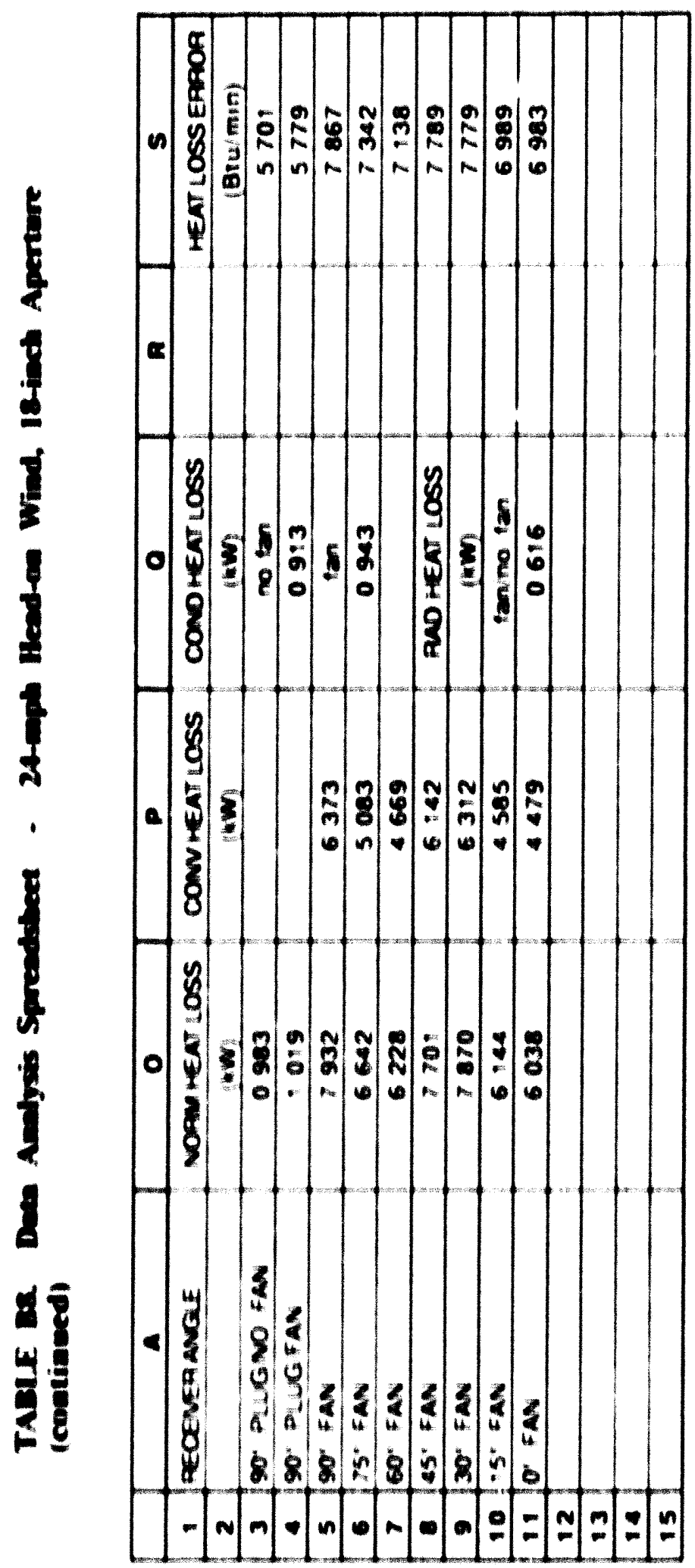




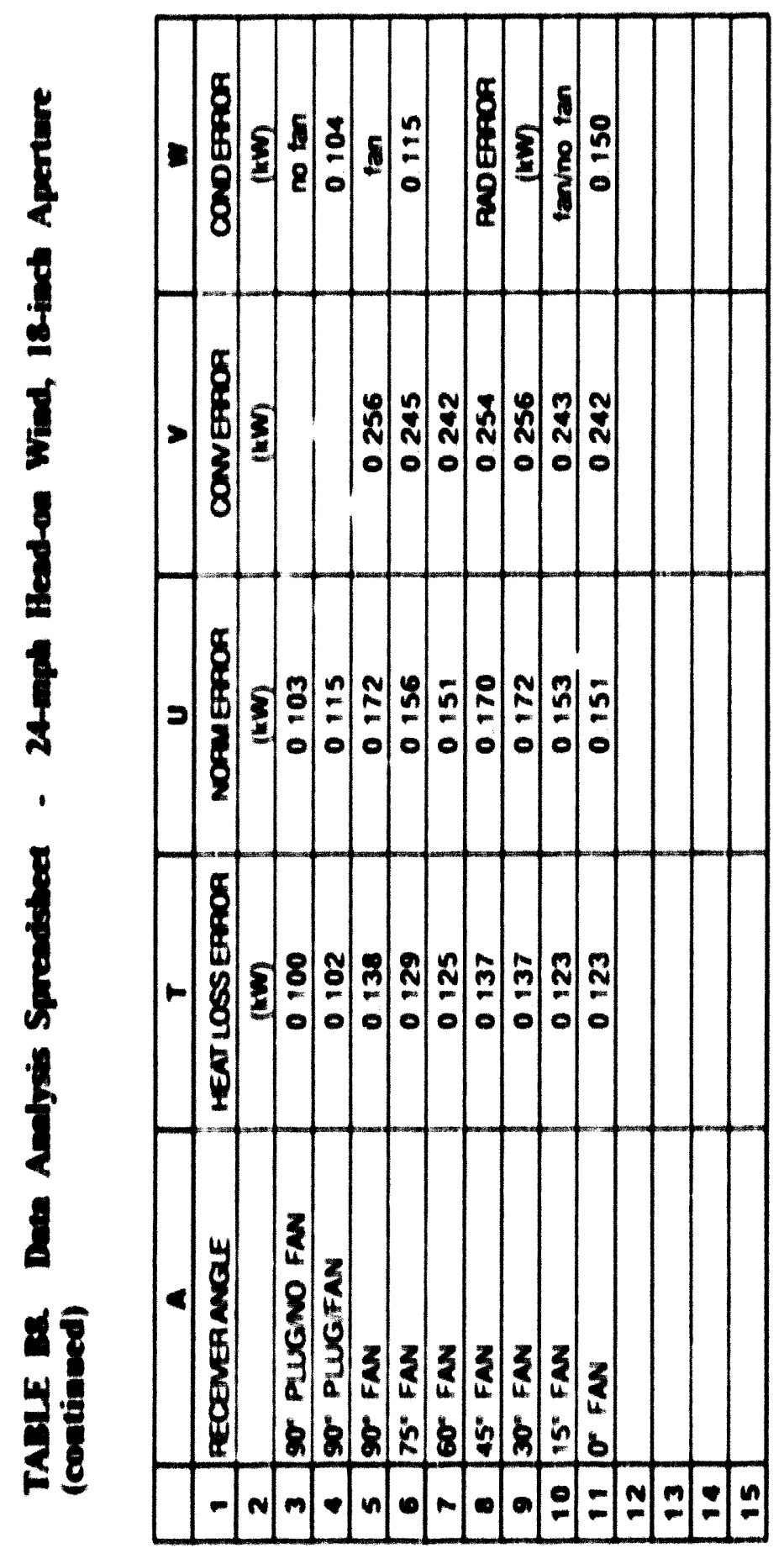




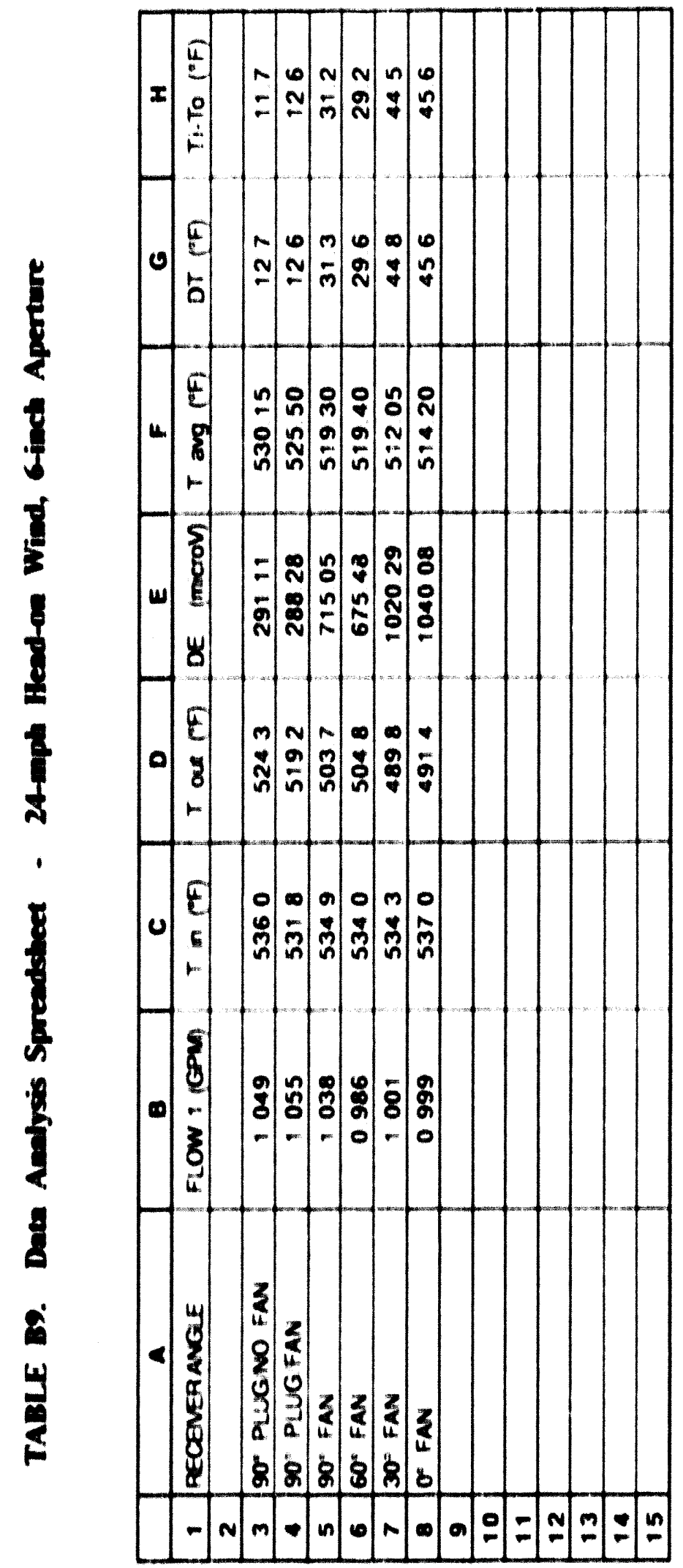




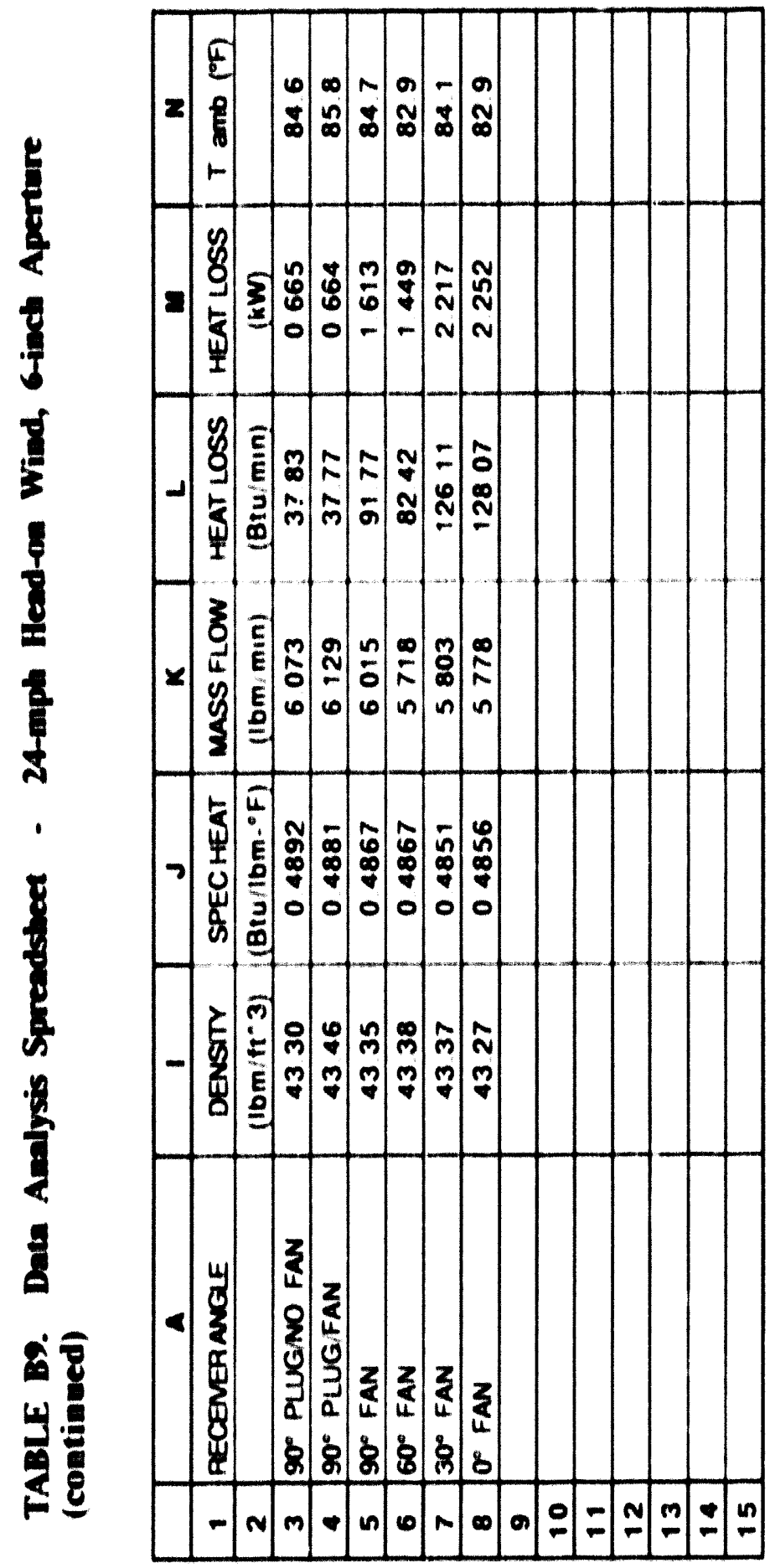




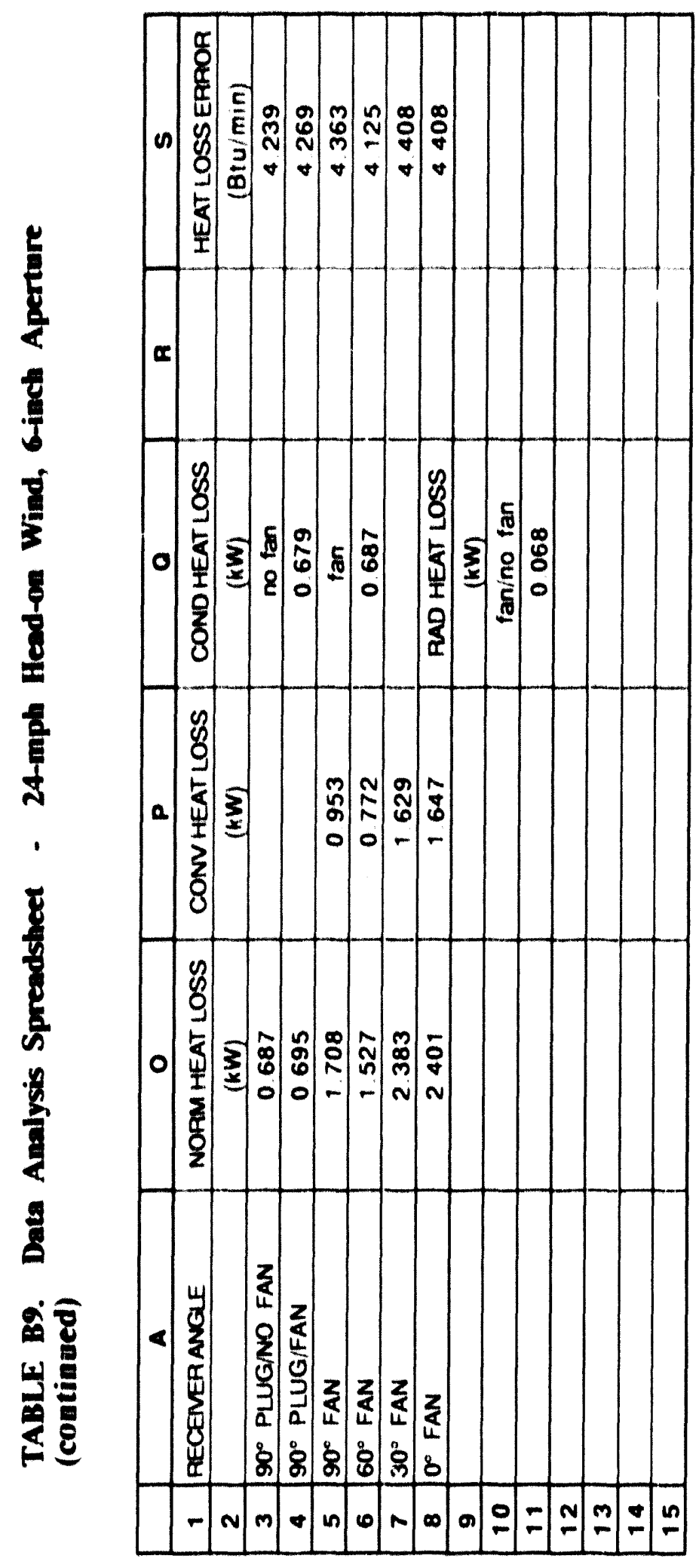




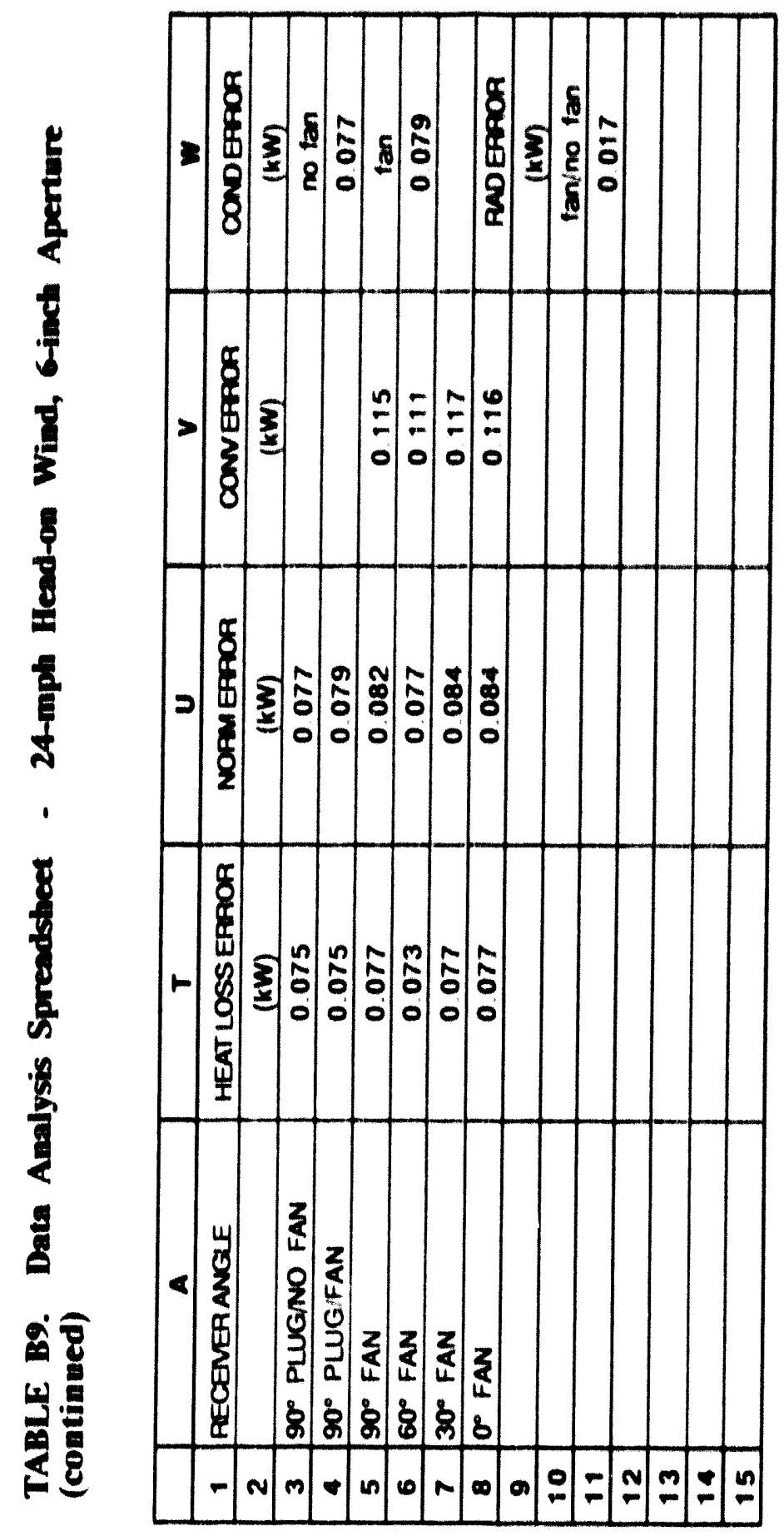




\section{Appendix C \\ Tabulated Summary of Receiver Heat Loss Results}


TABLE C1. Summary of Conduction, Radiation, and Convection Heat Losses from the Receiver at $5_{30}^{\circ} \mathrm{F}$ for the No-Wind Tests $(6$ Sets Corresponding to 6 Wind-Condition Sets) from the First Test Series

\begin{tabular}{|c|c|c|c|}
\hline $\begin{array}{c}\text { Test Sel/ } \\
\text { Heat Loss Mode }\end{array}$ & $\begin{array}{l}\text { Heat Loss } \\
(\mathrm{kW})\end{array}$ & $\begin{array}{c}\text { Uncertainty } \\
(\mathrm{kW})\end{array}$ & $\begin{array}{l}\text { Uncertainty } \\
\text { Percentage }\end{array}$ \\
\hline $\begin{array}{ll}\text { 6-mph Side-on Set } \\
\text { - Conduction } \\
\text { - Radiation } \\
\text { - Convection: } & 0^{\circ} \text { tilt angle } \\
& 30^{\circ} \\
& 60^{\circ} \\
& 90^{\circ} \\
& \\
\text { 8-mph Side-on Set } \\
\text { - Conduction } \\
\text { - Radiation } \\
\text { - Convection: } & 0^{\circ} \text { tilt angle } \\
& 30^{\circ} \\
& 60^{\circ} \\
& 90^{\circ} \\
\text { 20-mph Side-on Set } & \\
\text { - Conduction } & \\
\text { - Radiation } & \\
\text { - Convection: } & 0^{\circ} \text { tilt angle } \\
& 30^{\circ} \\
& 60^{\circ} \\
& 90^{\circ}\end{array}$ & $\begin{array}{l}0.656 \\
0.580 \\
2.089 \\
1.384 \\
0.422 \\
0.000 \\
\\
0.613 \\
0.603 \\
2.188 \\
1.487 \\
0.471 \\
0.000\end{array}$ & $\begin{array}{c}(0.105 \\
0.150 \\
0.218 \\
0.216 \\
0.212 \\
-\end{array}$ & $\begin{array}{c}17.0 \\
25.1 \\
10.2 \\
15.5 \\
52.2 \\
-\end{array}$ \\
\hline
\end{tabular}


TABLE C1. Summary of Conduction, Radiation, and Convection Heat Losses from the Receiver at $5530^{\circ} \mathrm{F}$ for the No-Wind Tests $(6$ Sets Corresponding to 6 Wind-Condition Sets) from the First Test Series (continued)

\begin{tabular}{|c|c|c|c|}
\hline $\begin{array}{l}\text { Test Condition/ } \\
\text { Heat Loss Mode }\end{array}$ & $\begin{array}{l}\text { Heat Loss } \\
(\mathrm{kW})\end{array}$ & $\begin{array}{c}\text { Uncerlainly } \\
(k W)\end{array}$ & $\begin{array}{l}\text { Uncertainty } \\
\text { Percentage }\end{array}$ \\
\hline $\begin{array}{ll}\text { 6-mph Head-on Set } \\
\text { - Conduction } \\
\text { - Radiation } \\
\text { - Convection: } & 0^{\circ} \text { tilt angle } \\
& 30^{\circ} \\
& 60^{\circ} \\
& 90^{\circ} \\
& \\
\text { 8-mph Head-on Set } \\
\text { - Conduction } \\
\text { - Radiation } \\
\text { - Convection: } & 0^{\circ} \text { tilt angle } \\
& 30^{\circ} \\
& 60^{\circ} \\
& 90^{\circ} \\
& \\
\text { 20-mph Head-on Set } \\
\text { - Conduction } \\
\text { - Radiation } \\
\text { - Convection: } & 0^{\circ} \text { tilt angle } \\
& 30^{\circ} \\
& 60^{\circ} \\
& 90^{\circ}\end{array}$ & $\begin{array}{l}0.584 \\
0.609 \\
1.930 \\
1.253 \\
0.374 \\
0.000\end{array}$ & $\begin{array}{c}(0.106 \\
0.152 \\
0.220 \\
0.217 \\
0.214 \\
.\end{array}$ & $\begin{array}{c}18.2 \\
25.0 \\
11.4 \\
17.3 \\
57.2 \\
-\end{array}$ \\
\hline
\end{tabular}


TABLE C2. Summary of Conduction, Radiation, and Convection Heat Losses from the Recelver at $5.30^{\circ} \mathrm{F}$ for Side.On Wind Tests from the First Test Series

\begin{tabular}{|c|c|c|c|}
\hline $\begin{array}{l}\text { Tesi Condilion/ } \\
\text { Heal Loss Mode }\end{array}$ & $\begin{array}{l}\text { Heal lows } \\
(\mathrm{kW})\end{array}$ & $\begin{array}{c}\text { Tncerfininiy } \\
(k w)\end{array}$ & $\begin{array}{l}\text { Oncertuinty } \\
\text { Percentuges }\end{array}$ \\
\hline $\begin{array}{l}\text { 6.mph Side-On Wind } \\
\text { - Conduction } \\
\text { - Radiation } \\
\text { - Convection: }\left(0^{\circ} \text { till angle }\right. \\
\\
\begin{array}{ll}(2)^{\circ} \\
(x)^{\circ} \\
()^{\circ}\end{array}\end{array}$ & $\begin{array}{l}(1.541 \\
0.548 \\
2.4117 \\
1.862 \\
1.0110 \\
(0.415\end{array}$ & $\begin{array}{l}0.1116 \\
0.150 \\
0.2211 \\
0.218 \\
10.215 \\
0.213\end{array}$ & $\begin{array}{c}17.9 \\
25.1 \\
4.1 \\
11.7 \\
21.3 \\
51.3\end{array}$ \\
\hline $\begin{array}{l}\text { 8.mph Side-On Wind } \\
\text { - Conduction } \\
\text { - Radiation } \\
\text { - Convection: } \\
\begin{array}{ll}()^{\circ} \text { lill angle } \\
3)^{\circ} \\
(\mathbf{( 0 )} \\
(\mathbf{x})^{\circ}\end{array}\end{array}$ & $\begin{array}{l}(1.621 \\
0.58(1) \\
2.767 \\
2.159 \\
1.277 \\
(1.636\end{array}$ & $\begin{array}{l}0.105 \\
0.148 \\
0.214 \\
0.216 \\
0.212 \\
0.211\end{array}$ & $\begin{array}{l}10.4 \\
25.5 \\
7.4 \\
10.0 \\
16.6 \\
3.3 .2\end{array}$ \\
\hline 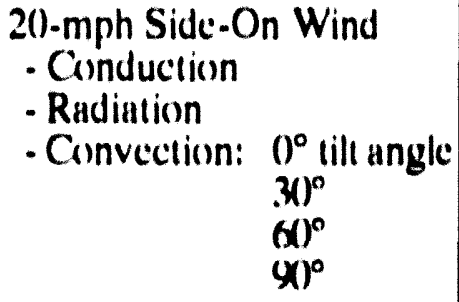 & $\begin{array}{l}0.655 \\
0.6(1) .3 \\
6.364 \\
5.462 \\
4.661 \\
4.479\end{array}$ & $\begin{array}{l}0.1015 \\
0.149 \\
0.247 \\
0.239 \\
0.233 \\
0.233\end{array}$ & $\begin{array}{l}16.0 \\
24.7 \\
3.9 \\
4.4 \\
5.0 \\
5.2\end{array}$ \\
\hline
\end{tabular}


TABI.F. (3. Summary of Conduction, Radiantion, and Convection lleat

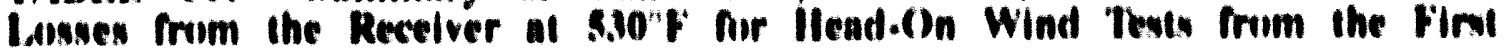
Test Serien

\begin{tabular}{|c|c|c|c|}
\hline $\begin{array}{l}\text { Tew Condiliont } \\
\text { Heal I Ams Mixlo }\end{array}$ & $\begin{array}{l}\text { Triil } \\
\left(k w_{2}\right)\end{array}$ & $\begin{array}{l}\text { Thiorluiny } \\
(k W)\end{array}$ & $\begin{array}{l}\text { Therefliningy } \\
\text { Percenlayes }\end{array}$ \\
\hline 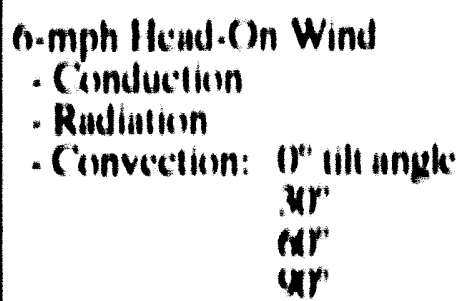 & 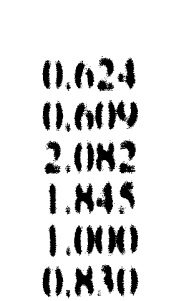 & $\begin{array}{l}11.1161 \\
11.152 \\
11.2211 \\
11.214 \\
11.216 \\
11.216\end{array}$ & $\begin{array}{l}17.11 \\
24.11 \\
111.0 \\
11.4 \\
21.0 \\
26.1\end{array}$ \\
\hline 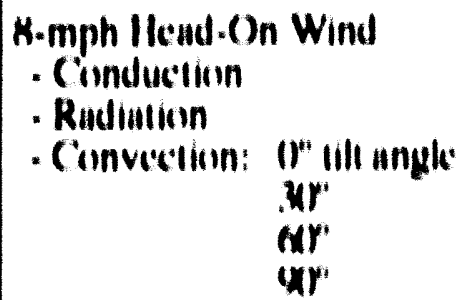 & $\begin{array}{l}11.7111 \\
11.654 \\
2.217 \\
2.144 \\
1.461 \\
1.412\end{array}$ & $\begin{array}{l}11.111 \times \\
11.152 \\
11.224 \\
11.224 \\
11.221 \\
11.222\end{array}$ & $\begin{array}{l}19.4 \\
21.2 \\
111.1 \\
111.2 \\
15.1 \\
15.7\end{array}$ \\
\hline 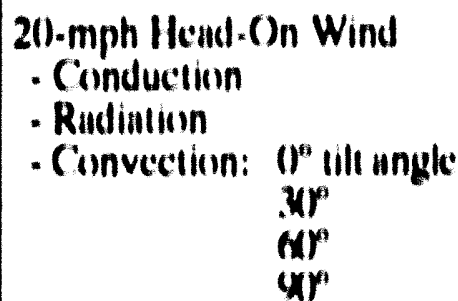 & $\begin{array}{l}1.1184 \\
11.644 \\
2.784 \\
4.450 \\
1.566 \\
4.3011\end{array}$ & $\begin{array}{l}11.1114 \\
11.151 \\
11.224 \\
11.241 \\
11.213 \\
11.2114\end{array}$ & $\begin{array}{l}111.11 \\
2.1 .1 \\
8.2 \\
5.4 \\
0.5 \\
5.5\end{array}$ \\
\hline
\end{tabular}


TABI.F. C4. Summary of Conduction and Convection Heut Laumes from the

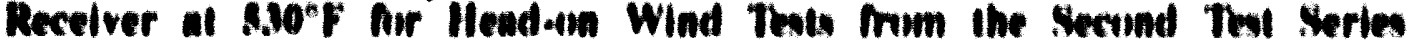

\begin{tabular}{|c|c|c|c|}
\hline $\begin{array}{l}\text { Tow Condilion } \\
\text { leal I im Minds }\end{array}$ & $\begin{array}{l}\text { TIind ink } \\
(k W)\end{array}$ & $\begin{array}{l}\text { Thioflainiy } \\
\left(k w^{\prime}\right)\end{array}$ & $\begin{array}{l}\text { Thivelainy } \\
\text { Mrexniaye }\end{array}$ \\
\hline 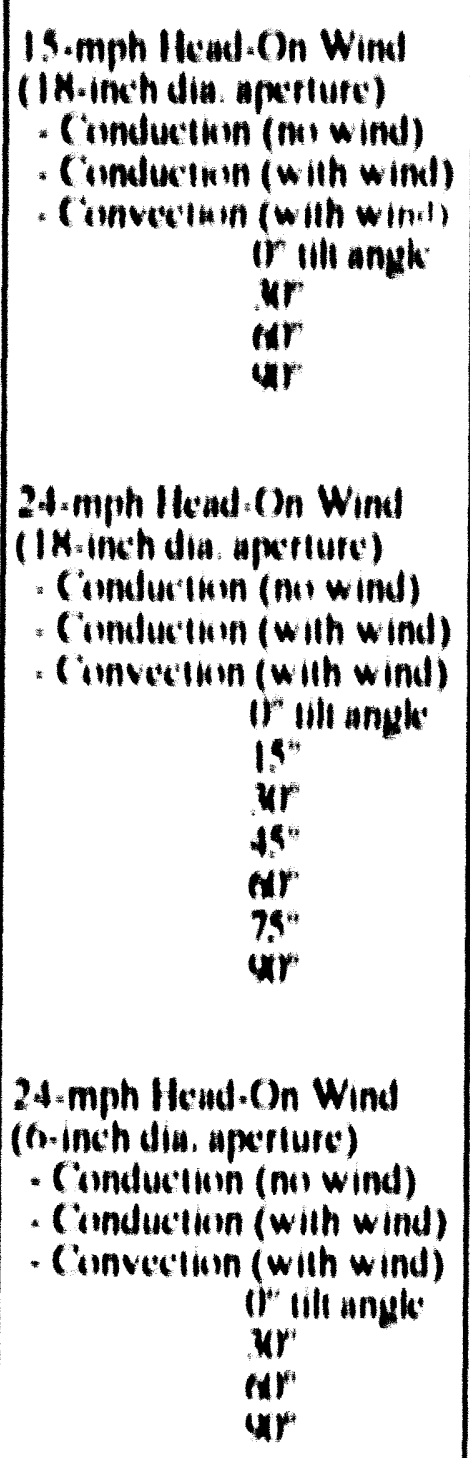 & 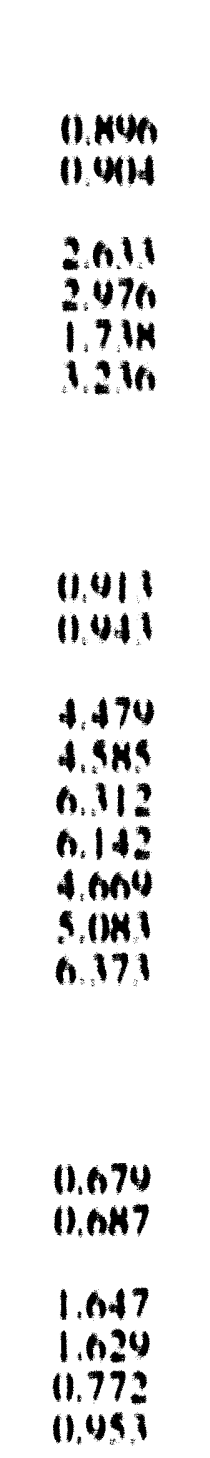 & 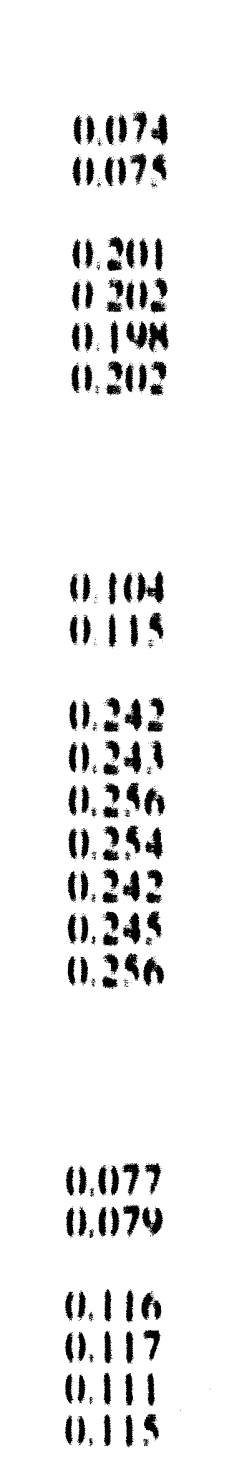 & $\begin{array}{l}11.4 \\
12.2 \\
5.4 \\
5.1 \\
4.1 \\
4.1 \\
5.2 \\
4.1 \\
4.11\end{array}$ \\
\hline
\end{tabular}


Appendix D

Tubulated Meanured Recelver Temperatures 


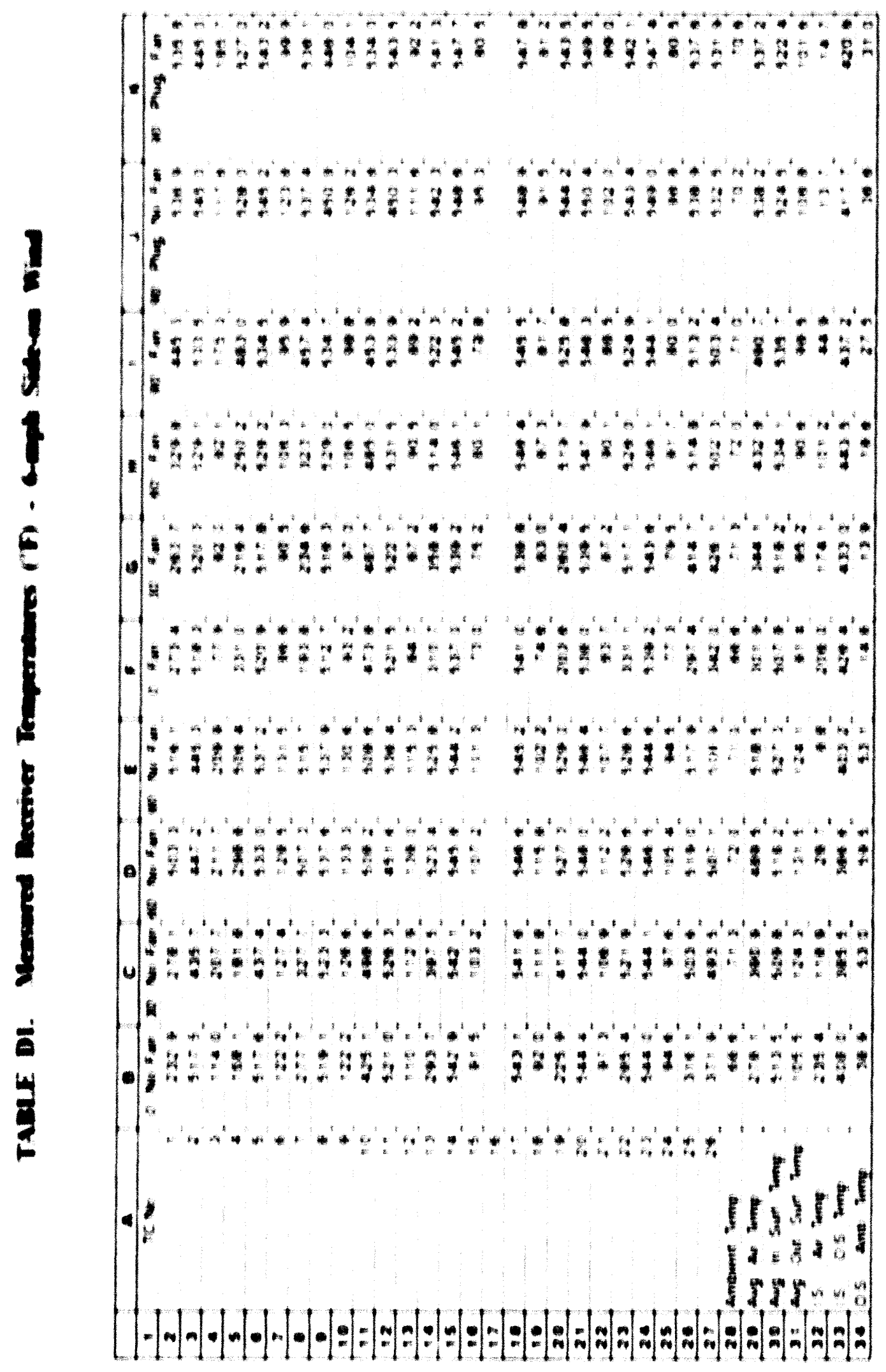




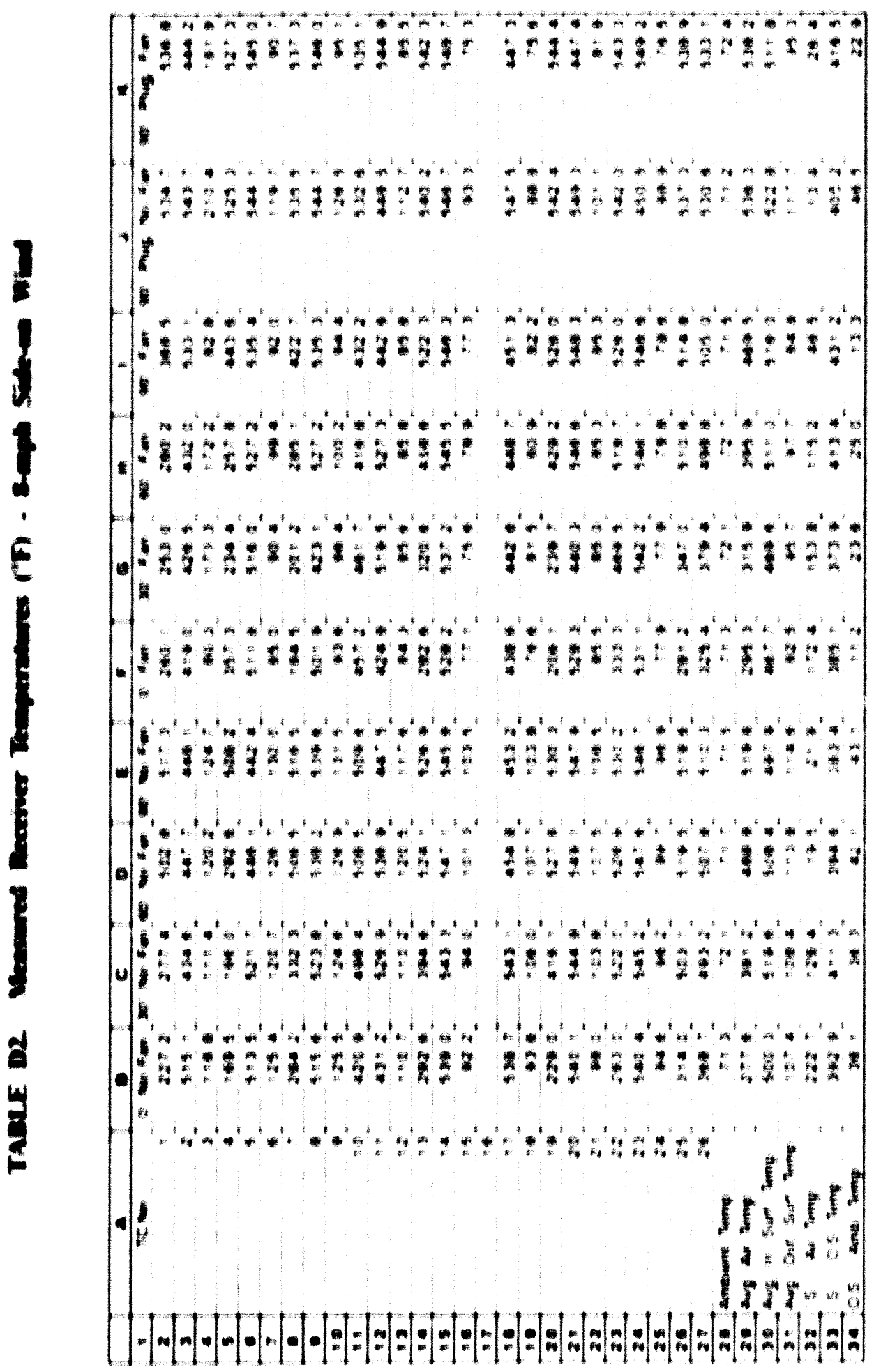




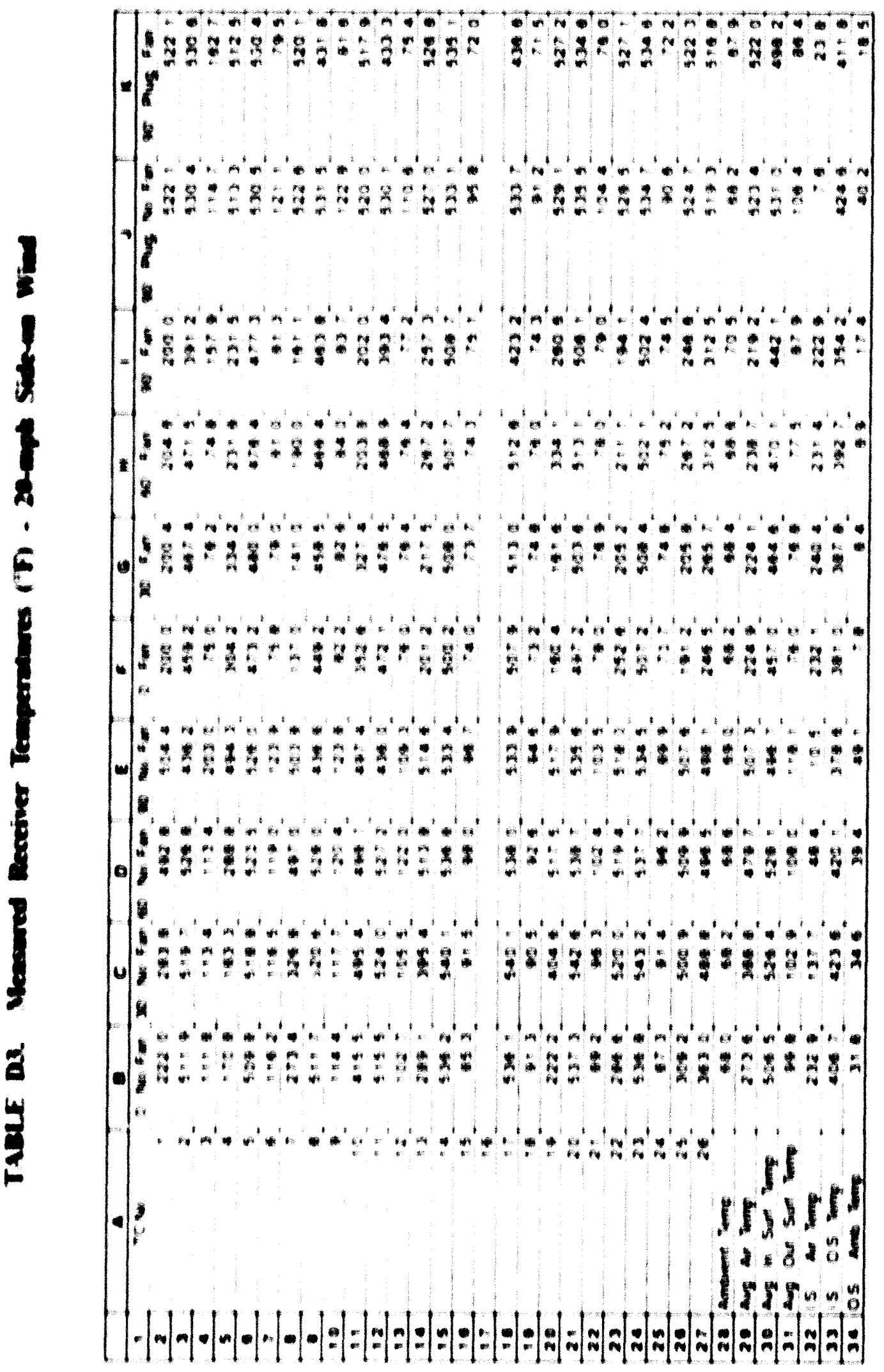

III 


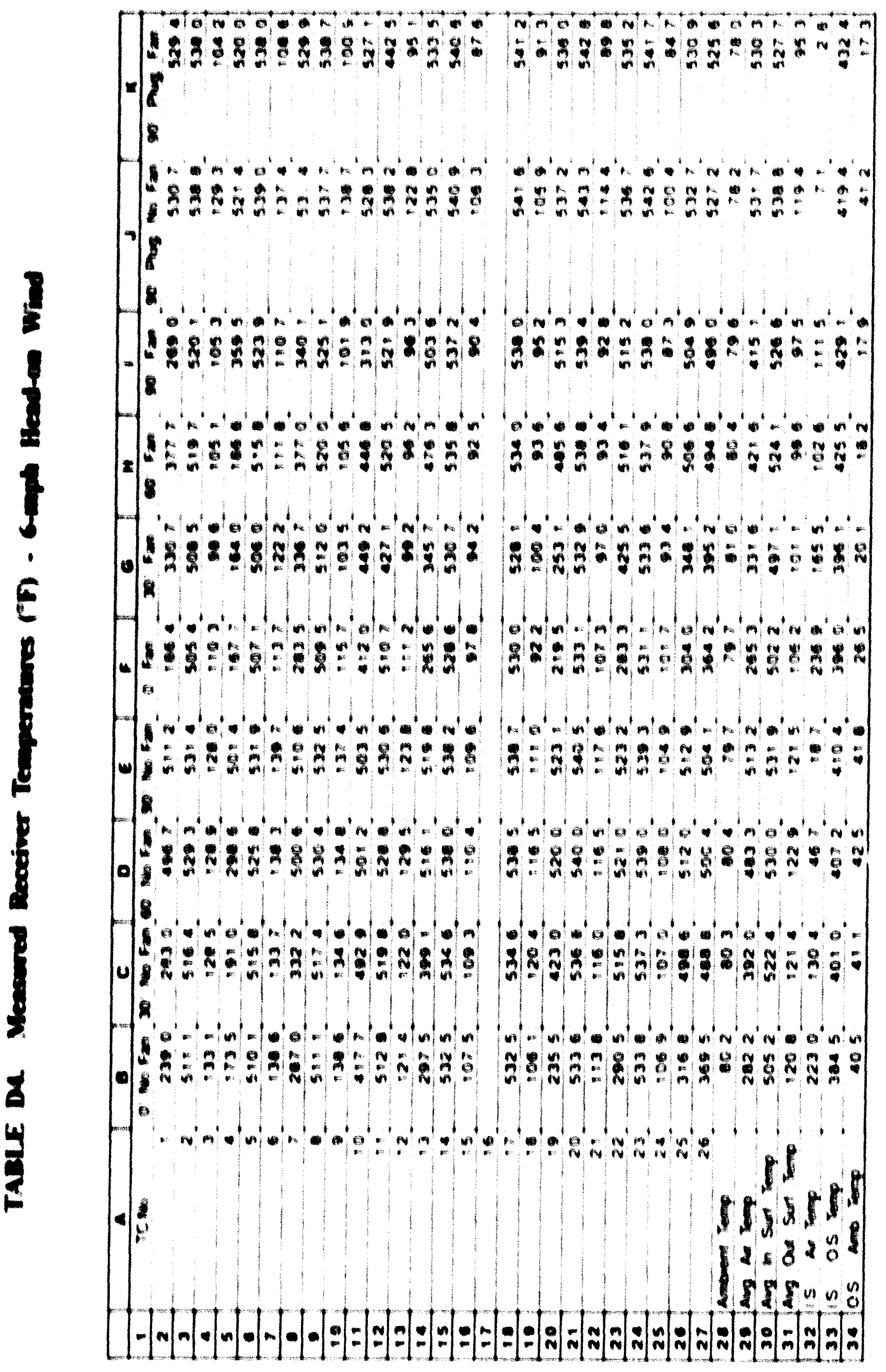




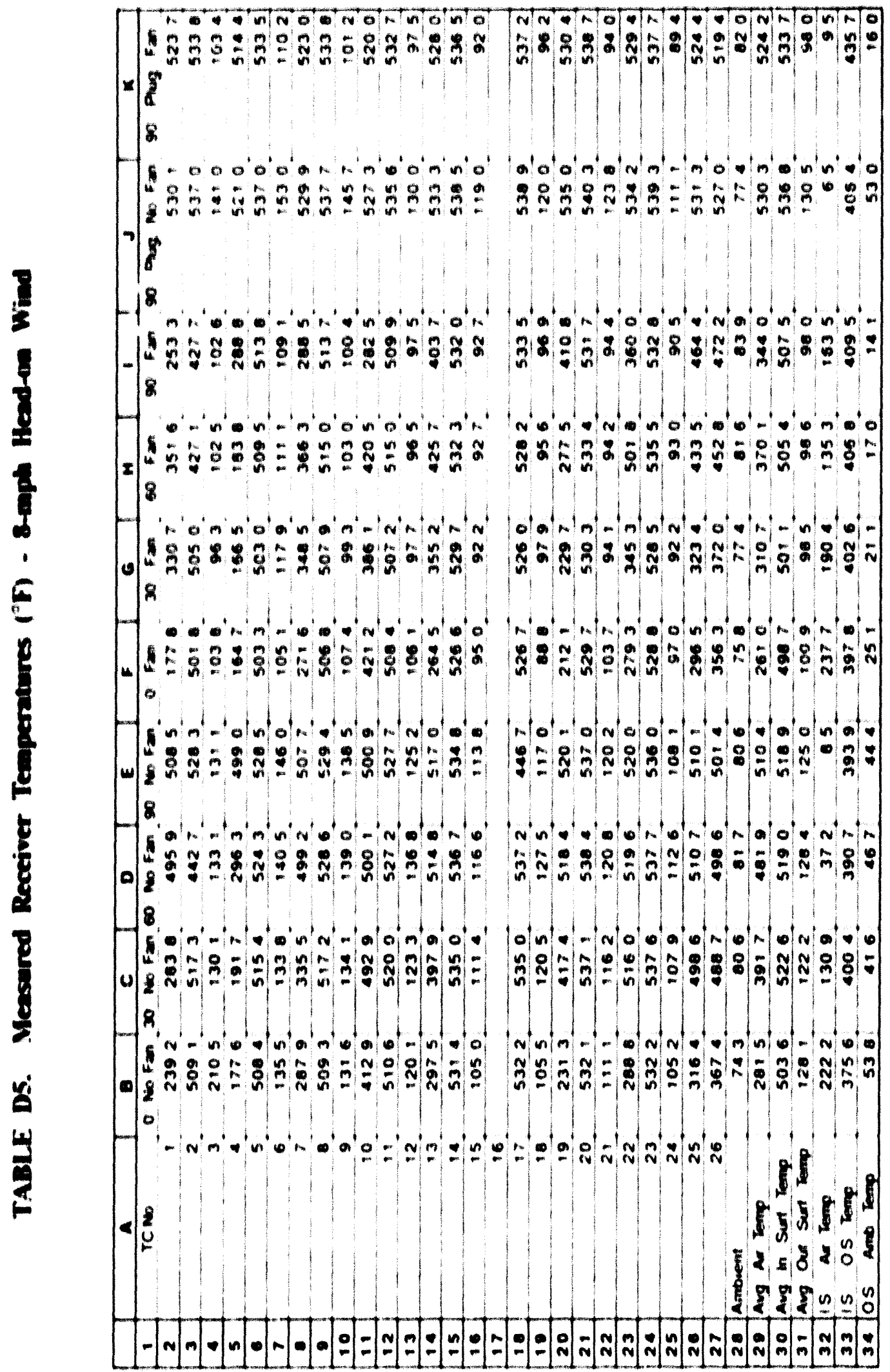




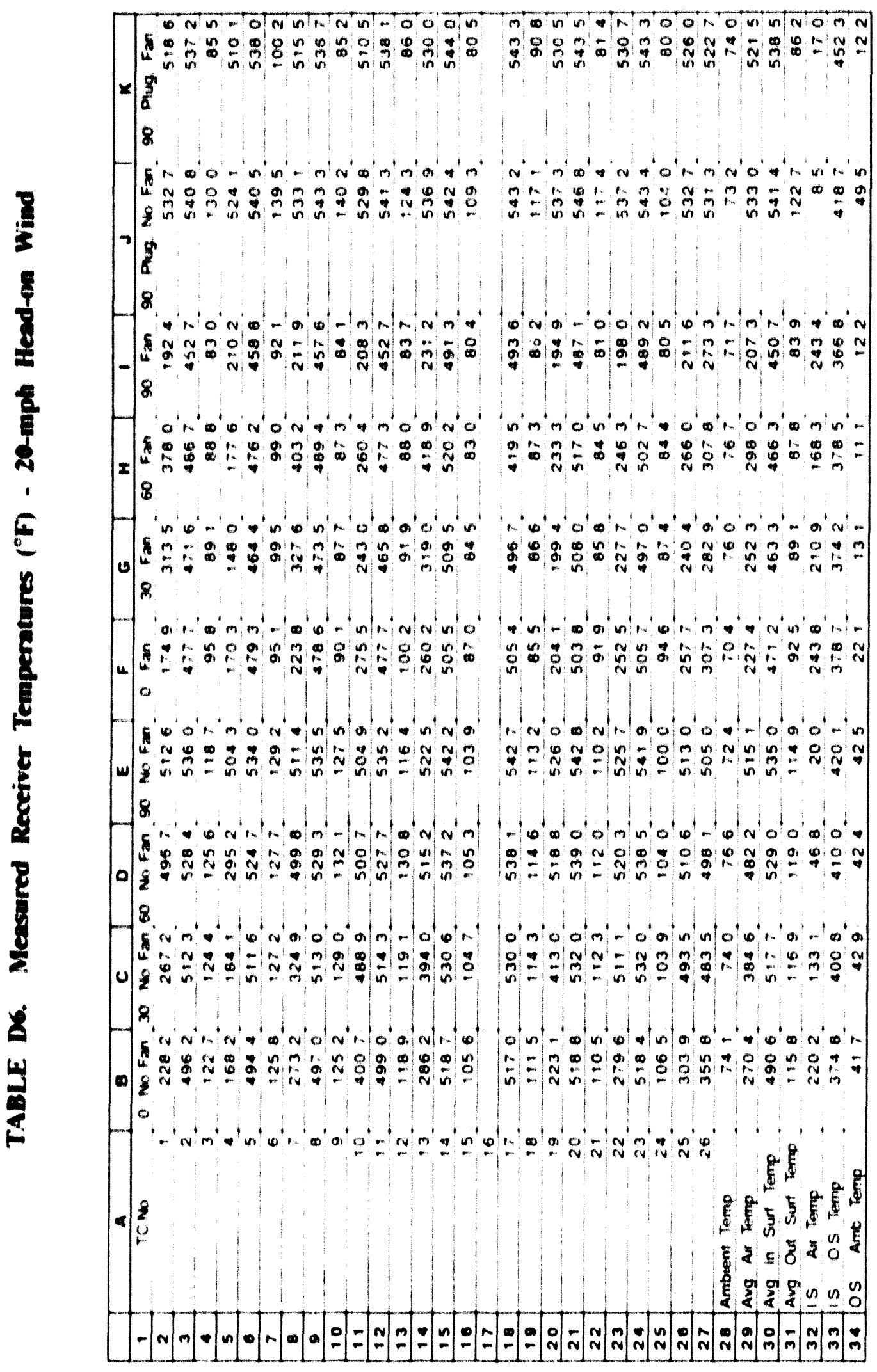




\section{Appendix E \\ Thermoelectric Characteristics of \\ Type-K Thermocouples}




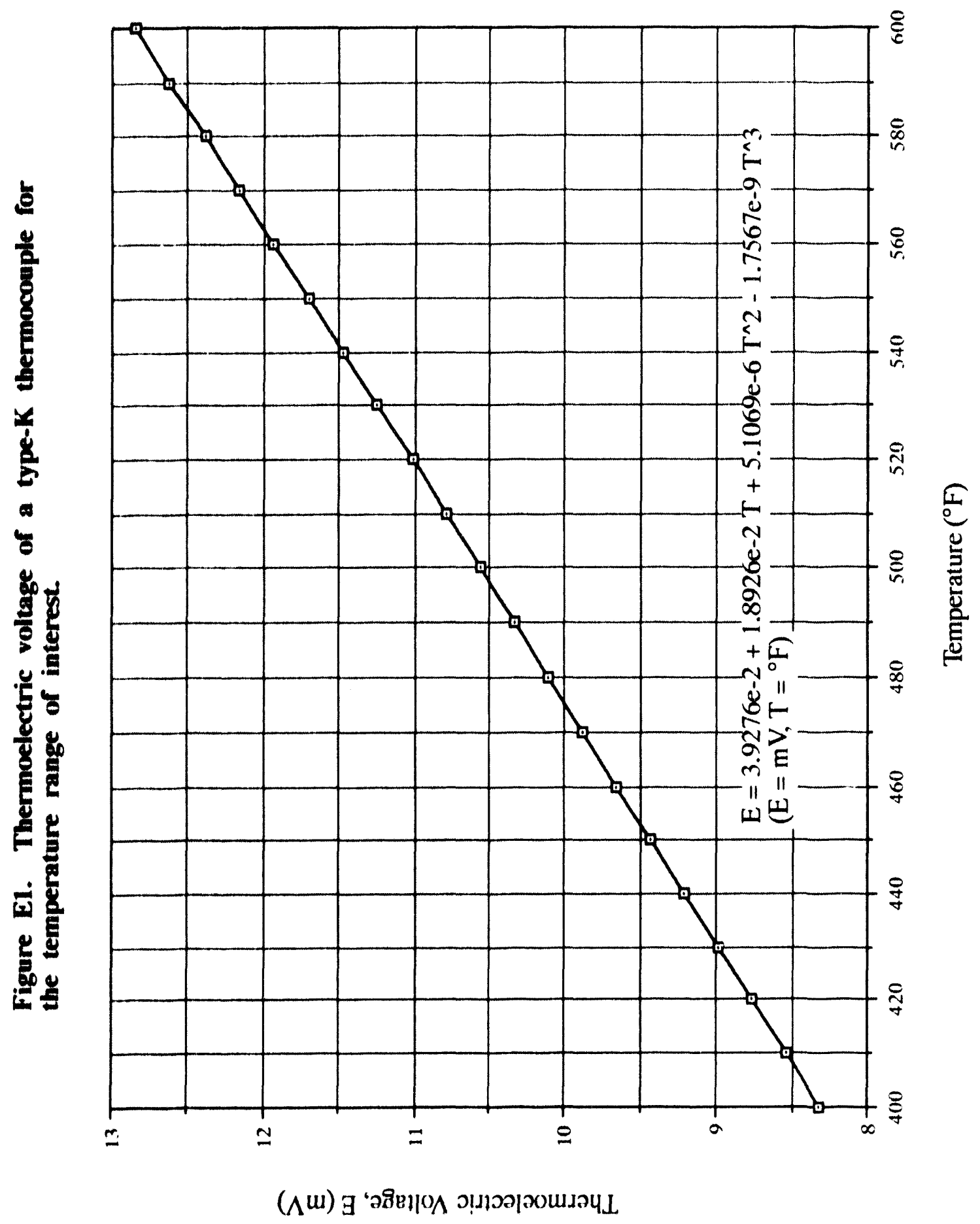




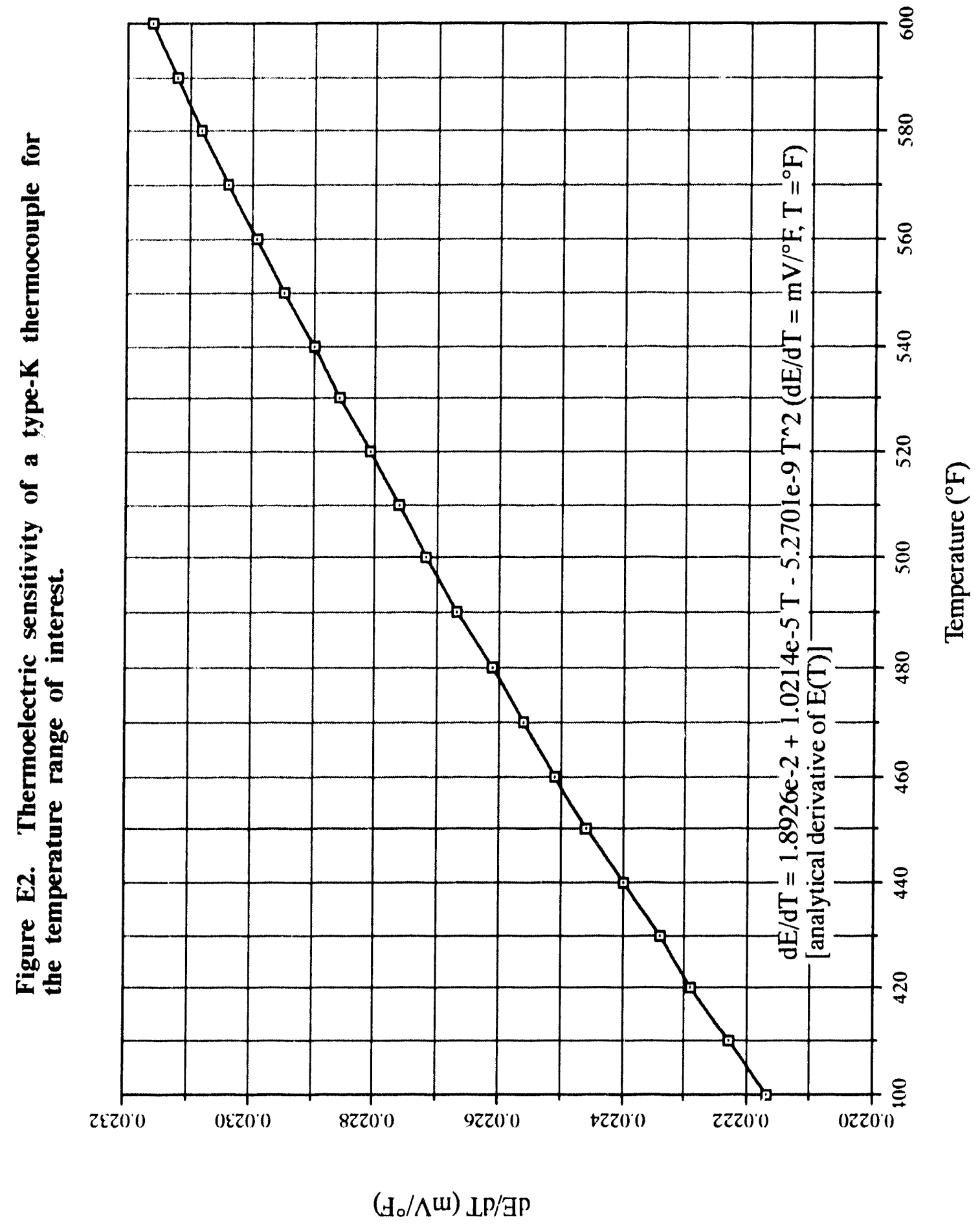


Appendix F

Uncertainty Analysis Procedure 


\section{Appendix $\mathbf{F}$ \\ Uncertainty Analysis Procedure}

This appendix summarizes the uncertainty analysis procedure used to produce the error bars shown in Figures 8 and 9 and the tabulated values in Tables C1-C4 in Appendix C.

\section{Uncertainty in Deriving Total Heat Loss Rate from Experimental Measurements}

Total receiver heat loss rate is derived from measurements using

$$
q_{\text {me:is }}=Q \mu c_{p} \Delta T
$$

where $4_{\text {me:is }}=$ total receiver heat loss rate calculated from measurements, Btu/min

$\mathrm{Q}=$ heat-transfer-fluid volume flow rate, $\mathrm{ft}^{3} / \mathrm{min}$

$\rho=$ heal-Iransfer-fluid density, $\mathrm{Ih}_{\mathrm{m}} / \mathrm{ft}^{3}$

$\mathrm{c}_{\mathrm{p}}=$ heat-transfer-fluid specific heat, Btu/( $\left(\mathrm{h}_{\mathrm{m}} \cdot{ }^{\circ} \mathrm{F}\right)$

$\Delta T=$ heat transler fluid temperature drop from receiver inlel to outlel, ${ }^{\circ} \mathrm{F}$

The uncertainty in the total heat loss rate is calculated using the following formula from Holman (1984):

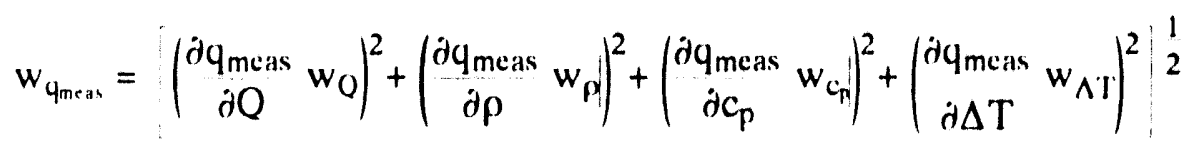

where the partial derivatives, derived from Eq. (F1), are

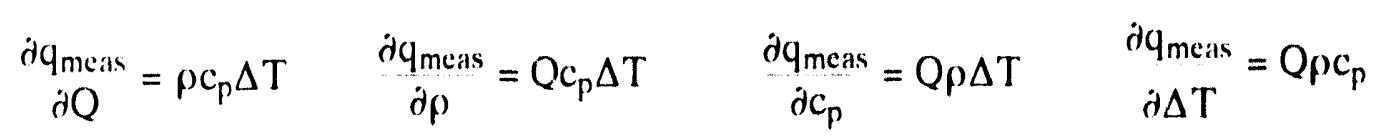

and the uncertainties of the individual parameters are

$$
\begin{aligned}
& w_{Q}=0.005 Q \\
& w_{c_{p}}=0.01 c_{p}
\end{aligned}
$$


$\left.w_{1}=11.1111\right)$

$w_{N 1}=1.414^{\circ} \mathrm{F}$ (hased on individual thermocouple uncortainly of $1 \%$ )

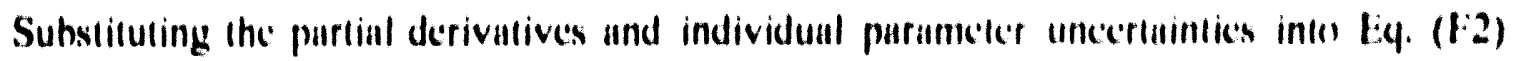
given

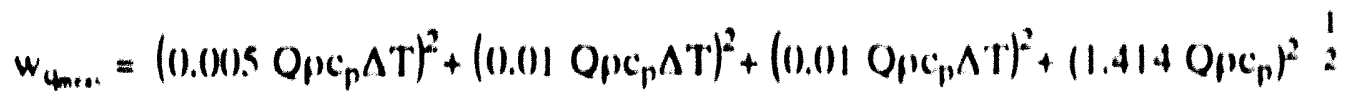

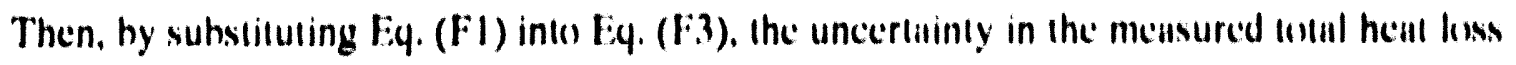
ralc is

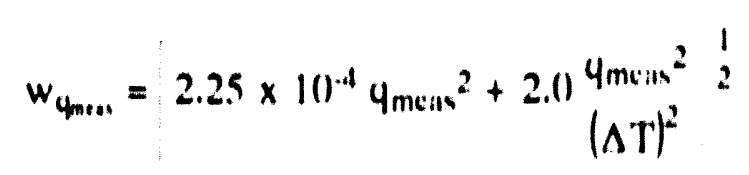

or in lerms of uncertainty percentage

$$
w_{\text {meen }}=2.25 \times 1\left(0^{-4}+\frac{2.0}{(\Delta T)^{2}}\right)^{1}
$$

\section{Error Introduced In Normalizing Total Heat lass Rate}

Since the receiver and air lemperatures varied from lest to lest, it is desirahle 10 normalize the lotal heat loss to nominal receiver and air temperatures so that dala manipulation can be performed and representative comparisons can be drawn. The overall heat loss rate is normalized using

$$
q_{\text {Iotal }}=\frac{q_{\text {meas }}\left(T_{\text {rec, norm }}-T_{\text {amb, norm }}\right)}{T_{\text {rec, meas }}-T_{\text {amb, meis }}}
$$

where $\quad y_{t o t a l}=$ normalized total heat loss rate

$$
q_{\text {meas }}=\text { total heat loss rate calculated from measurements using Eq. (F1) }
$$




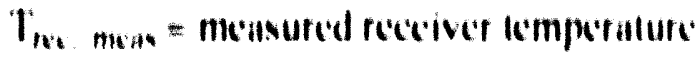

$$
\begin{aligned}
& \text { (average lemperalure al the heal iransler lluid) } \\
& T_{\text {amb, moas }}=\text { measured ambicill lemperalure } \\
& T_{\text {res, nurm }}=\text { mominul or nermal recesivet lemperalure } \\
& T_{\text {iams. norm }} \text { nominal or normal ambiconl lemperalure }
\end{aligned}
$$

For these experiments, the nominal receiver lemperalued is 5.310 t and the neminul ambient

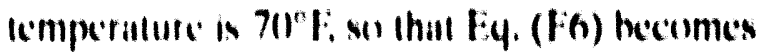

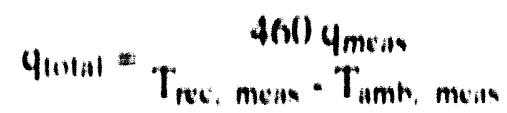

Now. The uncertainly in the nermulieed lobal heal less rale is cialculaled using

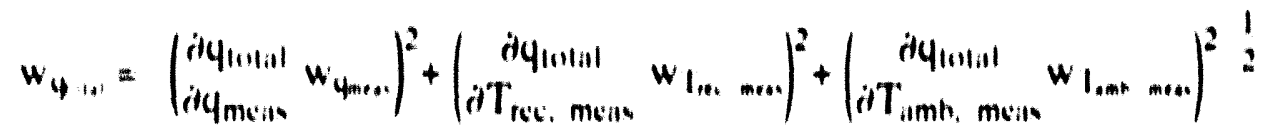

where the partial derivalives, derived from Eq. (F7), are

$$
\begin{aligned}
& d q_{10 t a 1}=46(1) \\
& \text { dymein }=T_{\text {rec, mein }} \cdot T_{\text {nmh, mein }}
\end{aligned}
$$

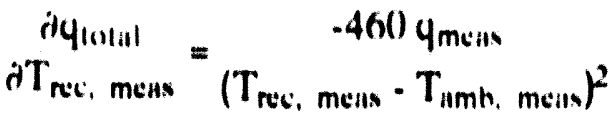

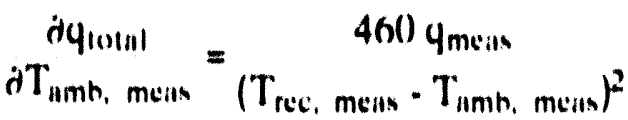

and the individual uncertainties are

wyme:in defined by Eq. (F4)

Wrec, meas $=1.414^{\circ} \mathrm{F}$ (hased on individual thermecouple uncertainly of $\pm 2^{\circ} \mathrm{F}$ )

WTamh, meis $= \pm 2^{\circ} \mathrm{F}$

Substituting the partial derivatives and individual uncertainties into Eq. (F8) results in 


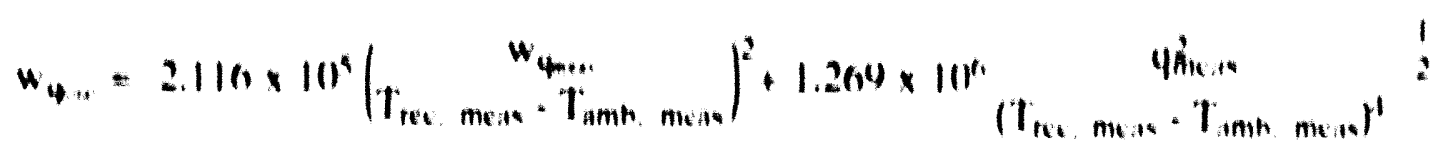

\section{Incertulnty In Heut Iass Components}

\section{A. Incertainty in Conduction Hent Iaws Rate}

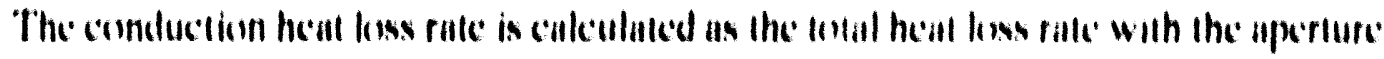
plugged minus the calculaled amount of heal conducted thresgh the aperlure:

$$
\text { Yound }=\text { Yplugped }- \text { Mapurturs }
$$

where Yound conduction henl loss ralce

Uplugged $\equiv$ lotal heal less rule with the aperlure plugged

Giperture $=$ calculated umount of heal conducted through the uperlure

The uncertuinly in the conduction heat loss rate is then culculaled using

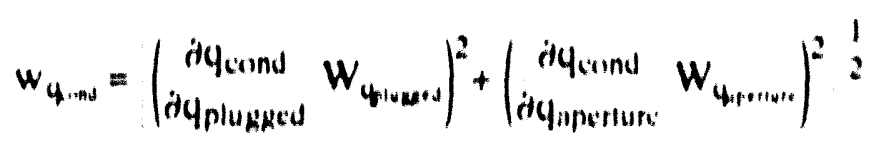

where the partial derivatives of Eq. (FIO) are

$$
\frac{\partial y_{\text {cond }}}{\partial y_{\text {plugged }}}=1 \quad \frac{\partial y_{\text {cund }}}{\partial y_{\text {ipurture }}}=-1
$$

The uncertainly in the conduction heal less rate is then

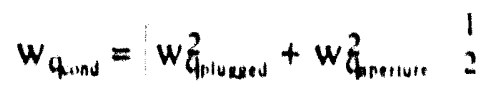

where the individual uncertainties are those for the aperture-plugged case and the amount of heal conducled through the aperlure, respectively. 


\section{B. Incertainty In Rudintlion Ileut I ams Rute}

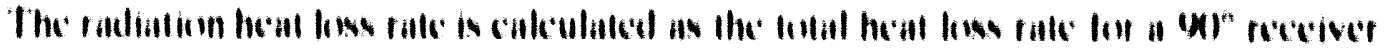

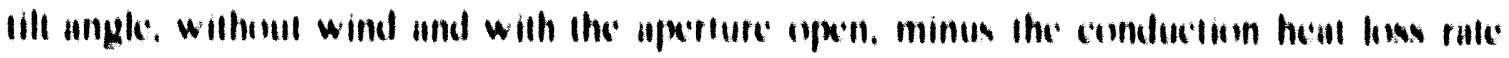
wilhinil wind:

$$
4_{\text {nod }}=Y_{11 p r n}+Y_{\text {wrind }} \text { nin nind }
$$

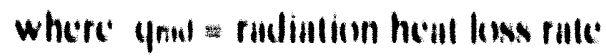

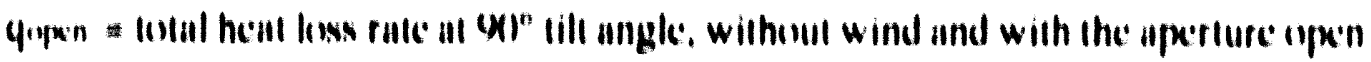

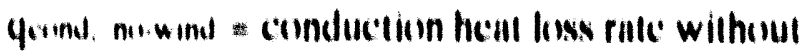

Following the same precedure as that used for delermining uncertainly in the conductuon

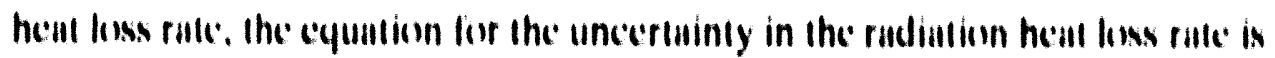

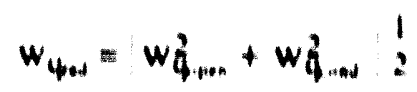

\section{Uncertuinty in Convective Heat lass Rute}

The convective heut loss rulce is colleulated hy sublracting conduction and radiution heall loss rale's from the lotul heal loss rule:

$$
\varphi_{\text {cunv }}=\varphi_{\text {lontil }} \cdot \varphi_{\text {mud }} \cdot \varphi_{\text {cond }}
$$

Following the same procedure as that used for delermining uncerlainly in the conduction heal less rate, the equation for the uncertainty in the convective heall loss rate is as follows:

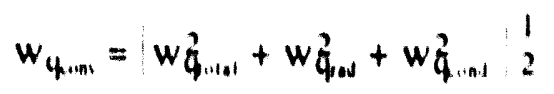


U.5. Depariment of tiveray (3) Porrenal Building

Code At: 13 .

IOXO Independence Arenue, SW

Wohingion, DC 20s4s

Alin: O. Burch

s. Cronich

U. 8 . Departmen of tinergy (2) Porresial Building

Code HEI 11

1000 Independence Avenue, SW

Wouhington, DC 20545

Alin: R. Annan

U.S. Department of Bnerty (2)

Albuquerque Operations Ornce

P.O. Box $\$ 400$

Albuquerque, NM 8711 s

Alin: O. Tennyson

N. Iackey

U.S. Department of linergy

San Proncisco Operation Orfice

133,3 Broadway

Oakland, CA 94612

Aitn: R. Hughey

Arizona Dept of Commerce

3800 N. Central, Sule 12(0)

Phoenix, AZ 85012

Alin: $\quad f$, Mancini

Ballelle Pacific Nortiwest Laluoratory

P.O. Box $9 \%$

Richland, WA 99352

Alti: D. Brown

California Polytechnic University

Dept. of Mechanical lingineering

3801 Wess Temple Avenue

Pomona, CA 91768

Alin: Dr. Wm. B. Stine (10)

Central and Soutliwest Services

Mall S(o) 7Rlis

1616 Woxdall Rogers Freeway

Dallus, TX 75202

Alln: lidward I. Ciastineau

\author{
Clever Fellow: \\ Innovation Consortium, Inc. \\ R. D. 1, thos 410, River Road \\ Melrow, NY 12121 \\ Alin: I. Corey, P.H. \\ Cummina Powet Cenerakina (2) \\ MC 60129 \\ P. O. Don sous \\ Columbus, IN 47202 3003 \\ Alti: R. Kubo
}

Cummins Puwer Conaredion south

180 Tunnehill Drive

Abilene, TX 79602

Altn: M. McOloun

Dynatherm Corporation

1 Beaver Court

P.O. Bon 398

Cockeyuville, MD 21030

Altn: David Wolf

Hlectric Power Rewearch Inatitute

P.O. Box 10412

Palo Aloo, Ca 94303

Alln: J. Schaeffer

Inergy Technology Inye. Center (2)

Rockwall International Corp.

P. O. Box 1449

Canogy Park, CA 91304

Alin: W. Bigelow

R. LeChevalier

Kurl Thoman licldman, Jr, Ph.D., P. I .

Mechunical Engineering Consuliani

1704 Sianford Dr. NE.

Albuquerque, NM 87106

Hilorida Solar tineryy Center

30) State Road, Suite 401

Cape Canaveral, HI. $\mathbf{3 2 9 2 0}$

Allin: lifbeary

Georgia Power

7 Solar Circle

Shenandoah, GA 30265

AlIII: W. King 
Insiline of lias Iechimlingy

424s siale Sires

Chliago, II. rakith

Alin Intary

Iat Iroyulstion I aluratory

atwio Oak (liove Drive

Pasulena, CA OIIOW

Alin $M$ Alpet

Iawrence Derkeley Iaburatory

MS (0) 2024

One Cyclowron Road

Herkeley, (A 4720

Alin A. Ilun!

Ios Alamos National I atworalory

MS I:II

I, Alamu, NM N7545

Alin: $M$. Merrigan

MeDommell Douglas Astronaules Company 5,101 Bulsa Avenue

llunington lloach, CA Q2047

Airn: R. I. Cervais,

J Rogan.

D. Steinmeyct

Mechanical Techoology, Inc: (2)

Y6: Albany Shaker Road

I allam, NY 12110

Alti: (i) Docha!

). Wugner

NASA lewis Rementch Center (4)

2I(X) Brook Park Rond

Cleveland, Oll 44139

Alii: R. Shaliens

J. Schrieber

National Renewable Inergy Laboratory (6)

1617 Cole Boulevard

Golden, $C O$ ROAO)

Alin $\mathrm{T}$, Williams

I. M. Murpliy

(i. Jorgensen

'T. Wendelin

A. Lewandowsk|

M. Bolin

Norllern Research and lingineering Corp

39 Oly mipla Avenue

Wolurn, MA OIB() 2073

Allii: J Kesseli
Thwer Kinelles, Ine

419 River sirnet

Troy, NY $121 \mathrm{mo} 2 \mathrm{k2}$

Alin: W. H. Nogen

Rosentch Intemulonal

In7os IA2nd Avenue NII

Wodinville, WA Got2

Alth: I. Sonki

Science Applratom Inernational Corporation $15000 \mathrm{~W}$. wh Aveme, sulte 202

Colden, CO 20401

Attn: Kelly Deninge

Sclence Applicalom Intemulional Corporalion Mail Stop 32

10260 Campu Boin Coun

San Dlego, CA 92121

Aitn: B. Butler

Soler tinercy Induntrles Assoc. (2)

777 North Cepliol SI. NI

sulie ens

Wahington, D.C. 20002

Atri: \$. Striar

K. Shoinkopf

Solar Kinetice, Ine. (2)

P.O. Box 540636

Dalle. TX 753540036

Alti: J. A. Hutchison

P. Scherts

Stirling Technology Company (3)

2952 Ceorge Wahington Way

Richland, WA 99352

Allin: Maurice A. Wille

Silfling Thermal Molors (2)

275 Melly Drive

Ann Arbor, MI 48103

Alin: Lennart Johanswon

Stirling Muchine World

I823 Ilummingbird Court

West Richland, WA 99352.9542

Alln: Brad Ross

Sinnpower, Inc.

6 Byard Sireet

Alhens, OHI 45701

AlIII: W. Beale 
Tech Reps, Inc. (2)

S000 Marble NB, sulle 222

Albuquerque, NM 87110

Alln: J Stikar

Thermacore, Inc. (2)

78) Bden Roud

Lancaster, PA 17601

Altn: Donald Ermat

Univeralty of Housion

Solat Energy Laboralory

4800 Calhoun

Houston, TX 77704

Alin: J. Richardion

University of Minnesola

Dept of Mechanical Ingineering

III Church S1. , SE

Minneapolis, MN 53455

Alin: E. A. Fleicher

Ausiralian National Univerality

Department of Engineering

Phyules

P. O. Box 4

Canberra ACt 2600 AUSTRALIA

Alin: S. Kanell

DLR

Pfaffenwaldring 38-40

7(OO) Stuligart BO CERMANY

Alin: R. Buck

linergy Research Centre

R. S. Phy. Sc,

Australian National University

Canberra ACT 2601 AUSTRALIA

Alin: K. Inall

Dr. David Hagen

134 Kiltchener St.

Garran, ACT 2603

AUSTRALIA

Pacific Power

Park and Elizabeth Streels

GPO Bux 5257. Sydney

New South Wales 2(x)I, Australia

Alin: Peler Lynch

Schlaich, Bergermann \& Parmer

Hohenzollerisstr. I

D - 7OXX) Stultgart I GLRMANY

Alin: W. Schicl

\begin{tabular}{|c|c|}
\hline 151.1 & D. R. Alkins \\
\hline 1511 & R. N. llogan \\
\hline 1913 & V. I Rounero \\
\hline 1511 & R. D. Skocyinec \\
\hline 1561 & f. L. Hoffman \\
\hline $\mid 561$ & C. M. Slone \\
\hline |811 & J. A VandenAvyle \\
\hline 2756 & (i. s Phipps \\
\hline 4.313 & J. P.Muir \\
\hline 60000 & D. L. Martley \\
\hline 6115 & W. C. Cinn \\
\hline 6200 & D. B. Arvizin \\
\hline 6201 & P. C. Klimas \\
\hline 6213 & A. R. Mahoncy \\
\hline 6215 & C. P.Cameron \\
\hline 6219 & K. S Rawlinson \\
\hline 6215 & L.tbrary (5) \\
\hline 6216 & C. I.Tyner \\
\hline 6216 & C. E.Andrakn \\
\hline 6216 & R. B. Diver \\
\hline 6210 & T. K. Mancini \\
\hline 6216 & D. F. Menicueel \\
\hline 6216 & J. B. Moreno \\
\hline 6216 & T. A. Moss \\
\hline 6216 & Lubrary (9) \\
\hline 7141 & Technical Library (\$) \\
\hline 7151 & C. C. Claycombl \\
\hline 7613.2 & $\begin{array}{l}\text { Dexumen Processing } \\
\text { for DOE/OSTI (10) }\end{array}$ \\
\hline & 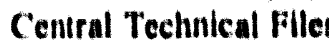 \\
\hline
\end{tabular}



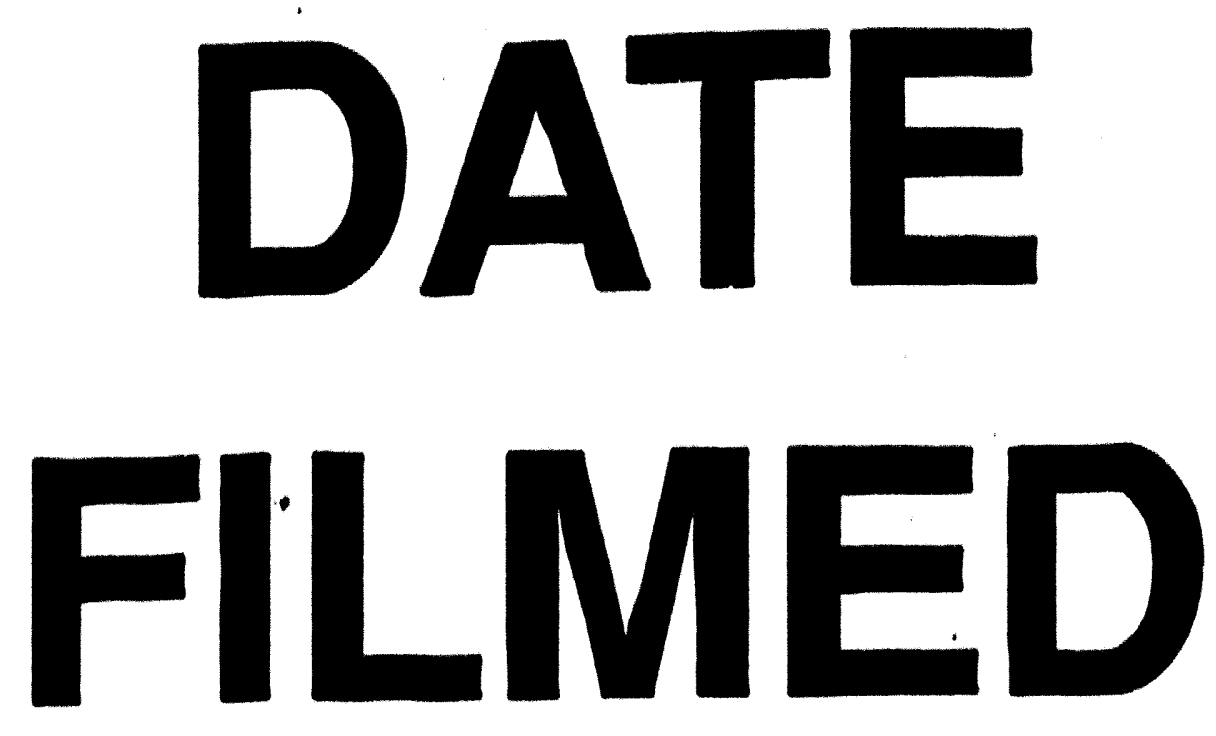

$1 / 4 / 94$
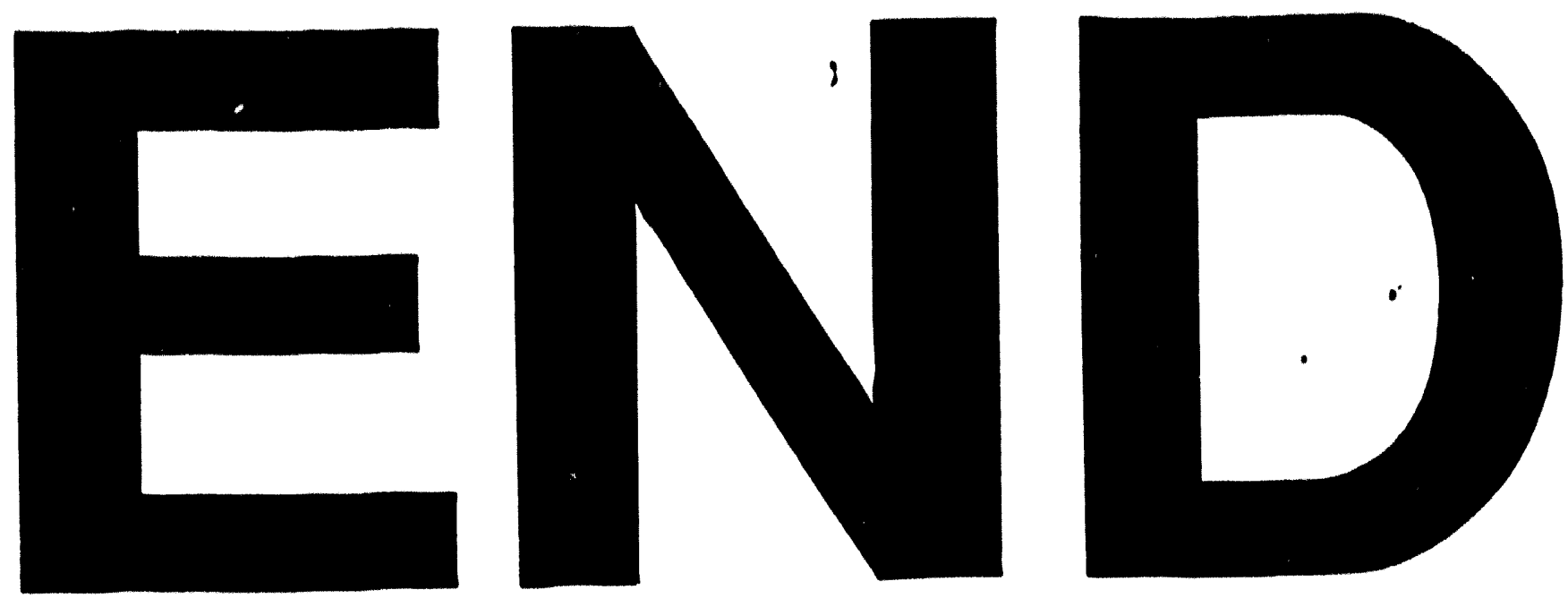

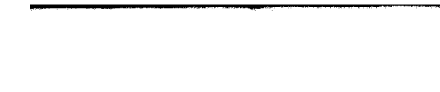